Universidade de São Paulo

Instituto de Física

\title{
Estudo da hipertermia como agente de controle e liberação de quimioterápicos: análise e desenvolvimento de dispositivos de aquecimento
}

\section{Tiago Ribeiro De Oliveira}

Orientador: Profa. Dra. Maria Teresa Moura Lamy

Banca Examinadora:

Profa. Dra. Maria Teresa Moura Lamy (IF/USP)

Prof. Dr. Antonio Domingues dos Santos (IF/USP)

Profa. Dra. Elisabeth Mateus Yoshimura (IF/USP)

Prof. Dr. Ernane José Xavier Costa (FZEA/USP)

Prof. Dr. Roberto Morato Fernandez (IB/UNESP) 


\section{FICHA CATALOGRÁFICA}

\section{Preparada pelo Serviço de Biblioteca e Informação}

do Instituto de Física da Universidade de São Paulo

Oliveira, Tiago Ribeiro de

Estudo da hipertermia como agente de controle e liberação de quimioterápicos: análise e desenvolvimento de dispositivos de aquecimento. São Paulo, 2014.

Tese (Doutorado) - Universidade de São Paulo. Instituto de Física. Depto. de Física Geral.

Orientador: Profa. Dra. Maria Teresa Moura Lamy

Área de Concentração: Física Biológica

Unitermos: 1. Biofísica; 2. Doxorrubicina; 3. Hipertermia; 4. Glioblastoma; 5. Lipossomos; 6. Entrega seletiva de fármacos. 


\section{Resumo}

O uso da elevação da temperatura local como recurso adjuvante no combate ao câncer tem sido explorado intensamente nas últimas décadas. A hipertermia, como é chamada essa elevação de temperatura local, apresenta seu maior potencial clínico quando combinada com a quimioterapia e/ou radioterapia, sendo capaz de promover benefícios terapêuticos significativos. Apesar dos resultados positivos, a hipertermia, até o momento, não se estabeleceu como terapia padrão, devido a limitações no controle da deposição de energia e no monitoramento da distribuição de temperatura em tempo-real. Neste trabalho, discutem-se características fundamentais da eficiência da hipertermia no tratamento de tumores cerebrais e de bexiga. O projeto foi todo ele desenvolvido em colaboração com o grupo de hipertermia do Department of Radiation Oncology da Duke University. Com relação à hipertermia aplicada ao cérebro, primeiramente apresenta-se o procedimento de desenvolvimento e teste de eficiência de um mini-aplicador de micro-onda dedicado ao aquecimento do cérebro de camundongos. Após estes, avaliou-se a capacidade de disponibilização termo-estimulada da doxorrubicina a modelos tumorais de glioblastoma. O método utilizado para monitoramento da liberação e distribuição da doxorrubicina foi a microscopia confocal de fluorescência intravital. O estudo do impacto da hipertermia sob a distribuição da formulação de doxorrubicina encapsulada em lipossomos termosensíveis demonstrou que a elevação moderada de temperatura promove alterações significativas na permeabilidade da barreira hematoencefálica, além de promover aumento do acúmulo total de droga e aumento no grau de penetração. Para a hipertermia aplicada à bexiga, apresenta-se um estudo de viabilidade de aquecimento para uma metodologia alternativa ao dispositivo de uso clínico padrão ("Synergo"), denominada magneto-hipertermia. Os ensaios com a magneto-hipertermia apontam que o uso de nanopartículas magnéticas sob influência de um campo magnético alternado $(40 \mathrm{kHz})$ é capaz de elevar a temperatura do lúmen da bexiga a $42^{\circ} \mathrm{C}$ de forma localizada, não promovendo efeitos significativos de aquecimento a tecidos do entorno. 


\section{Abstract}

The use of local heating to achieve adjuvant response in cancer treatment has been widely explored in the last decades. The thermal therapy has a well-known clinical benefit when combined to chemotherapy and/or radiotherapy. Despite all positive results, the use of thermal therapy has not yet been established as standard treatment, mainly due to the limitation on the control of energy deposition and real-time temperature mapping. This thesis discuss some of the fundamentals of the application of hyperthermia to treat bladder and brain tumors. All experiments were performed in collaboration with the Department of Radiation Oncology of Duke University. As regards brain experiments, we developed and built a microwave antenna dedicated to locally heating the mouse brain. After that, we assessed the ability of thermo release and thermo delivery of doxorubicin to glioblastoma tumor models. Intravital confocal fluorescence microscopy was used to monitor the drug release and distribution into brain tissue as a whole. Our findings indicated that a mild elevation in brain temperature $\left(42^{\circ} \mathrm{C}\right)$ modulates the permeability of the blood-brain barrier and promotes an increase on both total drug accumulation and drug penetration. Concerning bladder hyperthermia, we investigated the feasibility of magnetic-hyperthermia as an alternative heating source to the standard clinical device ("Synergo"). The magnetic-hyperthermia results indicate that the amount of heat dissipation by the magnetic nanoparticles, under the influence of alternating magnetic field $(40 \mathrm{KHz})$, was able to raise the temperature in the bladder lumen to $42^{\circ} \mathrm{C}$ and did not promote any significant heating effects on surrounding tissues. 


\section{Acknowledgements}

First and foremost, I would like to thank my principal advisor Dr. Maria Teresa Lamy for her support, encouragement, help, and for holding 'flexible' office hours. Her work ethics will always be an inspiration to me, as well as her integrity.

Secondly, I would like to thank my co-supervisors at Duke University, Professor Paolo Maccarini and Professor Paul Stauffer, for accepting me as a graduate student in your laboratory and for being such a wonderful supervisors. I appreciate the time and energy you put into my success, and for your encouragement, enthusiasm, and for providing a fruitful collaborative environment.

I thank the Hyperthermia Physics Lab, in special: Sara, Dario, Alina and Fabio for making this a wonderful period. I thank each of you for the smiles, the laughter, and the memories. I would like to give a special thanks also to Wiguins Etienne and Dr. Chelsea Landon for the hours we spent in the Actium project.

I wish to express my gratitude to Drs. Gerald Grant and Christy Wilson for the useful collaboration in the brain tumor project. They were always ready to assist me in any way possible. This thesis would not have been possible without your help.

I would like to thank all the funding resources, NIH and Actium Biosystems, for supporting my research work at Duke University. Software was supported by Ansys, COMSOL and VSG.

I can not miss out Deborah Stauffer and Irina Maccarini. I would like to thank you for your assistance in almost everything out of campus and for made me feel at home in Durham-NC.

I wish to acknowledge my family for pushing me to finish. Their support during this time was infallible, and I love them for that.

Finally, I want to thank my girlfriend, Renata Wassall, for her love, support and understanding of what it takes to complete a doctoral degree. Much of what I have accomplished would not have been done without you. 


\section{Nomenclatura}

BHE Barreira Hematoencefálica

DOX Doxorrubicina

EPR Efeito de Aumento de Permeabilidade e Retenção

GBM Glioblastoma Multiforme

HIFU Ultrassom Focalizado de Alta Intensidade

IFP Pressão do Fluido Intersticial

LTSL Formulação de Lipossomos Termosensíveis

MHT Magneto-Hipertermia

MRgFUS Cirurgia de Ultrassom guiada por MRI

MRI Imagem de Ressonância Magnética nuclear

MRTI Imagem Térmica por Ressonância Magnética nuclear

NPM Nanopartícula Magnética

RF Radiofrequência

SAR Taxa de Absorção Específica de Energia

SLP Potência de Dissipação Específica 


\section{Sumário}

1 Introdução 1

1.1 O microambiente tumoral $\ldots \ldots \ldots \ldots \ldots \ldots$

1.2 Tumores cerebrais . . . . . . . . . . . . . . . 8

1.3 Tumores de bexiga . . . . . . . . . . . . . . . . 12

1.4 A hipertermia como modalidade terapêutica para tumores sólidos . . . . . 13

1.4.1 Efeito citotóxico direto . . . . . . . . . . . . . . 14

1.4.2 Impacto da hipertermia no fluxo sanguíneo . . . . . . . . . . . 16

1.4.3 Interação da hipertermia com agentes quimioterápicos . . . . . . . 17

1.4.4 Interação da hipertermia com a radioterapia . . . . . . . . . . . 19

1.4.5 Efeitos da hipertermia no sistema imunológico . . . . . . . . . . 21

1.5 Lipossomos termosensíveis como sistema de entrega controlada de droga . . 22

1.6 A equação de calor em sistemas biológicos . . . . . . . . . . . . 26

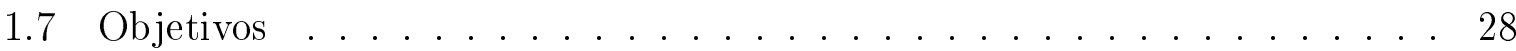

1.8 Sumário do conteúdo da Tese . . . . . . . . . . . . . . . 28

2 Desenvolvimento de um mini-aplicador de micro-onda dedicado ao aquecimento do cérebro de pequenos camundongos 31

2.1 Introdução . . . . . . . . . . . . . . . . . . . . . . 32

2.1.1 Princípio do aquecimento por micro-onda . . . . . . . . . . . 34

2.1.2 Alguns aspectos sobre ondas eletromagnéticas . . . . . . . . . 38 
2.1.3 Processos de otimização de antenas . . . . . . . . . . . . . . . 40

2.2 Materiais e Métodos . . . . . . . . . . . . . . 46

2.2.1 Termometria invasiva . . . . . . . . . . . . . . . 46

2.2.2 Medidas do parâmetro de espalhamento $S_{11} \ldots \ldots \ldots$. . . . . 47

2.2.3 Simulação numérica da radiação eletromagnética . . . . . . . . . . . 48

2.2.4 Modelo anatômico 3D . . . . . . . . . . . . . . . 50

2.2.5 Fabricação de fantomas tecido-equivalente . . . . . . . . . . 51

2.3 Projeto e construção do mini-aplicador de micro-onda . . . . . . . . . 52

2.3.1 Características básicas de uma guia de onda retangular . . . . . . 55

2.3.2 Desenvolvimento de instrumentação complementar . . . . . . . . 58

2.3.3 Projeto do mini-aplicador de micro-onda . . . . . . . . . . . . . 64

2.3.4 Processo de otimização do mini-aplicador de micro-ondas . . . . . . 66

2.3.5 A construção do mini-aplicador . . . . . . . . . . . . . 71

2.3.6 Estudo de performance e eficiência de aquecimento em sistema fatoma 71

2.3.7 Estudo de performance e eficiência de aquecimento in vivo . . . . . 78

2.4 Conclusões . . . . . . . . . . . . . . . . . . . 86

3 Estudo in vivo da entrega termo-estimulada de doxorrubicina ao sistema $\begin{array}{ll}\text { nervoso } & 87\end{array}$

3.1 Introdução . . . . . . . . . . . . . . . . . . . 88

3.1.1 A farmacocinética dos lipossomos termosensíveis . . . . . . . . . . 91

3.1.2 Introdução à microscopia confocal de fluorescência . . . . . . . . . . 96

3.2 Materiais e Métodos . . . . . . . . . . . . . . . . . 101

3.2 .1 Animais ........................... 101

3.2 .2 Implantação do tumor . . . . . . . . . . . . . . . . . . . . . 102

3.2.3 Procedimento de craniotomia . . . . . . . . . . . . . . 103 
3.2.4 Seleção das sondas fluorescentes . . . . . . . . . . . . . . 105

3.2.5 Microscópio confocal de fluorescência intravital . . . . . . . . 108

3.2 .6 Aquisição das imagens . . . . . . . . . . . . . . . . . 108

3.2.7 Método de análise das imagens de fluorescência . . . . . . . . . 109

3.2.8 Preparação dos lipossomos termosensíveis . . . . . . . . . . . . 112

3.2 .9 Protocolo de aquecimento . . . . . . . . . . . . . 113

3.3 Resultados e Discussões . . . . . . . . . . . . . . . . 113

3.3.1 Controle da disponibilização de DOX . . . . . . . . . . . . 113

3.3.2 Efeito de EPR nos tumores cerebrais . . . . . . . . . . 117

3.3.3 Rompimento térmico da barreira hematoencefálica . . . . . . . . . . 119

3.3.4 Efeito da elevação da temperatura local na distribuição dos lipossomos 121

3.3.5 Efeito da elevação da temperatura na distribuição de DOX . . . . . 122

3.4 Conclusões . . . . . . . . . . . . . . . . . . 125

4 Análise in vivo da viabilidade de uso da magneto-hipertermia para aque$\begin{array}{ll}\text { cimento da bexiga } & 127\end{array}$

4.1 Introdução . . . . . . . . . . . . . . . . . . . . 128

4.1.1 O magnetismo de nanopartículas . . . . . . . . . . . . . 131

4.1.2 Geração de calor por nanopartículas magnéticas . . . . . . . . . . 133

4.2 Materiais e Métodos . . . . . . . . . . . . . . 137

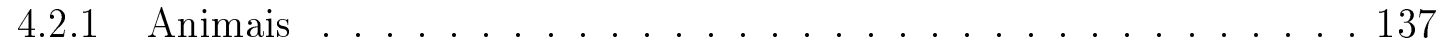

4.2 .2 Fluido magnético . . . . . . . . . . . . . . . . 137

4.2 .3 Medições de temperatura . . . . . . . . . . . . . . 138

4.2.4 O equipamento gerador de campo magnético . . . . . . . . . 138

4.2.5 Definição do parâmetro de "potência de dissipação específica" . . . . 140

4.2.6 Imagens de ressonância magnética nuclear . . . . . . . . . . . . . 140 
4.3 Resultados e Discussões ． . . . . . . . . . . . . . . . . . . 142

4.3.1 Capacidade de geração de calor do fluido magnético in vitro . . . . 142

4.3.2 Características da administração do fluido magnético na bexiga . 144

4.3.3 Eficiência de aquecimento do fluido magnético in vivo . . . . . . . 155

4.3.4 Características de controle do equipamento . . . . . . . . . 159

4.3.5 Ensaios de controle e estabilidade da temperatura in vivo . . . . . . 162

4.4 Conclusões . . . . . . . . . . . . . . . . . . . 165

5 Conclusões gerais

Referências Bibliográficas

A Artigos publicados ou em fase de submissão relacionados à Tese

A.1 Magnetic fluid hyperthermia for bladder cancer: A preclinical dosimetry study . . . . . . . . . . . . . . . . . . . . . 199

B Lista completa de publições durante o período de Doutorado

B.1 Primeiro autor . . . . . . . . . . . . . . . . 212

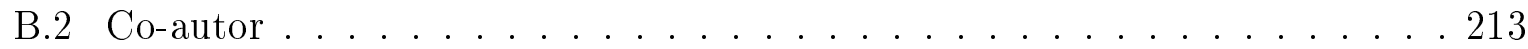




\section{Capítulo 1}

\section{Introdução}

Chama-se de câncer um grupo de doenças caracterizadas pelo crescimento e propagação desordenada e anormal de células. A falha do organismo em detectar e combater a propagação celular desordenada pode promover a morte do indivíduo portador da doença. Apesar da terapia oncológica ter sofrido um expressivo avanço nas últimas quatro décadas, a incidência e mortalidade populacional ainda são significativas na sociedade global. A American Cancer Society indicou para o ano de 2014 uma incidência de 1.665.540 de novos casos de câncer em todo os Estados Unidos, sendo que a expectativa de mortalidade deverá ser de 585.720 pacientes (cancer.gov, 2014a). Os números apresentados apenas justificam a necessidade de investimento em pesquisa na tentativa de reverter essa realidade.

Dentre os métodos terapêuticos convencionais de combate ao câncer, a quimioterapia, juntamente com a radioterapia e a cirurgia, representam a base terapêutica de atuação. O termo quimioterapia refere-se ao tratamento de doenças por substâncias químicas que afetam o funcionamento celular e interferem na capacidade de multiplicação das células cancerosas. Os quimioterápicos são fármacos desenhados para matar as células cancerígenas ou ao menos evitar que elas se dividam.

Atualmente existe um consenso clínico de que a quimioterapia sistêmica, aplicada ao combate de tumores sólidos, dificilmente atinge os níveis terapêuticos ideais de dose/concentração no ambiente tumoral sem que promova danos significativos a órgãos e tecidos sadios circunvizinhos. Desta forma, a cirurgia e a radioterapia normalmente são 
os procedimentos de primeira escolha (Holland, 2003). Na prática clínica moderna, a quimioterapia é prioritariamente utilizada como adjuvante pós-cirúrgico, no intuito de remover metástases microscópicas que possam ter se espalhado a partir da região original do tumor (Holland, 2003).

Dentre os diversos fatores considerados como limitantes à eficiência da quimioterapia, tem-se a heterogeneidade da distribuição dos quimioterápicos na região tumoral como um dos principais fatores limitadores (Chen et al., 2008). Por muitos anos, pesquisadores buscaram aumentar a eficácia da quimioterapia através da análise bioquímica, biofísica e da biologia molecular do câncer, para assim produzir drogas com maior especificidade às células tumorais.

Atualmente, os olhares voltaram-se também para a avaliação da distribuição espacial da droga no local de interesse, pois sabe-se que se as drogas anticâncer forem incapazes de acessar todas as células tumorais ativas, há grande possibilidade de que as células remanescentes no local se tornem um núcleo regenerador do tumor. As dificuldades apontadas de baixa distribuição de drogas no ambiente tumoral são atribuídas majoritariamente a barreiras fisiológicas intrínsecas no microambiente tumoral, que em muitos aspectos se diferencia das condições fisiológicas encontradas em um tecido normal (Vaupel \& Kelleher, 2010).

O transporte de solutos ou moléculas no espaço intersticial tecidual são governados por parâmetros fisiológicos e físico-químicos das moléculas e do ambiente intersticial (Jain, 1987b). As barreiras fisiológicas impostas à entrega dos medicamentos ao tumor são atribuídas diretamente, ou indiretamente, à organização caótica e tortuosa da rede vascular tumoral. A desorganização vascular produz um transporte limitado de oxigênio e de nutrientes para as células distantes dos vasos e como consequência promove o acúmulo de metabólitos, como os ácidos lático e carbônico, que reduzem o pH extracelular tumoral (Song et al., 1996). Esses fatores contribuem para a formação de regiões de hipóxia e anóxia, promovem o surgimento de um gradiente de proliferação e induzem um aumento na pressão intersticial.

Assumindo como real a relação entre fisiologia anormal do ambiente tumoral e má 
distribuição de fármacos, há de se esperar que alterações na condição fisiológica local possam promover pertubações na distribuição tecidual das drogas. Uma estratégia capaz de induzir modificações às condições fisiológicas do microambiente tumoral, consiste em elevar a temperatura local de forma modesta $\left(\right.$ de $37^{\circ} \mathrm{C}$ para $\left.42^{\circ} \mathrm{C}\right)$ por um longo período de tempo.

Diversos estudos relatam que elevar a temperatura local do tecido, ou induzir um processo de hipertermia, induz um aumento do fluxo sanguíneo tumoral, assim como modifica a permeabilidade da parede vascular. Essas características constituem um interessante adjuvante na tentativa de melhorar a distribuição e penetração dos anticânceres no tecido alvo. A alteração do fluxo sanguíneo aumenta a oxigenação local e a concentração de nutrientes em regiões inicialmente deficitárias, que tipicamente apresentam limitações no acúmulo destes elementos. O aumento da permeabilidade vascular, por sua vez, aumenta o extravasamento de moléculas, como os medicamentos, para o ambiente intersticial tumoral. De fato, existem diversos estudos que demonstram a sinergia positiva entre aquecimento local (hipertermia) e quimioterapia. No entanto, os efeitos benéficos da hipertermia podem ir além da conhecida modulação das condições fisiológicos locais, pois o calor interfere diretamente no ambiente celular, promovendo danos tanto em proteínas e complexos proteicos, quanto nos agentes reparadores de DNA, o que pode ajudar a aumentar a citotoxicidade dos agentes terapêuticos.

Como citado anteriormente, um os principais fatores limitantes da quimioterapia é o seu alto grau de toxicidade em tecidos e órgãos sadios. Na tentativa de modificar o grau de toxicidade dos medicamentos, diversos estudos têm proposto soluções alternativas que reduzem os efeitos deletérios dos mesmos (Holback \& Yeo, 2011; Shipton, 2012). Um dos sistemas de grande interesse na comunidade científica são os chamados sistemas transportadores de drogas. O conceito de sistema transportador de droga é definido como uma formulação ou dispositivo que possibilita a introdução de substâncias terapêuticas no corpo humano de forma a melhorar a eficácia e segurança da formulação. Os ganhos podem ser obtidos através do controle da taxa, tempo e local de liberação das drogas no corpo. 
Atualmente existe uma infinidade de tecnologias de transporte de droga em desenvolvimento, dentre os muitos existentes destaca-se os sistemas baseado em lipossomos (Drummond et al., 1999), sistemas micelares (Kataoka et al., 2001), transportadores de drogas macromoleculares (Duncan, 2003) e terapia fotodinâmica (Vrouenraets et al., 2003). Neste trabalho o interesse esteve em estudar sistemas de aquecimento capazes de viabilizar o estudo da sinergia entre hipertermia e quimioterapia, com principal interesse nos transportadores à base de lipossomos.

\section{$1.1 \quad \mathrm{O}$ microambiente tumoral}

Tumores sólidos representam 90\% dos casos de câncer diagnosticados. O impacto do microambiente tumoral em limitar a distribuição extravascular de drogas, tem estado sob grande evidência nos últimos anos (Au et al., 2001; Holback \& Yeo, 2011; Jain, 2012; Reddy, 2005; Zhao et al., 2007). A proliferação desregulada das células cancerígenas no interior do tumor, resulta no aumento da distância intervascular e provoca o surgimento de gradientes no suporte de oxigênio e nutrientes (Hockel \& Vaupel, 2001; Minchinton \& Tannock, 2006; Vaupel et al., 1989). O déficit no aporte sanguíneo ocorre, pois a taxa de crescimento (ou proliferação) das células tumorais é muito superior ao crescimento da rede vascular, o que propicia que muitas das células do tumor estejam além das distâncias de difusão do oxigênio (100-150 $\mu \mathrm{m})$. Além do impacto da taxa de crescimento, tem-se também o fato que o fluxo sanguíneo é menor nos poucos vasos tortuosos do ambiente tumoral, fazendo com que favoreça a condição de baixo fornecimento de nutrientes.

Atribui-se às características fisiológicas do microambiente tumoral os principais fatores de resistência à quimioterapia e à radioterapia (Hanahan \& Weinberg, 2000; Tatum, 2006; Vaupel \& Mayer, 2007). A combinação da expansão sustentada da população de células cancerígenas e a aberrante neovascularização leva à criação destes microambientes diferenciados. As células tumorais podem localizar-se até 20 camadas celulares de distância do vaso sanguíneo mais próximo, enquanto que na maioria dos tecidos normais as células localizam-se dentro de um perímetro de apenas algumas camadas celulares de um vaso mais próximo. 
A rede vascular dos tumores sólidos é composta por vasos recrutados da própria rede pré-existente na região hospedeira e por vasos resultantes da resposta angiogênica local. A organização dos mesmos pode ser completamente diferentes dependendo do tipo de tumor, da taxa de crescimento e localização. Apesar da rede vascular tumoral possuir sua origem a partir da vasculatura hospedeira local, e seus mecanismos de angiogênese serem muito semelhantes aos do tecido sadios (Jain et al., 2007; Konerding et al., 1999; Maeda et al., 2003), a vasculatura tumoral encontra condições que contrastam com os tecidos normais. (Figura 1.1).

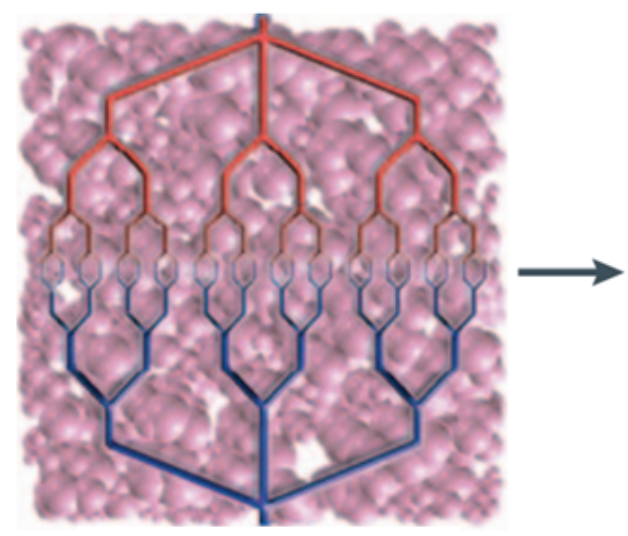

Vasculatura normal

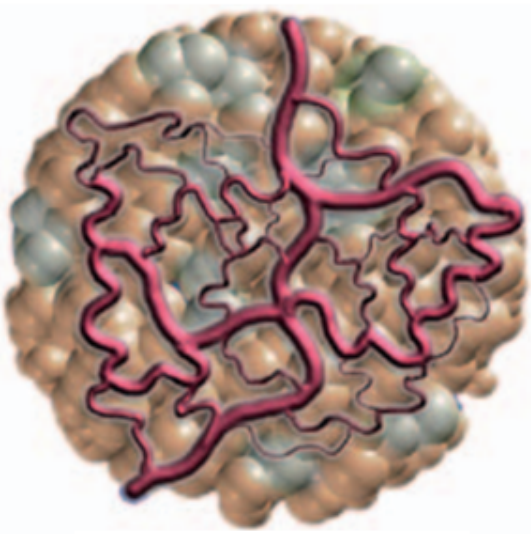

Vasculatura tumoral

Figura 1.1: Ilustração sobre as diferenças estruturais da rede vascular em regiões de tecido sadio e tumoral. Na vasculatura normal, o equilíbrio da sinalização pró e anti-angiogênicos mantém uma rede vascular organizada e eficiente. Essa organização adequada garante o suprimento de nutrientes necessários a todas as células do parênquima. Na vasculatura tumoral, fatores angiogênicos induzem o surgimento de uma rede vascular anormal e ineficiente. Esta rede tornase desorganizada, mal conectada e tortuosa, favorecendo o surgimento de falhas no suprimento de nutrientes [figura adaptada de (Jain et al., 2007)].

Vasos tumorais tendem a ser muito heterogêneos no diâmetro, com ramificações excessivas, voltas ineficientes, derivações arteriovenosas, anastomoses e extremidades abruptas sem conectividade (Bussolino et al., 2003; Jain, 2005). As paredes dos vasos do tumor frequentemente carecem de membranas basais, com fenestrações e lacunas entre as células endoteliais (Chen et al., 2008; Dreher et al., 2006a). Em contraste, vasos tumorais são deficientes na cobertura de pericitos e no músculo liso perivascular, tornando-os ineficazes na adaptação ao oxigênio ambiental e às flutuações metabólicas. Além disso, as paredes dos vasos são muitas vezes comprometidas por células tumorais que podem formar parte 
da parede do vaso ou se infiltrar no interior da parede do vaso (Pries et al., 2010; Vaupel et al., 1989).

A organização celular nos tecidos sadios facilita o fornecimento de oxigênio e nutrientes para todas as células que formam o tecido. De modo simplificado, um tecido biológico é dividido em três subcompartimentos: o vascular, o intersticial, e o celular. Além do que muitos tecidos sadios também apresentam canais linfáticos no compartimento intersticial (ver figura 1.2).

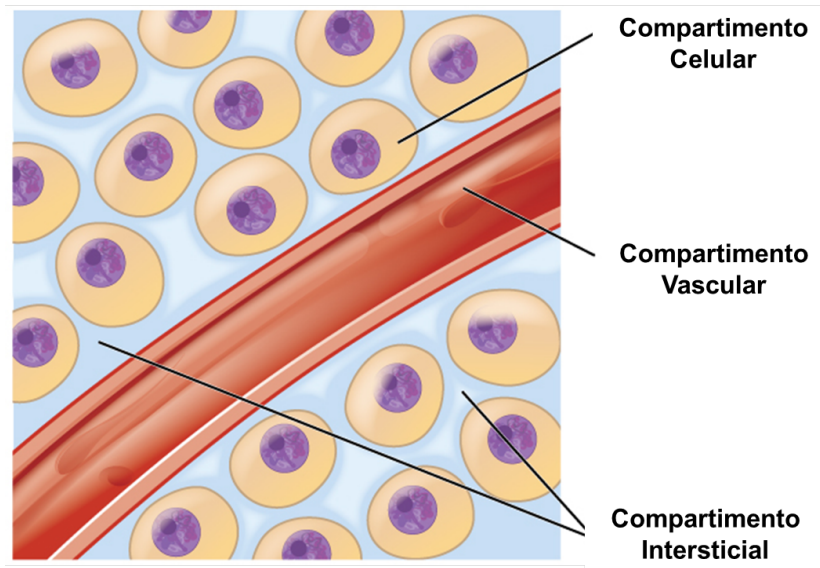

Figura 1.2: Ilustração dos subcompartimentos normalmente encontrados em um tecido biológico. O compartimento intersticial corresponde ao fluido que preenche o espaço entre as células e o compartimento vascular [figura adaptada de (cnx.org, 2014)].

Os agentes quimioterápicos são frequentemente administrados de forma sistêmica, portanto, uma vez na corrente sanguínea, a distribuição de medicamentos a uma dada região irá depender principalmente de quatro processos: (1) da distribuição da droga no compartimento vascular; (2) das características de transporte/permeabilidade do medicamento através da parede vascular; (3) da difusão no compartimento intersticial; e (4) da capacidade de internalização celular através da membrana. Além dos processos de difusão e mobilidade, existente em cada um dos subcompartimentos, a probabilidade de o medicamento ser metabolizado e/ou sofrer degradação e se ligar de forma não específica a proteínas ou outros componentes.

O grau de importância de cada processo na distribuição dos medicamentos depende fortemente das propriedades físico-químicas dos medicamentos (e.g., tamanho molecular ou de partícula, difusibilidade, ligação a macromoléculas) e das propriedades biológicas do 
tumor (e.g., vasculatura tumoral, componentes da matriz extracelular, pressão do fluído intersticial, densidade das células, estrutura e composição do tecido).

De modo geral, os medicamentos se distribuem nos tecidos sadios em consequência de efeitos combinados de difusão e convecção, sendo o fluxo de fluido total, a partir dos vasos sanguíneos, regulado pela relação de reabsorção nos vasos linfáticos. No entanto, no caso dos tumores, é comum que o sistema linfático não esteja funcional, o que acaba por levar a um desequilíbrio do fluxo de fluído e um aumento dos níveis da pressão do fluido intersticial (IFP) (Oliver \& Detmar, 2002; Witte et al., 2006). O aumento da IFP promove uma redução no efeito de convecção e inibi a distribuição de macromoléculas na região tumoral. A elevação da IFP em tumores é consequência também das anomalias da rede vascular, que possui alta permeabilidade a pequenas moléculas e grandes alterações na resistência do fluxo sanguíneo.

Devido as instabilidades vasculares, tumores sólidos apresentam regiões com níveis de oxigênio limitados (hipóxia). O desequilíbrio ocorre devido o aumento do consumo de oxigênio e a entrega insuficiente de oxigênio a partir da vasculatura desordenada do tumor (Dewhirst et al., 1996). A hipóxia intratumoral é tida como a responsável por alterações do metabolismo celular, por modificações fenotípicas invasivas e metastáticas, bem como responsável pela tolerância à radiação e quimioterapia. A hipóxia é reconhecida como a principal característica de resistência do câncer aos muitos tratamentos, e várias estratégias terapêuticas têm buscado modificar a oferta de oxigênio para os tumores (Moeller et al., 2007).

A hipóxia intratumoral não ocorre apenas nas células que estão localizadas afastadas de um vaso sanguíneo funcional. Existe uma flutuação dos níveis de oxigênio em todo o microambiente tumoral. O suprimento inadequado de oxigênio acaba induzindo uma série de reações nas células, tais como: inativação de vias apoptóticas e ativação de vias pró-sobrevivência, indução de fenótipos mais invasivos e metastáticos, interrupção do metabolismo glicolítico e indução de angiogênese. Todas essas respostas visam proporcionar a adaptação ou o escape do ambiente de hipóxia.

Relatos anteriores (Dewhirst et al., 2008; Speicher et al., 2014; Yu et al., 2013), 
propuseram que até um quinto das células tumorais podem sofrer de hipóxia cíclica, mesmo estas não estando em regiões adjacentes aos microvasos do tumor. Experimentos que correlacionaram o fluxo de células vermelhas do sangue com a concentração intersticial $p \mathrm{O}_{2}$, podem indicar que os resultados de hipóxia cíclica estão correlacionados a mudanças no fluxo das células vermelhas do sangue no interior dos microvasos tumorais. A extensão natural desta observação, consiste em buscar saber o que faz com que essas variações de fluxo dos eritrócitos ocorram. Uma fonte possível, embora provavelmente não explique todas as variações de fluxo, é a alteração na atividade vasomotora de fornecimento arterial no tumor.

\subsection{Tumores cerebrais}

O termo "tumor cerebral" refere-se a um conjunto de neoplasias intracranianas. As vezes esse termo é extrapolado e utilizado mesmo que as células não surjam de tecidos cerebrais (e.g., meningiomas e linfomas). Existem 12 categorias principais de tumores cerebrais e mais de 100 subcategorias com diferentes características biológicas, mas com certa sobreposição entre eles. O glioblastoma multiforme (GBM) é o tipo de tumor cerebral primário mais comum em adultos e geralmente apresenta baixo prognóstico, sendo sua taxa média de sobrevida de 12 meses, mesmo com resseção agressiva e radioterapia. Até o momento, o tratamento eficaz de ambos os tumores cerebrais primários e metastáticos representa um grande desafio. Tumores cerebrais podem apresentar diferentes agressividades, mas mesmo os chamados tumores benignos podem provocar a morte do paciente devido as propriedades de infiltração no tecido e a alta probabilidade de tornar-se maligno ao longo do tempo (Ricard et al., 2012).

Gliomas malignos são tumores histologicamente heterogêneos e invasivos e são derivados de células da glia encefálica. As células gliais são as que formam o tecido que envolve e suporta os neurônios no cérebro. A Organização Mundial da Saúde (OMS) classifica os astrocitomas em quatro graus de prognóstico, com base em suas características histológicas: grau I (Astrocitoma pilocístico), grau II (Astrocitoma difuso), grau III (Astrocitoma anaplásico) e grau IV (Glioblastoma). Tumores de grau III e IV são considerados gliomas 
malignos. O prognóstico dos pacientes com tumor cerebral está estreitamente associado ao grau histológico do tumor (DeAngelis, 2001).

Os glioblastomas representam aproximadamente de 60 a $70 \%$ dos casos de gliomas malignos, os astrocitomas anaplásicos representam de 10 a 15\% dos casos, e gliomas de origem oligodendrocítica (oligodendróglio) e gliomas mistos (oligoastrocitomas) representam 10\%. A incidência destes tumores tem sofrido um aumento nas últimas décadas, especialmente nos indivíduos de maior idade. Este fato é associado principalmente com a melhora nos métodos de diagnóstico por imagem. Até o presente momento ainda não se identificou quais seriam as principais causas do surgimento dos gliomas malignos. O único fator de risco devidamente estabelecido é o excesso de exposição a radiação ionizante. Embora existam especulações com relação aos fatores de riscos associados aos telefones celulares, ainda não existem estudos que comprovem este fato. Existe também a possibilidade da influência de fatores genéticos, mas estudos elucidativos ainda são necessários (Maher et al., 2001; Wen \& Kesari, 2008; Westphal \& Lamszus, 2011).

O tratamento de glioblastomas permanece difícil e nenhum dos procedimentos contemporâneos são curativos. Os desafios aos tratamentos são muitos e incluem o grau de heterogeneidade do tumor, a sua difícil localização, o rápido crescimento, e a alta taxa recidiva do tumor. Portanto, o tratamento de pacientes diagnosticados com gliomas malignos ainda permanece paliativo (Wen \& Kesari, 2008).

O tratamento padrão de glioblastomas recém-diagnosticados é a máxima resseção cirúrgica, seguida de radioterapia. A resseção cirúrgica é recomendada, pois reduz os sintomas do efeito de massa (massa tumoral pressionando as outras estruturas peritumorais), melhora a sobrevida, e aumenta a eficácia das terapias adjuvantes. A quimioterapia também vem sendo utilizada concomitante a radioterapia, através do uso do agente temozolamida (TMZ) (Stupp et al., 2005). No momento, não existe um tratamento padrão para tumores recorrentes. Pacientes que foram poupados de radioterapia ou quimioterapia comumente passam por essas terapias em caso de recorrência. Existem inúmeros agentes alternativos que estão sendo utilizados em casos de falha do tratamento primário, além de muitos estudos clínicos em execução que buscam resultados de maior eficácia(Van Meir 
et al., 2010).

Por causa dos altos riscos associados a resseção cirúrgica, procedimentos menos invasivos estão sendo propostos (Sherman et al., 2011). Um dos métodos não invasivos em estudo é a ablação térmica por ultrassom. Este método utiliza as propriedades de transferência de energia mecânica da onda acústica de ultrassom ao tecido biológico, com intuito de elevar a temperatura local para valores acima de $50^{\circ} \mathrm{C}$. A ideia principal é destruir as células tumorais com pouco ou nenhum efeito deletério ao tecido sadio do entorno. Com o uso de uma rede de sondas de ultrassom, uma frente de onda acústica pode ser criada e precisamente focalizada nas diferentes regiões do cérebro (Hynynen, 2010; McDannold et al., 2010; Tempany et al., 2011). Uma vantagem do uso da ablação térmica, é o fato de não utilizar radiação ionizante, e permitir a reaplicação no caso de recorrência.

A neurocirurgia baseada no ultrassom focalizado de alta intensidade (HIFU) pode ser guiada por imagem de ressonância magnética nuclear (MRgFUS) e representa uma abordagem inovadora para o tratamento de tumores intracranianos (Dervishi et al., 2013; McDannold et al., 2010; Medel et al., 2012). A imagem por ressonância magnética nuclear (MRI), permite a segmentação do tecido alvo e também fornece o sinal de realimentação de controle ao procedimento com imagens quantitativas de temperatura (MRTI) (Lüdemann et al., 2010). O uso da MRI como guia terapêutico também se demonstrou útil em procedimentos de ablação térmica por laser (Carpentier et al., 2011). Apesar dos diversos avanços ocorridos nos últimos anos, a neurocirurgia baseada em ultrassom ainda não está totalmente implementada na área clínica, pois existem alguns desafios a serem vencidos como: a falta de controle do processo e a dificuldades na aplicação de ultrassom por através do crânio.

O uso da quimioterapia no tratamento de tumores cerebrais tem sido utilizada de forma mais sistemática somente nos últimos 10 anos, pois tradicionalmente os agentes quimioterápicos ou são ineficazes no tratamento completo de gliomas ou exibem uma série de efeitos colaterais tóxicos para os tecidos normais. A aplicação clínica da quimioterapia é limitada pois os potenciais agentes terapêuticos são geralmente incapazes de penetrar a 
barreira hematoencefálica.

A barreira hematoencefálica (BHE) é um conjunto de estruturas específicas dos vasos cerebrais, que juntas são responsáveis por manter a homeostase do sistema nervoso central. Sua principal função é controlar a transferência de substâncias presentes na circulação sanguínea para o interior do parênquima cerebral. A especificidade da BHE é determinada pela estrutura especializada da vasculatura, que é composta principalmente por três tipos de células: células endoteliais, pericitos e astrócitos (Figura 1.3). Uma das características anatômicas especificas à BHE são as chamadas "junções apertadas" que atuam conectando as células endoteliais. De modo geral, a BHE seleciona o transporte de substâncias com base na solubilidade lipídica, tamanho molecular e carga.

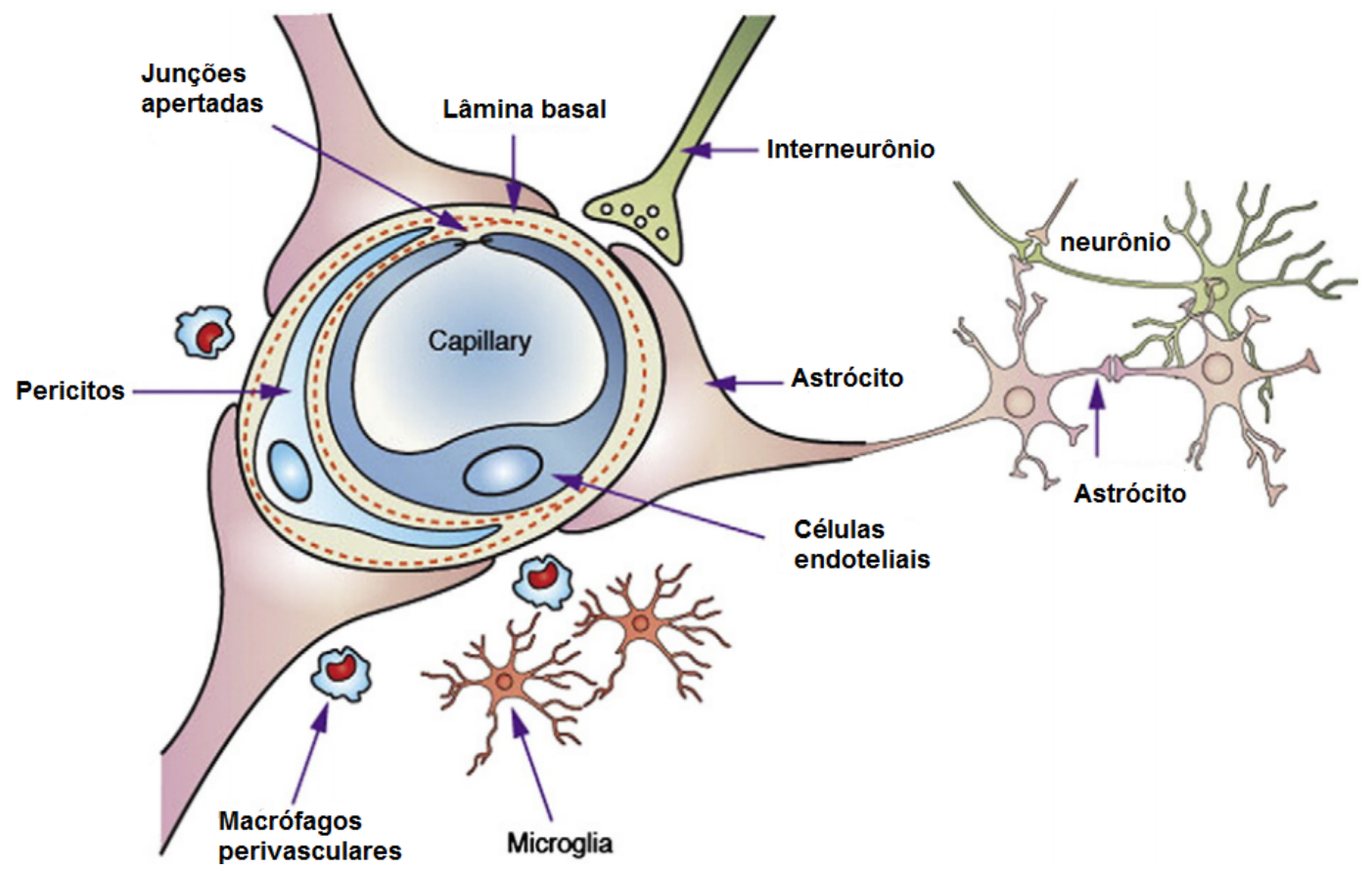

Figura 1.3: Representação esquemática da barreira hematoencefálica (BHE) e outros componentes de uma unidade neurovascular [figura extraída de (Chen \& Liu, 2012)].

Quando tumores primários ou metastáticos crescem além de 1-2 mm de diâmetro no interior do parênquima cerebral existe um efeito de comprometimento da BHE, tanto no quesito estrutural como funcional, sendo que esta alteração leva a uma perda parcial da seletividade. Desta forma, estudos funcionais indicam que a permeabilidade vascular de diferentes tumores com crescimento intracraniano são geralmente maiores que em condições normais. Estudos também sugerem que a perda da permeabilidade ocorre de forma 
não uniforme, e que o transporte através dos vasos da região tumoral ocorre de modo heterogêneo, tanto temporalmente como espacialmente.

\subsection{Tumores de bexiga}

Os cânceres de bexiga correspondem a segunda doença urológica mais comum no mundo ocidental. O câncer de bexiga é o quarto câncer mais comum em homens e o nono em mulheres nos Estados Unidos. Mais de $90 \%$ dos casos de câncer de bexiga são de carcinoma urotelial, que surgem em células do revestimento interno da bexiga chamado urotélio. Esta doença ocorre em três grandes fenótipos, separados normalmente de acordo com os objetivos de gerenciamento e prognóstico: têm-se o câncer de bexiga músculo não invasivo (NMIBC), o câncer de bexiga músculo invasivo (MIBC), e o câncer de bexiga metastático (TBC). Dentre estes fenótipos, $75 \%$ de todos os casos de cânceres de bexiga são diagnosticados como NMIBC (Owusu et al., 2013).

A classificação patológica do câncer de bexiga é definida de acordo com o padrão do tumor, as características do linfonodo, e grau de metástase. O grupo "T $a$ " é chamado de tumor papilar não-invasivo, " $\mathrm{T}_{1}$ " é definido como invasivo na lâmina própria, " $\mathrm{T}_{2}$ " - invasivo na camada muscular, " $\mathrm{T}_{3}$ " invasivo além da camada muscular até a gordura externa à bexiga, e "T $\mathrm{T}_{4}$ " invasivo em órgãos adjacentes. Considera-se como NMIBC os estágios $\mathrm{T}_{a}$ e $\mathrm{T}_{1}$ e músculo invasivo MIBC os estágios $\mathrm{T}_{2}, \mathrm{~T}_{3}$ e $\mathrm{T}_{4}$.

O NMIBC é um fenótipo que apresenta alta taxa de recidiva, porém baixo risco de metástase. Já o fenótipo MIBC apresenta grande capacidade de metástase. Logo, o gerenciamento terapêutico dos dois fenótipos é distinto. No caso do NMIBC a recidiva ocorre em um período de um ano com uma razão entre 15-61\% dos casos e para o período de cinco anos a recidiva ocorre entre $31-78 \%$ dos pacientes. Assim, o principal objetivo do tratamento de NMIBC é reduzir o risco de recidiva tumoral. Os fatores do prognóstico clínico de recidiva são o tamanho, multiplicidade, reação para terapia intravesical, estágio de evolução e presença de carcinoma in situ.

O gerenciamento padrão para tratamento do câncer de bexiga superficial consiste na completa resseção cirúrgica transuretral e na vigilância por cistoscopia. Após a resseção 


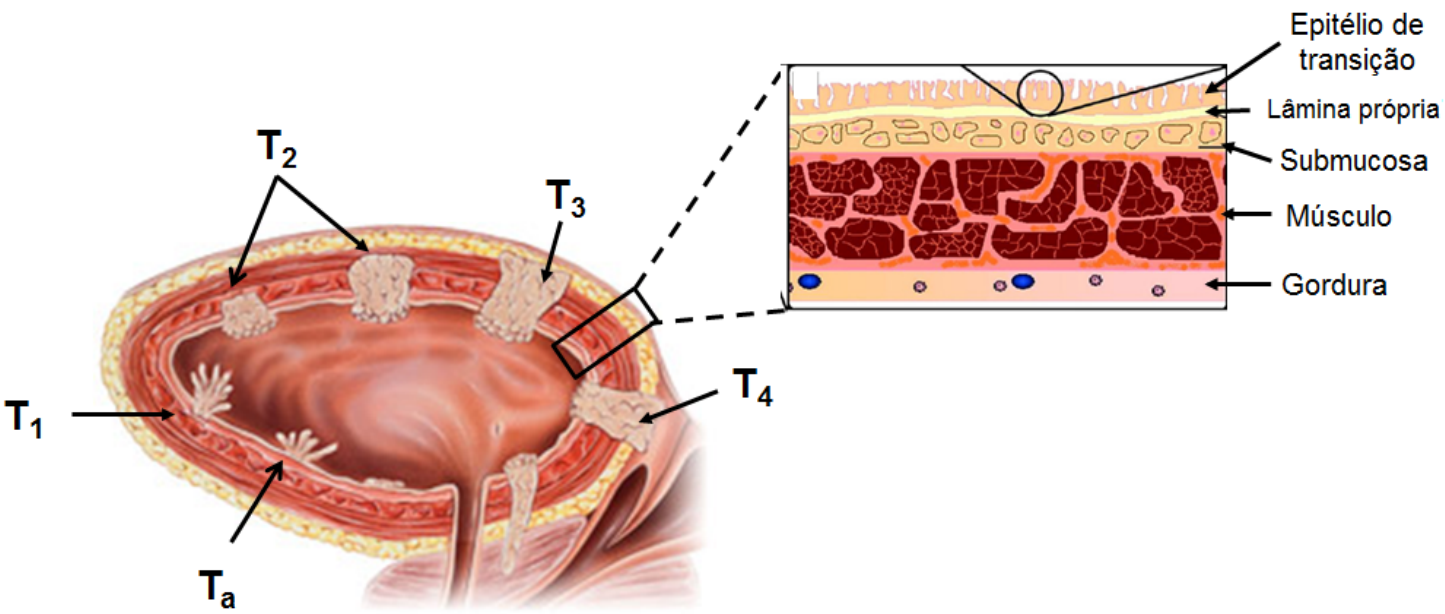

Figura 1.4: Representação esquemática dos diversos estágios do tumor de bexiga [figura adapta do (cancer.gov, 2014b)].

cirúrgica do tumor, terapias como a quimioterapia intravesical e a imunoterapia intravesical com Bacilo de Calmette-Guérin (BCG) são frequentemente utilizados com intuito de reduzir a probabilidade de recidiva. O uso de uma dose simples de quimioterapia intravesical administrada em até 24 horas após o procedimento cirúrgico pode reduzir a recidiva por uma taxa de até 30\%. A droga quimioterápica mais comum no uso intravesicular é a Mitomicina $\mathrm{C}(\mathrm{MMC})$ e Tiotepa. Infelizmente, as terapias intravesiculares correntes estão associadas com uma toxicidade indesejada ou a uma eficiência parcial. Uma das principais vantagens da aplicação da quimioterapia intravesicular, em vez da sistêmica é a localização na distribuição da droga no corpo, uma vez que restringe-se somente a bexiga e não atinge outras partes do corpo, evitando assim que os pacientes sofram muitos dos efeitos secundários indesejados.

\subsection{A hipertermia como modalidade terapêutica para tumores sólidos}

A hipertermia é o tratamento clínico para doenças malignas, no qual os tecidos tumorais são aquecidos por agentes externos a temperaturas de no mínimo $40-41^{\circ} \mathrm{C}$ e mantidas por um longo período de tempo. A hipertermia é normalmente administrada em conjunto com outras modalidades terapêuticas, formando uma estratégia terapêutica 
multimodal. A eficiência terapêutica da hipertermia depende de uma resposta diferenciada ao calor para o tecido tumoral em relação ao tecido sadio.

Em princípio, toda técnica capaz de aquecer uma dada região do corpo humano, pode ter uma atuação na hipertermia clínica. No entanto, dado o elevado número de métodos de aquecimento disponíveis para uso, é natural o questionamento de qual deve ser a melhor fonte de energia a um determinado tipo de tumor. A resposta a essa questão deve levar em consideração uma série de fatores clínicos que dificilmente são amplamente conhecidos. Assim a escolha da fonte de calor sempre estará sujeita a uma série de limitações.

\subsubsection{Efeito citotóxico direto}

A elevação da temperatura modifica a homeostase celular, uma vez que, promove alterações nos níveis de ácido nucleico, perturba a membrana celular e desequilibra o citoesqueleto. Os diversos efeitos do aquecimento podem estar associados a impactos diretos ou indiretos no funcionamento celular, estes podem induzir condições de apoptose, ou mesmo alterar o sistema de reparação e/ou mutação. Estudos de sobrevivência de células in vitro mostraram que o efeito citotóxico do calor é fortemente dependente do valor de temperatura e do tempo de exposição. Curvas de sobrevivência em função do tempo e da temperatura indicam a presença de um comportamento de dois estados no processo de desestabilização celular. Um estado com alta citotoxicidade (Temp $>43^{\circ} \mathrm{C}$ ), e um estado de temperaturas moderadas (Temp $<43^{\circ} \mathrm{C}$ ) em que as células são resistentes a uma exposição contínua ao calor (Figura 1.5).

A hipertermia é uma condição favorável à indução de morte celular por necrose e por apoptose, mas a forma induzida depende da temperatura e muda de apoptose para necrose acima de certos limites de temperatura. Relatos indicam um aumento significativo de processos de apoptose em regiões tumorais submetidos à elevação de temperatura (Hildebrandt et al., 2002; Sapareto et al., 1978). O grau de apoptose varia entre os diferentes tipos de células tumorais, assim como a localização do mesmo.

A dose térmica (proporcional ao tempo e temperatura de exposição) necessária à in- 


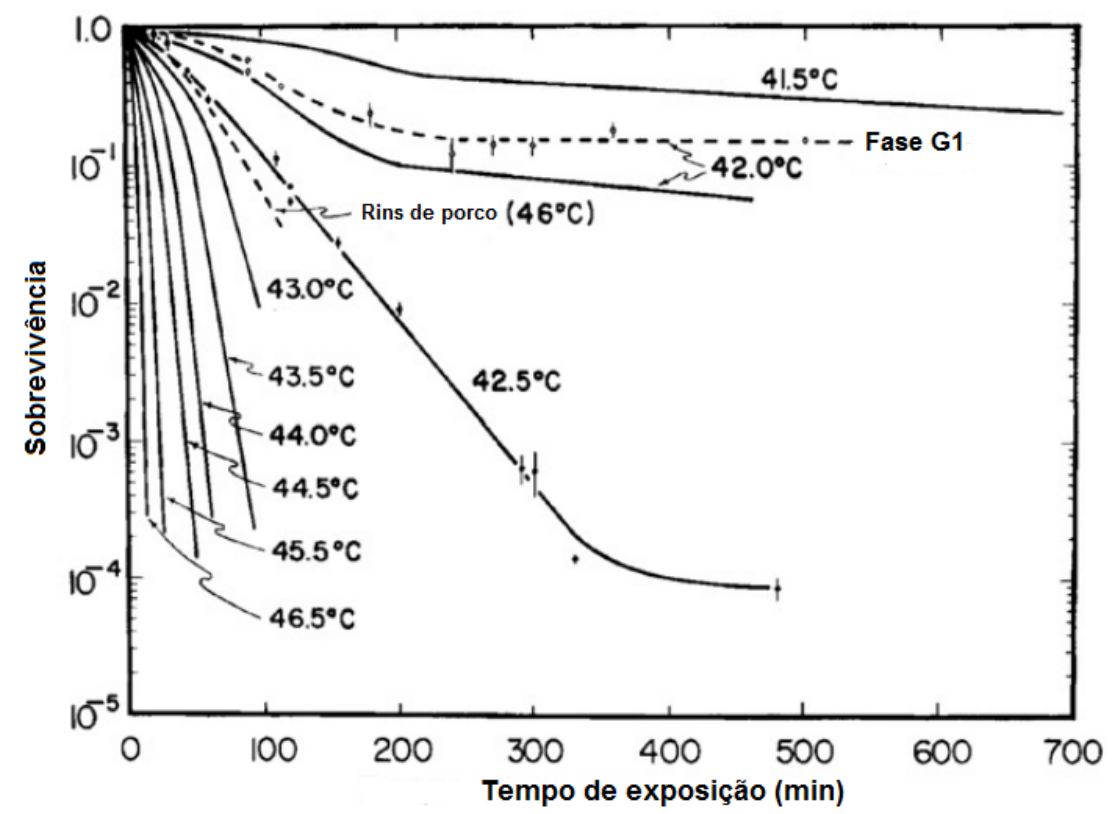

Figura 1.5: Curvas de sobrevivência para células do ovário de hámster chinês (CHO) aquecidas em diferentes temperaturas e em função do tempo. Para ilustrar a variabilidade da sensibilidade térmica das várias linhagens de células, a linha tracejada refere-se ao comportamento de uma linhagem de célula do rim de porco [figura extraída de (Sapareto et al., 1978)].

dução de morte celular é intimamente relacionada à quantidade de energia requerida para a desnaturação da proteína celular. Isso indica que o efeito citotóxico da hipertermia por si só é principalmente associado à desnaturação de proteínas de membrana, citoplasmáticas e nucleares. Os efeitos pleiotrópicos em função da temperatura e os eventos moleculares são ilustrados na Figura 1.6.

Durante o procedimentos de hipertermia, temperaturas intratumorais entre $40^{\circ} \mathrm{C}$ e $44^{\circ} \mathrm{C}$ podem ser escolhidas. No nível molecular os mecanismos de termosensibilização associam-se à desnaturação e agregação de proteínas, que impactam o maquinário de reparação do DNA e o ciclo de regulação celular. Contrário ao efeito deletério, temperaturas sub-letais induzem a um aumento da expressão de proteínas de heat shock (i.e. HSP70), que atuam tornando as células termoresistentes de forma transiente. Doses térmicas acima do ponto de transição $\left(43^{\circ} \mathrm{C}\right)$ provocam citotoxicidade direta e células tumorais morrem exponencialmente por indução de apoptoses e necrose. A morte celular induzida por calor é imunogênica através da liberação de HSPs e HSP-PC no ambiente extracelular. 


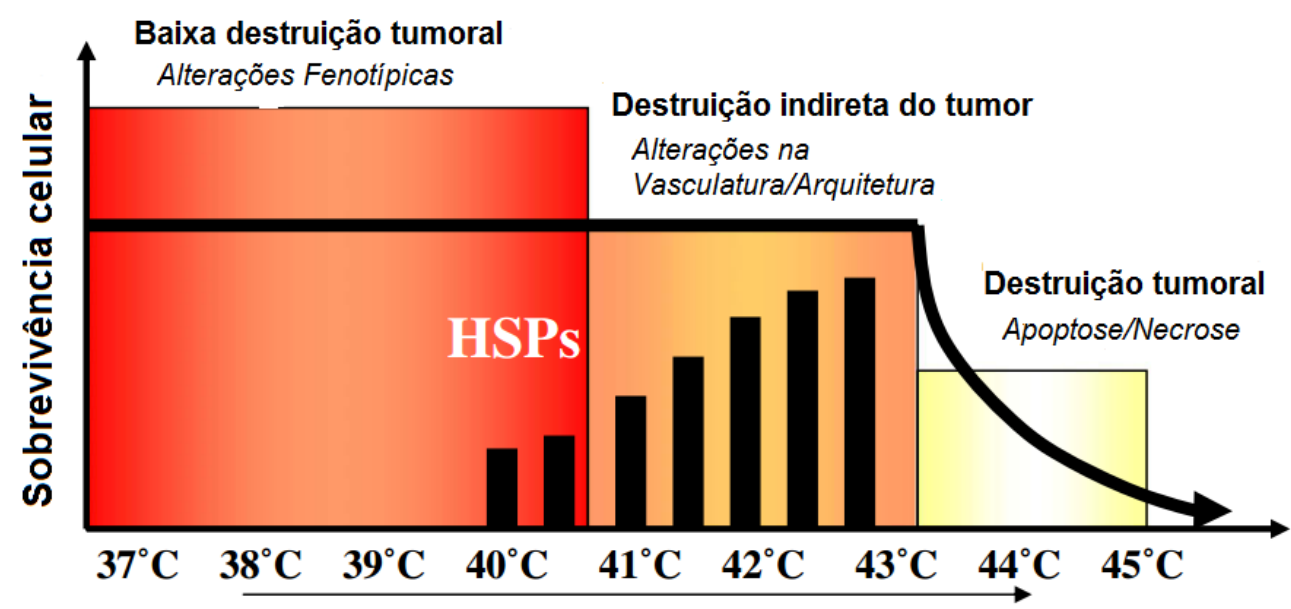

Figura 1.6: Ilustração do comportamento dos efeitos pleiotrópicos celular e efeitos moleculares em função da temperatura. Aquecimentos com doses térmicas menores que o ponto de transição (i.e. $43^{\circ} \mathrm{C} / 60 \mathrm{~min}$ ) não exerce uma citotoxicidade direta (temperatura sub-letal). O efeito antitumoral do calor é consequência da sensibilização ao quimioterápico e a radiação [figura extraída de (Issels, 2008)].

\subsubsection{Impacto da hipertermia no fluxo sanguíneo}

O fluxo sanguíneo em tumores varia consideravelmente entre os diferentes tipos de tumor. Mesmo no próprio tumor, a distribuição da vasculatura e fluxo sanguíneo são heterogêneos. O fluxo sanguíneo geralmente decresce conforme o tumor aumenta de tamanho, em parte devido o progressivo deterioramento da rede vascular e devido ao rápido crescimento da população celular com relação ao crescimento da rede vascular.

Contrário ao senso comum, que o fluxo sanguíneo deve ser menor a região tumoral que nos tecidos normais, o fluxo sanguíneo em muitos tumores, principalmente os menores, é maior que o fluxo nos tecidos sadios do entorno. No entanto, a resposta do fluxo à alteração de temperatura são distintas e comparado ao fluxo sanguíneo normal, os tumores possuem capacidade de modulação ao aquecimento muito menor. Com isso, regiões tumorais carecem de um sistema eficiente de troca de calor e sofrem elevações de temperatura superiores aos valores apresentados por tecidos sadios.

Em tecidos normais, é sabido que o calor induz uma rápida resposta de aumento do fluxo sanguíneo, que é acompanhando pela dilatação dos vasos e um aumento da permeabilidade da parede vascular (Song et al., 1996; Vaupel \& Horsman, 2010). O grau de 
mudanças patofisiológicas do sistema vascular, no caso sadio, é dependente da temperatura e da duração do calor. Um excesso de exposição dos tecidos ao calor resulta em um colapso da vasculatura seguida pela necrose do tecido. Um exemplo desse comportamento do fluxo sanguíneo em função da temperatura pode ser visualizado na Figura 1.7.

O fluxo sanguíneo no músculo aumenta de 3 e 6 vezes o valor de controle (4 $\mathrm{mL} / 100 \mathrm{~g} / \mathrm{min}$ ) durante um aquecimento de 60 minutos a 43 e $44^{\circ} \mathrm{C}$, respectivamente, e mantém-se elevado até duas horas de aquecimento (Figura 1.7B). A $45^{\circ} \mathrm{C}$, o fluxo sanguíneo do músculo aumenta até 9 vezes em 30 minutos, e retorna ao valor de controle inicial após duas horas de aquecimento.

No caso de tecidos tumorais, sabe-se que as alterações no fluxo sanguíneo, induzidas pelo calor, são consideravelmente distintas dos tecidos sadios. Achados anteriores (Figura 1.7A) indicam que o aumento do fluxo sanguíneo na região tumoral responde a um fator de aproximadamente 2 vezes quando aquecido por uma hora a $43,5^{\circ} \mathrm{C}$, enquanto o fluxo sanguíneo em tecidos sadios sofre um aumento muito superior.

Em resumo, existem diverso relatos que evidenciaram que a resposta da rede vascular tumoral ao calor é consideravelmente inferior ao comportamento do tecido sadio. O efetivo uso clínico da hipertermia depende da manipulação cuidadosa destes princípios biológicos. A vasculatura tumoral é menos eficaz em trocar calor, e mais propícia a ser danificada quando tratada com hipertermia.

\subsubsection{Interação da hipertermia com agentes quimioterápicos}

A combinação de calor com agentes quimioterápicos pode produzir um efeito cooperativo, que deve depender do agente específico. Em geral, a citotoxicidade de drogas demonstram um aumento na inibição clonogênica do crescimento celular (in vitro) em condições de temperaturas elevadas. Existem extensivas revisões avaliando os efeitos positivos da combinação da hipertermia e quimioterapia publicados na literatura (Colombo et al., 2003b; Issels et al., 2010a,b). O calor modifica a citotoxicidade de muitos agentes terapêuticos. A taxa de melhora térmica (TER) é maximizada para temperaturas entre 40,5 e $43^{\circ} \mathrm{C}$. 

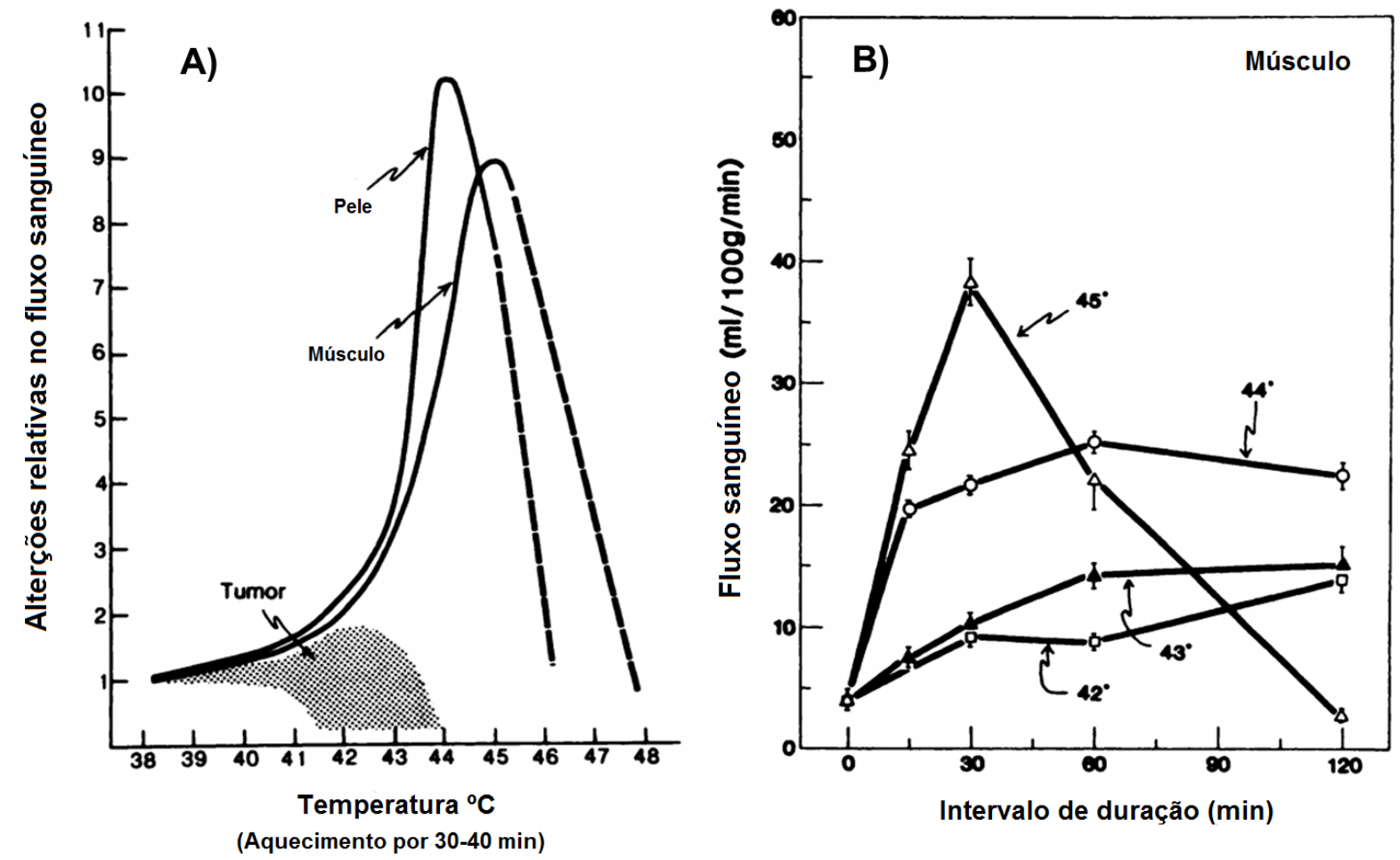

Figura 1.7: Gráfico A) apresenta mudanças relativas no fluxo sanguíneo na pele e no músculo de ratos em diversos tumores animais em diferentes temperaturas. Gráfico B) apresenta a resposta do fluxo sanguíneo em função do tempo de exposição para o músculo do rato durante o aquecimento em diferentes temperaturas [gráficos extraídos de (Song, 1984)].

Neste intervalo de temperatura existe o aumento do fluxo sanguíneo, este aumento melhora a oxigenação e a entrega de drogas em áreas de baixa vascularização, produzindo um aumento da concentração de droga no local. Além dos efeitos fisiológicos, a sinergia entre calor e medicamento pode promover benefícios no nível celular, pois devido ao impacto do calor no comportamento das proteínas e no sistema de reparação do DNA o efeito das drogas pode ser potencializado. Os benefícios do calor podem incluir também o aumento da absorção celular de medicamentos. Estudos apontam que, em geral, drogas administradas imediatamente depois de um pré-aquecimento são mais efetivas (Manzoor et al., 2012; Ponce et al., 2007a).

Complementarmente, tem sido mostrado que para a Mitomicina C, Nitrosureas, Cisplatina, Doxorrubicina e o Mitoxantrone a adição da hipertermia com a quimioterapia pode neutralizar a resistência aos medicamentos. Geralmente, essa interação positiva é 
vista somente quando os dois tratamentos são aplicados em uma sequência próxima. Na Figura 1.8 são apresentados um resumo de resultados de sobrevida para a combinação hipertermia-quimioterapia quando comparado à quimioterapia sozinha.

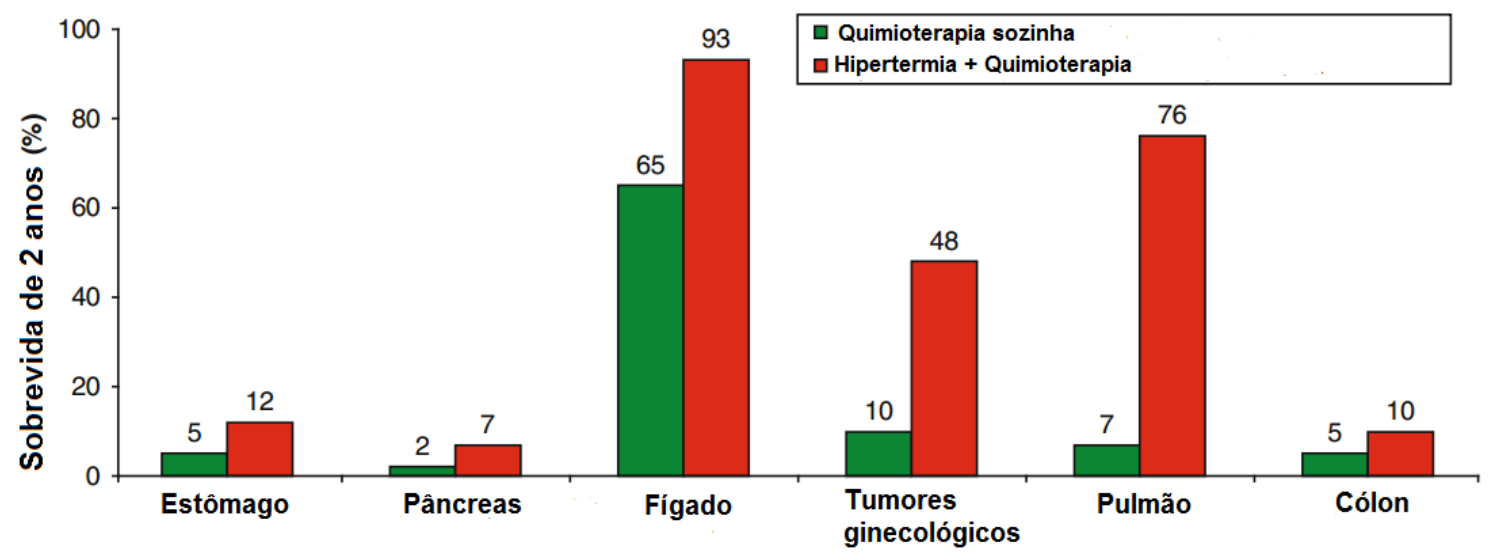

Figura 1.8: Comparação da sobrevida de 2 anos após tratamento com hipertermia e quimioterapia e quimioterapia sozinha. Os agentes usados foram em geral a Adriamicina, Bleomicina, Cisplatina, Mitomicina e 5FU. A hipertermia foi aplicada entre 40 e 60 minutos, utilizando-se um dispositivo de aquecimento capacitivo, excitado em $8 \mathrm{MHz}$ [figura extraída de (Szasz et al., 2011)].

De modo geral, a combinação hipertermia e quimioterapia apresenta impactos positivos no resultado terapêutico. O protocolo de experimentos clínicos da combinação de calor e droga deve também levar em consideração as mudanças induzidas na farmacocinética dos medicamentos sob condições de hipertermia.

\subsubsection{Interação da hipertermia com a radioterapia}

Diversos estudos experimentais e clínicos disponíveis na literatura propõem o uso combinado da radiação e hipertermia no tratamento do câncer (Gonzalez et al., 1986; van der Zee et al., 2000; Zagar et al., 2010) como estratégia para melhora terapêutica. A principal argumentação a favor desta terapia combinada está no fato que células em condições de hipóxia podem ser seletivamente mortas pelo efeito de radio-sensibilização.

Células em condições de hipóxia são aproximadamente três vezes mais radio-resistentes quando comparadas com células em condições normais de oxigenação e, portanto, regiões de hipóxia em tumores sólidos humanos, limitam o controle tumoral por radioterapia. A 
condição de baixa oxigenação reduz a sensibilidade do tumor à radiação ionizante, através de mecanismos indiretos que incluem mudanças proteômicas e genômicas. A hipertermia moderada pode alterar esta limitação, pois com a alteração do fluxo sanguíneo e melhora da permeabilidade dos vasos, promove um aumenta da pressão de oxigenação.

O tempo de exposição ao aumento de temperatura promove maior indução de morte celular por radiação ionizante na região de oxigenação limitada, e decresce se o intervalo entre a aplicação das duas modalidades aumentar. A máxima contribuição térmica ocorre quando radiação e hipertermia são aplicadas simultaneamente, porém cuidados são necessários, pois esse efeito catalizador das modalidades combinadas também altera a radiosensibilidade dos tecidos sadios. A Figura 1.9 apresenta um resumo dos resultados publicados pela Sociedade Japonesa de Hipertermia, que compara os procedimentos clínicos que utilizaram somente a radioterapia e tratamentos que combinaram a radioterapia e a hipertermia nos diferentes tipos de tumor.

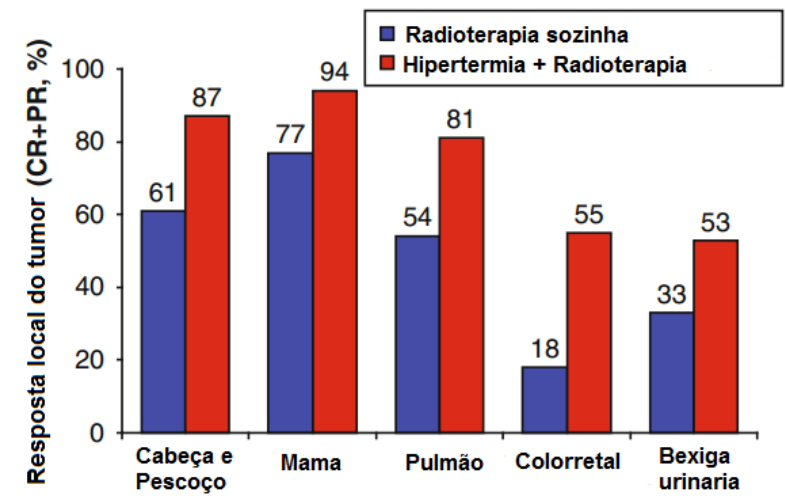

(a)

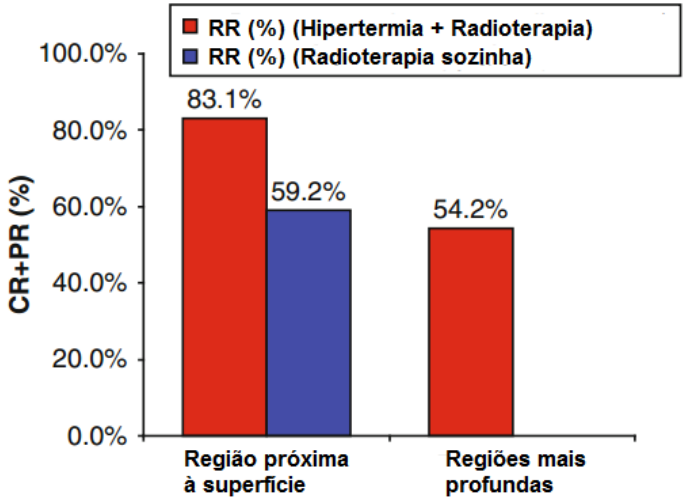

(b)

Figura 1.9: Resumo dos resultados obtidos pela Sociedade Japonesa de Hipertermia utilizandose a hipertermia capacitiva combinada com a radioterapia. Em (a) as siglas CR e PR são abreviações para: "Complete Remission/Response" (CR) e "Partial Remission/Response" (PR). Em (b) a sigla RR indica a abreviação para "Response Rate" (RR) [figura extraída de (Szasz et al., 2011)].

De modo geral, os resultados da Figura 1.9 indicam que a resposta do tratamento combinado (RT + hipertermia) é mais eficiente nos órgãos indicados acometidos por câncer. Assim, tem-se que a hipertermia constitui um dos mais potentes radiosensibilizadores conhecidos até hoje. 


\subsubsection{Efeitos da hipertermia no sistema imunológico}

Não há dúvida sobre a estreita ligação entre o câncer e o sistema imunológico,um exemplo disso é que o potencial clínico de diferentes estratégias de imunoterapia estão sendo avaliados (Rosenberg et al., 2004). A condição de febre é identificada como um mecanismo de defesa do organismo. Ela é parte do arsenal de combate a doenças do corpo, pois com aumento da temperatura corporal torna-se possível controlar muitos organismos causadores de doenças, diminuindo sua taxa de crescimento e reduzindo a sua capacidade de invadir a circulação do hospedeiro. Entre os vários desencadeadores possíveis, a febre pode ocorrer em resposta a agentes infecciosos, a tensões ambientais, a certos medicamentos e doenças. A partir de observações clínicas, o estado febril também foi encontrado em associação com a regressão espontânea de tumores (Cann et al., 2003; Hobohm, 2005). Por esta razão, a febre foi usada como uma ferramenta para o tratamento da doença pelo aumento deliberado da temperatura do corpo do paciente.

A consideração que a hipertermia externamente induzida possa mimetizar a condição febril do corpo, levando a uma reação imunológica aparente, estimulou vários estudos in vitro no início da década de 1980 (Azocar et al., 1982; Mullbacher, 1984; Tomasovic \& Klostergaard, 1989), buscando avaliar os efeitos do calor na estrutura dos linfócitos humanos, principalmente focando em funções imunológicas não migratórias dos linfócitos. De um ponto de vista recente, é muito difícil chegar a uma conclusão efetiva sobre os efeitos da hipertermia no sistema imune, pois eles são variados.

Em certas circunstâncias, a hipertermia parece estimular o sistema imune, como por exemplo inibir o crescimento tumoral por um desarranjo das paredes celulares. Já em outras situações a elevação da temperatura mostra-se como um inibidor da ação imune, devido a indução de danos específicos nos macrófagos e células T. Shen e colaboradores mostraram que para temperaturas menores que $40^{\circ} \mathrm{C}$, existe um aumento de células $\mathrm{NK}$ ativadas por linfocina ou LAK, em função a exposição a IFN-gama, porém estes efeitos são reversos quando temperaturas acima de $42^{\circ} \mathrm{C}$ são utilizadas (Shen et al., 1994). Em resumo, a relevância clínica dos efeitos da hipertermia no sistema imune ainda continua a ser compreendida (Hildebrandt et al., 2002; Zhang et al., 2008). 


\subsection{Lipossomos termosensíveis como sistema de entrega controlada de droga}

Como consequência dos diversos fatores limitantes, a quimioterapia sistêmica dificilmente atinge os níveis de eficiência desejados sem promover danos a órgãos e tecido sadios circunvizinhos. No entanto, contrária a esta dura realidade, diversos estudos propõem novas formulações que possam minimizar os efeitos deletérios dos medicamentos nos tecidos sadios, sem que haja perda de eficiência na região tumoral.

Uma destas soluções alternativas consiste no encapsulamento dos quimioterápicos em materiais biocompatíveis, que possam ser injetados na circulação sanguínea e que sirvam de carreador do medicamentos. Diferentes sistemas transportadores têm sido propostos na literatura (Langer, 1998; Roth \& Cristiano, 1997), sendo a maioria deles à base de polímeros biocompatíveis e/ou agregados de moléculas anfifílicas.

Moléculas anfifílicas são aquelas que contêm grupos polares e grupos apolares (como cadeias hidrocarbônicas ou parafínicas), com distintas propriedades de solubilidade. Assim, tanto em solvente aquoso como em solvente orgânico, podem formar agregados supramoleculares, nos quais ocorre separação espontânea das partes de diferentes polaridades. De maneira geral, em solução aquosa, os anfifílicos de duas cadeias hidrocarbônicas longas, e/ou cabeças polares pequenas, agrupam-se em bicamadas planas, que muitas vezes organizam-se naturalmente em vesículas (bicamadas fechadas com compartimento aquoso interno) unilamelares ou multilamelares, estas últimas também chamadas lipossomos.

O uso de lipossomos no transporte de drogas há muito tem sido estudado (Drummond et al., 1999; Lian \& Ho, 2001), devido a sua boa estabilidade na circulação sanguínea e alta camuflagem ao sistema de proteção (Moghimi \& Szebeni, 2003; Moghimi et al., 2001). No entanto, os lipossomos tem, de modo geral, baixa taxa de liberação da droga ao local da lesão. A especificidade na liberação está associada a fatores de interação droga-transportador e a fatores de interação transportador-alvo, os quais devem ser muito bem conhecidos para que se tenha uma boa eficiência. Idealmente, interações droga-transportador devem ser interações do tipo modulável, tal que estas sejam estáveis o suficiente durante o seu transporte, porém, instável o suficiente ao atingir o alvo 
desejado.

Os lipossomos são agregados supramoleculares, compostos por moléculas anfifílicas que agrupam-se em bicamadas planas no ambiente aquoso por consequência das interações hidrofóbicas entre as cadeias hidrocarbônicas longas dos anfifílicos e as moléculas da água, e acabam por formar as chamadas vesículas (Lasic, 1988; Lipowsky, 1991). O transporte de agentes quimioterápicos por sistemas vesiculares ocorre através do encapsulamento dos mesmos no interior das vesículas, para o caso do transporte de drogas hidrofílicas, ou por interiorização na bicamada lipídica ou adsorção na superfície, para o caso de drogas lipofílicas. Drogas encapsuladas em lipossomos podem ser liberadas passivamente por difusão e degradação do lipossomos, ou por mecanismos de ativação externos, como a alteração do pH ou temperatura local.

Os lipossomos quando injetados na circulação sanguínea possuem a tendência de acumular-se preferencialmente nos tumores sólidos (Lasic \& Papahadjopoulos, 1995; Papahadjopoulos et al., 1991). Este acumulo é justificado pela alta permeabilidade da vasculatura tumoral (EPR) e pelo longo período de circulação dos mesmos. Devido estas características, lipossomos constituem-se em um transportador de grande atrativo para agentes anticânceres.

Apesar das diversas vantagens associadas aos lipossomos como transportadores, os resultados clínicos apresentados na literatura não demostram melhorias significativas de eficiência terapêutica quando comparado ao tratamento com drogas livres (Becker et al., 2002). Isto ocorre parcialmente devido ao tamanho dos lipossomos (100nm de diâmetro), quando comparado à distância interfibrilar da matriz extracelular, por que os fazem acumular nas regiões perivasculares. Além do fator tamanho, os lipossomos também possuem baixa taxa de liberação da droga ao local da lesão (Chen et al., 2008; Dreher et al., 2006a).

Frente às diferentes limitações encontradas nas diversas aplicações anticâncer, temse buscado estratégias terapêuticas que possam utilizar os benefícios da hipertermia como agente modificador do ambiente fisiológico e facilitador da distribuição de fármacos, junto com os benefícios de redução da toxidade e acumulação dos lipossomos no tumor. Este conceito orientou os pesquisadores a buscar sistemas que possam liberar de forma contro- 
lada a droga encapsulada quando submetidos a variações de temperatura. Essa estratégia foi materializada quando desenvolveram-se os lipossomos termosensíveis (TSL), que são lipossomos que promovem uma entrega controlada ativada pelo aumento da temperatura local $\left(42^{\circ} \mathrm{C}\right)$. Essa liberação controlada incrementa o grau de especificidade à lesão, pois somente regiões com temperaturas acima de um certo limite estarão submetidas a altas concentrações de medicamento.

Os lipossomos termosensíveis surgiram no fim da década de 70 (Yatvin et al., 1978), cuja proposta era a utilização de aquecimento local moderado como ativador da liberação de drogas encapsuladas. Essa ideia surgiu baseada no trabalho de Jacobson e Papahadjopoulos, que observaram uma anomalia na permeabilidade das bicamadas lipídicas a pequenos íons quando próximos à temperatura de transição de fase principal (Jacobson \& Papahadjopoulos, 1975). Na época, o lipossomo utilizado por Yatvin era majoritariamente composto pelo fosfolipídio dipalmitoilfosfatidilcolina (DPPC), o qual possui temperatura de transição de fase ao redor de $41,5^{\circ} \mathrm{C}$.

Bicamadas lipídicas, de modo geral, podem apresentar dois estados de organização, um bastante organizado, ou empacotado, chamado de fase gel, e outro mais fluído ou desorganizado, chamado de fase líquido-cristalina. A transição entre os dois estados, gelfluido, também chamada transição de fase principal, é uma transição ordem-desordem das cadeias, que apresenta um calor latente, sendo bem caracterizada por calorimetria e por várias técnicas espectroscópicas e de espalhamento (por ex., ver (Gennis, 1989)).

Bicamadas ou monocamadas de anfifílicos, devido à composição interior essencialmente apolar, são barreiras eficientes à passagem de íons e moléculas polares. Esta propriedade tem sido de vital importância para todo tipo de célula que através de mediadores, como canais e bombas, podem realizar o transporte controlado de íons e moléculas através da membrana plasmática. Contudo, o trabalho de Jacobson (Jacobson \& Papahadjopoulos, 1975) demonstrou que mesmo na ausência de mediadores (canais e bombas) é possível modular a permeabilidade de bicamadas lipídicas a íons.

Apesar dos mais de trinta anos da primeira publicação abordando os lipossomos termosensíveis (TSL), diversas dificuldades como a velocidade de liberação da droga e o 
baixo tempo de meia-vida de circulação na corrente sanguínea, impediram os TSL de serem aplicados na clínica médica. Porém, este cenário começou a ser alterado quando muitos dos problemas anteriores foram minimizados com o advento de uma nova formulação proposta em 1996 por Gaber (Gaber et al., 1996). A proposta de Gaber foi aprimorada anos depois por Needham (Needham et al., 2000) que por fim batizou a formulação de "LTSL".

A LTSL constitui-se de lipossomos termosensível formados por lisofosfolípidios, que aumentam a permeabilidade da bicamada ao medicamento, e lipídios PEGlados (Polietilenoglicol) que tornam o tempo de vida na circulação sanguínea maior. Após o desenvolvimento da LTSL, estes ganharam um novo interesse na comunidade científica e diversos estudos pré-clínicos tem demonstrado a sua eficácia como agente anticâncer (Kong et al., 2000a; Yarmolenko et al., 2010). Resultados demonstram uma capacidade de liberação da droga ao tumor até trinta vezes superior às atingidas com as drogas livres e de três a cinco vezes superior a um lipossomo tradicional (Kong et al., 2000a, 2001).

Após os diversos resultados pré-clínicos positivos, as LTSL sofreram um rápido avanço e surgiu a primeira formulação aprovada para o uso em estudos clínicos. Essa primeira formulação é chamada de ThermoDox@(Celsion corporation, Columbia, MD, USA), pois transporta a droga doxorrubicina (DOX) encapsulada nos LTSL. Em 2006 iniciaram-se os primeiros estudos clínicos fase I nos Estados Unidos. Atualmente, existem três estudos clínicos fase III em andamento nos Estados Unidos (celsion.com, 2014), todos utilizando a formulação ThermoDox. O estudo voltado para o câncer loco-regional de mama recorrente conta com a participação da Duke University Medical Center.

O uso mais sistemático das LTSL em estudos clínicos fizeram com que novos desafios e problemáticas emergissem. Os novos desafios de aplicabilidade clínica das LTSL norteiam a execução deste trabalho de doutorado. Especificamente, o interesse aqui está em avaliar uma metodologia capaz de determinar a distribuição espacial dos quimioterápicos encapsulados em LTSL, quando submetidos ao procedimento de aquecimento, de modo não-invasivo. 


\subsection{A equação de calor em sistemas biológicos}

Informações confiáveis de temperatura durante a clínica de hipertermia e ablação térmica é essencial para o controle adequado do tratamento, tanto na região do tumor, como em potenciais locais de hot spot no tecido normal. A termometria clínica geralmente é realizada de forma invasiva, com sondas de termometria inseridas na extremidade fechada de cateteres. O número de medidas invasivas é limitado para evitar a dor e infecções no paciente.

O transporte de energia térmica em tecidos biológicos é um processo complexo que envolve múltiplos mecanismos fenomenológicos como a condução, convecção, radiação, metabolismo, evaporação, e mudanças de fase. A compreensão dos mecanismos de transferência de calor em biomateriais requer um conhecimento preciso das propriedades térmicas e de perfusão do tecido. A presença da vasculatura é o principal fator que diferencia os tecidos biológicos de materiais não biológicos. Devido o grande número de vasos e sua complexa arquitetura é possível imaginar que a descrição individual de cada vaso seja inviável ao estudo do processo de transferência de calor, com exceção somente às grandes artérias e veias. Em primeira aproximação, tecidos biológicos comportam-se como um sólido homogêneo como propriedades térmicas dependendo da quantidade de água contida no volume tecidual.

Define-se fluxo sanguíneo como sendo a fração de volume de sangue transportado por unidade de tempo. O fluxo sanguíneo é normalmente medido através de uma superfície e inclui ambas as propriedades, direção e amplitude. Por exemplo, um fluxo cardíaco de saída de " $5 \mathrm{~L} / \mathrm{min}$ " indica que o coração deve bombear aproximadamente $83 \mathrm{~mL}$ de sangue por segundo por através da válvula aórtica. Com relação a termodinâmica deste sistema, grande parte dos efeitos de transferência de calor ocorrem nas arteríolas terminais (pequenos vasos com diâmetros de aproximadamente 50-100 $\mu \mathrm{m}$ ). Como, existem milhões de arteríolas terminais em um tecido típico, seria inviável analisar a transferência de calor de um conjunto enorme de arteríolas. Afim de resolver isso, é usado a definição de 
perfusão, que é a taxa de fluxo de massa de sangue por volume de tecido:

$$
\dot{\omega}_{b} \equiv \frac{\text { massa }_{\text {sangue }}}{\text { volume }_{\text {tecido }} \cdot \text { tempo }} \quad\left(\mathrm{kg} / \mathrm{s} \cdot \mathrm{m}^{3}\right)
$$

Esse método de descrever a perfusão sanguínea é denominado como modelo contínuo. O modelo contínuo da transferência microvascular busca avaliar o efeito médio sobre os diversos vasos do volume tecidual, tal que, a velocidade sanguínea não necessita ser modelada em detalhe. Este tipo de modelo normalmente é usado em equações de difusão de calor modificado, no qual os efeitos da perfusão são computados por um ou mais termos adicionais na equação. Logo, a solução deste tipo de equação não fornecerá informação do comportamento da temperatura próximo a um determinado vaso, mas fornecerá um comportamento médio da temperatura do tecido.

O modelo contínuo de maior expressão é o modelo desenvolvido pelo fisiologista Harry Pennes em 1948 (Pennes, 1948), que inicialmente foi designada para predizer a distribuição de temperatura do antebraço humano. Pennes, em seu modelo, assumiu que a principal região de equilibro térmico ocorre no leito capilar e cada volume do tecido possui um aporte de sangue arterial na temperatura basal do corpo $\left(T_{a}\right)$. Atualmente o modelo continuo de Pennes se transformou na conhecida "Bio-heat transfer equation" (BHT) e é normalmente descrita como:

$$
\nabla \cdot \kappa \nabla T_{t}+\epsilon \dot{\omega}_{b} \rho_{b} c_{b}\left(T_{a}-T_{t}\right)+\dot{q}^{\prime \prime \prime}+Q=\rho c \frac{\partial T_{t}}{\partial t}
$$

sendo " $\mathrm{T}_{t}$ " a temperatura instantânea do tecido $\left({ }^{\circ} \mathrm{C}\right)$, " $\rho$ " e "c" são a densidade de massa $\left(\mathrm{kg} / \mathrm{m}^{3}\right)$ e calor específico $(\mathrm{J} / \mathrm{kg} . \mathrm{K})$ do tecido, respectivamente; " $\kappa$ " é a condutividade térmica (W/m.K), " $\dot{\omega}_{b}$ " é a taxa volumétrica de fluxo sanguíneo $\left(\mathrm{kg} / \mathrm{s} \cdot \mathrm{m}^{3}\right)$, " $\rho_{b}$ " é a densidade do sangue $\left(\mathrm{kg} / \mathrm{m}^{3}\right)$, " $c_{b}$ " o calor específico do sangue $(\mathrm{J} / \mathrm{kg} \cdot \mathrm{K})$, " $T_{a}$ " é a temperatura arterial do sangue, nominalmente definida como $37^{\circ} \mathrm{C}$, "Q" corresponde a uma densidade de fonte de calor $\left(\mathrm{W} / \mathrm{m}^{3}\right)$ e $\dot{q}^{\prime \prime \prime}$ corresponde a taxa metabólica de produção de calor.

Até o momento, a descrição clássica da equação de Pennes continua sendo amplamente aceita e considerada como a melhor abordagem para fins práticos. Isto ocorre pois muitos outros modelos ainda padecem de resultados experimentais ou são extremamente complexos para serem implementados na rotina clínica. Embora a anatomia real do sistema biológico possa ser inserida ao problema, a simplicidade de solução da equação de 
Pennes faz com que este modelo seja o modelo de escolha para a maioria dos estudos dos processos de transporte de calor em situação de hipertermia.

A falta de informação anatômica não invalida o modelo, desde que o volume médio escolhido seja grande o suficiente para englobar diferentes vasos de diferentes tamanhos onde o equilíbrio irá ocorrer, e desde que o retorno venoso não troque calor significativamente após sair da região de equilíbrio.

\subsection{Objetivos}

O principal objetivo deste trabalho foi viabilizar o estudo da entrega e distribuição termo-estimulada de quimioterápicos ao cérebro de camundongos monitorados por microscopia fluorescente confocal intravital. Para tanto, foi necessário desenvolver um dispositivo de aquecimento, capaz de aquecer somente parte do cérebro, e toda instrumentação de suporte.

Em paralelo, estudou-se a viabilidade e aplicabilidade de novas fontes de calor dedicadas ao aquecimento localizado e específico de tecidos profundos. Neste trabalho, a bexiga foi a estrutura de escolha e a metodologia avaliada foi a magneto-hipertermia, através de estudo in vivo

\subsection{Sumário do conteúdo da Tese}

Esse trabalho foi executado em colaboração com a divisão de Hipertermia da Duke University Medical Center, nos Estados Unidos, e contou com a supervisão dos professores Paul Stauffer e Paolo Maccarini. O texto aqui apresentado está dividido em seis capítulos. No Capítulo 2 apresenta-se todo o desenvolvimento do mini-aplicador de micro-onda dedicado ao aquecimento não-invasivo do cérebro de camundongo, desde o projeto até os testes de eficiência. O Capítulo 3 mostra o estudo de eficiência de liberação termoestimulada da doxorrubicina na região de tumores modelos de glioblastoma através da visualização da distribuição local do medicamento por microscopia confocal de fluorescência, consequência do aquecimento gerado pelo mini-aplicador de micro-onda. O Capítulo 
4 discute a viabilidade do uso de nanopartículas magnéticas como fonte de calor para o aquecimento da bexiga de ratos. O capítulo 5 resume os principais achados deste estudo e fornece as conclusões finais. 


\section{Capítulo 2}

\section{Desenvolvimento de um mini-aplicador de micro-onda dedicado ao aquecimento do cérebro de pequenos camundongos}

Um dos principais desafios da termoterapia está justamente no desenvolvimento de instrumentação compativel com os requisitos terapêuticos. Em princípio, o sistema de hipertermia ideal consiste de um dispositivo, composto por várias antenas, capaz de transferir energia eletromagnética para o tecido biológico de forma controlada, e com grande resolução espacial. Entretanto, na situação real, existe um número grande de limitações práticas que dificultam a construção do sistema ideal, embora atualmente os sistemas estejam lentamente se aproximando das condições ideais. Neste capitulo, apresentamos o projeto, a construção e os testes de eficiência de aquecimento de um sistema eletromagnético, guia de onda, dedicado exclusivamente ao uso em ensaios in vivo, e que permite o estudo da hipertermia no cérebro de camundongo. Os resultados aqui apresentados apontam que o sistema pode ser considerado satisfatório. 


\subsection{Introdução}

Existe um consenso na comunidade de hipertermia de que a qualidade do tratamento de hipertermia determina o resultado do tratamento (Franckena et al., 2010; Lagendijk, 2000; Paulides et al., 2013). Diversos experimentos clínicos demonstraram a correlação entre o resultado terapêutico e os parâmetros de dose térmica. A determinação de um parâmetro de segurança deve auxiliar na prática e no uso da hipertermia como adjuvante da radioterapia e quimioterapia (Canters et al., 2009). Uma das principais causas de inomogeneidade da temperatura, ou consequente baixa qualidade do tratamento de hipertermia, é o efeito do suporte sanguíneo local. O sangue arterial atinge a área de aquecimento com a temperatura basal, e a complexidade da vasculatura local provoca uma heterogeneidade da perfusão sanguínea e uma consequente má distribuição da dose térmica. Portanto, um dos maiores desafios da hipertermia está em promover uma distribuição de temperatura homogênea, com alto controle e com segurança para uma determinada região do corpo.

Desde o princípio da hipertermia clínica, as pesquisas têm sido direcionadas para o desenvolvimento de técnicas tanto quase-estática como radioativas para aplicar e controlar a hipertermia usando energia eletromagnética. A utilização de radiofrequência (RF) na medicina tem seu início na década de 1920, quando pela primeira vez RF foi usada em cirurgia para cortar e coagular (Bovie, 1928). Na década de 1950, S. Arino e B. J. Covos foram os primeiros a utilizar e comercializar um sistema de RF para uso em neuro-cirurgia (Vander Vorst et al., 2006). O uso da hipertermia tornou-se mais intenso na década de 1970 com o surgimento de dispositivos mais eficientes. Ao longo das décadas de 1980 e 1990 a instrumentação de hipertermia sofreu grande avanço, o que promoveu um aumento significativo dos estudos clínicos. Boa parte da base teórica da hipertermia foi desenvolvida neste período. Atualmente, os dispositivos comerciais e acadêmicos são sistemas robustos com grande credibilidade para o uso em aplicações clínicas da hipertermia.

A aplicação da hipertermia usando radiação eletromagnética é tradicionalmente dividida em equipamentos para hipertermia superficial (i.e., aquecimento de tumores que se estendem a profundidades de $3 \mathrm{a} 4 \mathrm{~cm}$ ) e a hipertermia loco-regional ou aquecimento em 
profundidade (i.e., tumores com profundidade maiores que $4 \mathrm{~cm}$, ou situados centralmente no corpo). A estratégia de desenvolvimento de antenas para a hipertermia superficial é completamente diferente das utilizadas para loco-regional.

Os dispositivos de aquecimento por radiação eletromagnética geralmente usam as frequências de $120 \mathrm{MHz}, 433 \mathrm{MHz}, 915 \mathrm{MHz}$ e $2450 \mathrm{MHz}$, que são frequências permitidas para uso em equipamentos médicos. Diferentes aplicadores para hipertermia, nas mais diversas frequências, além das usuais, têm sido pesquisados nos últimos anos (Stauffer \& Maccarini, 2011; Van Rhoon, 2012). A Figura 2.1 apresenta algumas das possibilidades disponíveis.

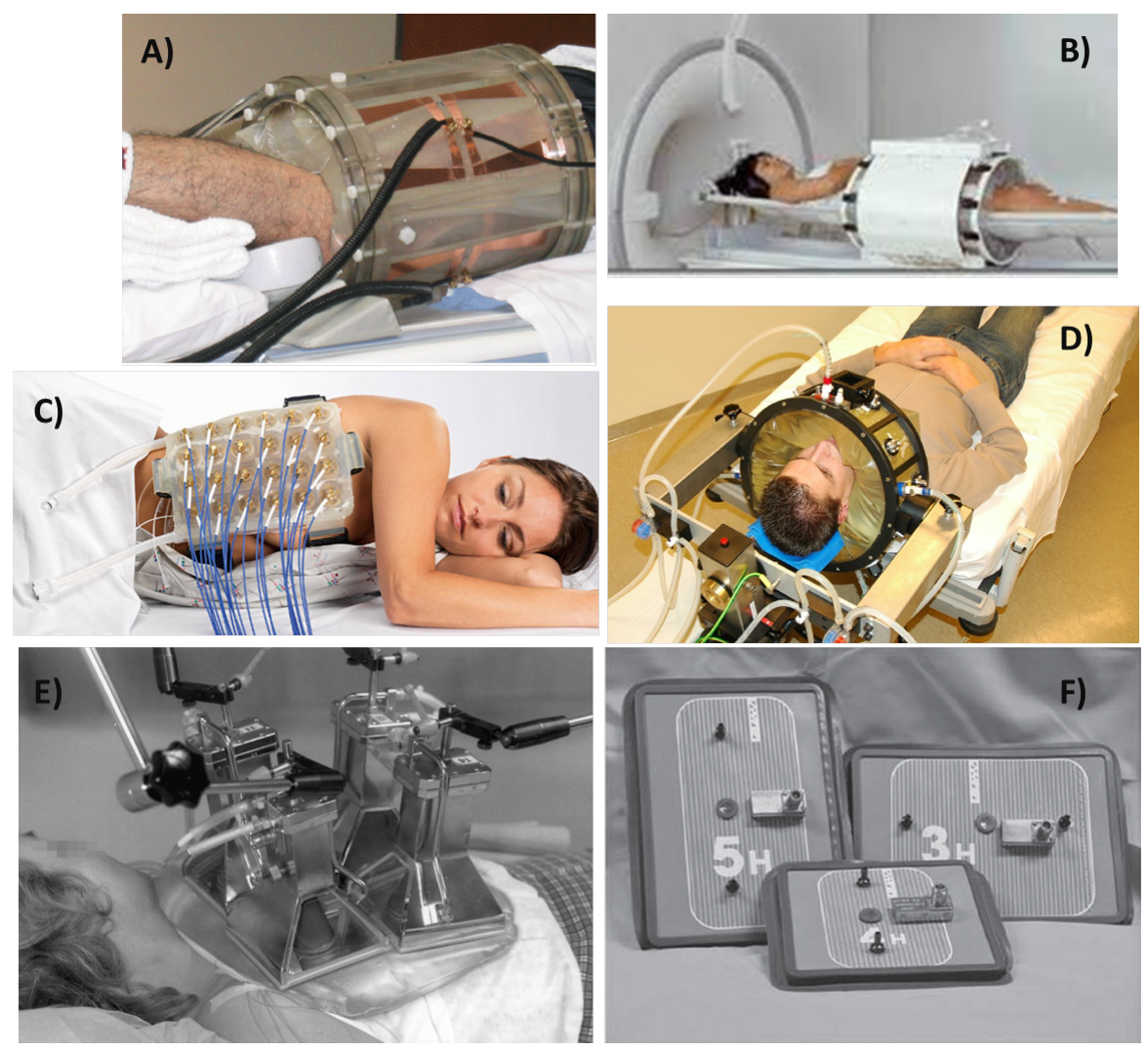

Figura 2.1: Diferentes dispositivos eletromagnéticos empregados na hipertermia: a) Mini-annular phased array - usado no aquecimento de sarcoma (Li et al., 2011), b) BSD - 2000 phased-array - antena compatível com a ressonância magnética nuclear e usado para aquecimento profundo (Turner et al., 1989), c) BSD-500 patch array - usado no aquecimento superficial, D) HYPERcollar applicator - uso no aquecimento da cabeça e pescoço (Paulides et al., 2007) e) LCA system - conjunto de guia de ondas para aquecimento superficial (Van Rhoon et al., 1998) e F) Contact flexible microstrip applicators, tipos $3 \mathrm{H}, 4 \mathrm{H}$, e $5 \mathrm{H}$ - uso no aquecimento superficial (Kok et al., 2010). 
Os desafios para o desenvolvimento de antenas com objetivo de aplicações médicas incluem uma efetiva transferência de energia e penetração no meio heterogêneo do corpo humano. Por exemplo, operar com antenas em condições de radiação de campo-próximo e controlar o padrão de deposição de energia nas três dimensões para obter um aquecimento uniforme em regiões irregulares e de complexa anatomia. Tipicamente, os problemas com as antenas tradicionais incluem alto custo e complexidade de operação, tamanhos desproporcionais e limitado ajuste à anatomia do paciente, estreita banda de operação e desacoplamento para muitos pacientes, e baixo controle da deposição de energia devido a limitações na construção dos aplicadores.

Os futuros dispositivos de hipertermia devem ser desenhados de forma a atender as necessidades de simplicidade de uso e fácil controle da dose térmica aplicada. A inovação na tecnologia da hipertermia deve se focar em melhorar a qualidade do tratamento através do aumento de controle da deposição de energia para o tumor.

\subsubsection{Princípio do aquecimento por micro-onda}

Tecidos biológicos são materiais heterogêneos que contêm água, moléculas orgânicas dissolvidas, macro-moléculas, íons e material insolúvel. Esses constituintes são altamente organizados em estruturas celulares e subcelulares que formam elementos macroscópicos. A presença de íons exerce um importante papel na interação com campos elétricos, pois é responsável pela condutividade iônica e pelos efeitos de polarização. Íons carregados em movimento geram correntes elétricas e inicializam mecanismos de polarização através do acúmulo em determinadas interfaces, que ocorrem em vários níveis de organização. As propriedades dielétricas dos tecidos refletem as contribuições de polarização tanto da estrutura como da composição.

A interação do tecido biológico com campos eletromagnéticos oscilantes irá ocorrer basicamente por efeito de três mecanismos diretos: (1) por acoplamento do campo elétrico com o tecido na faixa de baixa frequência; (2) por acoplamento do campo magnético, também na faixa de baixa frequência; e (3) por absorção de energia na faixa das altas frequências. A exposição a campos elétricos e magnéticos de baixa frequência 
normalmente resultam em uma absorção de energia desprezível e um aumento de temperatura insignificante no corpo humano. Entretanto, exposição a campos eletromagnéticos a frequências acima de $100 \mathrm{kHz}$ pode levar a uma absorção considerável de energia e um consequente aumento de temperatura local. Em geral, a exposição a campos eletromagnéticos uniformes (onda-plana) resulta em uma deposição e distribuição de energia não-uniformes no interior do corpo, que deve ser acessada por dosimetria ou cálculos computacionais. No tratamento de hipertermia o interesse está nos efeitos de absorção de energia pelo tecido na faixa de frequência entre $100 \mathrm{MHz}$ e alguns GHz.

A quantidade de energia que um material irá absorver da radiação depende da frequência de operação, intensidade do feixe, e tempo de exposição. O mais importante destes parâmetros é a frequência de operação. A radiação eletromagnética (na faixa do $\mathrm{RF} / \mathrm{MW}$ ) pode excitar modos translacionais e vibracionais das moléculas e gerar calor. A intensidade do feixe é também um fator que determina quanto de energia é absorvido. Quanto maior a intensidade e duração da irradiação, maior a energia para ser transferida e absorvida.

Para determinar a energia transmitida ou absorvida via campo eletromagnético nos tecidos, é útil iniciar considerando o teorema de Poynting. Este teorema basicamente estipula a conservação de energia em um volume contido em uma superfície fechada e pode ser expresso como:

$$
\int_{S}(\vec{E} \times \vec{H}) d S=\frac{\partial}{\partial t} \int_{V}\left(\epsilon \vec{E} \cdot \vec{E}+\mu_{0} \vec{H} \cdot \vec{H}+\omega_{c p}\right) d V
$$

Os termos na integral de volume representam a energia instantânea armazenada no campo elétrico, no campo magnético, e nas partículas carregadas (" $\omega_{c p}$ ") no interior do volume " $V$ ". O produto vetorial $\vec{E} \times \vec{H}$ representa o vetor de Poynting e "S" a superfície que engloba o volume " $V$ ". Para um campo senoidal, a energia média armazenada no campos elétrico e magnético é zero, e portanto, a Eq. 2.1 pode ser reescrita como:

$$
-\int_{S}\langle P\rangle d S=\int_{V}\left\langle P_{c p}\right\rangle d V
$$


em que $P_{c p}$ é a potência média transferida para as partículas carregadas no interior do volume.

A taxa de absorção específica (SAR) é identificada como a taxa de variação da energia absorvida ou dissipada (dW) por unidade de massa de material (dm) contido no volume dV de um meio de densidade " $\rho$ " (Eq. 2.3) (Moros, 2012).

$$
S A R=\frac{d}{d t}\left(\frac{d W}{d m}\right)=\frac{d}{d t}\left(\frac{d W}{\rho d V}\right)
$$

Então, de acordo com as equações Eq. 2.2 e Eq. 2.3, é possível dizer que a SAR médio no volume do corpo como um todo $\left(S A R_{w b}\right)$ será descrito por:

$$
S A R_{w b}=\int_{V} \sigma \frac{\left|E_{0}\right|^{2}}{2 \rho} d V \quad \text { ou } \quad S A R_{w b}=\int_{V} S A R_{\text {local }} d V
$$

sendo " $\sigma$ " a condutividade elétrica do tecido e " $\rho$ " a sua respectiva densidade de massa. Os efeitos térmicos da absorção de radiação eletromagnética dependem profundamente da distribuição espacial da SAR mas, de modo geral, o valor mínimo de SAR para produzir algum efeito terapêutico é de $15 \mathrm{~W} / \mathrm{kg}$. Uma limitação na determinação da SAR é a necessidade de conhecer a intensidade de campo elétrico, o que na prática somente em raras situações será acessível. Portanto, uma prática comum em experimentos de dosimetria baseia-se no conceito de elevação da temperatura produzida em um curto espaço de tempo (<30 segundos) por uma determinada exposição de radiação (a curta duração é insuficiente para uma troca efetiva de calor por convecção ou condução para os tecidos ). Neste caso, a taxa de variação da elevação inicial de temperatura pode ser relacionada a SAR local por:

$$
S A R_{\text {local }}=c \frac{\Delta T}{\Delta t}
$$

onde $\Delta T$ é a temperatura de incremento $\left({ }^{\circ} \mathrm{C}\right.$ ), "c" é o calor específico do tecido ( em J $\mathrm{kg}^{-1}{ }^{\circ} \mathrm{C}^{-1}$ ), e $\Delta t$ representa o tempo de duração. Deve-se destacar que os fatores que descrevem o SAR dependem da definição de volume de tecido. No uso comum atribui-se 1 ou $10 \mathrm{~g}$ de tecidos na forma de um cubo para a determinações de SAR.

Como foi visto na Eq. 2.4, a condutividade elétrica do tecido possui influência direta na quantidade de energia absorvida de campos eletromagnéticos. Na faixa de frequência 
da micro-onda, acima de $100 \mathrm{MHz}$, três efeitos contribuem para a chamada condutividade do tecido: tem-se a contribuição devido à polarização interfacial de tecidos sólidos (efeito de Maxwell-Wagner); a contribuição das perdas dielétricas de pequenas moléculas polares e extremidades polares de cadeias de proteínas; e a relaxação dielétrica da água. A relaxação dielétrica da água é o fator dominante nos tecidos na frequência da micro-onda, e representa a capacidade dos dipolos das moléculas de água em orientarem-se com campo elétrico.

Um bom conhecimento da complexa permissividade do material biológico é essencial para uma adequada determinação das ações dos campos eletromagnéticos no meio biológico. A permissividade, a constante dielétrica e a condutividade apresentam uma dependência única com a frequência. Um exemplo do comportamento dessas propriedades em tecidos biológicos (músculo) é apresentado na Figura 2.2, representando um tecido com grande quantidade de água. Tipicamente, a constante dielétrica diminui e a condutividade aumenta em função do aumento da frequência.

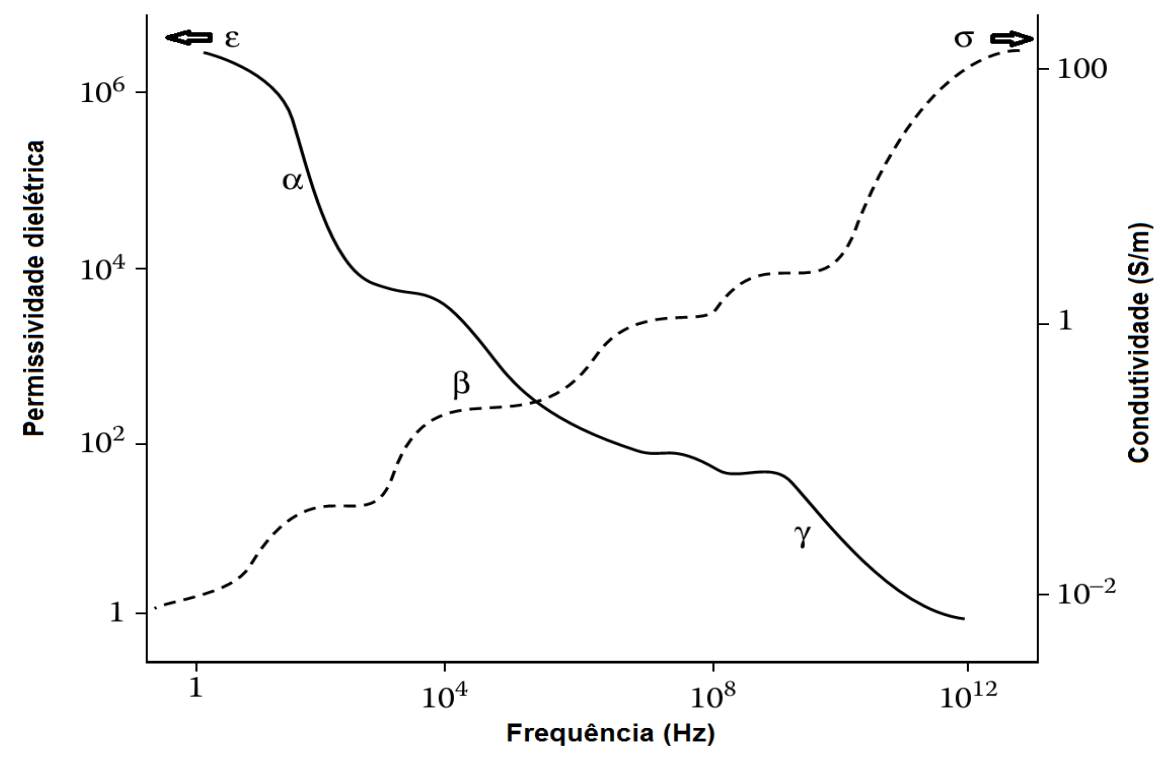

Figura 2.2: Exemplo de permissividade dielétrica e condutividade elétrica do tecido biológico (músculo) em função da frequência [figura extraída de (Lin, 2011)-figure 1.1]

No espectro apresentado na Figura 2.2 a permissividade dielétrica é dividida em três regiões de dispersão $\alpha, \beta$ e $\gamma$. As regiões de dispersão são extensas e podem apresentar sobreposições. A região de dispersão $\alpha$, ou de baixa frequência, é caracterizada por altos 
valores de permissividade que normalmente são atribuídos, pelo menos parcialmente, ao movimento de difusão dos contra-íons. Esse tipo de dispersão pode ser previsto por teorias de difusão iônica em meios heterogêneos. A dispersão $\beta$ ocorre em frequências intermediárias, e é originária principalmente de cargas capacitivas da membrana celular e conectores de organelas celulares. Este fenômeno também é conhecido como polarização interfacial. A dispersão $\gamma$ é devido à polarização dipolar da água dos tecidos. Para frequências acima de $100 \mathrm{MHz}$, onde a resposta da água no tecido é dominante, a permissividade do mesmo pode ser modelada em termos de quatro equações de Cole-Cole mais a condutividade (Gabriel et al., 1996c).

$$
\hat{\epsilon}(\omega)=\epsilon_{\infty}+\sum_{n=1}^{4} \frac{\epsilon_{s n}-\epsilon_{\infty}}{1+\left(\jmath \omega \tau_{n}\right)^{\left(1-\alpha_{n}\right)}}-\jmath \frac{\sigma_{s}}{\omega \epsilon_{0}}
$$

em que " $\epsilon_{\infty}$ " é a permissividade infinita, " $\epsilon_{s n}$ " é a permissividade estática, " $\tau_{n}$ " são tempos de relaxação, " $\sigma_{s}$ " é a condutividade estática, " $\alpha_{n}$ " é uma constante e " $\omega$ " é a frequência de oscilação da onda.

Estudos avaliando as propriedades dielétricas dos tecidos tumorais mostram que o tumor apresenta características muito diferentes das observadas em tecidos normais (Foster \& Schepps, 1981; Joines et al., 1994). A quantidade água é muito superior à normalmente encontrada em tecidos sadios. A necrose tumoral promove o rompimento das membranas celulares, o que possibilita uma maior fração do tecido transportar correntes na baixa frequência. Dados experimentais demonstram que na região de necrose a condutividade pode ser de 5 a 10 vezes maior, enquanto a permissividade é geralmente menor em relação a tecidos sadios.

\subsubsection{Alguns aspectos sobre ondas eletromagnéticas}

A definição de impedância da onda pode ser aplicada para vários movimentos ondulatórios. Para ondas eletromagnéticas (ondas transversal eletromagnético (TEM) e ondas com componentes longitudinais) a impedância da onda é definida com a razão entre a componente do campo elétrico transverso e a componente perpendicular do campo magnético transverso. O conceito de impedância da onda é muito útil a diversos problemas 
de propagação de onda. Para ondas eletromagnéticas propagando-se na direção do eixo " $\hat{z}$ ", a impedância da onda é definida por

$$
Z_{w}^{+}=\frac{E_{x}}{H_{y}}
$$

Um conceito importante no estudo da hipertermia é o conceito de região de radiação de campo próximo. Esta região trabalha com os campos eletromagnéticos muito próximos da antena ou da estrutura de radiação. Nela os campos elétrico e magnético não exibem uma relação de onda-plana, e a potência não decresce com o quadrado da distância com relação ao ponto de emissão. A região de campo-próximo é ainda normalmente dividida em zona reativa (reactive near-field zone), que corresponde à região próxima a estrutura de radiação, e que contém boa parte da energia armazenada, e a zona de radiação de campo próximo (radiating near-field zone), onde o campo de radiação prevalece sobre o campo reativo, mas ainda não apresenta muito das características de uma onda-plana. A caracterização dos campos eletromagnéticos nesta região sempre corresponde a uma estrutura complicada.

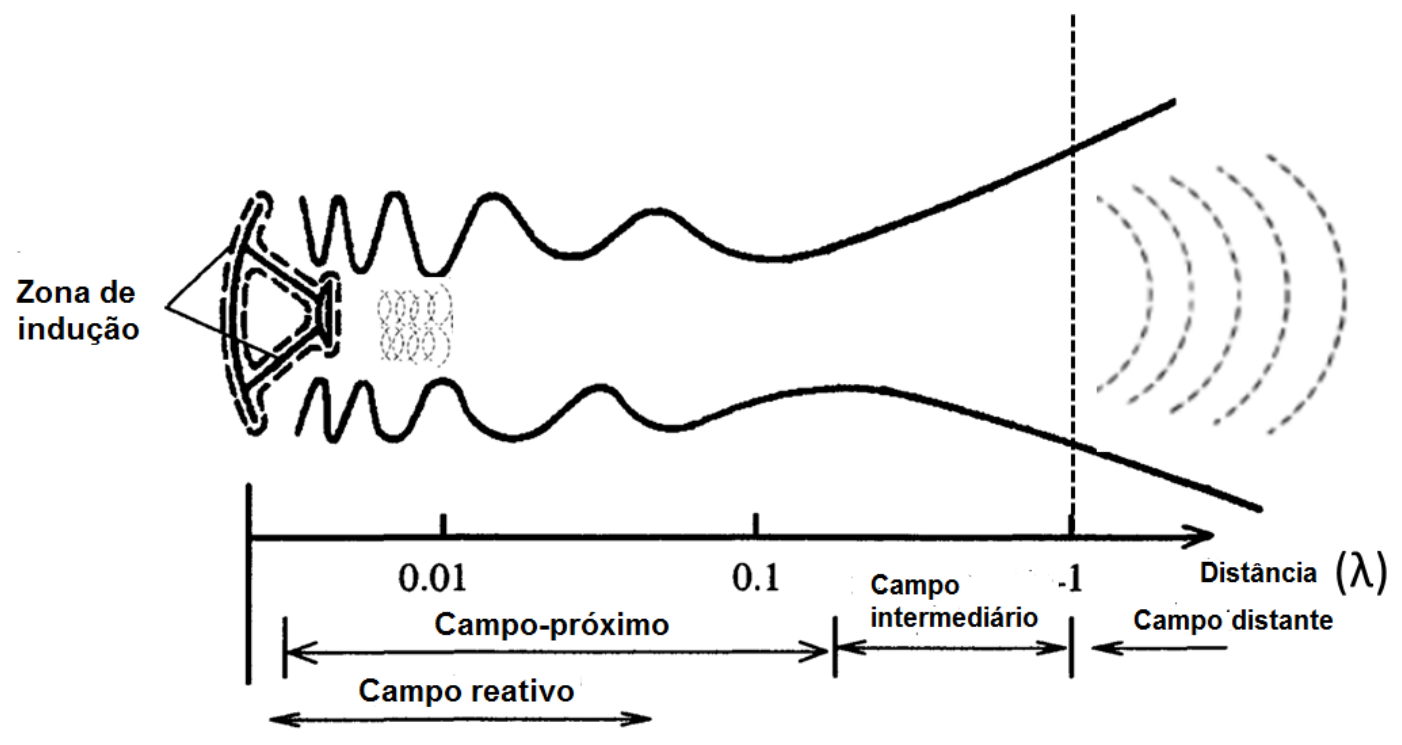

Figura 2.3: Regiões de campo próximos a antenas que são iguais, ou maiores que metade do comprimento de onda de radiação [figura extraída de (Trzaska, 2005)-figure 2.2.].

A Figura 2.3 apresenta os modos de campo de radiação próximo à antena. Para antenas fisicamente maiores que a metade do comprimento de onda da radiação emitida, 
o limite entre radiação de campo próximo e radiação de campo distante é definida em termos da distância de Fraunhofer $\left(d_{f}\right)$ (Trzaska, 2005),

$$
d_{f}=\frac{2 D^{2}}{\lambda}
$$

sendo "D" a maior dimensão da antena e $\lambda$ o comprimento de onda da radiação. Esta condição é amplamente aceita na literatura como condição de transição entre campo próximo e campo distante, sendo abaixo desta distância a zona considerada como de campo próximo.

Uma característica importante na descrição eletromagnética em hipertermia é a penetração da micro-onda nos tecidos biológicos. Para uma onda plana propagando-se em um meio homogêneo isotrópico, a profundidade de penetração de um campo eletromagnético é definida como a distância requerida para atenuar a amplitude do campo elétrico para aproximadamente $37 \%$ da amplitude incidente $\left(E=E_{0} e^{-1}\right)$. O grau de penetração em um tecido, depende das propriedades dielétricas do meio e da frequência de oscilação da onda. A amplitude do campo elétrico decai exponencialmente no interior do material biológico, sendo a constante de decaimento definido como na Eq. 2.9.

$$
\delta=\frac{1}{\omega \sqrt{\mu \varepsilon}\left\{\frac{1}{2}\left[\sqrt{1+\left(\frac{\sigma}{\omega \varepsilon}\right)^{2}}-1\right]\right\}^{1 / 2}}
$$

O parâmetro " $\delta$ " é chamado de skin depth ou profundidade pelicular. A Figura 2.4 mostra um exemplo da variação da potência absorvida dentro do corpo como função da profundidade em diferentes frequências de micro-ondas.

\subsubsection{Processos de otimização de antenas}

(Texto baseado em: Koziel \& Ogurtsov (2014))

O desenvolvimento de antenas de micro-onda envolve sempre grandes desafios. O projeto e construção de qualquer antena é um processo que busca ajustar as geometrias 


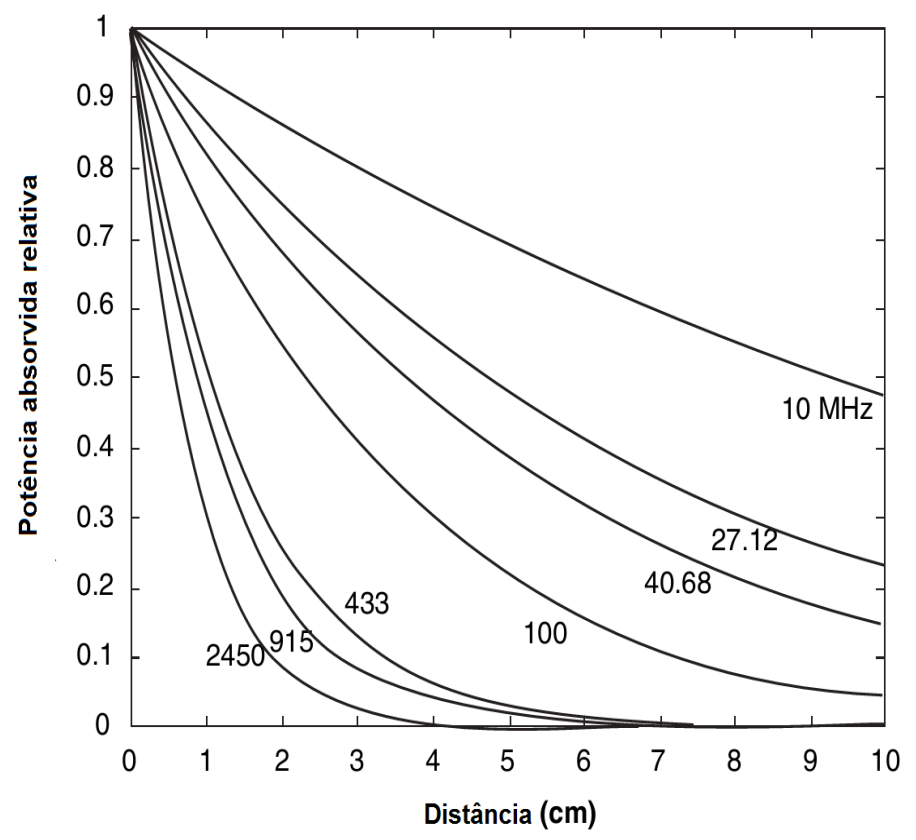

Figura 2.4: Potência absorvida no tecido biológico (Músculo) em função da profundidade no tecido para diferentes frequências de oscilação da onda [ figura extraída de (Vander Vorst et al., 2006)-figure 1.8].

características e definir as características dos materiais que forneceram a resposta de performance desejada para a aplicação de interesse. A avaliação da performance muitas vezes envolve características como impedância de entrada, padrão de radiação, eficiência de radiação e outros.

A configuração do sistema irradiador que melhor se adapta a uma dada aplicação é uma informação desconhecida na maioria dos projetos. Para inferir sobre as características ótimas do projeto, análises computacionais de diversos modelos de antenas podem auxiliar na decisão e fornecer um método de baixo custo para o desenvolvimento de potenciais designs ou protótipos. O uso de recursos computacionais possibilita a simulação de diferentes situações de operação, e ajuda na avaliação de casos de interações complexas no interior da antena, ou mesmo no ambiente que a cerca.

O objetivo no projeto de uma antena consiste em estabelecer a melhor configuração possível para a referida aplicação. Contudo, para que isso seja possível deve-se proceder com o método de otimização. O método de otimização consiste em uma forma de obter a melhor combinação de elementos $x^{*}$, característicos da antena, que juntos forneçam o 
melhor arranjo (ou mais eficiente) que possa ao final conduzir à construção do protótipo. O critério de ótima configuração, expressa na forma de uma função matemática, é chamado de função objetivo. A função objetivo é a função matemática que deve ser submetida ao processo de minimização ou maximização.

Considerando que $\mathrm{R}_{f}(x)$ represente a eficiência da antena para um dado elemento característico "x", tem-se então que $\mathrm{R}_{f}(x)$ representará a performance da antena em função de parâmetros, como o coeficiente de reflexão $\left|S_{11}\right|$ ou o ganho sobre uma dada banda de frequência. Um conjunto de elementos " $\mathrm{x}$ " pode compor um vetor $\hat{x}=\left[x_{1}, x_{2} \ldots x_{n}\right]$, que representa o conjunto completo de parâmetros variáveis do sistema. O processo de desenvolvimento da antena pode ser formulado como um problema de minimização (Fletcher, 2013):

$$
x^{*}=\arg \min U\left(R_{f}(x)\right)
$$

sendo "U" a função escalar de mérito que engloba as especificações do projeto, $x^{*}$ o design "ótimo" encontrado. A composição $\mathrm{U}\left(\mathrm{R}_{f}(x)\right)$ é referida com a função objetivo. A função "U" é implementada tal que o melhor design corresponde ao menor valor da $\mathrm{U}\left(\mathrm{R}_{f}(x)\right)$.

O problema de otimização está sempre sujeito a certas restrições de design. Essas restrições são normalmente introduzidas para garantir que a estrutura da antena seja fisicamente viável, além de garantir que as dimensões físicas (comprimento, largura, área) não ultrapassem certos valores assumidos.

Geralmente, o processo de otimização é composto por um algorítimo que pode ser dividido em duas classes básicas: determinístico e probabilístico. O algorítimo determinístico não contem instruções que usam números aleatórios com intuito de decidir os próximos passos de modificação dos dados. O algorítimo determinístico é frequentemente utilizado quando a relação entre as possíveis soluções e a dependência das características são conhecidas. Assim, a busca pela solução é feita através da varredura do domínio das variáveis. No entanto, se a relação entre a solução candidata e sua dependência com os elementos de controle não é óbvia, ou é complicada, tem-se que obrigatoriamente varrer o domínio completo das variáveis para que seja garantido que a solução encontrada seja ótima. Porém, isso torna o processo exaustivo e de alto custo computacional, mesmo para 
pequenos problemas.

O algoritmo probabilístico utiliza artifícios estatísticos para tomada de decisão e escolha dos próximos passos. Uma família especial de algorítimos probabilísticos é o baseado na abordagem de Monte-Carlo. Inicialmente a população é aleatória, e então uma função heurística ajuda na definição do conjunto de possíveis soluções, e deve ser avaliada a seguir criando um processo interativo (Rahmat-Samii \& Michielssen, 1999).

Apesar dos desafios citados anteriormente, a abordagem comumente empregada na simulação dirigida do design de antenas segue conceitos determinísticos ou paramétricos, baseando-se na varredura dos diversos parâmetros (normalmente, um parâmetro por vez). Esta abordagem é normalmente mais viável que abordagens robustas de otimização, que utilizam os algoritmos probabilísticos; porém, este procedimento é mais trabalhoso, demorado e demanda uma significativa influência do projetista. Este tipo de varredura de parâmetros, como processo de otimização, não garante que a solução final seja a ótima, devido às limitações no número de parâmetros que podem ser varridos.

O processo de otimização em tratamentos de hipertermia possui um ou mais dos seguintes objetivos: atingir uma determinada distribuição de temperatura, priorizar o aquecimento ao tumor e preservar o tecido sadio, evitar hot spots. Para atingir estes objetivos, a escolha natural consiste em realizar o processo de otimização baseado na distribuição de temperatura no objeto de interesse, pois assim encontram-se meios simples de conexão entre os resultados do modelo e os efeitos terapêuticos. No entanto, a previsão da temperatura local é uma tarefa difícil e composta de várias incertezas. A abordagem de maior simplicidade é através da solução da equação de bio-heat transfer (Eq.1.2).

A equação de BHT consiste de termos relacionados à potência de calor e termos relacionados à perfusão sanguínea. O termo de perfusão sanguínea é conhecido somente por aproximação para um paciente específico. A perfusão sanguínea é um processo dinâmico, que se altera durante o tratamento hipertérmico, dependendo da potência e do tempo de aquecimento. Uma aproximação incorreta da perfusão levaria ao surgimento de erros significativos na previsão da temperatura.

Uma alternativa à temperatura no processo de otimização do dispositivo de aqueci- 
mento, seria a utilização da distribuição da SAR como fator de prognóstico. A interação da radiação eletromagnética com os diferentes tecidos, que possuem diferentes permissividades e condutividades, resulta em um padrão de deposição de energia. O cálculo da distribuição da SAR é fortemente dependente destas constantes, mas possui sensibilidade mínima para o fluxo sanguíneo, favorecendo-o como um fator de prognóstico terapêutico. O uso da otimização por SAR também auxilia na redução de hot spots. Para se obter o máximo de benefício da otimização pautada em SAR deve-se criar um conexão com os parâmetros clínicos. Existem diversos estudos que buscam fornecer essa correlação (De Greef et al., 2010, 2011) e indicam as diferenças entre os processos de otimização baseados na temperatura e na SAR. De modo geral, é possível encontrar parâmetros que conectam os indicadores de SAR e a temperatura tumoral.

A função objetivo mais simples da abordagem da otimização por SAR é a razão entre a SAR observado no tecido alvo e a SAR para o tecido na vizinhança. Este método foi primeiro proposto por Strohbehn (Strohbehn et al., 1989), que define o procedimento como maximizar a deposição de potência no volume pré-definido como alvo, sujeito à restrição de que a deposição de energia no volume fora da área de interesse seja menor que um determinado nível. Matematicamente, este problema é definido como:

$$
f(\vec{v})=\frac{\int_{\text {Vtarget }} S A R d v}{\int_{\text {Vnormal }} S A R d v} \quad f_{P, \text { min }} \leq \frac{P_{r}}{P_{\text {Total }}} \leq f_{P, \text { max }}
$$

O vetor " $\vec{v}$ ” é o vetor que armazena a frequência e a amplitude do campo elétrico, "SAR" a densidade de absorção de potência local, " $P_{r}$ " e " $P_{\text {Total }}$ são a potência refletida na interface antena/tecido e a potência total imprimida no sistema, respectivamente. A fração " $f_{P, \text { min }}$ " e " $f_{P, \text { max }}$ " são limites de segurança que especificam a mínima e máxima contribuições da fonte ao sistema.

O primeiro fator que influencia significativamente a eficiência da hipertermia é o acoplamento elétrico entre o aplicador eletromagnético e o tecido alvo. A função" $f_{P, \max }$ " é a restrição que impõe um mínimo de acoplamento entre a antena e o tecido. O acoplamento entre os dois meios é caracterizado pela análise equivalente de circuitos, como o casamento de impedâncias, no qual espera-se que a impedância da carga $Z_{L}$ (tecido) seja 
similar à do circuito de micro-onda $\mathrm{Z}_{c}$ (antena). $\mathrm{O}$ casamento de impedâncias garante que o coeficiente de reflexão seja próximo a zero, portanto, em um processo de otimização da antena deve-se buscar esse nível de funcionamento. Normalmente, atribui-se como limite máximo de reflexão a fração de $10 \%$.

Para alterar as características da antena e avaliar sua eficiência é preciso criar a metodologia de análise do dispositivo de micro-onda. Normalmente, analisa-se o sistema de micro-onda como um circuito elétrico equivalente, pois assim evita-se a necessidade de resolver todos os campos e/ou ondas no interior da estrutura, aplicando-se apenas conceitos mais simples de circuitos elétricos. Os dispositivos de micro-onda aplicado à hipertermia em geral podem ser avaliados como uma rede de duas portas; "Porta 1" correspondendo à fonte de potência, e a "Porta 2" à interface entre a antena e o tecido biológico. Neste contexto, existe um parâmetro constituinte do circuito de micro-onda chamado de "S", ou matriz espalhamento, que é muito usado para medir a quantidade de potência transmitida e refletida em uma rede elétrica linear, como ilustrado na Figura 2.5.

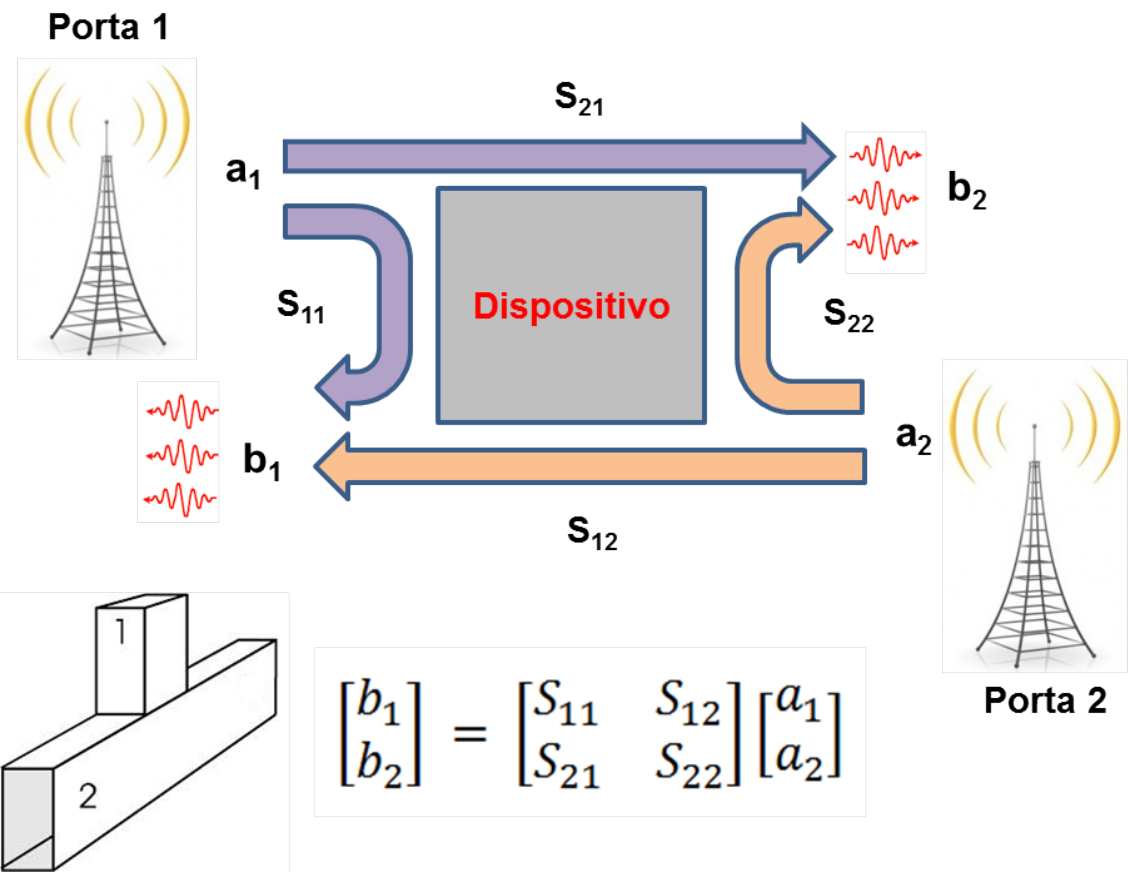

Figura 2.5: Esquema ilustrando a análise de circuito equivalente para uma rede de micro-onda de duas portas. As amplitudes das ondas refletidas b1, b2, e as amplitudes das ondas incidentes a1, a2, são destacadas na imagem. A figura mostra também um exemplo de dispositivo de rede de duas portas (uma guia de onda retangular). A representação matricial da rede de micro-onda é apresentada na parte inferior da figura. 
A matriz espalhamento é uma construção matemática que quantifica como a energia da micro-onda se propaga na rede de multi-portas. A matriz-S é o que permite descrever propriedades complicadas da rede de uma forma simples. Para um sinal de micro-onda incidente em uma dada porta, uma fração do sinal será refletida para a mesma porta e a outra fração será transmitida para outra porta da rede. A matriz de espalhamento [S] relaciona as amplitudes das ondas refletidas b1 e b2, com as amplitudes da onda incidente a1 e a2. Na prática, as medidas dos parâmetros $\mathrm{S}$ se relacionam com ganhos ou perdas $\left(S_{12}\right.$ ou $\left.S_{21}\right)$ e com os coeficientes de reflexão $\left(S_{11}\right.$ ou $\left.S_{22}\right)$.

O módulo do parâmetro $\left|S_{11}\right|$, que pode ser medido com um analisador de rede, é definido como a razão entre a potência refletida $(\mathrm{Pr})$ e a potência emitida $(\mathrm{Pe})$ na porta de excitação "1". Em geral o parâmetro $\left|S_{11}\right|$ é apresentado na escala de decibel $(\mathrm{dB})$, conforme relação a seguir.

$$
d B\left(S_{11}\right)=\left(10 \log _{10} \frac{P_{r}}{P_{e}}\right)
$$

\subsection{Materiais e Métodos}

\subsubsection{Termometria invasiva}

O monitoramento invasivo da temperatura, tanto in vivo como nos sistemas fatomas, foi realizado por sensores de temperatura em fibra óptica de diferentes diâmetros $(0,18$ $\mathrm{mm}, 0,28 \mathrm{~mm}$ e $0,56 \mathrm{~mm}$ ). A opção por um dos três diâmetros de sensor disponível ocorreu baseada em questões de acessibilidade e questões anatômicas. Para aquisição da temperatura utilizou-se os módulos de leitura Luxtron 3100 e Luxtron 812 (LumaSense Technologies, Santa Clara, CA, USA). O módulo Luxtron 812 é compatível somente aos sensores de 0,18 e 0,28 mm de diâmetro. O módulo Luxtron 3100 foi utilizado para leitura com os sensores de diâmetro 0,56 mm (Figura 2.6).

Os valores de temperatura foram validados em procedimento de calibração utilizando o termômetro digital Fluke 54-II. A visualização e armazenagem dos dados em função do tempo foi processada em um microcomputador pessoal através de uma interface de controle desenvolvida no software LabVIEW (National Instruments, Austin, TX, USA). 


\section{Luxtron 812}

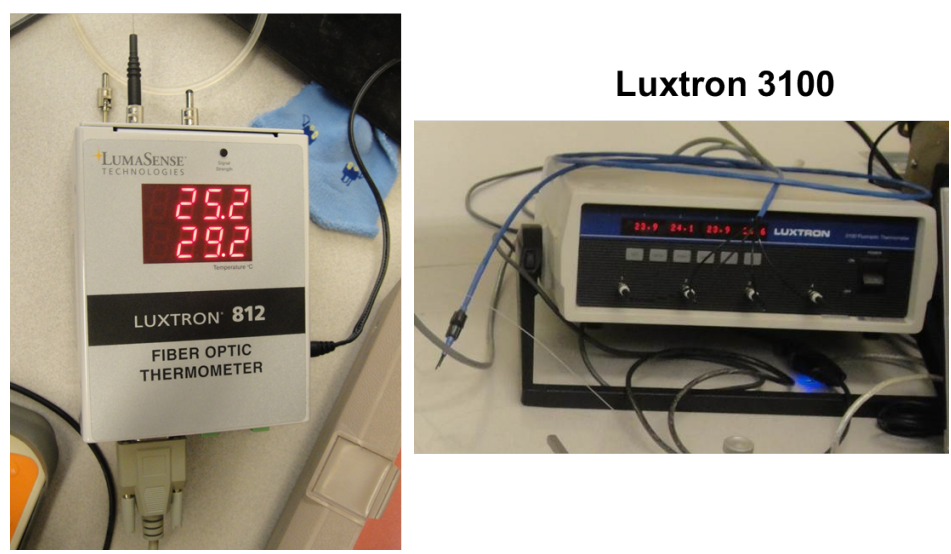

Figura 2.6: Módulos de leitura dos sensores ópticos de temperatura Luxtron 812 e Luxtron 3100.

\subsubsection{Medidas do parâmetro de espalhamento $S_{11}$}

Para avaliação das características de acoplamento da antena de micro-onda com o sistema in vivo e o sistema fantoma, foram realizadas medidas do parâmetro de espalhamento $S_{11}$ sob a excitação coaxial. O parâmetro $S_{11}$ avalia a fração de potência transmitida (Eq. 2.12) e potência refletida na interface entre a antena e o tecido ou sistema fantoma, a uma dada frequência de oscilação. As medidas de reflexão de $S_{11}$ foram realizadas em função da frequência de oscilação, e monitoradas pelo dispositivo analisador de rede (Model E5071C, Agilent Corp., Santa Clara, CA).

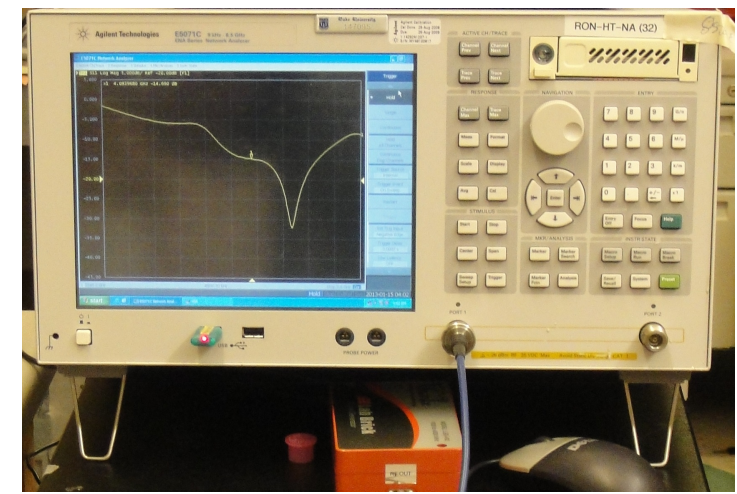

Figura 2.7: Imagem do analisador de rede Modelo E5071C (Agilent Corp., Santa Clara, CA, USA).

Complementarmente às propriedades de espalhamento, foram também monitorados as propriedades dielétricas dos sistemas fantoma e in vivo com o uso do analisador de 
rede E5071C e a sonda de impedância de alta-temperatura (Model 85070C, HP/Agilent Corp., Santa Clara, CA), USA). As medidas nos fantomas foram realizadas a temperatura ambiente $\left(\approx 24^{\circ} \mathrm{C}\right)$. Para avaliar a uniformidade das amostras, medidas foram tomadas na superfície e na base plana de cada amostra, e três medidas foram realizadas para diferentes posições.

\subsubsection{Simulação numérica da radiação eletromagnética}

O design e o processo de otimização das antenas de micro-onda apresentadas nesta tese foram executados utilizando-se o software comercial Ansoft High Frequency Structure Simulator (HFSS ${ }^{\mathrm{TM}}$ ) versão 15.0 (Ansys Inc., Canonsburg, PA, USA). O HFSS ${ }^{\mathrm{TM}}$ é um software de alta performance que permite a simulação de campos eletromagnéticos (EM) de onda completa em geometrias 3D arbitrárias. A técnica de simulação utilizada pelo software para calcular o campo EM no interior da estrutura 3D é baseada no método de elementos finitos (FEM). Basicamente, o simulador transforma as equações de Maxwell em um conjunto de equações matriciais, e torna possível a solução numérica das mesmas.

O método de elementos finitos divide o domínio completo da solução em milhares de pequenas regiões, e representa o campo EM em cada sub-domínio com uma função local. No HFSS ${ }^{\mathrm{TM}}$, o modelo geométrico é automaticamente dividido em diversos tetraedros, em que um único tetraedro é basicamente uma piramide de quatro faces. A coleção destes tetraedros é referida como malha de elementos finitos.

O método de elementos finitos resulta de técnicas matriciais de cálculos de estrutura mecânica discreta ou semi-discreta, e consistiu em uma ferramenta para resolver diversas equações diferenciais parciais. Normalmente, em electromagnetismo, o FEM é associado com o método variacional ou o método residual. No primeiro caso, o procedimento numérico estabelece um funcional a ser minimizado. Para cada problema um funcional particular deve ser definido, tornando a tarefa custosa. O método variacional não trabalha diretamente com as equações físicas relacionadas ao problema, mas sim com correspondente funcional. Atualmente, a maioria dos métodos FEM trabalham utilizando o método residual (Davidson, 2005; Meunier, 2010). 
Diferente do método variacional, o método residual é estabelecido diretamente das equações físicas a serem resolvidas. Este residual é a diferença entre a solução aproximada e a solução exata, e normalmente deve se aproximar a zero no domínio de interesse. O método de Galerkin é uma forma particular do método residual, amplamente utilizada em electromagnetismo, pois fornece resultados de grande precisão e acurácia (Pelosi et al., 2009).

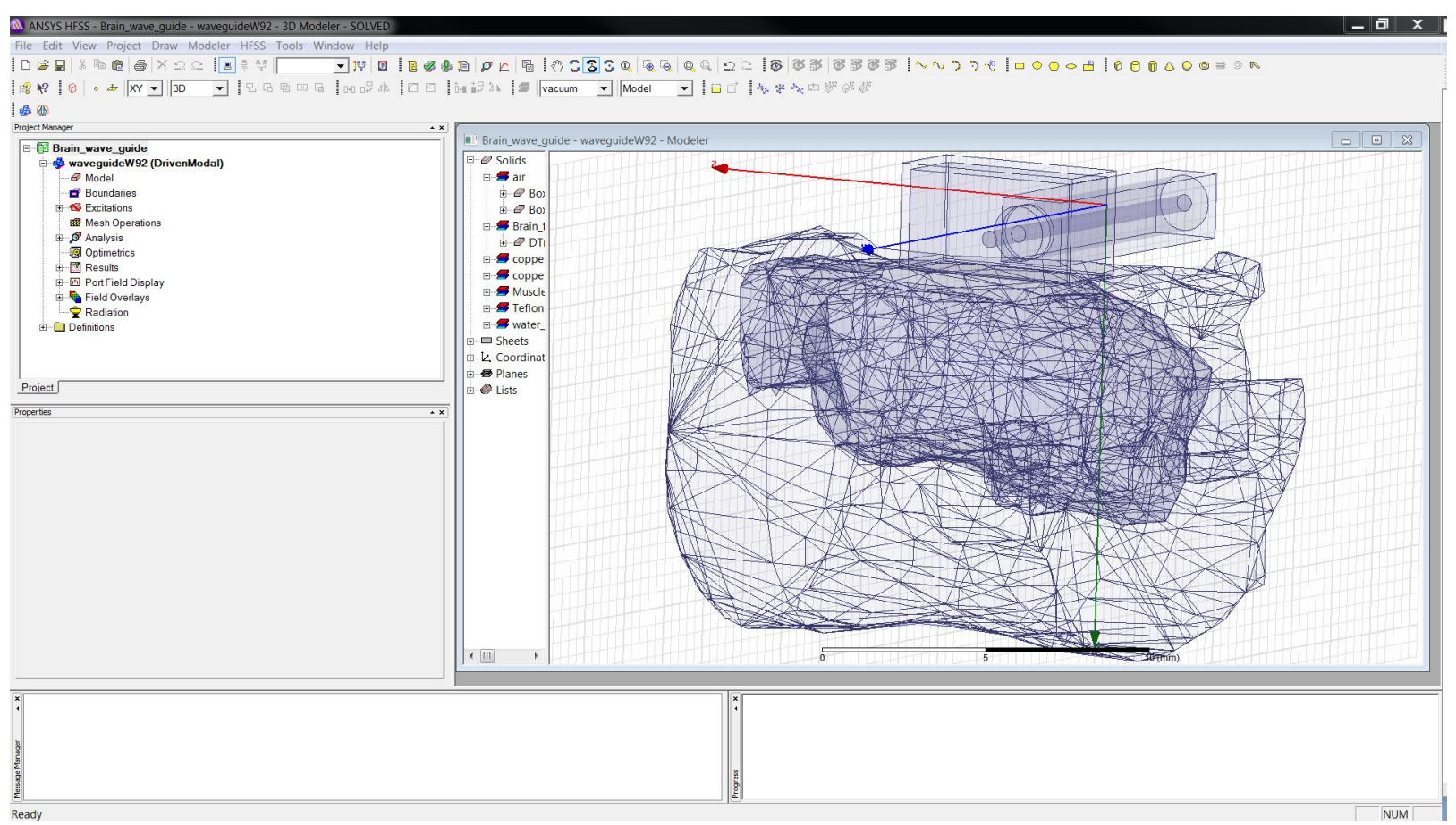

Figura 2.8: Imagem da interface do software HFSS 15.0. A imagem apresenta um exemplo de design utilizado nesta tese.

No FEM, existe uma relação entre a dimensão dos elementos da malha (mesh), o nível de acurácia desejada, e a disponibilidade de recursos computacionais. A acurácia da solução depende de quão pequeno os elementos individuais (tetraedros) possam ser. De modo geral, soluções obtidas com uma malha de milhares de elementos são mais precisas que soluções obtidas com uma malha de centenas de elementos. Para gerar uma descrição precisa do campo, cada elemento deve ocupar uma área pequena o suficiente para que o campo seja precisamente interpolado entre os pontos nodais. Neste contexto, o algorítimo no $\operatorname{HFSS}^{\mathrm{TM}}$ utiliza um processo de análise adaptativa da solução, que basicamente avalia a solução para cada região do domínio e, iterativamente, refina a malha para que o erro 
da solução em uma dada região atinja valores pré-estipulados. Portanto, o usuário define um critério de controle adaptativo da malha, e o algorítimo gera uma malha heterogênea com tamanho dos elementos que o satisfaça.

\subsubsection{Modelo anatômico 3D}

As simulações em hipertermia da propagação de campos EM e da distribuição da temperatura local dependem da correta caracterização da geometria do sistema, da identificação das estruturas presentes, e da parametrização das constantes físicas envolvidas. O primeiro passo na elaboração do modelo numérico aplicado à hipertermia consiste na construção do modelo anatômico realístico, normalmente em três dimensões, para delinear o domínio computacional. O domínio computacional é definido como a região física onde os cálculos computacionais serão executados.

O método usual de criar o modelo anatômico de distribuição tecidual "3D" é chamado de segmentação de imagens. A segmentação é o processo de identificação de uma dada região da imagem que corresponde a um determinado tecido (Greenbaum, 2004). Comparado ao planejamento terapêutico para a radioterapia, a segmentação para o planejamento terapêutico da hipertermia é mais exigente, com a distinção das estruturas e acurácia na determinação dos parâmetros dielétricos e térmicos. O conhecimento exato da forma do tecido e suas interfaces auxilia na previsão de pontos espúrios de aquecimento, especialmente em regiões próximas à pelve.

O modelo anatômico realista foi gerado utilizando-se os diferentes métodos de segmentação disponíveis no software VSG Avizo 6.3. Após o desenvolvimento do modelo geométrico do paciente ou animal, as superfícies foram importadas no software HFSS ${ }^{\mathrm{TM}}$ para a execução do processo de otimização da antena. As propriedades térmicas e dielétricas dos tecidos segmentados foram assinados conforme literatura disponível (niremf.ifac, 2011; Valvano, 2011).

Para exemplificar o processo de segmentação, apresenta-se na Figura 2.9 o resultado para a segmentação da estrutura esquelética de um rato. Neste exemplo, a segmentação ocorreu analisando o valor da unidade de Hounsfield (HUs) de cada voxel das imagens 
de tomografia computadorizada adquiridas. Portanto, com a metodologia de filtro foi possível distinguir nas imagens regiões classificadas como ar, músculo, gordura e osso.

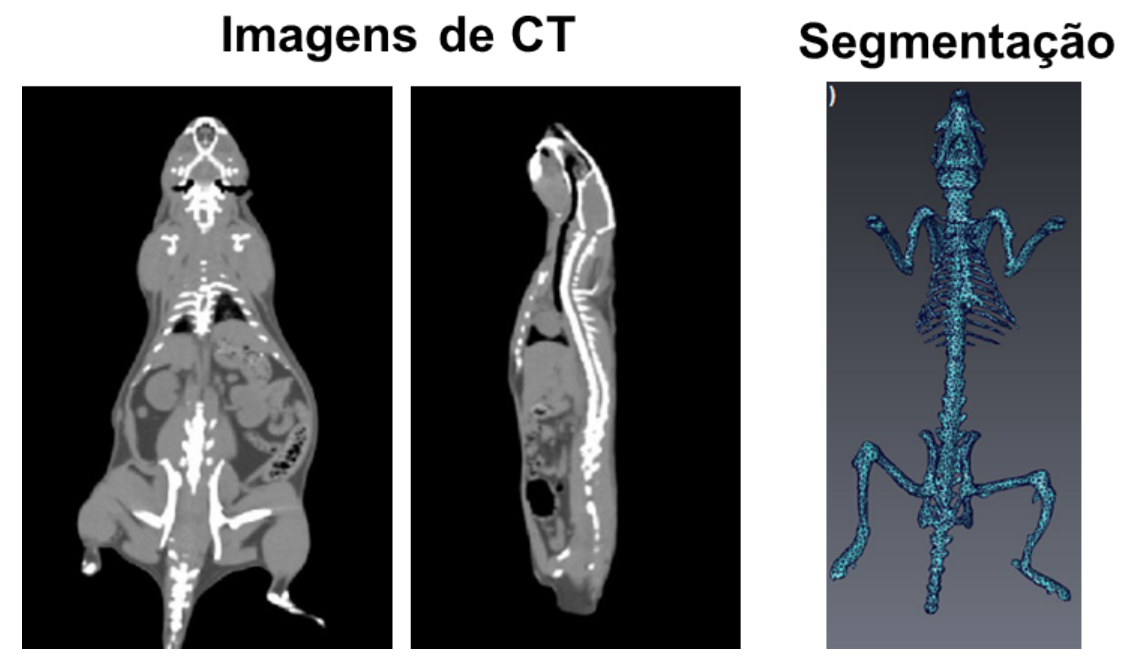

Figura 2.9: Imagem à esquerda apresenta dois cortes (coronal, sagital) do conjunto de imagens obtidas com a técnica de $C T$ para um rato. Imagem à direita ilustra o resultado para a superfície obtida no processo de segmentação com o software VSG Avizo, utilizando-se critérios de coeficiente de atenuação dos raios-X.

A superfície apresentada na Figura 2.9 exemplifica a capacidade de segmentação do software Avizo. O método de assinatura permitiu identificar claramente estruturas como a estrutura esquelética do animal. Nesta tese, todos os modelos anatômicos 3D foram obtidos com processos similares a este apresentado aqui.

\subsubsection{Fabricação de fantomas tecido-equivalente}

Em sistemas fantomas, os materiais utilizados para sua construção buscam mimetizar as propriedades físicas dos tecidos humanos. Estes sistemas exercem papel fundamental no teste e desenvolvimento de dispositivos para hipertermia.

Os materiais usados para a fabricação dos fantons tecido-equivalentes foram especificados conforme procedimento descrito em (Yuan et al., 2012b). Os materiais foram baseados numa dispersão óleo-gelatina, com diferentes percentuais de volume de óleo, com objetivo de simular, as propriedades dielétricas de vários tecidos, como os de alta quantidade de água como músculo e tumor. Em (Lazebnik et al., 2005) um conjunto de fantomas, com diferentes frações de óleo, foi medido em um intervalo de frequência de 500 
MHz a $20 \mathrm{GHz}$, e o resultado apresentou grande concordância entre as propriedades dielétricas dos fantomas e o modelo de $4^{\mathrm{a}}$ ordem de Cole-Cole para tecidos humanos (Eq.2.6) (Gabriel et al., 1996a,b,c). Outra característica importante destes sistemas fantomas é a ótima estabilidade estrutural, essencial quando se quer construir sistemas complexos.

O fantoma desenvolvido aqui foi designado não somente para simular as propriedades dielétricas, mas também as propriedades térmicas de tecidos humanos. O óleo utilizado foi o óleo vegetal de canola com intuito de tornar o material fantoma compatível com a técnica de ressonância magnética nuclear. As propriedades dielétricas e térmicas do óleo vegetal se assemelham às propriedades da gordura no corpo humano. A gelatina utilizada foi a "225 bloom gelatin" (225 bloom bakers gelatin, Gelatin Innovations Inc., Schiller Park, IL- USA). A gelatina foi dispersa em solução salina de água destilada e cloreto de sódio $(\mathrm{NaCl})$.

\subsection{Projeto e construção do mini-aplicador de micro- onda}

Embora diversos sistemas de entrega direcionada de droga, de forma passiva ou ativa, sejam capazes de ultrapassar algumas das barreiras biológicas impostas ao processo de biodisponibilização, ganhos ao sistema são obtidos quando este responde a estímulos complementares como; pH, temperatura, ou potencial redox (Danhier et al., 2010; Jain, 2001). Nos últimos tempos, boa parte dos engenheiros e físicos que trabalham no desenvolvimento de instrumentação específica para o método de hipertermia estão focados na instrumentação de nível clínico, ou seja, visam à aplicação em seres humanos. No entanto, recentemente o intenso avanço da nanotecnologia fez surgir diversos novos transportadores termosensíveis de medicamentos, com as mais diversas estruturas (e.g., sistemas micelares, dendrímeros, hidrogéis e polipeptídeos) (Shao et al., 2011). Esse intenso desenvolvimento de transportadores faz com que a demanda por ensaios pré-clínicos (em animais), para a efetiva validação in vivo, cresça proporcionalmente.

Apesar da demanda crescente por ensaios de hipertermia, não existem dispositivos comerciais disponíveis no mercado dedicados ao estudo in vivo. Sendo assim, cabe a cada 
grupo interessado desenvolver sua própria instrumentação para a realização deste tipo de ensaio in vivo. A necessidade de instrumentalização, por sua vez, limita o desenvolvimento de novos transportadores termosensíveis, pois não são todos os grupos que possuem pesquisadores com a formação necessária para desenvolver a mesma.

Na tentativa de suprimir a carência de dispositivos de aquecimento in vivo, os diversos grupos buscam por fontes de calor alternativas. O método mais comum de hipertermia in vivo utiliza banho térmico ajustado a temperaturas hipertérmicas. O laboratório de hipertermia da Duke University por muito tempo utilizou o método tradicional de banho térmico (Figura 2.10) como fonte de calor para hipertermia. A temperatura do banho é normalmente ajustada para $43,5^{\circ} \mathrm{C}$ e os animais são parcialmente submersos no líquido (água). Este tipo de dispositivo limita a modalidade de experimentos compatíveis, além de sofrer com baixa de penetrabilidade, de aquecimento e de seletividade.

\section{Arranjo Experimental}

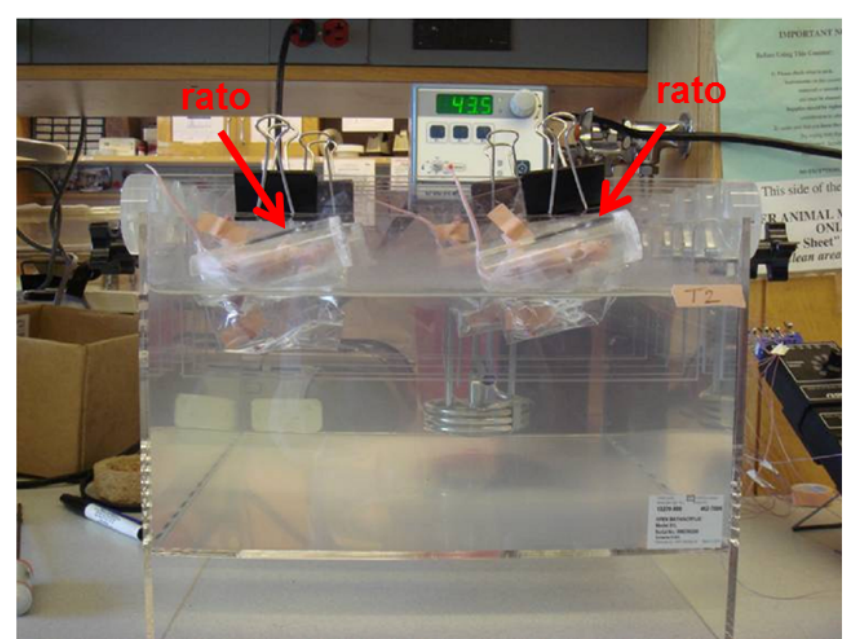

\section{Esquemático}

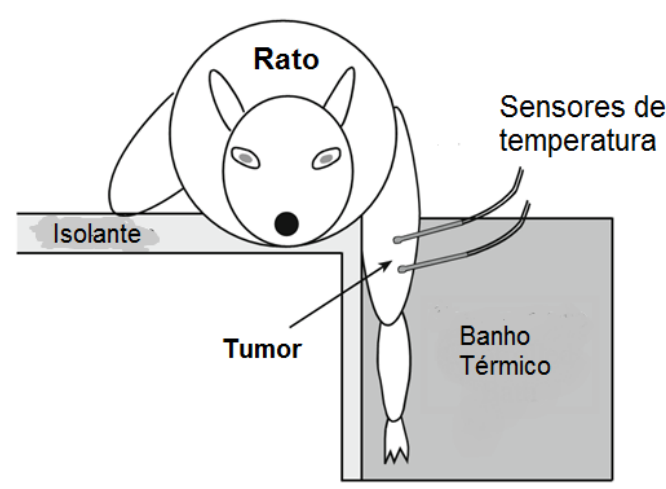

Figura 2.10: Ilustração do dispositivo tradicionalmente utilizado nos estudos de hipertermia local na Duke University. O dispositivo consiste em um banho térmico com um suporte para que os sujeitos do estudo sejam posicionados de forma a manter submerso apenas a área que desejase avaliar a hipertermia. Apresenta-se também um desenho esquemático deste sistema [figura extraída de (Valvano, 2011)].

Como apontado anteriormente, os agentes quimioterápicos possuem grande limitação de acesso ao parênquima cerebral, devido à presença da barreira hematoencefálica (BHE). Diversas metodologias buscam induzir o aumento da difusão de agentes terapêuticos através das paredes vasculares cerebrais (Pardridge, 2005, 2007). A elevação da 
temperatura local apresenta-se como uma das metodologias capazes de alterar as condições fisiológicas locais da BHE.

O grande obstáculo para promover aquecimento controlado no interior do cérebro é associado à presença do crânio. O crânio é responsável por gerar diferentes aberrações na distribuição do calor, e por gerar os chamados hot spot. Atualmente, a focalização da deposição de energia através do crânio pode ser atingida utilizando uma rede de multielementos que aplica diferentes amplitudes de fase e de modulação de ultrassom para sobrepor os efeitos do crânio. Apesar de existirem poucos estudos clínicos usando a técnica de ultrassom focalizado (HIFUS) no cérebro, o modo FUS transcranial possui enorme potencial para o uso futuro no tratamento do câncer.

O rápido avanço tecnológico do FUS e de outros equipamentos de uso clínico, fez retomar o interesse do uso da hipertermia na região cerebral. A grande disponibilidade de novos transportadores termosensíveis fez surgir também o interesse por estudos préclínicos, com intuito de verificar-se as características in vivo destes novos dispositivos terapêuticos. O grupo de hipertermia da Duke University possui extensa tradição no desenvolvimento de transportadores termosensíveis, é detentor da patente da formulação ThermoDox $\AA$, e tem investido em novas gerações de transportadores, como os transportadores termosensíveis elastin-like polypeptide (McDaniel et al., 2010) e gold nanostars (Yuan et al., 2012a).

Estudos combinando hipertermia e quimioterapia aplicados ao cérebro, mesmo para a formulação tradicional ThermoDox $®$, ainda são escassos. Por este motivo, houve a necessidade desta etapa de desenvolvimento de toda a instrumentação e dosimetria necessárias para viabilizar os estudos de hipertermia em cérebro de camundongos. Para isso, foi necessário projetar, construir e testar dispositivos de aquecimento viáveis a esta tarefa.

Algumas alternativas ao banho térmico já foram propostas na literatura para o estudo da hipertermia in vivo. Existem relatos de dispositivos baseados em transdutores de ultrassom (McDannold et al., 2004), antenas de RF (Aoki et al., 2004) e nanopartículas magnéticas (Johannsen et al., 2010). Embora todos esses métodos sejam potencialmente eficientes, antenas de RF ou micro-onda são as que apresentam o menor custo de cons- 
trução e implementação. Os ensaios em camundongos impõem uma condição adicional devido às pequenas dimensões associadas ao cérebro, isso limitando o uso de transdutores de ultrassom.

Após optar pelo dispositivo de aquecimento baseado em ondas eletromagnéticas, partiu-se para a determinação da configuração do sistema. Definiu-se o dispositivo de guia de onda retangular como aplicador de micro-onda deste trabalho. A decisão foi tomada após uma análise comparativa entre as diversas classes de antenas disponíveis a essa função. Nessa análise foram cogitados sistemas irradiadores como, dipolos, monopolos, e microstrip antenas. Contudo, concluiu-se que a guia de onda seria a configuração de melhor custo-benefício dentre elas. Os fatores que levaram a essa conclusão foram a facilidade de projeto e design, baixo custo de construção, alto grau de direcionalidade dos campos EM e a alta capacidade de transmissão de potência. Assim, considerando todos estes fatores partiu-se para a elaboração e construção de uma guia de onda retangular dedicada ao aquecimento do cérebro de pequenos camundongos.

\subsubsection{Características básicas de uma guia de onda retangular}

(Texto baseado em: Balanis (1989); Collin (2007); Pozar (2009))

A guia de onda atua no direcionamento da propagação de ondas eletromagnéticas (EM), assim como uma linha de transmissão. A guia de onda pode assumir diversas configurações, e devido a sua simplicidade de construção é amplamente utilizada em uma vasta gama de aplicações. A configuração hollow-pipe wave-guide destaca-se pelo número de aplicações. Na Figura 2.11 ilustra-se a configuração básica de uma guia de onda hollow-pipe do tipo retangular.

Como as direções $\hat{x}$ e $\hat{y}$ são limitadas por paredes condutoras, as dimensões laterais "a"e "b"influenciam diretamente a propagação da onda eletromagnética (EM) na direção $\hat{z}$.

Uma das propriedades mais importantes que depende das dimensões da guia de onda é a chamada frequência de corte $\left(f_{c}\right)$, ou menor frequência de operação em que uma onda eletromagnética pode propagar-se no interior da guia de onda. 


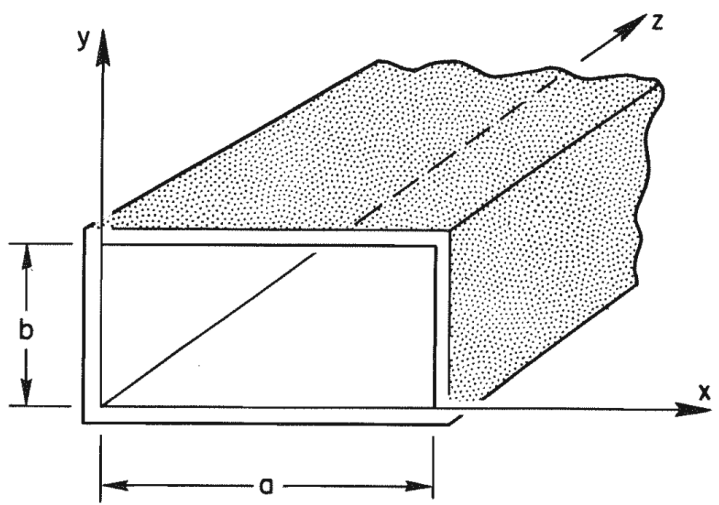

Figura 2.11: Diagrama esquemático da guia de onda retangular apresentando a definição dos eixos de coordenadas e das arestas "a"e "b"da guia de onda.

Campos eletromagnéticos oscilando em frequências inferiores a " $f_{c}$ " devem ser evanescentes. Campos evanescentes são campos que possuem um decaimento exponencial espacial, e não são capazes de conduzir potência de modo real. Entretanto, campos eletromagnéticos terão um caráter oscilatório, e se propagarão na guia caso satisfaçam um espectro de autovalores, associado a um conjunto ortogonal de soluções oscilatórias, os chamados modos de propagação da guia de onda.

No presente trabalho busca-se trabalhar com o modo de propagação $T E_{m, n}$, ou campo elétrico transverso $\left(E_{z}=0\right)$, pois esse modo é o que gera maior quantidade de calor no tecido alvo. Em $T E_{m, n}$, os modos de propagação possuem frequência de corte " $f_{c}$ " distintas quando a dimensão lateral respeita a relação $a>b$, dada por:

$$
\left(f_{c}\right)_{m, n}=\frac{1}{2 \pi \sqrt{\mu \epsilon}} \sqrt{\left(\frac{m \pi}{a}\right)^{2}+\left(\frac{n \pi}{b}\right)^{2}} \text { para } m, n=1,2,3 \ldots
$$

sendo " $\mu$ " a permeabilidade magnética do meio, " $\varepsilon "$ a permissividade elétrica do meio e "m" e "n" os autovalores associados às direções " $\hat{x}$ " $\mathrm{e}$ " $\hat{y}$ ", respectivamente. Em geral, o modo de menor frequência de corte é denominado modo dominante ou fundamental. Em $T E_{m, n}$, sendo $a>b$, o modo dominante será o modo $T E_{10}$, no qual a frequência de corte é definida por:

$$
\left(f_{c}\right)_{10}=\frac{1}{2 \pi \sqrt{\mu \epsilon}}\left(\frac{\pi}{a}\right)
$$


O modo $T E_{10}$ foi priorizado neste trabalho justamente por ser o modo de menor frequência de corte, e por possuir boa homogeneidade na distribuição dos campos. A distribuição dos campos elétricos e magnéticos no interior da guia de onda são apresentados na Figura 2.12.

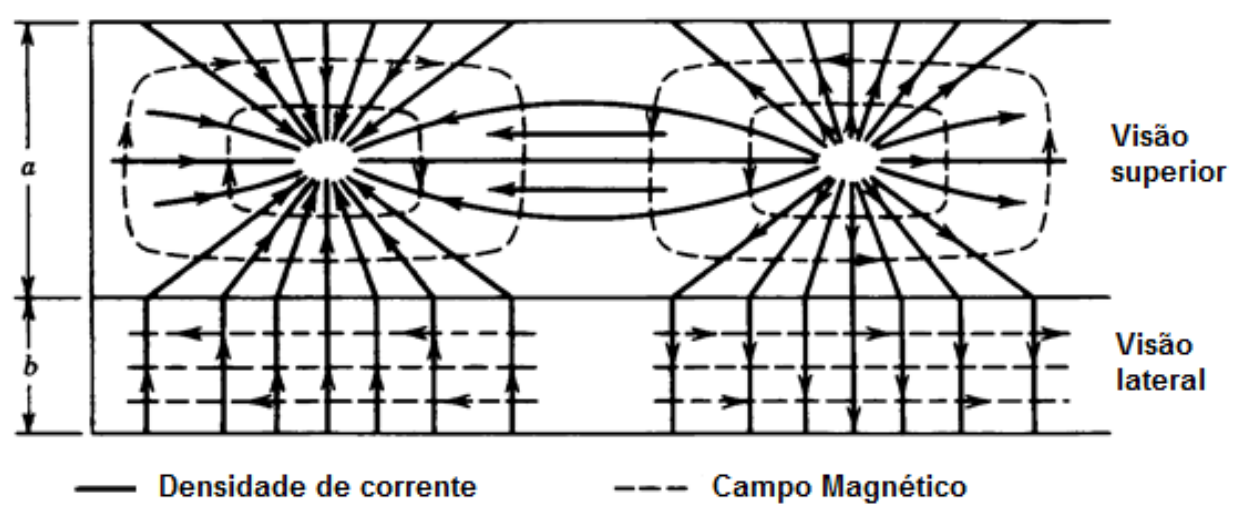

Figura 2.12: Distribuição dos campos elétricos e magnéticos no interior da guia de onda para o modo de propagação $T E_{10}$ [ figura extraída de (Collin, 2007)].

Considerando satisfatória a premissa de que os campos eletromagnéticos presentes no interior da guia de onda possam ser descritos com uma dependência temporal harmônica, tem-se que os campos elétricos e magnéticos no modo de propagação $T E_{10}$ podem ser descritos por:

$$
\begin{gathered}
E_{x}=0, \quad E_{z}=0, \quad H_{y}=0 \\
E_{y}=-\frac{A_{10}}{\epsilon} \frac{\pi}{a} \sin \left(\frac{\pi}{a} x\right) e^{-i \beta_{z} z} \\
H_{y}=-\frac{A_{10}}{\epsilon} \frac{\beta_{z}}{\omega \mu \epsilon} \frac{\pi}{a} \sin \left(\frac{\pi}{a} x\right) e^{-i \beta_{z} z} \\
H_{z}=-i \frac{A_{10}}{\omega \mu \epsilon}\left(\frac{\pi}{a}\right)^{2} \cos \left(\frac{\pi}{a} x\right) e^{-i \beta_{z} z}
\end{gathered}
$$

assumindo-se,

$$
\beta_{x}^{2}+\beta_{y}^{2}+\beta_{z}^{2}=\beta^{2}=\mu \epsilon \omega^{2}
$$


sendo " $\omega$ " a frequência angular de oscilação da onda, em rad/s, " $A_{10}$ " a amplitude dos campos no referido modo. A partir das equações anteriores, é possível definir a equação para a potência total transmitida neste modo como:

$$
P_{10}=\frac{\left|A_{10}\right|^{2}}{\omega \mu \epsilon^{2}} \frac{a b}{4} \frac{\pi^{2}}{a^{2}} \beta_{z}^{2}
$$

para,

$$
\beta_{z}=\beta \sqrt{1-\left(\frac{f_{c}}{f}\right)}
$$

Uma vez que " $\beta$ " é o vetor de propagação da onda.

\subsubsection{Desenvolvimento de instrumentação complementar}

Devido ao caráter pioneiro deste arranjo experimental, foi necessário construir todo um aparato complementar de instrumentação para que pudéssemos viabilizar os experimentos de aquecimento do cérebro de camundongos.

\section{Automação do sistema de aquisição de temperatura e controle da movimen- tação de sensores}

Para a aquisição e armazenamento dos dados de temperatura gerados pelos equipamentos de leitura (Luxtron 812 e Luxtron 3100) em tempo-real, foi necessário criar uma interface de comunicação com um microcomputador. Utilizado-se o software de controle LabVIEW (National Instruments, USA), e a porta de comunicação USB, foram criadas duas interfaces de aquisição e controle dos dispositivos de leitura de temperatura.

Uma destas interfaces foi criada com o objetivo exclusivo de leitura e armazenagem da temperatura em tempo-real. As temperaturas de até seis sensores eram apresentadas ao usuário, em tempo-real, para permitir que o mesmo pudesse acompanhar a evolução dos experimentos de hipertermia.

A outra interface foi criada com o objetivo de controlar o motor de passo que determinava a posição dos sensores no interior do tecido. Esse sistema foi utilizado para mapear a distribuição da temperatura local. Esta interface apresentava dois tipos de gráficos, os de temperatura em função do tempo e os de temperatura em função da posição 
do sensor. A Figura 2.13 exemplifica pedaços do painel de controle e do diagrama de bloco das interfaces geradas no LabVIEW.

\section{Sistema de aquisição de temperatura}
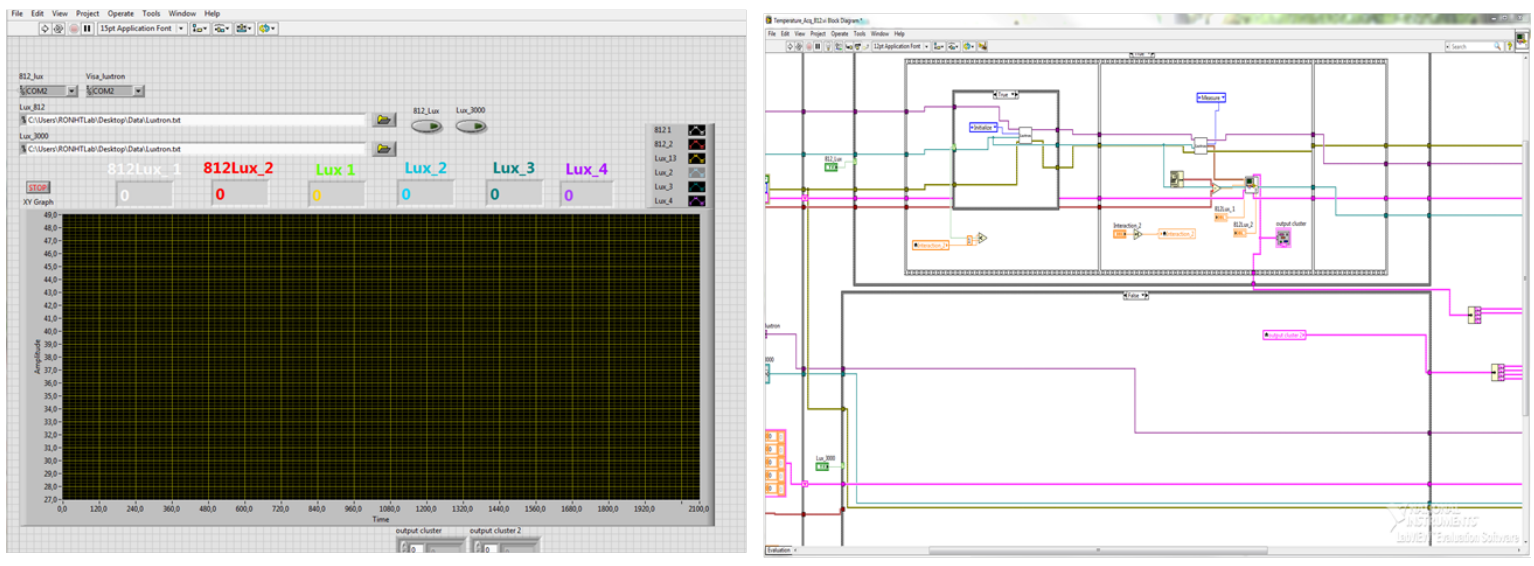

Sistema de aquisição de temperatura e movimentação dos sensores

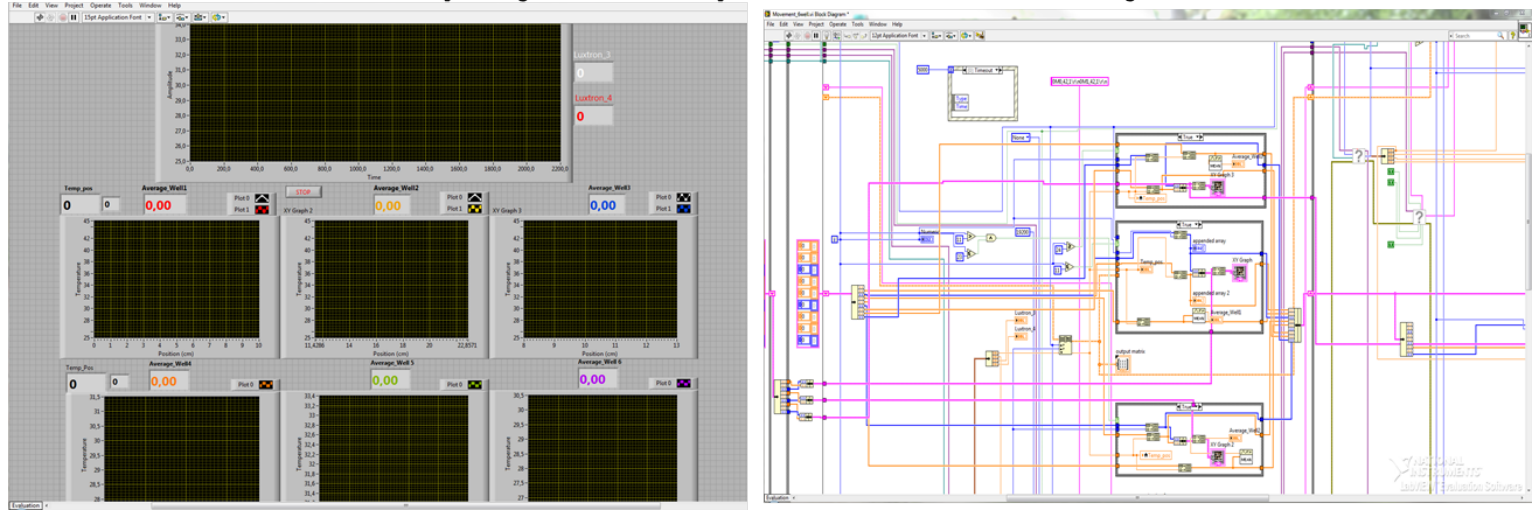

Figura 2.13: Ilustração das interfaces desenvolvidas em LabVIEW para controle e armazenagem dos dados de temperatura dos experimentos de hipertermia. Na imagem observa-se o painel de controle e parcialmente o diagrama de blocos.

\section{Fatoma tecido-equivalente}

Para a realização dos ensaios de eficiência de aquecimento da antena de microonda foi construído um dispositivo capaz de armazenar o fantoma tecido-equivalente e simultaneamente permitir a varredura espacial dos sensores de temperatura. Basicamente o dispositivo criado era composto por uma caixa acrílica que fora preenchida com o gel fantoma (Figura 2.14) tecido equivalente. A gelatina final possui dimensão de 4,6 x 5,6cm e a caixa acrílica foi selada com uma película de Mylar@ de 0,125mm. 
Nessa caixa foram criados pequenos canais que funcionavam como guia na varredura espacial dos sensores de temperatura. Os canais foram criados pela inserção de cateteres de 20 ga a uma distância da superfície de $1 \mathrm{~mm}, 2 \mathrm{~mm}$ e $3 \mathrm{~mm}$, conforme a configuração apresentada na Figura 2.14. Pequenas janelas foram criadas nos cateteres para garantir um contato direto entre os sensores de temperatura e o material do fantoma.
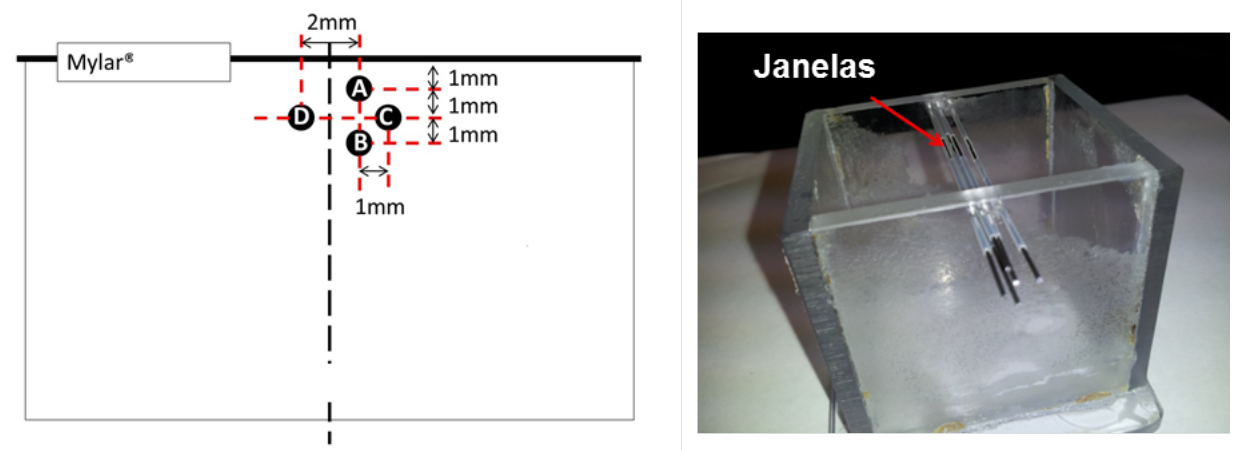

Figura 2.14: Diagrama esquemático da distribuição dos canais na caixa acrílica de suporte do gel fantoma. Visão da caixa acrílica e dos canais na sua posição final.

Como citado no item de materiais e métodos, o fantoma gel preparado busca mimetizar as propriedades dielétricas dos tecidos biológicos de interesse. Os valores médios das propriedades dielétricas do cérebro de camundongos não são reportadas na literatura, portanto, usou-se como referência valores médios do cérebro humano. A composição do cérebro humano pode ser divida em quatro compartimentos principais: sangue (12\%), fluido cerebrospinal (8\%), fluido intersticial (16\%), células do cérebro (64\%). Logo, definiu-se como contante dielétrica e condutividade elétrica média do cérebro como uma média ponderada dos quatro compartimentos na frequência de $3,7 \mathrm{GHz}\left(\varepsilon_{r}=48,8 ; \sigma=2,9(\mathrm{~S} / \mathrm{m})\right)$.

A Figura 2.15 apresenta a configuração final do dispositivo fantoma. As características dielétricas do gel fantoma foram medidas com um network analyzer e a constante dielétrica obtida em 3,7 GHz foi de $\varepsilon_{r}=46,6$ e a condutividade foi de $\sigma=2,7(\mathrm{~S} / \mathrm{m})$.

\section{Dispositivo para controle da posição de inserção dos sensores de temperatura no cérebro}

Um dos maiores desafios instrumentais deste projeto foi buscar um método que permitisse um bom controle da profundidade dos sensores de temperatura com relação 


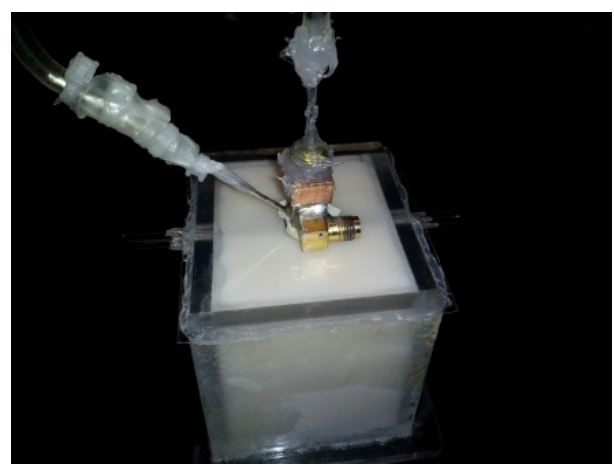

Figura 2.15: Configuração final do dispositivo fatoma para teste do mini-aplicador de microondas dedicado ao aquecimento do cérebro de camundongos.

à superfície da antena. O sensor superficial possuía complexidade de inserção menor, pois havia uma referência visual maior. Para o posicionamento do sensor no interior do cérebro, criou-se um dispositivo em acrílico alinhado com o aparelho estereotáxico. Este dispositivo possuía furos em três profundidades $(2 \mathrm{~mm}, 3 \mathrm{~mm}, 4 \mathrm{~mm})$ com relação à superfície. A agulha utilizada para inserção dos sensores de temperatura era suportada por um dos furos da estante de acrílico e assim garantia um melhor alinhamento do posicionamento do sensor (Figura 2.16).
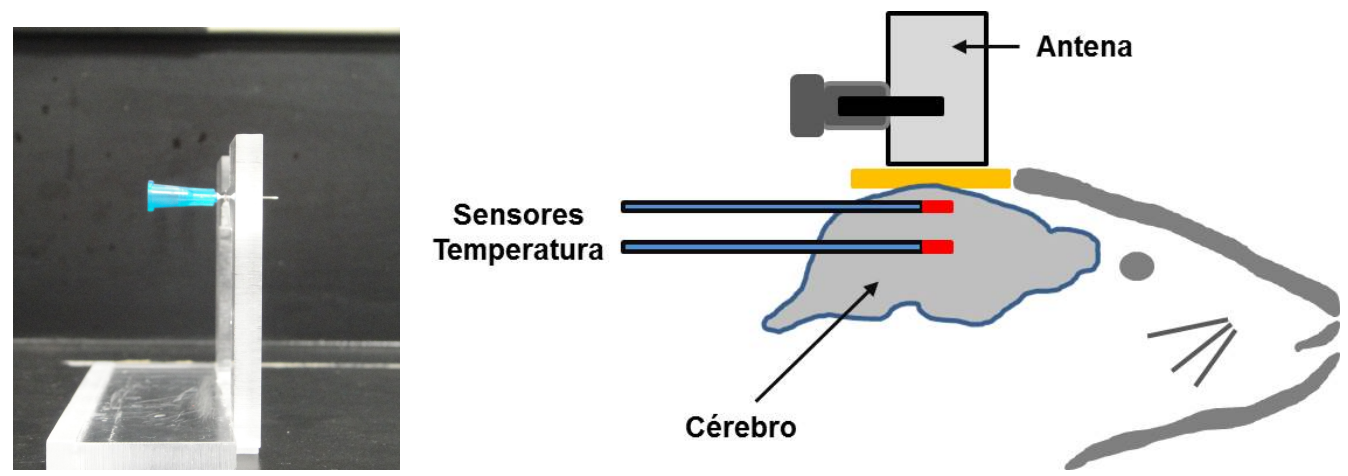

Figura 2.16: Estante usada para guiar o posicionamento dos sensores de temperatura. Esquemático da posição dos sensores no cérebro com relação à posição da antena.

Procedimentos de dissecação foram executados para confirmar a profundidade dos sensores de temperatura no cérebro.

\section{Dispositivo de controle da temperatura corpórea dos animais}

Os efeitos da anestesia na temperatura corpórea tem sido medidos em várias espécies, normalmente com o uso de termistores ou termopares e, ocasionalmente, com 
imagens térmicas. Em grande mamíferos, incluindo primatas, as temperaturas do interior do cérebro e do couro cabeludo, espaço subaracnóideo, e superfície cortical, são todas similares à temperatura basal, de aproximadamente $38^{\circ} \mathrm{C}$ (Hayward, 1968; Hayward \& Baker, 1969), mas durante uma anestesia profunda, a temperatura do cérebro pode reduzir vários graus (Hayward \& Baker, 1969). Portanto, em roedores anestesiados com temperatura basal normal entre $37-38^{\circ} \mathrm{C}$, deve-se esperar que a temperatura da superfície do neocórtex atinja valores de temperaturas de aproximadamente $33-35^{\circ} \mathrm{C}$.

O objetivo desta etapa do projeto era promover um aquecimento controlado no cérebro de camundongos submetidos a um procedimento de craniotomia, que basicamente consiste na retirada das camadas teciduais protetoras do cérebro (calota craniana e couro cabeludo), expondo o cérebro ao meio externo. Todo experimento de hipertermia depende de um controle preciso da temperatura basal do animal, pois um controle inadequado desta temperatura irá dificultar a aquisição dos dados, e poderá também colocar a vida do animal em risco. Existe também uma exigência do comitê de ética da Duke University, que impõe a necessidade do uso de fontes auxiliares de calor para controle da temperatura basal.

Há diversos dispositivos disponíveis comercialmente que controlam a temperatura basal de animais. Normalmente, estes dispositivos são simples e não possuem controle de temperatura preciso, pois são para uso geral. Foram testados sistemas comerciais disponíveis no laboratório de hipertermia, porém os mesmos não apresentaram um grau de controle satisfatório aos experimentos, isto porque os animais eram muito pequenos e estavam sujeitos a grande influência do meio externo. Neste contexto, foi necessário desenvolver um dispositivo capaz de promover uma maior estabilidade e precisão no controle da temperatura basal dos animais. Dentre as opções disponíveis estava o uso de circulação de água quente no interior de uma manta e o uso de sistema peltier. Optou-se pelo sistema peltier devido à possibilidade de se obter uma resposta rápida ao controle de corrente elétrica. A Figura 2.17 apresenta um esquema do sistema peltier, a imagem final do arranjo experimental e a visão final do dispositivo.

Na configuração do dispositivo foram utilizadas duas pastilhas peltier de corrente 


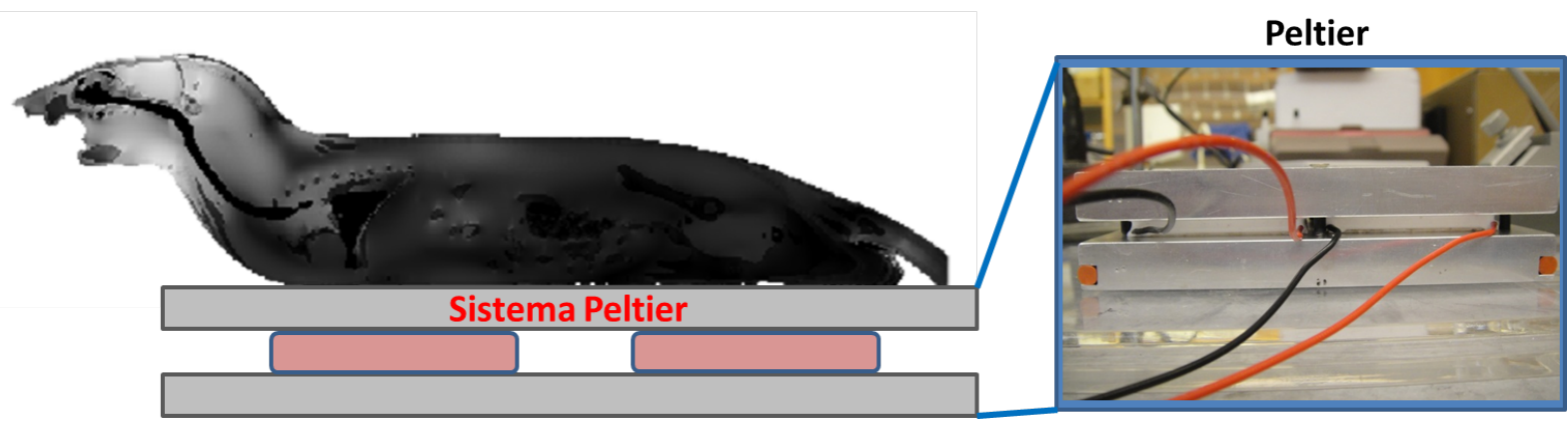

Figura 2.17: Ilustração do sistema de peltier utilizado para controle de temperatura basal dos camundongos. Imagem à direita apresenta a configuração final do sistema.

máxima de $6 \mathrm{~A}$. Como suporte das pastilhas foram utilizadas duas placas de alumínio, para assim garantir uma boa homogeneidade na transferência de calor. A corrente elétrica de circulação nos peltier foi controlada por uma fonte DC externa.

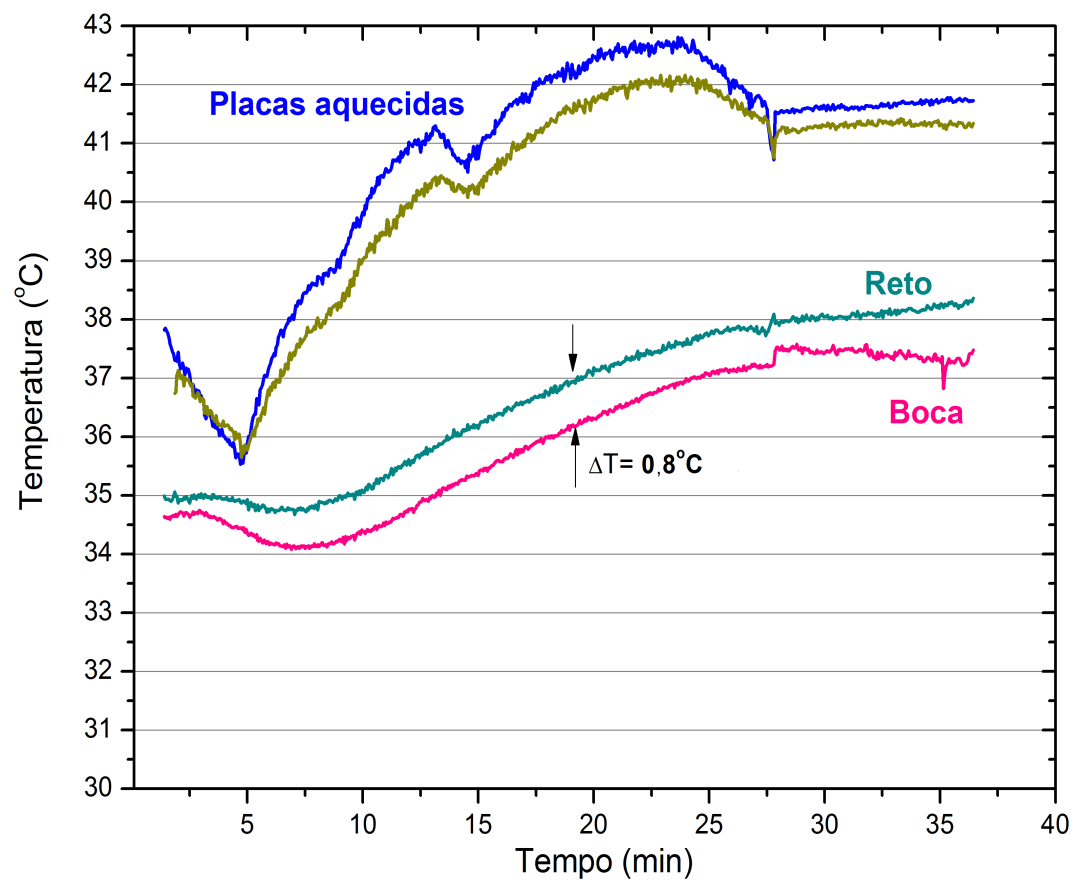

Figura 2.18: Teste de viabilidade do uso do sistema peltier no controle da temperatura basal do camundongo. O sensores de temperatura foram posicionados no camundongo (Boca e Reto) e na superfície da placa de alumínio do sistema peltier.

Testes de viabilidade de funcionamento da placa foram realizados, e na Figura 2.18 exemplifica-se a resposta da temperatura corpórea do camundongo em função da temperatura da placa de alumínio. 


\subsubsection{Projeto do mini-aplicador de micro-onda}

Neste item busca-se apresentar os conceitos e restrições que nortearam o projeto de construção da antena de micro-onda.

O primeiro passo em qualquer projeto de uma guia de onda, consiste, necessariamente, em definir as dimensões características envolvidas no problema e qual a geometria requerida. As configurações geométricas de guia de ondas comumente utilizadas são as de secção-transversal circular e retangular. De modo geral, as duas configurações apresentam propriedades similares, diferindo somente nos modos de propagação e na distribuição espacial dos campos EM. A escolha de uma determinada configuração depende do alvo de interesse. Para a estrutura geométrica do cérebro do camundongo, concluiu-se que uma guia de onda retangular é a que melhor se ajusta às condições do projeto.

\section{Definição da dimensão básica da guia de onda}

As dimensões da guia de onda, devem respeitar as características anatômicas do tecido alvo. Para determinar as dimensões médias do cérebro do camundongo utilizou-se um conjunto de imagens de MRI de três camundongos. As dimensões observadas são exemplificadas na Figura 2.19.

As imagens (Figura 2.19) indicam que a extensão do maior eixo no cérebro do camundongo é da ordem de $10 \mathrm{~mm}$ e a extensão do eixo perpendicular a este é de 7 $\mathrm{mm}$. O objetivo principal deste projeto foi de promover aquecimento local somente em um dos hemisférios do cérebro. Respeitando as restrições anatômicas, chegou-se a uma configuração de dimensões de 2,46 x 5,63 mm de secção horizontal da guia de onda. A representação da área ocupada pela guia de onda na superfície do cérebro (retângulo amarelo) é ilustrada na Figura 2.19 B.

\section{Definição da frequência mínima de operação}

Todo modo de propagação que existe na guia de onda possui sua própria frequência de corte. Para que essa propagação seja eficiente a frequência de operação deve ser superior a frequência de corte de cada modo. Para uma guia de onda retangular a frequência de 

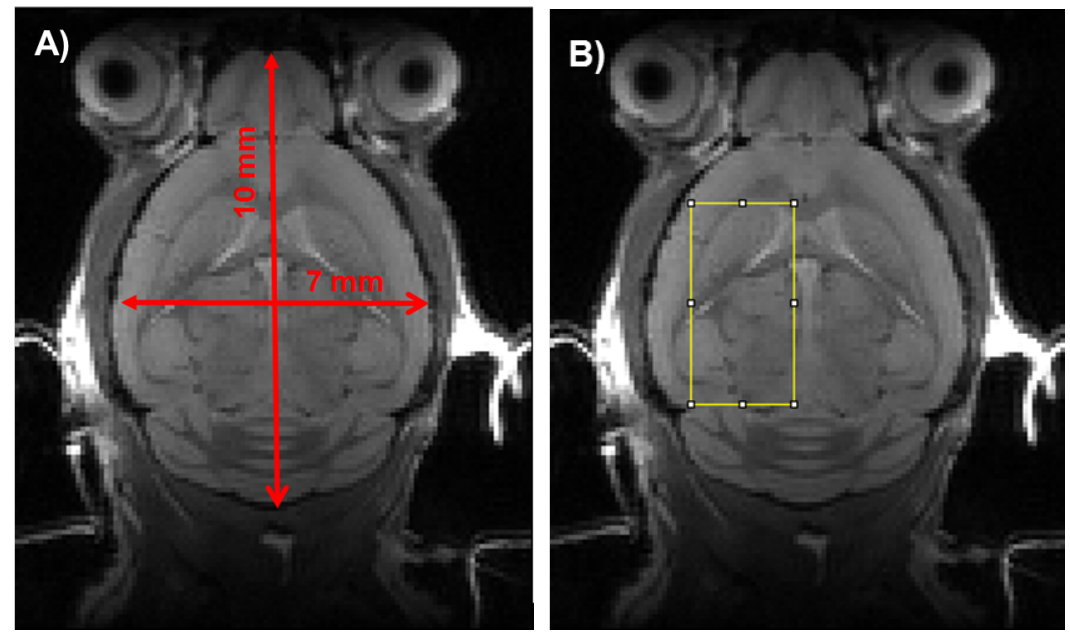

Figura 2.19: Imagens de ressonância magnética (7T) na visão coronal do cérebro de um camundongo. $\mathrm{Na}$ imagem $\mathrm{A}$ ) estão representados as dimensões em milímetros dos eixos principais do cérebro $(7 \times 10 \mathrm{~mm})$. A imagem B) apresenta a indicação da área ocupada, na superfície do cérebro, pelo mini-aplicador de micro-onda (retângulo amarelo), que representa as dimensões estipuladas para a guia de onda $(2,46 \times 5,63 \mathrm{~mm})$.

corte para o modo $T E_{m n}$ é dado pela equação 2.13. Conforme especificado pela equação da frequência de corte as dimensões das laterais juntamente com o meio dielétrico de preenchimento determinam os valores das frequências de corte.

Com intuito de obter uma maior homogeneidade na distribuição do campo, busca-se operar em um regime de frequência em que somente o modo $T E_{10}$ esteja presente, para isso é necessário determinar as frequências de corte dos dois primeiros modos de propagação. A Figura 2.20 apresenta a simulação para o comportamento da constante de propagação dos modos $T E_{10}$ e $T E_{20}$. Valores zero da constante de propagação implicam que a onda não se propaga no interior da guia de onda (onda evanescente). $\mathrm{O}$ intervalo entre as duas primeiras frequências de corte é definido como modo fundamental.

$O$ resultado da simulação indica que o modo $T E_{10}$ será dominante no intervalo de frequência de 3,0 a 6,0 GHz (Figura 2.20). Para os dois modos de propagação, pode-se observar que a taxa do incremento da constante de propagação reduz com o aumento da frequência.

Avaliando o modo fundamental $\left(T E_{10}\right)$, observa-se que a distribuição da intensidade de campo elétrico é caracterizada conforme a Figura 2.21. 


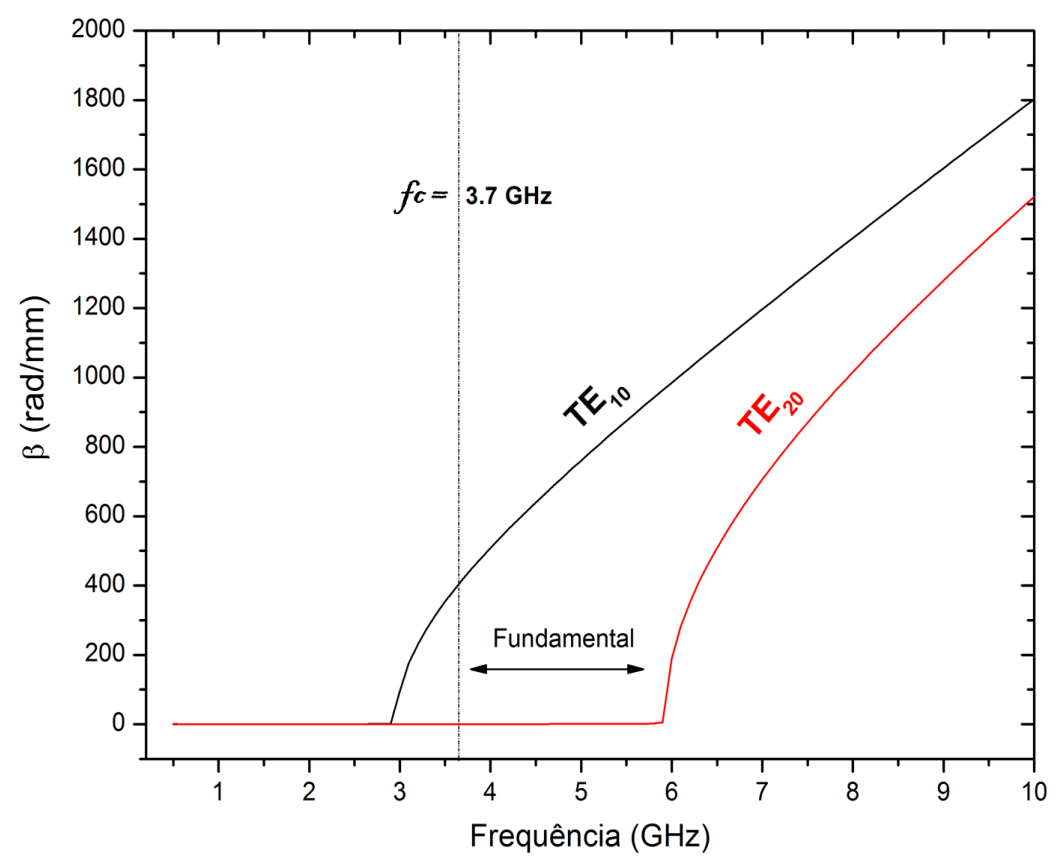

Figura 2.20: Simulação do comportamento da constante de propagação para a guia de onda retangular em função da frequência de excitação. Os modos $T E_{10}$ (preto) e $T E_{20}$ (vermelho) correspedem aos dois primeiros modos de propagação.

A variação da distribuição do campo no interior da guia de onda é um fator crucial para a distribuição do aquecimento no tecido alvo. De modo geral, pode-se assumir que a intensidade máxima do campo elétrico é atingida na região central da secção transversal (Figura 2.21).

\subsubsection{Processo de otimização do mini-aplicador de micro-ondas}

A partir das especificações básicas dos itens anteriores partiu-se para o processo de otimização da antena propriamente dito, ou seja, executou-se o processo de busca das condições ótimas de funcionamento. O design da antena foi gerado no próprio HFSS ${ }^{\mathrm{TM}}$, usando a ferramenta Ansoft Designer. O aplicador desenhado foi uma guia de onda com secção transversal retangular e com uma das extremidades fechada por uma superfície condutora e a outra aberta. Uma antena sonda monopolo foi utilizada para realizar a transição do cabo coaxial para a guia de onda. A parte central do cabo coaxial foi prolongada para o interior da guia de onda, enquanto que a parte externa foi conectada à superfície condutora da guia de onda. 


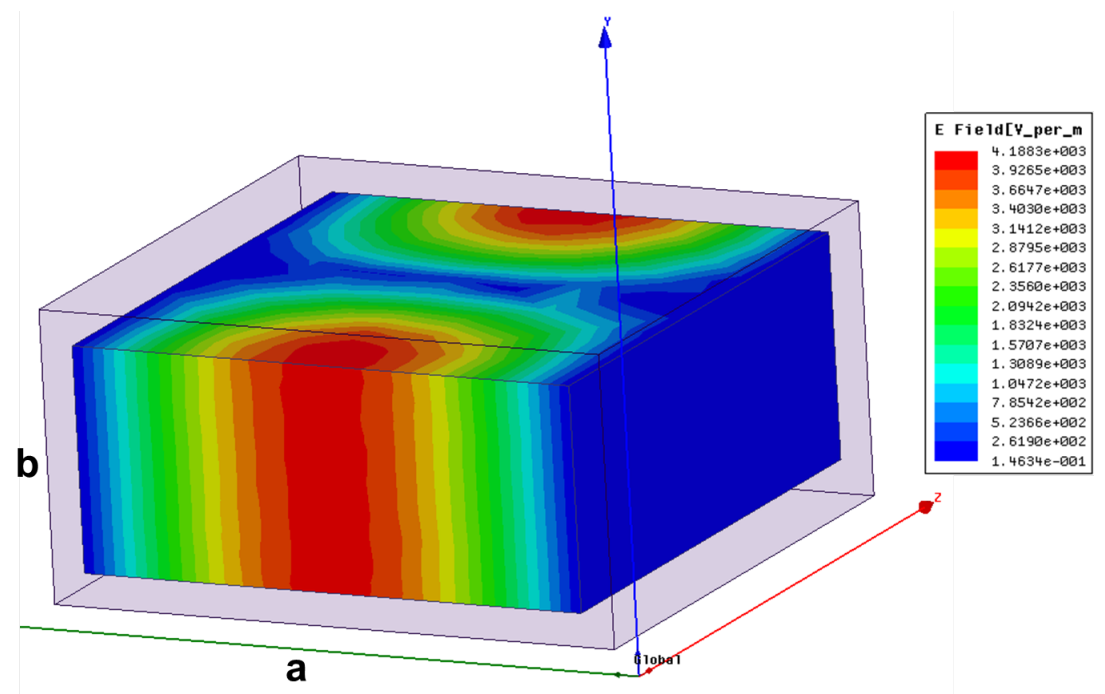

Figura 2.21: Variação do campo elétrico no interior da guia de onda no modo $T E_{10}$ e frequência de excitação de $3,7 \mathrm{GHz}$.

Com imagens de MRI adquiridas previamente, foram segmentadas as superfícies 3D da cabeça, do crânio e do cérebro do camundongo, estas superfícies foram consideradas como volumes uniformes dos tecidos. Uma vez importado no HFSS ${ }^{\mathrm{TM}}$, a dependência com a frequência da propriedade dos tecidos foi atribuída para cada volume. As propriedades dielétricas dos tecidos biológicos foram obtidos em (niremf.ifac, 2011). A Tabela 2.1 apresenta as diferentes propriedades dos tecidos para a frequência de 3,7 GHz.

Tabela 2.1: Propriedades dielétricas e térmicas dos diferentes tecidos da cabeça do camundongo na frequência de $3,7 \mathrm{GHz}$

\begin{tabular}{lcccccc}
\hline Tecido & $\varepsilon_{\mathrm{r}}$ & $\begin{array}{c}\sigma \\
(\mathrm{S} / \mathrm{m})\end{array}$ & $\begin{array}{c}\omega \mathrm{b} \\
\left(\mathrm{kg} / \mathrm{s} \cdot \mathrm{m}^{3}\right)\end{array}$ & $\begin{array}{c}k \\
(\mathrm{~W} / \mathrm{m} \cdot \mathrm{K})\end{array}$ & $\begin{array}{c}c \\
(\mathrm{~J} / \mathrm{kg} \cdot \mathrm{K})\end{array}$ & $\begin{array}{c}\rho \\
\left(\mathrm{kg} / \mathrm{m}^{3}\right)\end{array}$ \\
\hline Osso & 5.17 & 0.16 & 0.06 & 0.65 & 1590 & 1908 \\
Matéria cinzenta & 47.01 & 2.81 & 9.1 & 0.565 & 3680 & 1045 \\
Substância branca & 34.80 & 1.94 & 4.8 & 0.503 & 3600 & 1041 \\
Músculo & 51.20 & 2.74 & 0.36 & 0.56 & 3639 & 1090 \\
\hline
\end{tabular}

As características estruturais da guia de onda retangular foram parametrizadas conforme Figura 2.22.

Na configuração retangular da guia de onda (Figura 2.22), são quatro os parâmetros disponíveis para otimização :

(1) $\mathrm{d} 1(\mathrm{~mm})$ - Distância entre o pino de alimentação e a superfície condutora do 


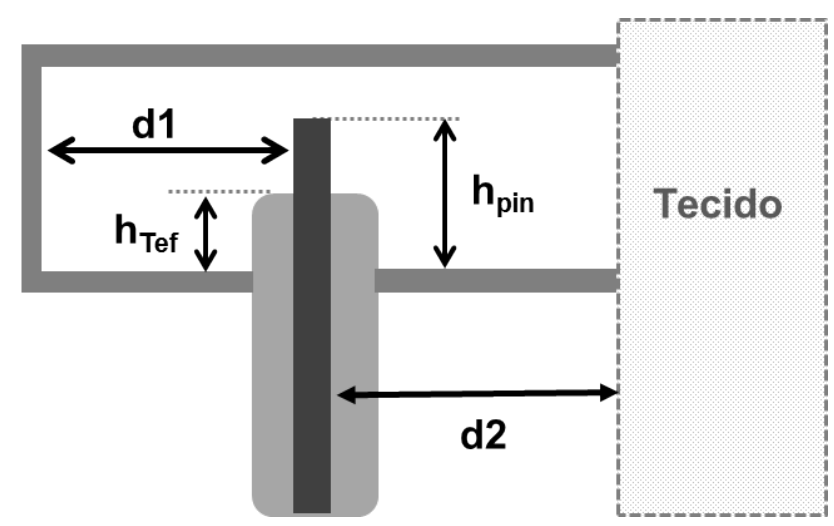

Figura 2.22: Definição dos parâmetros estruturais que influenciam o acoplamento entre a guia de onda e o cabo coaxial

fundo ("back shorted").

(2) d2(mm) - Distância entre o pino de alimentação e a interface de transição com o tecido biológico.

(3) $\mathrm{h}_{\text {pin }}(\mathrm{mm})$ - Profundidade do pino de alimentação no interior da guia de onda.

(4) $\mathrm{h}_{\text {Tef }}(\mathrm{mm})$ - Profundidade do teflon de isolamento no interior da guia de onda.

\section{Função objetivo}

Para avaliação da eficiência da guia de onda durante o processo de otimização, utilizou-se a função objetivo descrita previamente na Equação 2.11. Esta função avalia a razão entre o valor de SAR em volume considerado como alvo e o restante do volume considerado como sadio $f(\vec{v})=\frac{\int_{V \text { target }} S A R d v}{\int_{V \text { normal }} S A R d v}$. O volume alvo foi definido como um esfera de diâmetro $1.5 \mathrm{~mm}$ posicionada a $3 \mathrm{~mm}$ de profundidade com relação à superfície do cérebro. A representação do volume alvo no sistema de otimização é apresentada na Figura 2.23.

\section{Condições de contorno ou restrição}

No processo de otimização foram utilizadas duas condições de restrição. A primeira relacionada ao espalhamento $S_{11}$, e a segunda com relação a SAR mínima requerida para a produção da elevação da temperatura em $5^{\circ} \mathrm{C}$. O limite mínimo aceitável para o acoplamento de impedância neste projeto foi definido como $S_{11} \leq-10 \mathrm{~dB}$. 


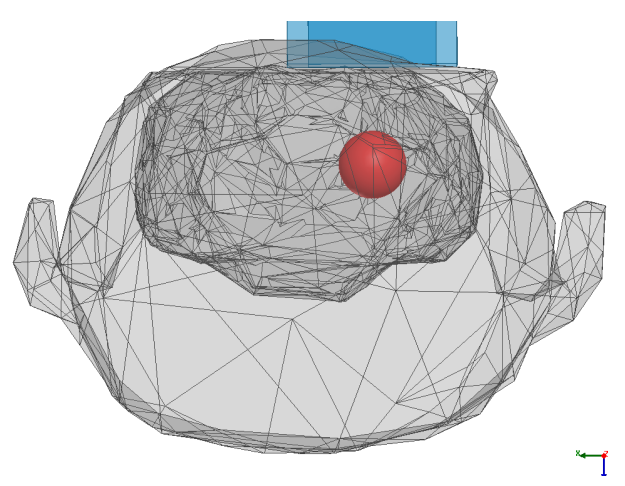

Figura 2.23: Ilustração do sistema utilizado para otimização da guia de onda com base nos valores de SAR. A esfera vermelha indica a definição do volume alvo utilizado para obter a melhor configuração possível.

Com relação ao SAR mínimo necessário para a hipertermia, existem alguns estudos que propõem valores necessários de SAR para os diferentes experimentos in vivo. Os valores utilizados aqui basearam-se nos dados apresentados em (Gordon et al., 1986a,b). A Figura 2.24 reproduz os valores de SAR mínimo para a elevação de $1^{\circ} \mathrm{C}$ no corpo de diferentes animais.

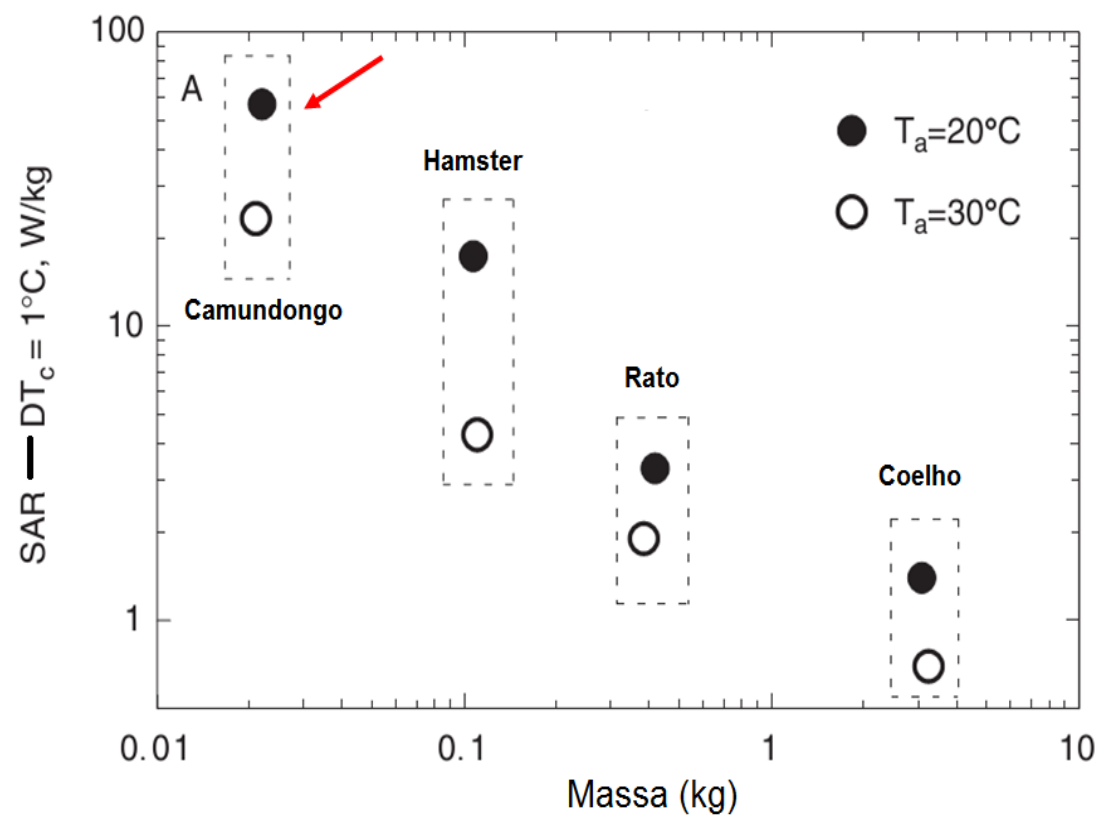

Figura 2.24: Taxa específica de absorção (SAR) a requerida para aumentar $1{ }^{\circ} \mathrm{C}$ na temperatura interna em função da massa corpórea de várias especies expostas a radiofrequência por 90 minutos, com temperatura ambiente de 20 e $30^{\circ} \mathrm{C}$. Dados adaptados de (Gordon et al., 1986a,b)

A partir dos resultados ilustrados na Figura 2.24, fica claro que a SAR mínima 
necessária para promover a elevação de $5^{\circ} \mathrm{C}$ no camundongo deve ser de aproximadamente $100 \mathrm{~W} / \mathrm{kg}$. Portanto as condições de restrição podem ser expressas como:

$$
S_{11} \leq-10 d B \quad, \quad S A R>100\left(W k g^{-1}\right)
$$

\section{Otimização da SAR}

Para o processo de otimização do mini-aplicador variou-se os quatro parâmetros estruturais possíveis $\left(\mathrm{d} 1, \mathrm{~d} 2, \mathrm{~h}_{\text {pin }}, \mathrm{h}_{T e f}\right)$. O intervalo observado respeitou os limites físicos de cada parâmetro. Para cada conjunto de dados foi calculado o $\mathrm{S}_{11}, \mathrm{SAR}_{\text {target }} \mathrm{e}$ $\mathrm{SAR}_{\text {normal }}$. A impedância da guia de onda pode ser acoplada com o gerador de microondas através do adequado design da transição do cabo coaxial para a guia de onda. A variação dos parâmetros $h_{\text {pin }}$ e d1 influenciam o parâmetro $S_{11}$. Um exemplo da resposta do parâmetro $\mathrm{S}_{11}$ em função da variação do $\mathrm{h}_{p i n}$ e d1 é apresentado na Figura 2.25.

Combinando os quatro parâmetros estruturais, e realizando um procedimento de varredura paramétrica dentro de um intervalo extenso, foi possível encontrar o conjunto de configurações que satisfaz as condições de otimização, e configura a parametrização ideal. A simulação do parâmetro de acoplamento $\mathrm{S}_{11}$ em função da frequência de excitação para a configuração ótima é apresentada na Figura 2.26.

O monitoramento da função objetivo do SAR apontou que a frequência que melhor concilia penetrabilidade com máximo valor de SAR encontra-se na região do $3,75 \mathrm{GHz}$ (Figura 2.26). Logo, definiu-se para esse sistema a frequência de operação como sendo 3,7 GHz. A distribuição final do SAR na secção axial e sagital no modelo do cérebro do camundongo é apresentada na Figura 2.26. O valor máximo de SAR obtido nesta simulação foi de $4300 \mathrm{~W} / \mathrm{kg}$.

O resultado anterior demonstra boa homogeneidade da distribuição de SAR, com o máximo valor coincidindo com o centro da guia de onda. Baseado na expectativa experimental de SAR (Figura 2.24), pode-se dizer que a antena otimizada apresenta características mais que suficientes para atender as condições de hipertermia. 


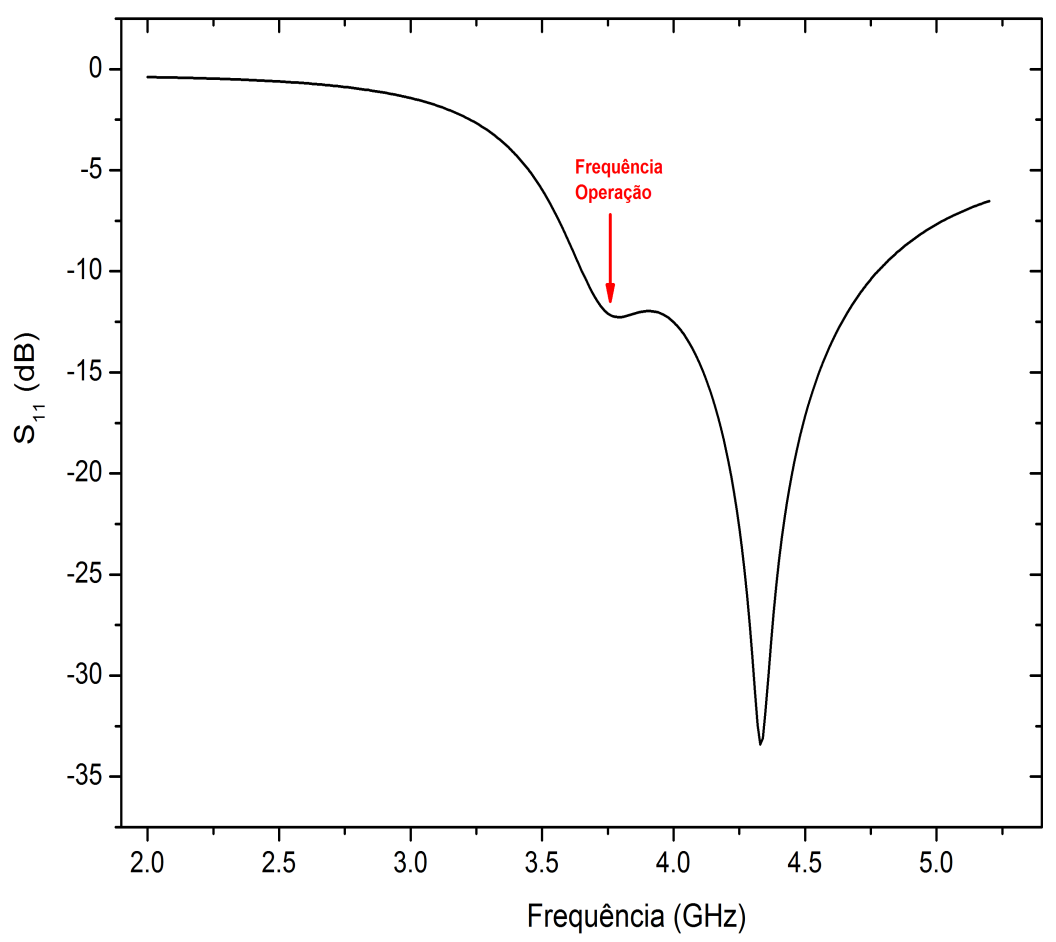

Figura 2.25: Simulação com HFSS do parâmetro de espalhamento $\mathrm{S}_{11}$ em função da frequência para a guia de onda, na configuração considerada ótima do sistema modelo do camundongo

\subsubsection{A construção do mini-aplicador}

A guia de onda retangular foi manualmente construída utilizando-se uma liga de cobre (Alloy 260) de 2,46 x 5,63 mm. A excitação da guia de onda foi realizada por um cabo coaxial rígido com pino central de $0.51054 \mathrm{~mm}$. As dimensões físicas da antena respeitaram os resultados obtidos no processo de otimização. As dimensões finais do mini-aplicador foram $\mathrm{h}_{\text {pin }}=2,3 \mathrm{~mm}, \mathrm{~d} 1=1,8 \mathrm{~mm}$ e $\mathrm{d} 2=2,6 \mathrm{~mm}$. O resultado final é apresentado na Figura 2.27.

\subsubsection{Estudo de performance e eficiência de aquecimento em sis- tema fatoma}

A experimentação animal constitui uma etapa obrigatória no desenvolvimento de qualquer metodologia ou terapia no tratamento do câncer. O comitê de ética animal da Duke University impõe como condição obrigatória a aprovação de um protocolo de experimentação animal em que todos os testes e recursos tecnológicos, baseados em sistemas 


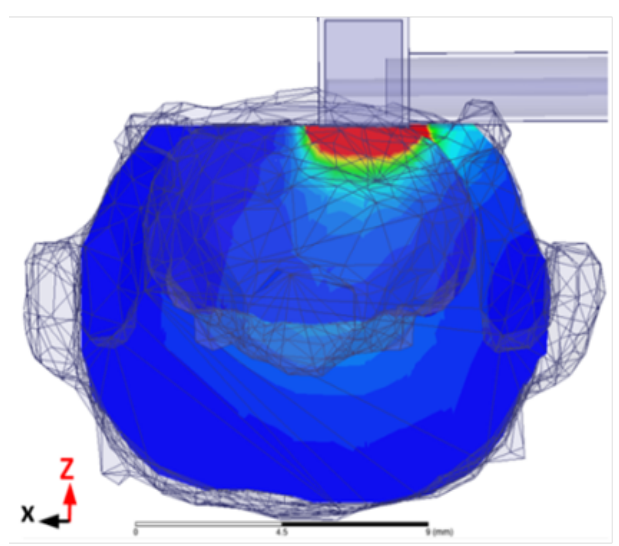

Axial
SAR Field $[\mathrm{W} / \mathrm{kg}]$

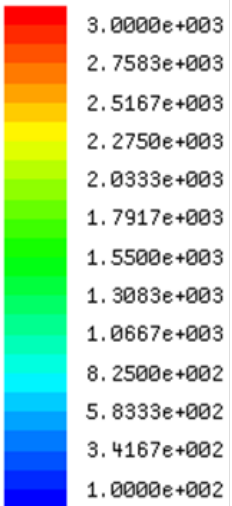

$1.0000 e+002$

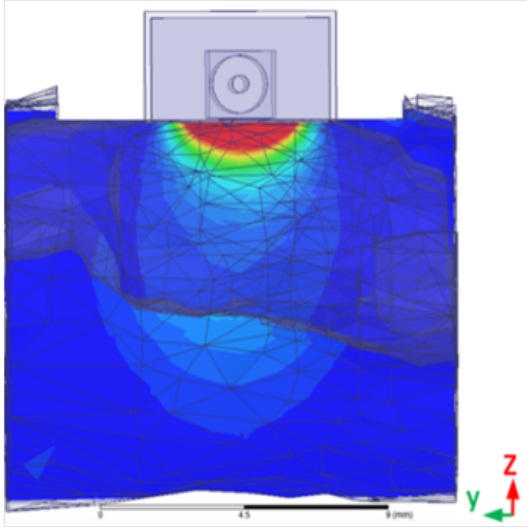

Sagital

Figura 2.26: Simulação com HFSS da distribuição do SAR no sistema modelo para a frequência $3,7 \mathrm{GHz}$ nas duas visões padrão: Axial e Sagital

modelo, tenham sido previamente exauridos, antes que qualquer animal seja utilizado como sujeito de estudo. Tudo isso para minimizar o número de sujeitos necessários a cada estudo. O conjunto de dados aqui apresentados representam os resultados obtidos no processo de validação do sistema de aquecimento por micro-onda, e foi utilizado para obtenção da aprovação do protocolo de experimentação animal.

\section{Validação da deposição de energia "SAR"}

A eficiência de uma dada antena em depositar energia eletromagnética (SAR) no tecido alvo é o principal parâmetro a ser conhecido no desenvolvimento de dispositivos de aquecimento para hipertermia. O conhecimento da distribuição espacial da SAR permite prever, com precisão, a elevação de temperatura local, e auxilia no planejamento e controle terapêutico.

Existem várias formas de se obter a distribuição da SAR, contudo o método de maior precisão consiste em determinar a intensidade do campo elétrico em um ponto específico do espaço. Normalmente, existem sondas capazes de determinar essa intensidade. No entanto essas sondas possuem dimensões finitas que limitam a resolução espacial entre pontos consecutivos. No caso do mini-aplicador para o cérebro de camundongo, suas dimensões milimétricas não permitem o uso desse tipo de sonda, pois as mesmas são 


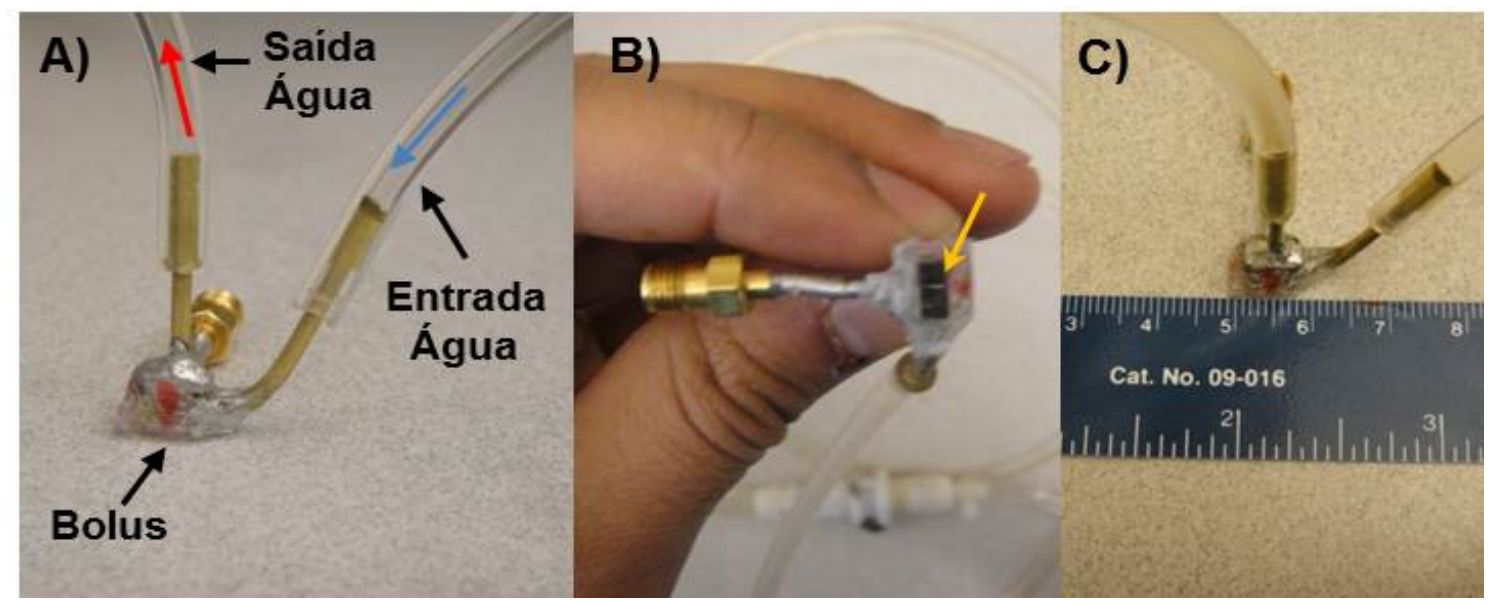

Figura 2.27: Ilustração da configuração final do mini-aplicador de micro-onda. Na imagem A) apresenta-se a visão lateral do dispositivo juntamento com o indicativo do sentido de circulação da água, sendo que na porta de entrada tem-se água fria, e na porta de saída a água encontra-se aquecida devido a troca de calor no interior da guia de onda. Na imagem B) tem-se uma visão da cavidade da guia de onda, no qual é possível visualizar o pino emissor (indicado pela seta). Na imagem C) o mini-aplicador é colocado sob uma régua indicando o tamanho do mesmo (menor que $1 \mathrm{~cm})$.

da ordem do tamanho do aplicador. Neste sentido, buscou-se determinar algumas das características de deposição de energia por métodos indiretos. A solução encontrada aqui foi monitorar a intensidade de deposição de energia através da medição da elevação de temperatura local.

O uso da elevação da temperatura como parâmetro proporcional ao SAR possui algumas limitações, pois mesmo áreas não sujeitas à incidência de campo eletromagnético podem sofrer elevação de temperatura devido aos efeitos indiretos de condução de calor. Esse efeito de condução gera incertezas na localização e amplitude da SAR. Para a realização dos testes, utilizou-se o dispositivo fantoma desenvolvido especialmente para este fim (ver item 2.3.2). Quatro sensores de temperatura de fibra óptica $(0,58 \mathrm{~mm}$ de diâmetro) foram introduzidos nos canais de varredura, e, simultaneamente, conectados a um motor de passo para que o deslocamento fosse controlado em incrementos de $0,5 \mathrm{~mm}$. O motor de passo utilizado foi controlado por uma interface desenvolvida no software Labview (National Instruments, Austin, Texas), desenvolvida especialmente a esse projeto. A temperatura local foi adquirida em tempo-real, utilizando-se o medidor Luxtron 3010, que também foi controlado por uma interface de Labview. 
A caixa fantoma utilizada possuía 4 canais dispostos em diferentes profundidades com relação à superfície. A antena foi posicionada na superfície, tal que a maior aresta $(5,63 \mathrm{~mm})$ estivesse orientada de forma paralela aos canais, e o centro da antena foi posicionado no centro do canal A. Os experimentos de aquecimento foram realizados com a excitação de micro-ondas em $12 \mathrm{~W}$, e as temperaturas foram adquiridas em tempo-real. A Figura 2.28 apresenta os resultados da distribuição de temperatura em condições de equilíbrio para a varredura espacial dos quatro canais (A,B,C,D).

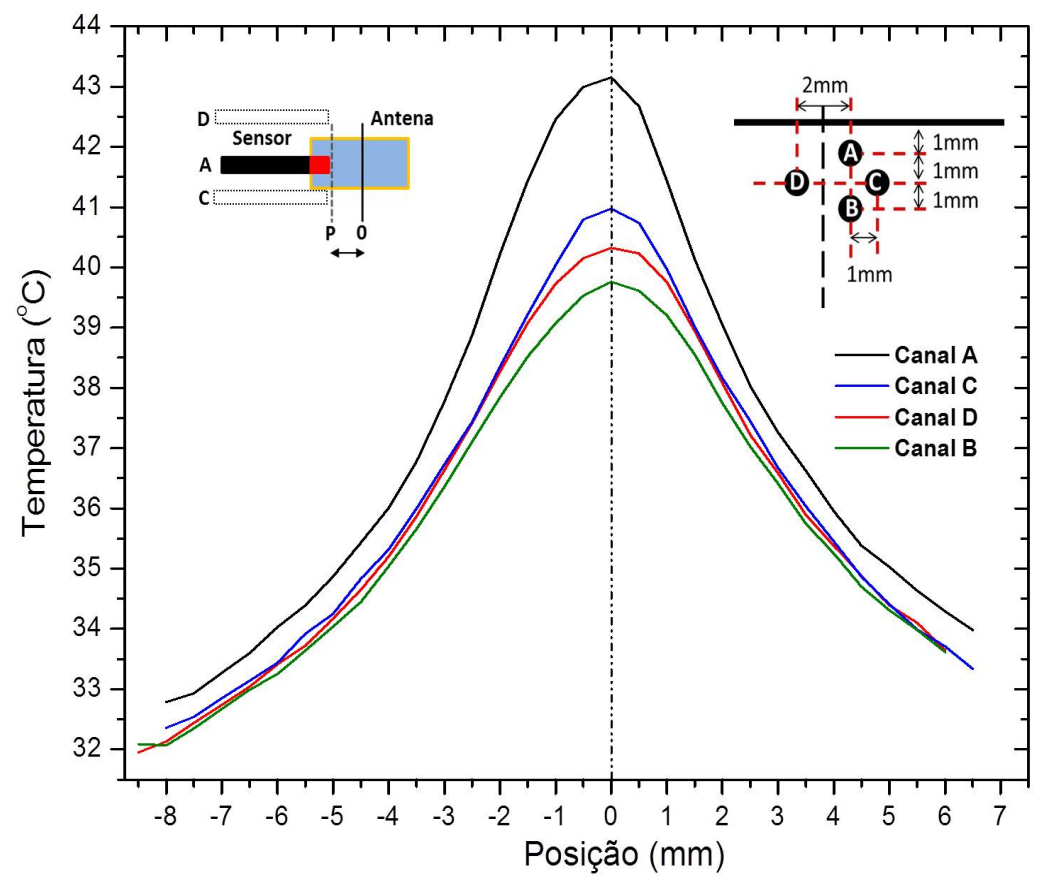

Figura 2.28: Distribuição espacial da temperatura interior da caixa fantoma sob influência de $12 \mathrm{~W}$ de micro-ondas a $3,7 \mathrm{GHz}$. As curvas representam a temperatura local em função da varredura espacial dos sensores (passo de $0,5 \mathrm{~mm}$ ) no interior dos quatro canais. O parâmetro posição no eixo da abcissa indica distância entre a ponta do sensor e o centro da antena (ver esquema do lado esquerdo superior). A disposição dos canais é apresentado no esquema no lado direito superior.

Os resultados da Figura 2.28 demonstram que a potência de 12 W, nas regiões monitoradas de maior deposição de energia, promove um aumento na temperatura de pelo menos $7^{\circ} \mathrm{C}$. Observa-se que a distribuição espacial da temperatura pode ser considerada simétrica com relação ao centro da antena para os quatro canais monitorados. Como esperado, observa-se também que a área de atuação do impacto da elevação da temperatura é muito maior que as próprias dimensões da antena, indicando assim um efeito de 
condução de calor. Esse resultado é muito positivo pois demonstra a homogeneidade da distribuição do campo elétrico, não se observando pontos singulares de sobreaquecimento. A partir desses resultados pode-se esperar que a área de atuação da micro-onda no cérebro do camundongo deva ser limitada a alguns milímetros no entorno do centro da antena.

\section{Grau de penetração}

A penetração dos campos eletromagnéticos no interior do tecido alvo é um parâmetro que ajuda a definir o volume de atuação dos mesmos. A penetração de uma determinada onda eletromagnética é definida pelas propriedades elétricas do tecido alvo e pela frequência de oscilação da onda incidente. De modo geral, a penetração nos tecidos biológicos por ondas eletromagnéticas é inversamente proporcional à frequência de oscilação da mesma. Portanto, na lógica no processo terapêutico da hipertermia, estipulou-se que quando os tumores estão localizados em regiões profundas do corpo, a frequência da onda eletromagnética deve ser pequena $(120 \mathrm{MHz})$, para aumentar a penetrabilidade. No entanto, se o tumor está localizado superficialmente, deve-se optar por frequências maiores $(915 \mathrm{MHz})$ para assim localizar boa parte da deposição de energia na superfície. No caso desse projeto, as dimensões da guia de onda restringiram-se ao intervalo de frequência de operação na regiões do $\mathrm{GHz}$, o que limita a penetração da onda eletromagnética no cérebro.

A avaliação do grau de penetração no tecido é um parâmetro importante, pois auxilia na determinação do volume de ação da micro-onda. A estimativa da penetração foi obtida utilizando-se os sensores de temperatura em uma posição fixa nos canais de varredura (posição central). Os resultados obtidos são apresentados na Figura 2.29.

A expectativa quanto ao comportamento da penetração de campos eletromagnéticos em tecidos biológicos, ou em um material dielétrico qualquer, é sempre de um decaimento exponencial. Nos resultados apresentados na Figura 2.29 esse decaimento exponencial não é evidente, mas fizemos uma proposta para essa função (linha vermelha). A informação relevante obtida na análise destes dados refere-se a área de ativação da liberação termoestimulada de droga. Como a droga só será liberada em regiões com temperaturas acima de $41,3{ }^{\circ} \mathrm{C}$, pode-se afirmar que muito provavelmente a área de ativação estará circunscrita 


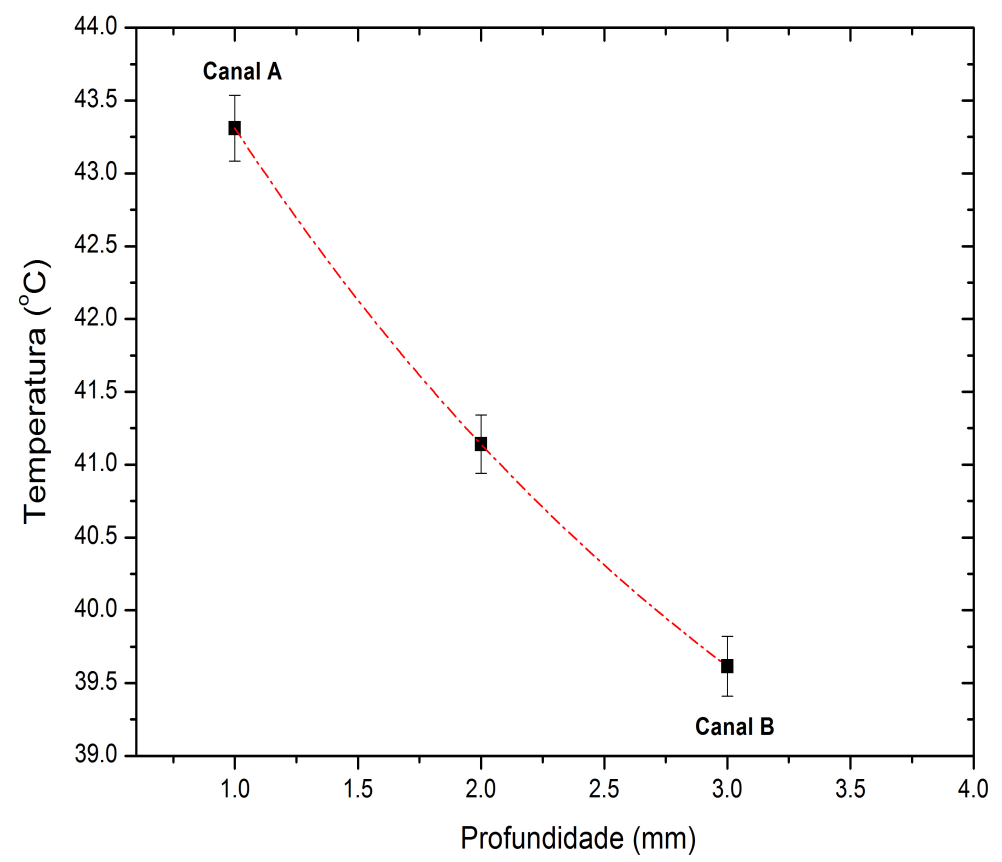

Figura 2.29: Valores de temperatura média em função da profundidade com referência à superfície da antena. Os valores apresentados representam um conjunto de dois experimentos distintos. A temperatura observada na profundidade $2 \mathrm{~mm}$ é composta por um conjunto de experimentos que não se utilizou dos canais previamente estipulados. A linha vermelha corresponde a um tentativa de ajuste por decaimento exponencial.

até $2 \mathrm{~mm}$ de profundidade da superfície.

\section{Validação do aquecimento por micro-onda}

O controle da deposição de energia é fundamental em hipertermia. Para maior confiabilidade de que o calor produzido no interior da caixa fantoma foi induzido pela interação com a micro-onda, e não por um efeito indireto de aquecimento da água no interior da guia de onda, realizou-se um experimento simples em que se comparou a distribuição do aquecimento produzido pela incidência de micro-onda e o aquecimento produzido apenas pela presença de água aquecida no interior da guia de onda, ou seja, sem a presença de micro-onda. O resultado da comparação é apresentado na Figura 2.30 em função da varredura do sensor no canal A (próximo à superfície) da caixa fantoma.

O resultado da Figura 2.30 demonstra que a distribuição espacial obtida com a presença de água aquecida é maior que a obtida com a presença de micro-onda. Essa 


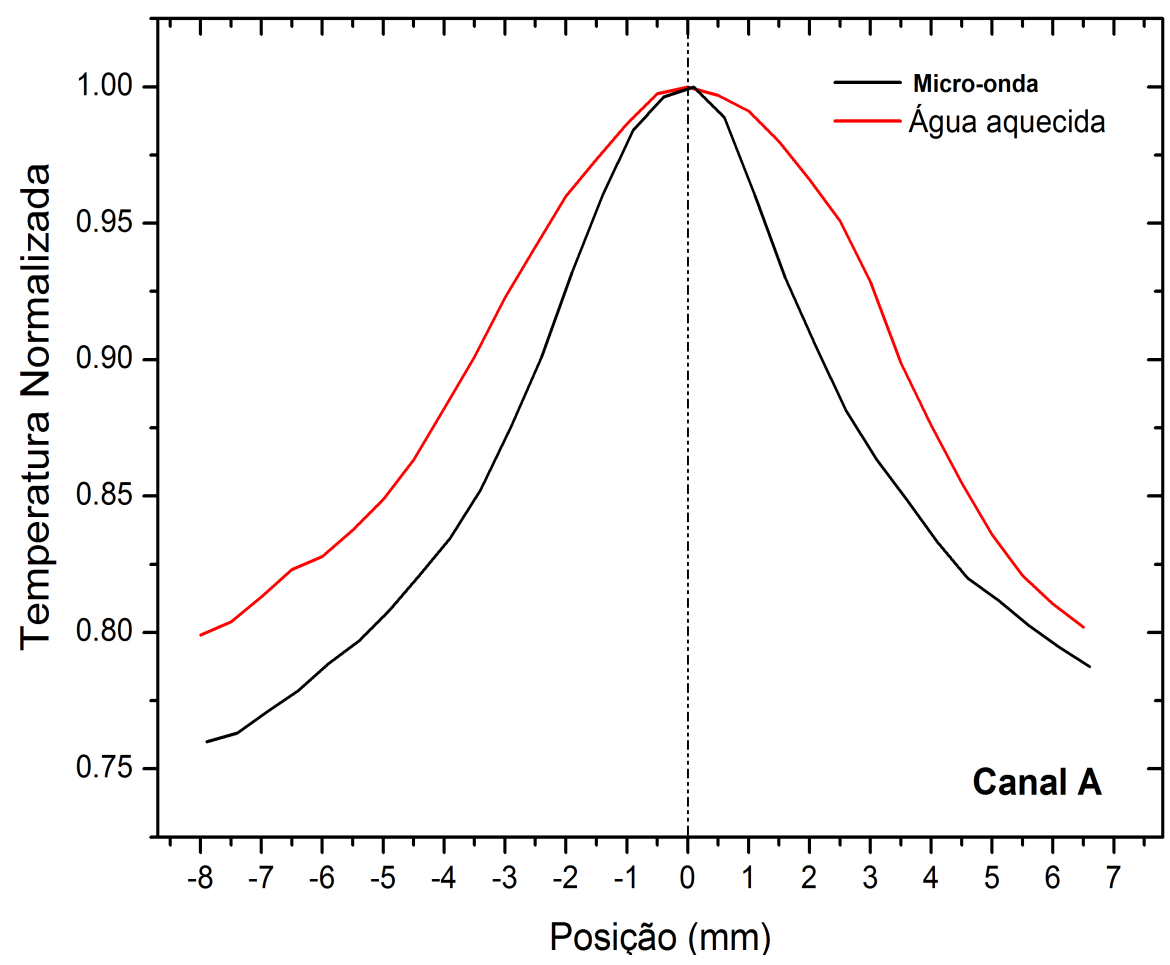

Figura 2.30: Perfis de temperatura obtidos com a varredura de diferentes posições dos sensores de temperatura no interior do canal A na caixa fantoma. O intervalo do passo do motor foi ajustado para $0,5 \mathrm{~mm}$. As curvas apresentadas representam duas condições experimentais distintas. A curva preta representa a distribuição espacial da temperatura induzida na presença de microonda no sistema. A curva vermelha representa distribuição espacial da temperatura induzida pela presença de água a $65^{\circ} \mathrm{C}$ no interior da guia de onda. As temperaturas foram normalizadas com intuito de facilitar a comparação das distribuições.

diferença da distribuição espacial indica que os efeitos de aquecimento são distintos e não podem ser associados a mesma fonte de calor. Portanto, o aquecimento observado na curva preta é majoritariamente promovido por consequência da presença de micro-onda, comprovando assim a eficiência do sistema desenvolvido neste projeto.

Uma outra forma de determinar se o aquecimento é promovido por absorção de micro-onda, e não por condução de calor, é através a resposta da elevação da temperatura em função do tempo. Para contribuir com a análise realizada anteriormente, os sensores de temperatura foram posicionados no centro da antena com incidência de $12 \mathrm{~W}$ de potência de micro-onda a 3,7 GHz. A evolução temporal deste experimento é apresentado em Figura 2.31.

Um olhar minucioso na Figura 2.31 nos permite comprovar a afirmação de que o 


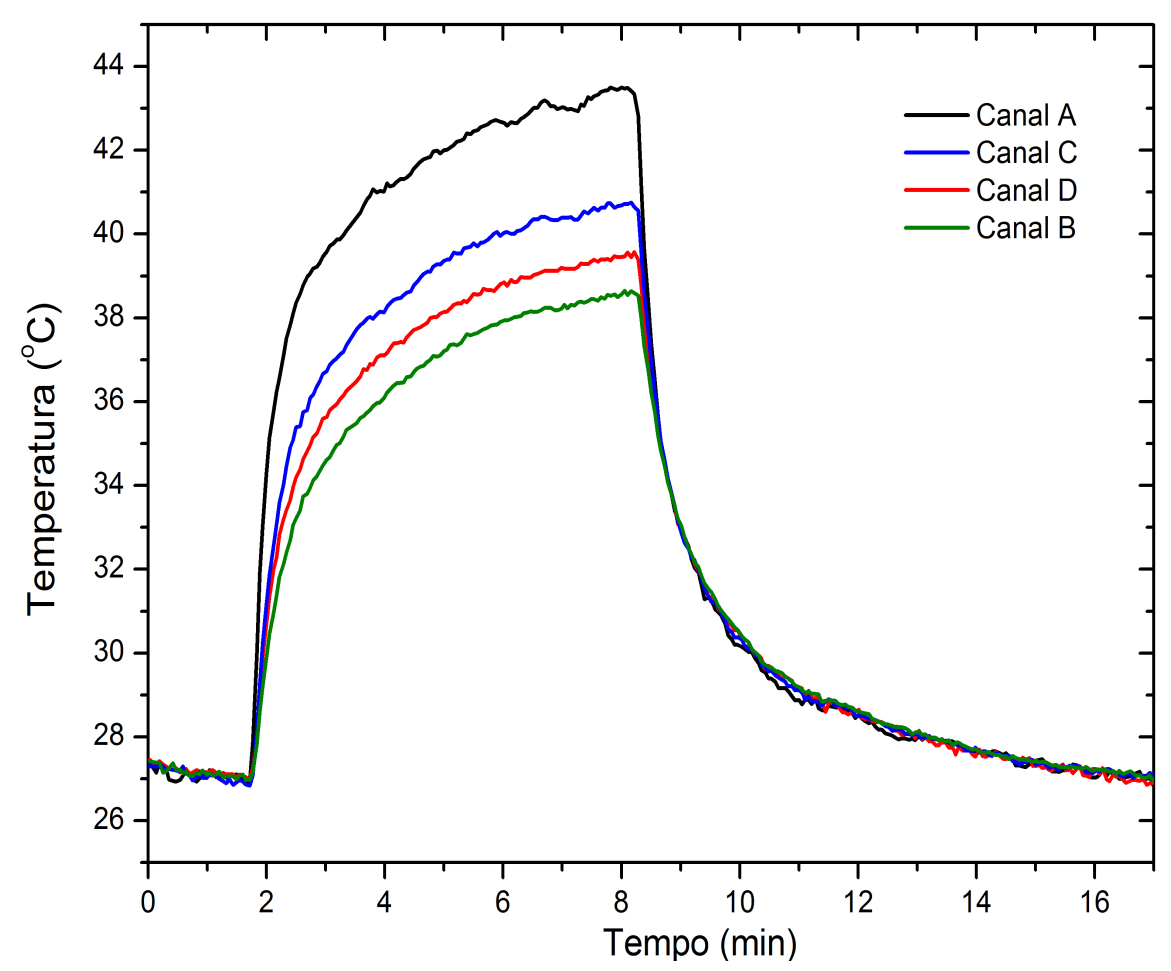

Figura 2.31: Perfis de temperatura em função do tempo para os quatro canais da caixa fantoma. A potência micro-onda utilizada foi de $12 \mathrm{~W}$ e a frequência de oscilação foi de $3,7 \mathrm{GHz}$. Os sensores de temperatura foram posicionados no centro da antena.

aquecimento é induzido por micro-onda. Uma vez que, logo após o início da incidência da micro-onda (Tempo $=2 \mathrm{~min}$ ), observa-se uma resposta na elevação da temperatura imediata para todas as profundidades. Esse efeito não pode ser justificado por efeito de condução de calor, pois nestes casos existem uma escala de tempo e gradiente de temperatura necessários para produzir algum impacto nas regiões mais profundas, e portanto, deve-se observar um efeito em cascata e não simultâneo como o apresentado nos dados. Através desse procedimento adicional não resta dúvida que o aquecimento promovido está associado à absorção de energia.

\subsubsection{Estudo de performance e eficiência de aquecimento in vivo}

A eficiência do tratamento de hipertermia, e a capacidade de indução de liberação de droga termo-estimulada, são extremamente dependentes da habilidade de manter controlado a elevação de temperatura na região de interesse. A termometria do tecido 
alvo, em tempo-real, é obrigatória para o controle preciso da temperatura terapêutica. A introdução de sensores de temperatura na região de interesse corresponde a um método simples de aquisição, porém limitado a procedimentos cirúrgicos e a informações pontuais do tecido. Adicionalmente, a introdução de sensores especificamente no cérebro são indesejáveis para experimentos de microscopia, pois os sensores, quando introduzidos, promovem pequenas hemorragias que impossibilitam a aquisição de imagens de qualidade por microscopia.

Uma alternativa aos sensores de temperatura seria utilizar métodos não-invasivos como a imagem de ressonância magnética (MRI) para monitorar a temperatura, pois assim evita a perturbação na aquisição das imagens. No entanto, devido à pequena dimensão do cérebro do camundongo e a incompatibilidade do dispositivo de aquecimento com a técnica de MRI, foi necessário procura outra metodologia. A solução encontrada foi realizar um procedimento dosimétrico prévio para determinar as condições ideais de irradiação, através de sensores invasivos. Porém, com a obtenção das condições médias de potência de micro-onda, capaz de elevar a temperatura local a $42^{\circ} \mathrm{C}$, partiu-se para os experimentos de microscopia sem o monitoramento ou uso de controle da temperatura.

A primeira etapa consistiu em avaliar as condições ideais de potência de microonda, para tanto, realizou-se ensaios em cinco camundongos saudáveis e dois camundongos com tumores induzidos. Os sensores de temperatura (de 0,18 $\mathrm{mm}$ de diâmetro) foram inseridos em duas posições (Figura 2.16) , na superfície do cérebro $(0,5 \sim 1,0 \mathrm{~mm})$ e em profundidade $(4 \mathrm{~mm})$. A ideia neste procedimento foi observar a elevação da temperatura com a correspondente potência de excitação. A Figura 2.32 exemplifica a resposta da temperatura na superfície do cérebro em função da potência de excitação da guia de onda.

O intuito da Figura 2.32 é de apresentar, para um mesmo animal, o comportamento da elevação de temperatura em função da irradiação de micro-onda. Os três primeiros picos do perfil temperatura representam a resposta a pulsos de micro-onda de curta duração de tempo, sendo a potência de excitação distinta ( $3 \mathrm{~W}, 4 \mathrm{~W}$ e $5 \mathrm{~W})$ para cada pulso executado. Observa-se neste período inicial ( $<5 \mathrm{~min})$, que logo após a interrupção do 


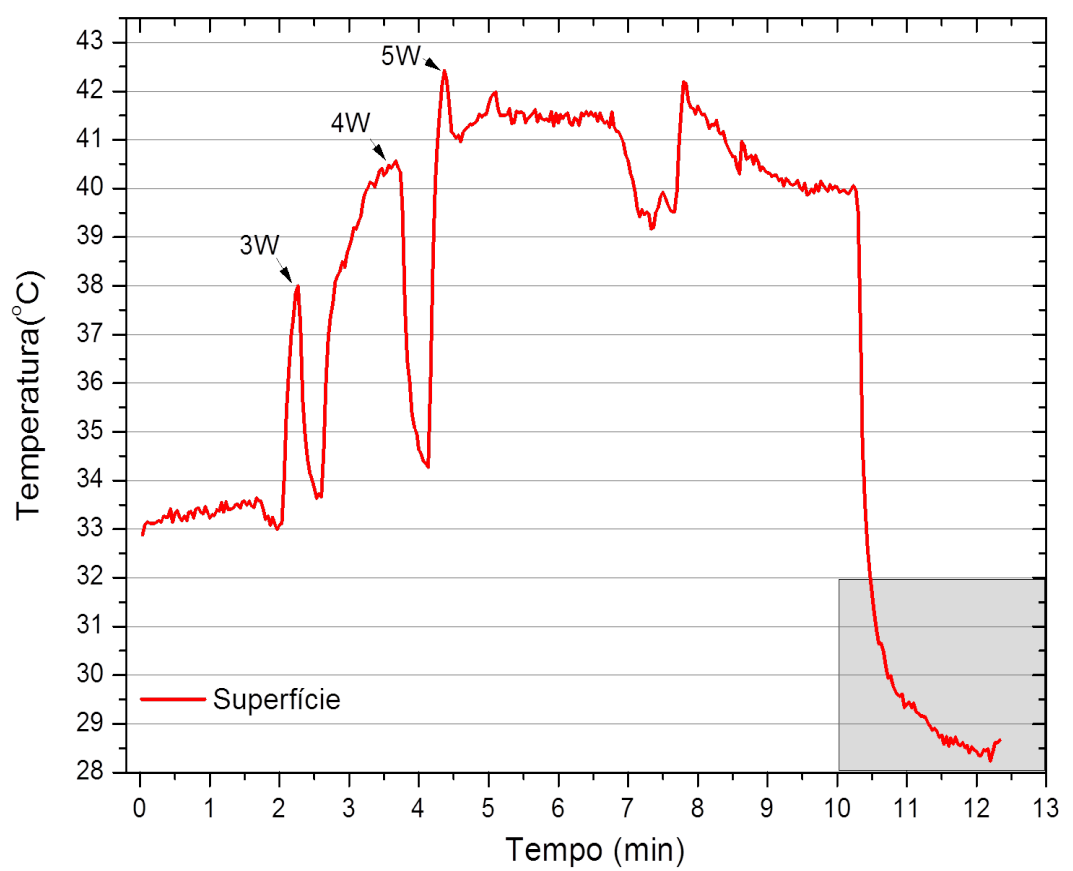

Figura 2.32: Exemplo da elevação de temperatura em função da potência de excitação do aplicador observado para um único camundongo. O perfil de temperatura apresentado é a resposta do sensor de temperatura posicionado próximo à superfície $(0,5 \sim 1,0 \mathrm{~mm})$. Os três picos inicias indicam três pulsos de micro-onda com potências distintas de excitação $(3 \mathrm{~W}, 4 \mathrm{~W}$ e $5 \mathrm{~W})$. A área em destaque indica que o animal após o procedimento perdeu a capacidade de controle de temperatura.

fornecimento de energia, nos pontos $3 \mathrm{~W}$ e $4 \mathrm{~W}$, a temperatura sofre uma queda brusca, indicando portanto a existência do processo competitivo entre a perfusão sanguínea e o aquecimento por micro-onda.

Neste teste preliminar foi possível observar que a potência ideal de excitação deve estar próxima a 5W. Avaliando a sequência da evolução temporal da temperatura (tempo $>5 \mathrm{~min}$ ), constata-se a resposta a pequenos ajustes realizados utilizando-se potências intermediárias (entre 3,5 e 4,8 W). Ao término de 10 minutos a micro-onda foi interrompida e a temperatura sofreu um rápido declínio, no entanto, o valor da temperatura de homeostase atingiu $28,5^{\circ} \mathrm{C}$, valor muito inferior ao inicial $\left(33^{\circ} \mathrm{C}\right)$. Esse fato indica que o animal perdeu a capacidade de controle da temperatura.

Durante o procedimento de irradiação, a antena/aplicador está sob influência da circulação interna de água destilada. Essa água circulante exerce duas funções no interior da antena; a primeira é a de garantir um melhor acoplamento entre a guia de onda e o 
tecido alvo, a segunda consiste em resfriar a superfície de contado para evitar o superaquecimento da mesma. A temperatura da água de circulação é sujeita às condições locais de troca de calor e condições do experimento. Submeter as superfícies de contato a temperaturas relativamente baixas implica, necessariamente, em utilizar potências maiores de excitação.

A estratégia de utilizar superfícies resfriadas como modulador da distribuição da temperatura é muito comum em protocolos de hipertermia (Arunachalam et al., 2009; Van der Gaag et al., 2006), uma vez que torna possível deslocar a região de maior aquecimento para regiões mais profundas do corpo. O objetivo nesta etapa foi o de buscar uma condição no qual fosse obtido a maior profundidade de aquecimento possível. Para tanto, realizamos um experimento teste de variação da temperatura de circulação da água e variação da potência de excitação. Na Figura 2.33 apresenta-se um exemplo do comportamento da temperatura em função da variação de potência e da temperatura da água de circulação.

A troca de calor por condução entre a superfície da antena e a superfície do cérebro é de curto alcance e de resposta lenta. A incidência de micro-ondas, por sua vez, possui penetração maior no cérebro e promove um aquecimento rápido. A influência da troca de calor por condução ocorre nas regiões de superfície, portanto regiões do interior são pouco impactadas. O aumento da potência de irradiação que coincide com o decréscimo da temperatura da água de circulação, deve manter de certa forma a temperatura da superfície do cérebro no mesmo patamar inicial. Porém, no interior do cérebro, deve ocorrer um aumento da temperatura, pois este não sofre impacto da temperatura da água de circulação. Este efeito pode ser observado na Figura 2.33. Para cada nível de potência (6W, 9W e $11 \mathrm{~W}$ ) a temperatura obtida na posição de $4 \mathrm{~mm}$ de profundidade sofreu aumento proporcional de $38,1^{\circ} \mathrm{C}$ para $39,2^{\circ} \mathrm{C}$. A temperatura de superfície foi mantida praticamente no mesmo patamar de $44^{\circ} \mathrm{C}$ para todos os níveis de potência.

Apesar do aumento significativo da potência de excitação de micro-onda, o aumento de temperatura no interior do cérebro não foi substancial $\left(\triangle T=1,1^{\circ} \mathrm{C}\right)$. Portanto, avaliando o resultado anterior decidiu-se por manter a temperatura de circulação da água em 


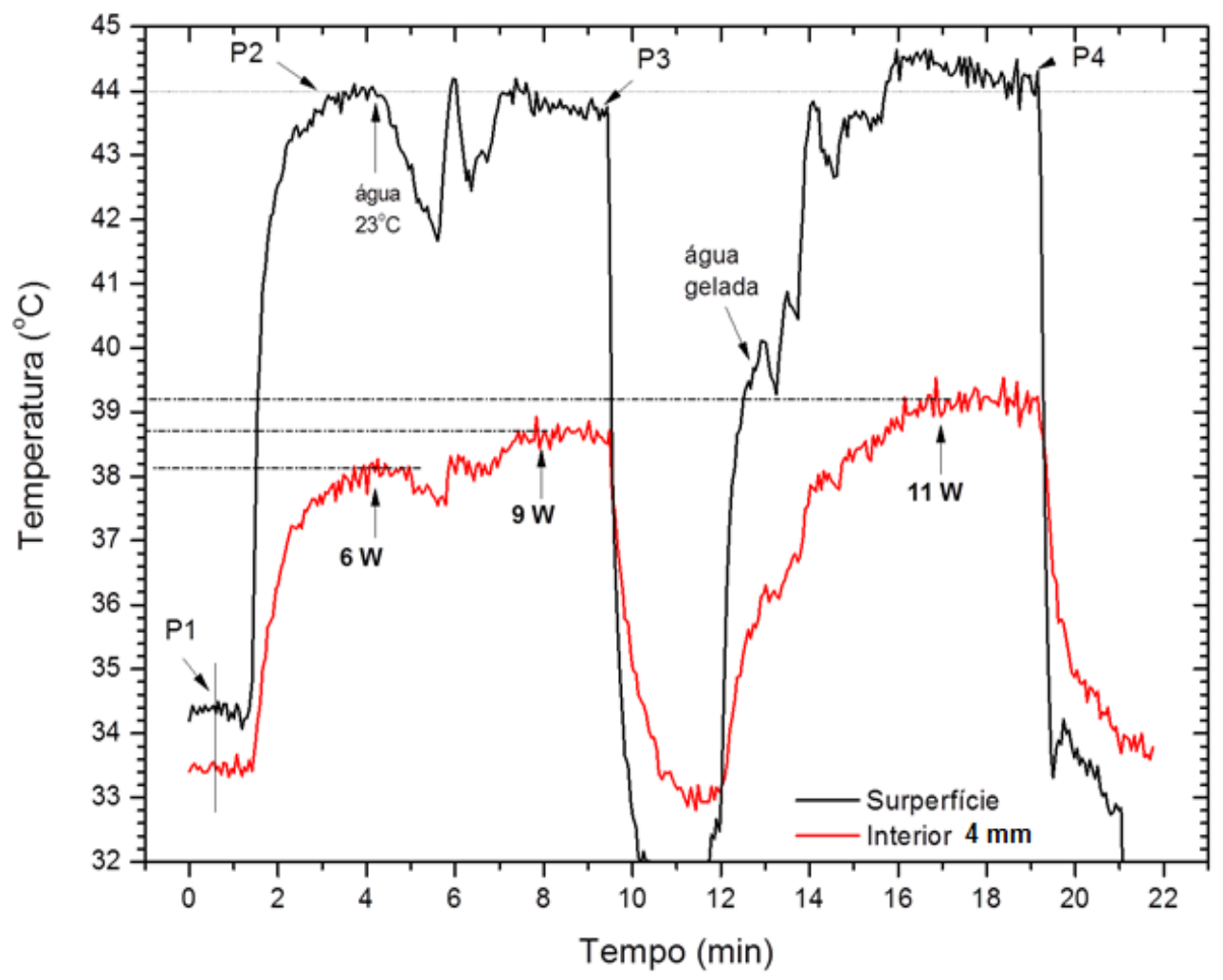

Figura 2.33: Perfil de temperatura para duas posições no interior do cérebro do camundongo (Superfície e $4 \mathrm{~mm}$ ) em função da variação da temperatura da água de circulação do interior da cavidade e em função da potência de excitação da micro-onda. O ponto P1 indica a condição inicial, ou seja, sem a presença de micro-ondas. O ponto P2 indica a temperatura na superfície obtida com a excitação da antena ajustada para $6 \mathrm{~W}$. Neste momento a temperatura da água de circulação interna era de $37^{\circ} \mathrm{C}$. Na altura do "4" min na escala de tempo a temperatura da água de circulação foi alterada para $23^{\circ} \mathrm{C}$. Como consequência da alteração da temperatura da água de circulação ocorreu uma queda brusca na temperatura superficial, e para compensar essa queda aumentou-se a potência para $9 \mathrm{~W}$ (P3). Como último procedimento, alterou-se novamente a temperatura da água de circulação para $7^{\circ} \mathrm{C}$ e a potência de excitação para $11 \mathrm{~W}$ (P4).

$37^{\circ} \mathrm{C}$.

Após os testes preliminares, os ensaios para definir os valores da potência ideal de irradiação foram iniciados. Este parâmetro foi determinado observando a elevação espontânea da temperatura na superfície do cérebro em cinco camundongos, e para diferentes potências irradiação (Figura 2.34). A temperatura terapêutica de $42^{\circ} \mathrm{C}$ foi constantemente obtida para a potência de $5 \mathrm{~W}$. Para todos os experimentos, a reflexão de potência foi considerada menor que 5\% (parâmetro de espalhamento $S 11<-13 \mathrm{~dB}$ ). Sendo assim, definiu-se $5 \mathrm{~W}$ como potência padrão ideal de excitação da antena. 


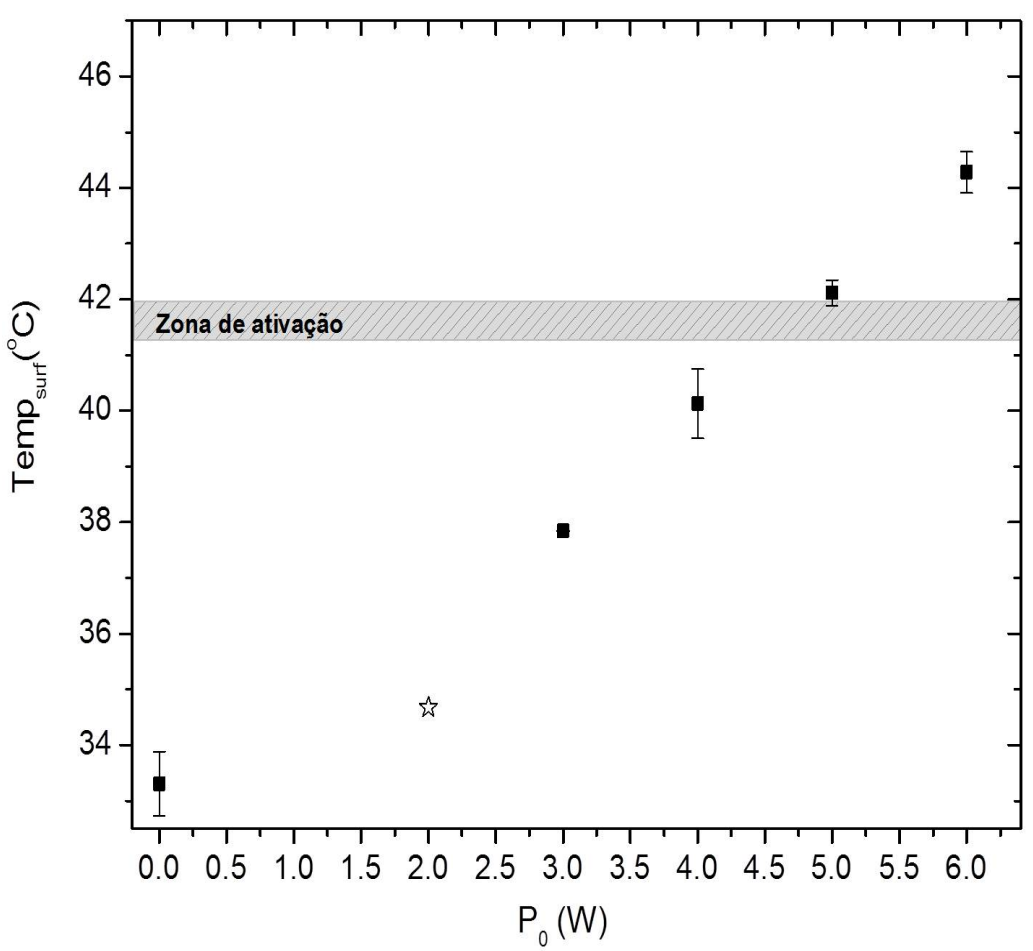

Figura 2.34: Temperatura induzida na superfície do cérebro $(0,5 \sim 1,0 \mathrm{~mm}$ de profundidade) em função da potência de micro-onda irradiada $\left(\mathrm{P}_{0}\right)$ a $3,7 \mathrm{GHz}$. Os pontos apresentados representam a média de pelo menos três experimentos, e as barras determinam os desvios padrão. A única exceção à estatística é o ponto $2 \mathrm{~W}$, que representa apenas um experimento (estrela). O intervalo de temperatura que ocorre a liberação termo-estimulada de droga é destacado por um retângulo achurado.

Para estimar a distribuição de temperatura no volume cerebral, a Figura 2.35 apresenta os valores de temperatura estacionários obtidos para duas posições distintas no cérebro, quando submetidos a $5 \mathrm{~W}$ de potência de micro-onda. A elevação da temperatura na região do sensor a $4 \mathrm{~mm}$ da superfície foi de $3{ }^{\circ} \mathrm{C}$ com relação à condição de homeostase. O ponto de maior profundidade $(7 \mathrm{~mm})$ na Figura 2.35 foi adicionado à curva de distribuição com intuito de contribuir para a análise, mas pertence a outro conjunto de experimentos.

Através da expectativa teórica, uma onda plana propagando-se em um meio dissipativo deve sofrer atenuação em função da distância percorrida, sendo a amplitude do campo eletromagnético descrito por um decaimento exponencial $\left(\vec{E}=\vec{E}_{0} e^{-\alpha z}\right)$. Desta forma, é esperado que a variação de temperatura em função da profundidade do tecido deva também seguir um decaimento exponencial. Na Figura 2.35 destaca-se o possível 


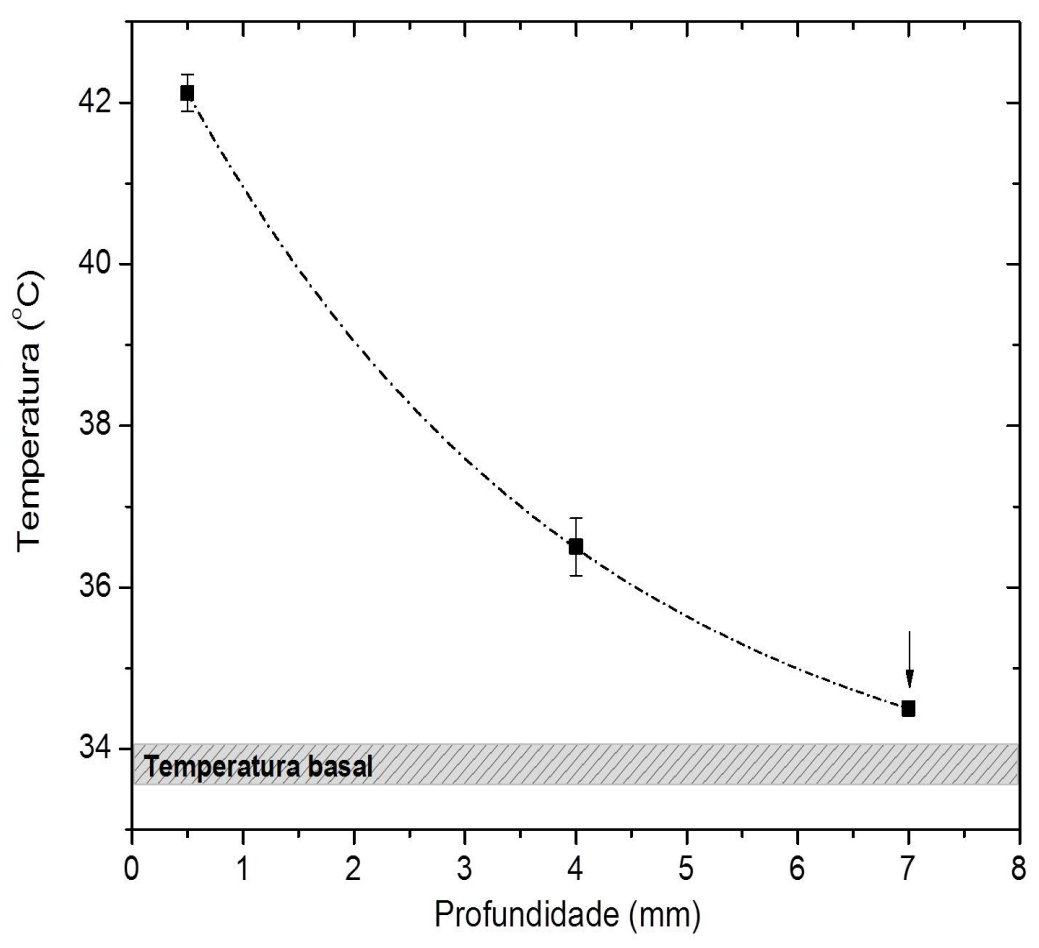

Figura 2.35: Temperaturas obtidas para diferentes profundidades e em condição de estabilidade do cérebro do camundongo submetido à irradiação de $5 \mathrm{~W}$ de micro-ondas. O sensores foram posicionados considerando a ponta do sensor alinhada com o centro da antena. O intervalo de temperatura normalmente observado na condição de homeostasia é destacado com o retângulo listrado. O pontos representam a média de três medidas.

decaimento exponencial sofrido pela elevação de temperatura em função da profundidade.

Observando o provável perfil do decaimento exponencial da temperatura, constatase que a região apta a promover a liberação termo-estimulada de droga está concentrada na região próxima a superfície do cérebro. Este perfil de aquecimento não é problema, pois como o monitoramento por microscopia confocal de fluorescência da distribuição de droga no cérebro também está limitado à região superficial, não há resolução suficiente para monitorar droga em regiões profundas.

\section{Ensaios de controle e estabilidade da temperatura in vivo}

Excitando o mini-aplicador de micro-onda com a potência ótima de 5W, foi observada a estabilidade da temperatura durante todo período estipulado para o protocolo de distribuição da droga. Na Figura 2.36 apresenta-se o resultado representativo dos experi- 
mentos, sendo que resultados similares foram observados para todos os sujeitos observados $(\mathrm{N}=7)$. Avaliando os resultados da Figura 2.36, vemos o alto grau de estabilidade que a temperatura na superfície do cérebro atingiu durante o período de protocolo. Tem-se que 15 min de aquecimento são suficientes para a liberação de toda droga encapsulada nos lipossomos, e permite que a mesma penetre ao tecido local. Depois de aproximadamente 25 minutos, a micro-onda foi desligada e a temperatura decaiu rapidamente.

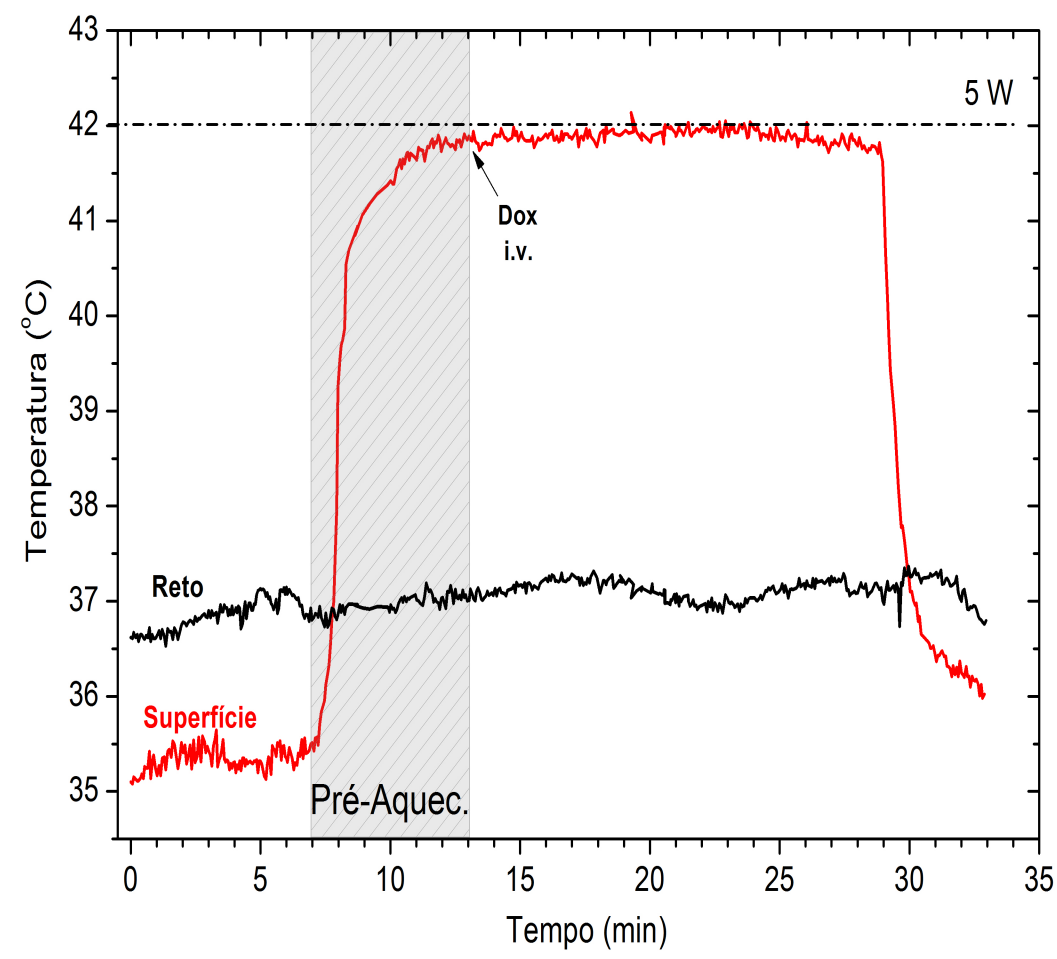

Figura 2.36: Típico perfil de temperatura obtido no cérebro do camundongo durante os 30 minutos do protocolo de hipertermia. A temperatura da superfície é apresentada pela curva vermelha e a temperatura corpórea, representada pelo reto, é apresentada pela curva preta. Uma potência de $5 \mathrm{~W}$ de micro-onda foi necessária para a obtenção da temperatura de ativação de $42^{\circ} \mathrm{C}$ na superfície do cérebro.

Outra constatação quanto à Figura 2.36, refere-se ao período de estabilidade (0 a 6 min), observa-se um pequeno gradiente entre a temperatura do reto e a superfície do cérebro. Essa diferença pode ser justificada em parte pela troca de calor existente entre a janela cranial e o ambiente. Durante o período de hipertermia, a temperatura corpórea variou ligeiramente de 1,0 a $1,2^{\circ} \mathrm{C}$.

Baseado nos resultados deste item foi possível demonstrar que o mini-aplicador de 
micro-onda é capaz de aquecer e manter um aquecimento estável na região abaixo do aplicador, utilizado-se uma potência de excitação de 5W, durante o período desejado de 15 minutos.

\subsection{Conclusões}

Neste item, investigou-se a habilidade de um mini-aplicador de micro-onda, em depositar energia eletromagnética localmente em um dos hemisférios do cérebro de um camundongo. Até o momento, não existiam métodos viáveis e de baixo custo capazes de promover este aquecimento no cérebro de roedores.

O aplicador de micro-ondas discutido neste item é uma guia de onda de secção retangular, e composto ainda por uma antena de monopolo para realização da transição entre o cabo coaxial e a guia de onda. Para criar o primeiro protótipo do aplicador utilizouse a simulação eletromagnética de onda completa (HFSS) para realização do processo de otimização da guia de onda. Do resultado das simulações, concluiu-se que a frequência de operação deveria ser 3,7 GHz. Em seguida, construiu-se o protótipo e validou-se sua capacidade de aquecimento em ensaios com sistema fantoma.

Após os experimentos em fantoma, partiu-se para a validação da eficiência de aquecimento em ensaios in vivo. Para o sistema in vivo, primeiramente executou-se um estudo dosimétrico em diversos camundongos. Para todos os animais encontrou-se o parâmetro $\mathrm{S}_{11} \leq-13 \mathrm{~dB}$. Os resultados demonstraram também que o mini-aplicador foi capaz de promover um aquecimento localizado estável durante o período de 15 minutos. A potência necessária para garantir a temperatura de $42^{\circ} \mathrm{C}$ na superfície do cérebro foi de $5 \mathrm{~W}$.

Os resultados destes experimentos confirmam a eficiência de funcionamento do dispositivo, que de forma não invasiva, e com baixo custo, permite a indução do aquecimento do cérebro de camundongos a temperaturas hipertérmicas. O dispositivo está agora disponível para estudos pré-clínicos de viabilidade do uso sinérgico da quimioterapia e hipertermia no tratamento de câncer do cérebro. Esse dispositivo foi usado nos experimentos discutidos no capítulo seguinte. 


\section{Capítulo 3}

\section{Estudo in vivo da entrega termo-estimulada de doxorrubicina ao sistema nervoso}

O sucesso no desenvolvimento e construção do mini-aplicador de micro-onda, dedicado ao aquecimento parcial do cérebro de camundongos, viabilizou o estudo experimental dos processos de entrega e liberação termo-estimulada de quimioterápicos. Neste capítulo serão apresentados os principais resultados obtidos no estudo de eficiência de entrega da doxorrubicina a tumores modelo de glioblastoma. O método utilizado para monitoramento da liberação e distribuição da droga foi a microscopia confocal de fluorescência intravital. O uso desta técnica possibilitou avaliar de forma direta o padrão de resposta dos vasos sanguíneos ao tratamento térmico induzido. O objetivo deste capitulo é apresentar a discussão sobre os achados farmacológicos observados no uso da hipertermia como agente facilitador da entrega de medicamentos ao sistema nervoso. 


\subsection{Introdução}

Dentre os diversos fatores considerados limitantes à eficiência da quimioterapia, tem-se a má distribuição dos quimioterápicos na região tumoral como um dos principais fatores (Chen et al., 2008). A presença de diversas barreiras fisiológicas, específicas do ambiente tumoral, são apontadas como os responsáveis pela baixa distribuição de drogas (Vaupel \& Kelleher, 2010). Diversos pesquisadores tem buscado avaliar métodos para induzir alterações às condições fisiológicas adversas para tentar promover algum ganho terapêutico.

Relatos anteriores em estudos do cérebro demonstraram que a temperatura local pode modular a permeabilidade da barreira hematoencefálica (BHE) para determinadas drogas (Gong et al., 2011; Lin \& Lin, 1982; Moriyama et al., 1991). Acredita-se que o calor provoque um aumento na permeabilidade vascular devido a um maior espaçamento entre as junções apertadas. Embora potencialmente eficiente, o uso de aquecimento local é sempre rodeado de preocupações quanto a possibilidade da indução de danos térmicos ao paciente. Os diversos tipos de células nervosas são altamente sensíveis ao calor, e o limite entre os benefícios terapêuticos e a indução de danos térmicos significativos pode ser uma linha tênue. Hoje em dia, busca-se avaliar os limites de segurança à exposição térmica do cérebro, e o grau de reversibilidade dos efeitos promovidos, porém ainda existe uma grande ambiguidade na literatura (Yarmolenko et al., 2011) e os reais efeitos ainda são desconhecidos.

No caso de doenças oncológicas, os tecidos tumorais já estão comprometidos, e portanto, os riscos associados à termoterapia podem ser ignorados, desde que os tecidos vizinhos sadios sejam preservados. O uso do aquecimento local no sistema nervoso possui diversas vantagens quando comparado com metodologias não-térmicas (Landon et al., 2011; Ponce et al., 2006). Além do potencial de promover a ruptura da BHE, a elevação moderada da temperatura $\left(<43^{\circ} \mathrm{C}\right)$ pode também levar ao aumento da perfusão sanguínea e a indução e ativação da liberação da entrega de drogas termo-ativadas. A sinergia no uso da hipertermia e quimioterapia, baseada em carreadores termosensíveis, pode reduzir a toxicidade sistêmica e aumentar o acúmulo de droga na região do tumor. 
Atualmente, a formulação de transportadores termo-ativados de maior expressão é a chamada ThermoDox $\AA$ (Celsion corporation, Columbia, MD, USA), que devido aos ensaios clínicos fase-III em andamento, está próxima da aprovação para uso em larga escala. A literatura de carreadores termo-ativados é vasta, porém poucos são os relatos encontrados abordando os efeitos sinérgicos deste método a patologias cerebrais, devido às limitações experimentais inerentes no trato do cérebro. Os estudos pré-clínicos existentes neste tópico utilizaram-se de sistemas de aquecimento invasivos e de baixo controle da distribuição de calor, o que dificulta uma análise mais completa (Aoki et al., 2004; Kakinuma et al., 1996).

Métodos de imagem tornaram-se uma importante ferramenta de pesquisa e análise clínica do cérebro. O grande escopo de técnicas disponíveis oferece excelente sensibilidade à visualização de estruturas e funções cerebrais, atingindo desde o nível molecular até o cérebro como um todo. Muitos métodos de imagem são não-invasivos e permitem um processo dinâmico de monitoramento em tempo-real. Normalmente, as técnicas de imagens são agrupadas conforme três aspectos: (1) energia, (2) resolução espacial, e (3) tipo de informação obtida (Weissleder \& Pittet, 2008).

As energias geralmente usadas por estas técnicas são divididas em energias de raios- $\mathrm{X}$ (e.g., clássica imagem de raios-X, tomografia computadorizada (TC), e tomografia computadorizada multicamadas), de campos magnéticos (e.g., MRI e difusão de MRI), de pósitrons (e.g., PET), ultrassom (e.g., imagens de ultrassom), fótons (e.g., imagem bioluminescência, imagem de reflectância fluorescente, tomografia mediada por fluorescência, e imagem de microscopia por varredura laser), e algumas combinações dessas modalidades (e.g., PET-TC, PET-RM, TC, or MRI com tomografia mediada por fluorescência). As técnicas podem também ser agrupadas de acordo com a resolução espacial e do tipo de informação: (1) macroscópica, (2) mesoscópica, e (3) microscópica ou (1) anatômica, (2) fisiológica, e (3) celular ou molecular.

Clinicamente, a ressonância magnética nuclear (MRI) tornou-se a técnica de diagnóstico por imagem mais importante em neurociência. Um dos principais benefícios da MRI aplicada ao sistema nervoso central é justamente o fato da radiofrequência possuir 
boa penetrabilidade no crânio e na medula espinhal, o que permite que tecidos internos sejam monitorados sem grandes interferências. O MRI fornece as melhores visualizações de anomalias no parênquima, incluindo tumores, infecções, lesões vasculares e traumas lesionais.

No estudo por imagem da ruptura da barreia hematoencefálica, a ressonância magnética (MRI) tem sido a técnica de escolha da maioria dos relatos publicados (Hynynen et al., 2001; Vlachos et al., 2010). Contudo, para avaliar a integridade da BHE por MRI é necessário o uso de agentes de contraste, como o gadolínio, para se obter as informações locais pretendidas. A metodologia de MRI é extremamente útil, mas o fato de requerer um agente de contraste limita a detecção direta da distribuição da maioria das drogas. Normalmente, as informações de distribuição são obtidas de forma indireta, através do co-encapsulamento de agentes de contraste com a droga (Ponce et al., 2007b; Viglianti et al., 2006). Uma outra limitação está associada ao volume do voxel e o nível de detalhe que é possível adquirir de um único vaso sanguíneo. Os estudos de elevação de contraste em tempo-real mostram uma análise global do sistema e perdem detalhes dos vasos, que podem omitir algumas das heterogeneidades da permeabilidade dos mesmos.

Em oposição a baixa resolução espacial do MRI, no estudo de vasos individuais, a microscopia de fluorescência apresenta-se como uma alternativa viável de acesso direto ao comportamento dos vasos. Embora técnicas ópticas possuam baixa penetração a tecidos biológicos, elas tem demonstrado grande valor no estudo da funcionalidade da BHE (Howles et al., 2010).

A penetração nos tecidos por fótons varia de acordo com o tipo do tecido alvo, e geralmente possui uma dependência específica com comprimento de onda incidente. A profundidade de penetração para o cérebro humano foi reportada ser em média de 2,5 mm a $635 \mathrm{~nm}$, porém esse valor pode variar com as condições do tecido (Muller \& Wilson, 1986).

O principal objetivo desta etapa do projeto foi o de demonstrar, mesmo que qualitativamente, que modalidades térmicas aplicadas a regiões sensíveis do corpo, como o cérebro, podem promover ganhos à distribuição de quimioterápicos de forma segura. Desta 
forma, são apresentados os resultados experimentais obtidos que sustentam a hipótese do uso sinérgico de lipossomos termosensíveis e hipertermia moderada para promoção de maior distribuição de quimioterápicos na região da lesão.

\subsubsection{A farmacocinética dos lipossomos termosensíveis}

(Texto baseado em: El-Kareh \& Secomb (2000); Gasselhuber et al. (2012, 2010); Lankelma (2002); Lankelma et al. (2000, 2003); Zhang et al. (2009))

A hipótese assumida neste projeto considera que o aumento da concentração e distribuição de droga na região doente gera melhores resultados terapêuticos. Assim, apresenta-se a seguir um pequeno resumo da farmacocinética envolvida no processo de disponibilização de doxorrubicina ao local de interesse, para que se tenha uma visão geral das implicações envolvidas nos processos de entrega de medicamentos.

Modelos farmacocinéticos visam prever a variação da concentração de substâncias no interior do corpo com decorrer do tempo. Os modelos matemáticos apresentados a seguir são um resumo dos modelos propostos na literatura.

Drogas podem ser introduzidas ao corpo humano por diferentes rotas anatômicas. A escolha da rota de administração depende da doença, dos efeitos desejados e dos produtos disponíveis. A administração intravenosa (i.v.) é um modo efetivo de se entregar drogas ao corpo do paciente, pois possibilita a administração de grandes doses e evita o efeito de primeira passagem. Após sua injeção, a droga deverá atingir primeiro os órgãos de maior vascularização (como sistema nervoso central, pulmão, coração). Uma vez na circulação sanguínea, a droga estará sujeita a processos de absorção, metabolismo e eliminação (Figura 3.1).

O fígado promove uma redução da concentração de fármaco do plasma através de ações metabólicas, ou seja, os fármacos são alterados no fígado por reações bioquímicas. O metabolismo hepático basicamente causa a biotransformação das moléculas do medicamento em produtos metabólicos (metabólitos) mais polares e hidrossolúveis, sendo que em muitos casos estes acabam tornando-se ineficientes.

As drogas disponíveis no plasma também podem sofrer ligações com as proteínas 


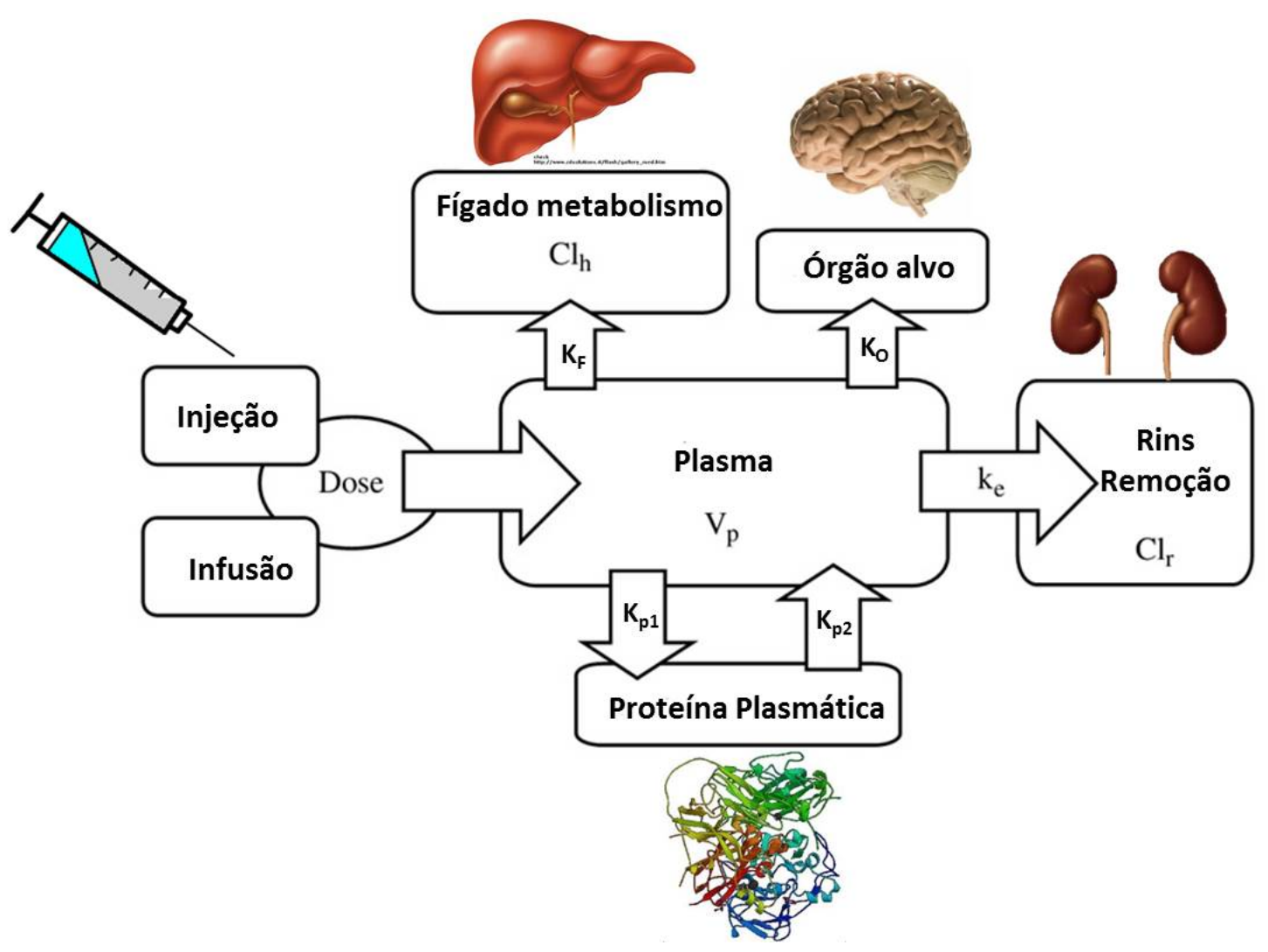

Figura 3.1: Ilustração do processo de biodisponibilização de fármacos administrados via injeção intravenosa. O fígado exerce papel importante na remoção ou inibição de parte da droga disponível no plasma sanguíneo através de processos de metabolização. Os rins também influenciam no nível de medicamento através do processo de remoção ou filtragem (clearance) da droga. A absorção do medicamento no órgão alvo deve ocorrer com uma taxa $K_{o}$, a qual depende de diversas propriedades locais do sistema. Os índices K's indicam a taxa com que os eventos de compartimentalização do fármaco ocorre para cada processo [Figura adaptada de (Vergnaud \& Rosca, 2010) - "figure 2.1"].

plasmáticas. A disponibilidade da droga será afetada pelo grau em que ela se liga a proteínas no plasma sanguíneo. Quanto menos ligante a droga for, mais eficientemente ela pode transpor as membranas celulares ou se difundir pelo corpo. As proteínas em que as drogas mais se ligam são a albumina, lipoproteínas, glicoproteínas e globulinas $\alpha, \beta$, e $\gamma$. Portanto, um medicamento existirá no sangue em duas formas: ligada e não ligada a proteínas, dependendo da afinidade da droga específica pelas proteínas plasmáticas.

A eliminação definitiva da droga ocorre nos rins, com uma taxa de remoção chamada de clearance. A clearance é o parâmetro farmacocinético que avalia a capacidade de excreção renal (Vergnaud \& Rosca, 2010). Cada substância possui uma clearance que 
depende das características de filtragem nos rins. A clearance ocorre em função da filtração glomerular, secreção pelos capilares peritubulares para o néfron, e reabsorção do néfron aos capilares peritubulares. No caso dos lipossomos carreadores, o processo de clearance é dependente da: (1) taxa de clearance do próprio lipossomo, (2) da taxa de dissociação do complexo, encapsulado, ou solubilizado na membrana lipídica do transportador, e (3) da taxa de clearance e metabolismo da droga livre após sua liberação (Vergnaud \& Rosca, 2010).

A eventual concentração de droga intracelular e extracelular no espaço intersticial depende de como a concentração vascular varia com o tempo, por isso os efeitos citados anteriormente são importantes. As drogas não são sequestradas pelas células quando os níveis começam a decair no plasma sanguíneo, pois tendem a retornar para o espaço vascular. A concentração vascular de droga pode ser descrita como uma dose inicial que decresce de acordo com os diferentes parâmetros fisiológicos. No caso dos transportadores termossensíveis, como o DOX-LTSL, a concentração de droga no plasma sanguíneo pode ser considerada sob duas condições; (1) na situação em que os lipossomos e os fármacos compõem um único elemento, ou seja, antes de qualquer liberação termo-estimulada, e (2) após a liberação estimulada onde se tem a droga difundindo livremente (Figura 3.2).

Na condição inicial, os lipossomos (DOX-LTSL) são injetados ao corpo e transportados na vasculatura via plasma sanguíneo até a região de interesse. Devido os efeitos de eliminação, característicos da interação entre o transportador e o organismo, a concentração de lipossomos tem um decaimento bi-exponencial (fato constatado empiricamente com estudos in vivo (El-Kareh \& Secomb, 2000) como apresentado na Eq. 3.1.

$$
C_{L, V}=\frac{M}{M_{g}}\left(A_{1} e^{-k_{1} t}+A_{2} e^{-k_{2} t}\right)
$$

sendo " $C_{L, V}$ "a concentração de lipossomo no plasma (mg por ml de plasma), "M"caracteriza a dose de droga fornecida ao animal $\left(m g / m^{2}\right.$ por área superficial do animal), e " $M_{g}$ "é a dose calculada a partir dos parâmetros farmacocinéticos do lipossomo: $A_{1}, A_{2}, k_{1}$, e $k_{2}$ que são constantes obtidas através de ajustes experimentais.

Na Eq. 3.1 o primeiro termo dos parênteses representa uma fase rápida de distri- 


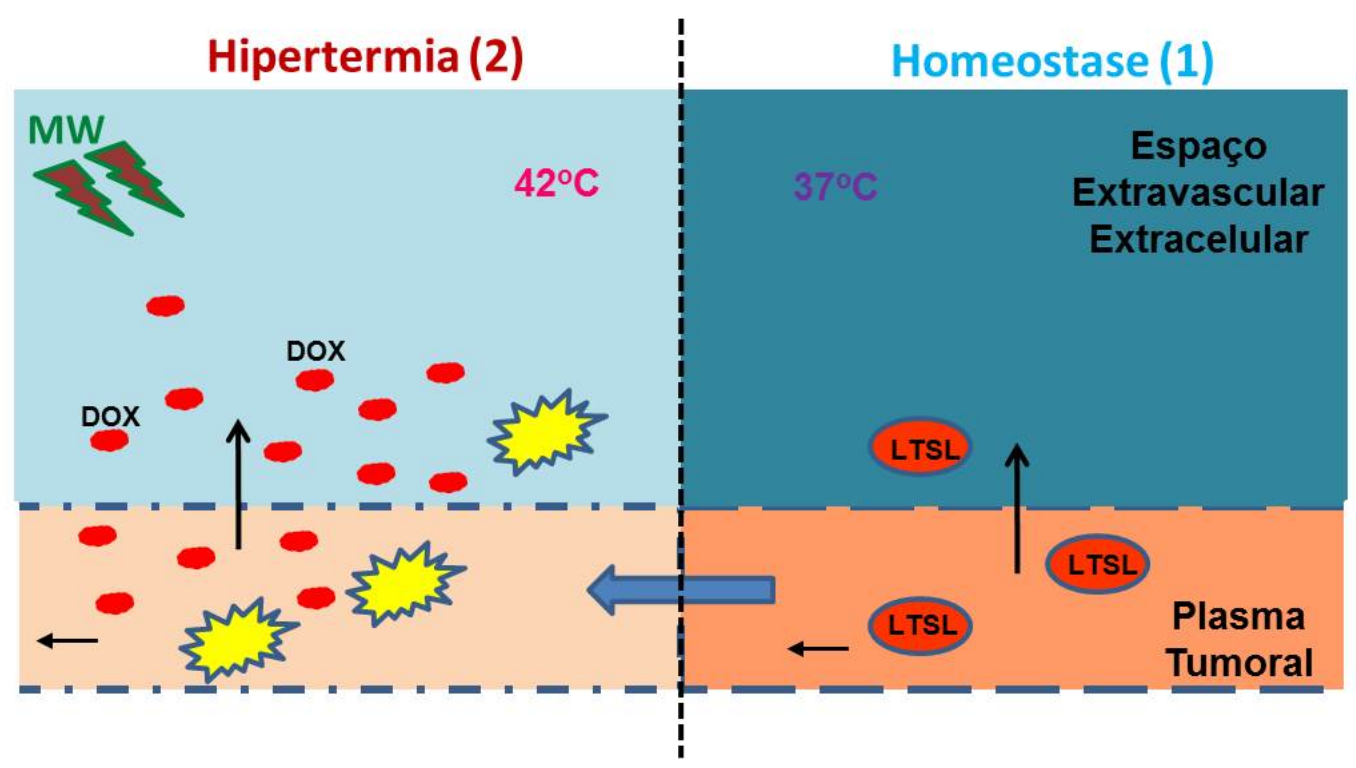

Figura 3.2: Imagem ilustrando o processo de disponibilização local da doxorrubicina. Logo após sua administração a DOX encontra-se encapsulada nos lipossomos LTSL e está sujeita basicamente a cinética do lipossomo. Ao acessar uma região sob influência de aquecimento $\left(\approx 42^{\circ} \mathrm{C}\right.$ ), ocorre a liberação termo-estimulada da DOX e neste momento sua cinética iguala-se a da DOX-Livre. A taxa com que o medicamento transpõe as paredes do vasos e acessa o meio extracelular depende de parâmetros locais do sistema.

buição da droga, em que uma menor fração da dose injetada $\left(A_{1}\right)$ é eliminada através do processo de excreção (cinética de constante $k_{1}$ ). O segundo termo é uma distribuição mais lenta, em que a fração maior da dose inicial $\left(A_{2}\right)$ é eliminada com constante $k_{2}$. Resultados experimentais prévios determinaram que $k_{1}$ e $k_{2}$ possuem valores diferentes em ratos e humanos.

Os lipossomos em circulação estão também sujeitos a transpor as paredes dos vasos, deixando o fluxo sanguíneo e acessando o ambiente intersticial. A transferência entre os dois compartimentos (vascular e extracelular) ocorre como consequência da sobreposição dos efeitos de difusão e convecção. A permeabilidade aparente $\left(P_{L, a p p}\right)$ dos vasos é o parâmetro normalmente usado para quantificar o transporte transvascular misto. Em geral, assume-se que a taxa de transferência transvascular dos lipossomos seja proporcional à permeabilidade vascular aparente $\left(P_{L, a p p}\right)$, à diferença de concentração no meio intra e extra vascular e à área superficial dos vasos. De modo aproximado, a taxa com que uma substância atravessa a parede do vaso $\left(J_{s}(\mathrm{~g} / \mathrm{s})\right)$ deve respeitar a forma generalizada do modelo friccional de Spiegler-Kedem-Katchalsky (ou modelo de S-K-K) (Jain, 1987a; 
Zhang et al., 2009), que é normalmente escrita como:

$$
J_{s}=P_{L, a p p} A_{v}\left(C_{L, V}-C_{L, E}\right)
$$

sendo " $C_{L, E}$ " a concentração de lipossomos no espaço intersticial e " $A_{v}$ " a área superficial da parede dos vasos.

A região central dos vasos sanguíneos é desprezada na contribuição da concentração dos lipossomos, pois o fluxo laminar dentro dos vasos limita o transporte extravascular dos lipossomos, e somente os lipossomos próximos à parede terão um termo de permeabilidade significativo. Similarmente ao caso do parâmetro de permeabilidade dos vasos, que esta sob influência dos movimentos de difusão e convecção do sistema, tem-se que o coeficiente de difusão da droga também será um coeficiente aparente $\left(D_{\text {app }}\right)$, e dependerá dos movimentos de difusão e convecção do sistema.

O transporte de lipossomos para o tecido tumoral, e a distribuição do fármaco no local, podem ser analisados por um modelo dinâmico de transporte de massas que incorpora os efeitos de difusão e eliminação do sistema (Eq. 3.3).

$$
\frac{\partial C_{L, E}}{\partial t}=D_{L, a p p} \nabla^{2} C_{L, E}+P_{L, a p p} A_{v}\left(C_{L, V}-C_{L, E}\right)-\frac{C_{L, E}}{\tau_{r}}
$$

Considerando $C_{L, E}$ a concentração de lipossomos, com DOX encapsulada, no espaço extracelular (mg/ml volume do tumor); $D_{L, a p p}$ é o coeficiente de difusão aparente dos lipossomos $\left(\mathrm{cm}^{2} / \mathrm{s}\right)$. Na equação, o primeiro termo do lado direito representa a difusão no tecido, o terceiro termo considera a taxa de liberação da droga pelos lipossomos. Os lipossomos liberaram as drogas seguindo uma cinética de primeira ordem, com constante de decaimento $\tau_{r}$.

A equação 3.3 busca estimar a distribuição local de DOX considerando um sistema de dois compartimentos (intravascular e extravascular), e uma situação de temperatura próxima à de homeostase corpórea $\left(\approx 37^{\circ} \mathrm{C}\right)$. Nesta situação a DOX encontra-se majoritariamente encapsulada nos lipossomos, por isso a distribuição local da droga se assemelha à distribuição dos lipossomos. No entanto, a razão com que a DOX é liberada dos lipossomos depende fortemente da temperatura local $(\mathrm{T})$. Em condições hipertérmicas $(\mathrm{T} \approx$ 
$42^{\circ} \mathrm{C}$ ) a equação 3.3 deve sofrer modificações para levar em consideração os efeitos de temperatura na difusão da DOX. A taxa de liberação $\left(R_{R}\right)$ da DOX é considerada como sendo bi-exponencial, de acordo com o ajuste dos dados experimentais de fração de liberação entre 37 e $47^{\circ} \mathrm{C}$.

Um fator importante a ser considerando, em situações de hipertermia, é o tempo de permanência dos lipossomos na região de aquecimento. A quantidade de DOX-Livre depende do tempo de permanência na região aquecida $\left(t_{r e s}\right)$ dos LTSL; sendo $t_{r e s}$ inversamente proporcional ao fluxo plasmático no ambiente tumoral ou da perfusão local. O transporte de DOX-Livre através das paredes dos vasos irá depender das diferenças de concentração intravascular e intersticial, e será proporcional a permeabilidade aparente $\left(P_{D, a p p}\right)$. Assim, as concentrações de DOX-Livre nas regiões periféricas do tumor podem ser determinadas por:

$$
\frac{\partial C_{D, E}}{\partial t}=D_{D, a p p} \nabla^{2} C_{D, E}+P_{D, a p p} A_{t}\left(C_{D, V}-C_{D, E}\right)+C_{D, E} R_{R}-\frac{\partial C_{D, I}}{\partial t}\left(1-\varphi_{e}\right)
$$

em que " $C_{D, E}$ " é a concentração de droga livre no espaço extracelular, " $C_{D, I}$ " é a concentração de droga internalizada pela célula, $\varphi_{e}$ a fração de volume intersticial e " $C_{D, V}$ " é a concentração de droga livre no compartimento vascular. Acredita-se que a internalização da droga na célula ocorre por transporte passivo através da membrana celular, como efeito de captação.

Sendo assim, a descrição da distribuição local de DOX deve ser realizada levando em consideração as duas equações de difusão ( 3.3 e 3.4 ) para que se tenha uma melhor descrição do sistema.

\subsubsection{Introdução à microscopia confocal de fluorescência}

Este item se inicia com uma pequena discussão sobre os conceitos de fluorescência e logo após a apresentação da discussão sobre a microscopia confocal. 


\section{Conceitos de fluorescência}

Quando um feixe de luz incide sobre um conjunto de moléculas, existe a probabilidade que parte dos fótons sejam absorvidos. A probabilidade de uma molécula mudar de estado por absorção de fótons depende da natureza das funções de onda dos estados inicial e final, do grau de interação entre a luz e as moléculas, e da intensidade da luz incidente. A fluorescência (luz espontaneamente emitida) ocorre quando um elétron no estado excitado (normalmente S1) retorna ao estado fundamental emitindo fóton. O fóton emitido em geral possui um comprimento de onda maior que o absorvido, pois há perda de energia e envolvimento com processos não-radioativos, como relaxação vibracional.

O estado eletrônico de muitas das moléculas orgânicas pode ser dividido em estados singletos e tripletos, em que todos os elétrons na molécula são spin emparelhados ou spin desemparelhados, respectivamente. Como uma regra simples, a transição energeticamente favorável irá ocorrer entre o último orbital molecular ocupado (HOMO), normalmente um estado singleto fundamental, $S_{0}$, para o primeiro orbital molecular desocupado de menor energia (LUMO), e a espécie resultante é chamada de estado singleto excitado $S_{1}$.

A Figura 3.3 apresenta um diagrama com as transições eletrônicas possíveis nos processos de absorção e emissão de fótons. Esse diagrama é conhecido como diagrama de Jablonski.

\section{Microscopia confocal intravital}

(Texto baseado em: Olympus Microscopy Resource Center: Confocal Microscopy Introduction)

Diferente de outros modelos de microscopia óptica, que dependem de características macroscópicas do espécime, como gradiente de fase, absorção de luz e birrefringência, a microscopia de fluorescência é capaz de obter informações de um único elemento do espécime baseado em suas propriedades de emissão fluorescente. Assim, a microscopia de fluorescência facilita a localização precisa de componentes intracelulares que, marcados com sondas fluorescentes, podem fornecer informações sobre coeficientes de difusão, características de transporte, e interações com outras biomoléculas. Além dos fatores da 


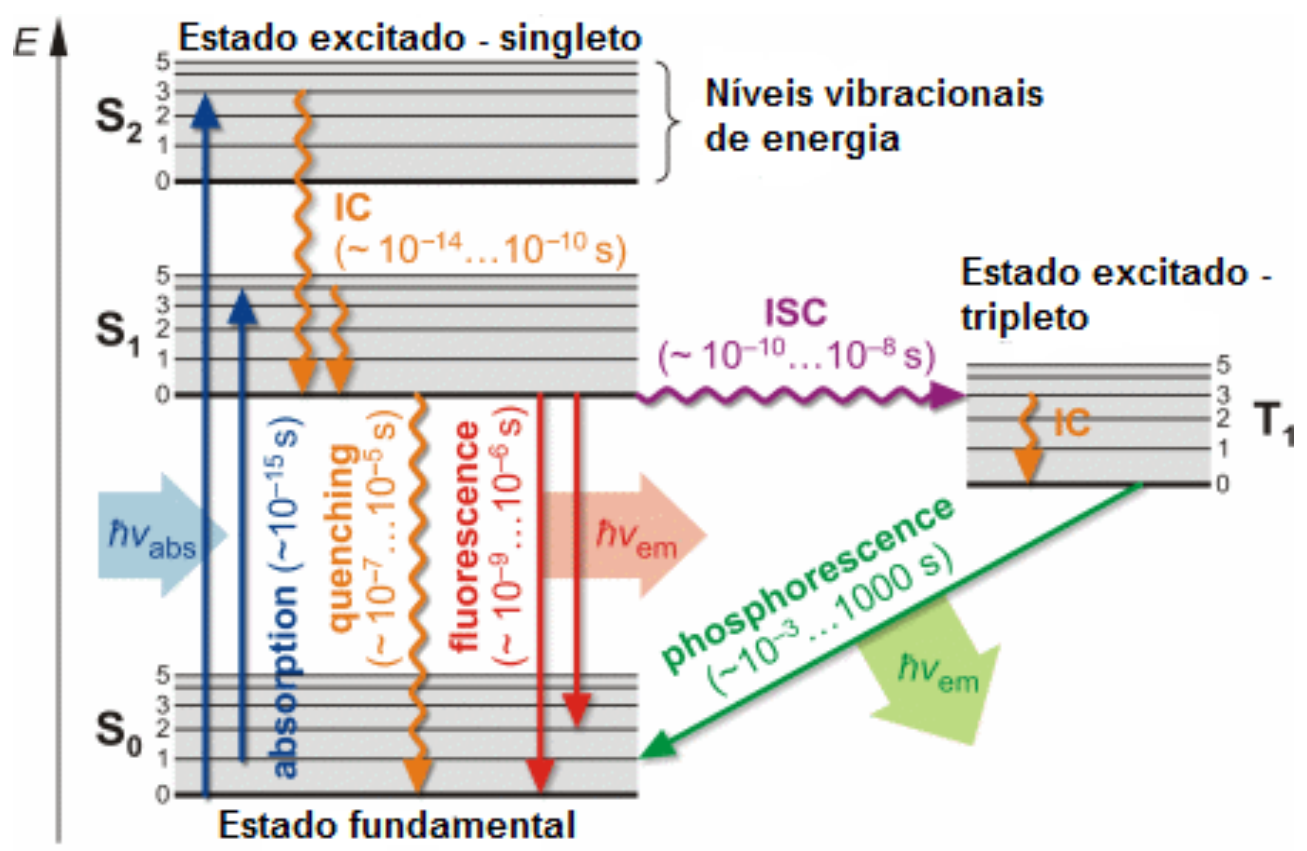

Figura 3.3: Diagrama de Jablonski, mostrando as possíveis transições entre os níveis vibracionais do estado fundamental $S_{0}$ e dos estados excitados $S_{1}, S_{2}$ e $T_{1}$. As linhas em cada nível eletrônico representam os níveis vibracionais. As transições estão marcadas por linhas verticais, as que envolvem radiação são linhas retas, enquanto as linhas onduladas representam processos nãoradioativos.(Imagem extraída de: http://www.uni-leipzig.de)

própria molécula, a fluorescência possui forte dependência com propriedades do ambiente, no qual a molécula se localiza e pode auxiliar no monitoramento do $\mathrm{pH}$ local, viscosidade, índice de refração, concentração iônica, potencial de membrana, e polaridade do solvente em células ou tecidos in vivo.

A microscopia confocal oferece diversas vantagens sobre a microscopia óptica convencional, incluindo controle de profundidade de campo, eliminação de imagens espúrias fora do foco, e a habilidade de coletar sequências de secções ópticas em espécimes espessas. O diferencial da abordagem confocal está em usar filtros espaciais (Pinholes) que eliminam sinais de luz fora do foco de espécimes que sejam mais espessas que o plano focal.

Na microscopia tradicional de campo largo, a objetiva cria o foco em um cone largo de iluminação que atinge um grande volume do espécime (ilustrado na Figura 3.4B). A maioria da emissão fluorescente neste cone acaba retornando ao microscópio e sensibiliza os detetores. O resultado deste efeito é uma quantidade significativa de sinal devido a 


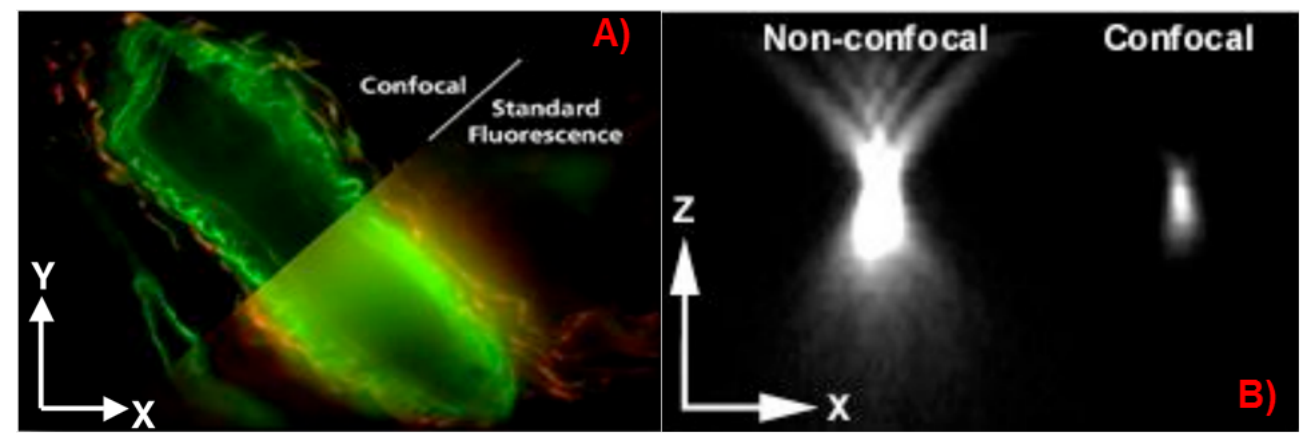

Figura 3.4: Imagem A) exemplifica as diferenças de qualidade da imagem entre a microcopia de fluorescência convencional e a microscopia confocal. Nota-se que as imagens de microscopia confocal são mais nítidas e claras. A imagem B) apresenta a comparação entre as microscopias no campo de visão na direção de propagação da luz "z" . Observa-se na microscopia convencional um cone largo de iluminação, já na microscopia confocal observa-se uma melhor resolução na direção "z" e somente um pequeno volume será observado. (Imagem extraída de: http://www.zmb.uzh.ch/resources/download/CLSM.pdf)

emissões de fundo ou autofluorescência de áreas acima ou abaixo do plano focal, logo, comprometendo seriamente a resolução e contraste das imagens (Figura 3.4A).

Na microscopia confocal, a fluorescência emitida pelo espécime utiliza o mesmo caminho óptico da incidência, porém com um obstáculo adicional que o feixe necessita passar, esse obstáculo é uma pequena abertura (pinhole) posicionado antes de atingir a fotomutiplicadora/detector. Devido ao pinhole, somente a luz proveniente do plano focal será detectada, pois os feixes de luz vindos de outros planos não conseguem passar através do pinhole (Figura 3.5). Quanto menor o pinhole menor a intensidade de luz espalhada ou fora de foco que irá atingir o detector.

A microscopia confocal de varredura a laser (LSCM) vem se destacando por possuir algumas vantagens na qualidade da imagem de vasculaturas com relação aos microscópios confocais fluorescentes tradicionais. Nesta modalidade, para se obter a imagem completa da região, a amostra deve ser varrida no plano x-y normal ao caminho da luz orientado na profundidade "z". No LSCM , a varredura do plano x-y pelo feixe de laser ocorre devido à deflexão do feixe por dois conjuntos de espelhos (Figura 3.5B). Os espelhos são instalados em um sistema acoplado a um servo motor; a frequência da resposta mecânica da varredura é da ordem alguns $\mathrm{kHz}$, a qual determina a taxa de varredura. O plano da objetiva, como um todo, é monitorado ponto-por-ponto e linha-por-linha. 


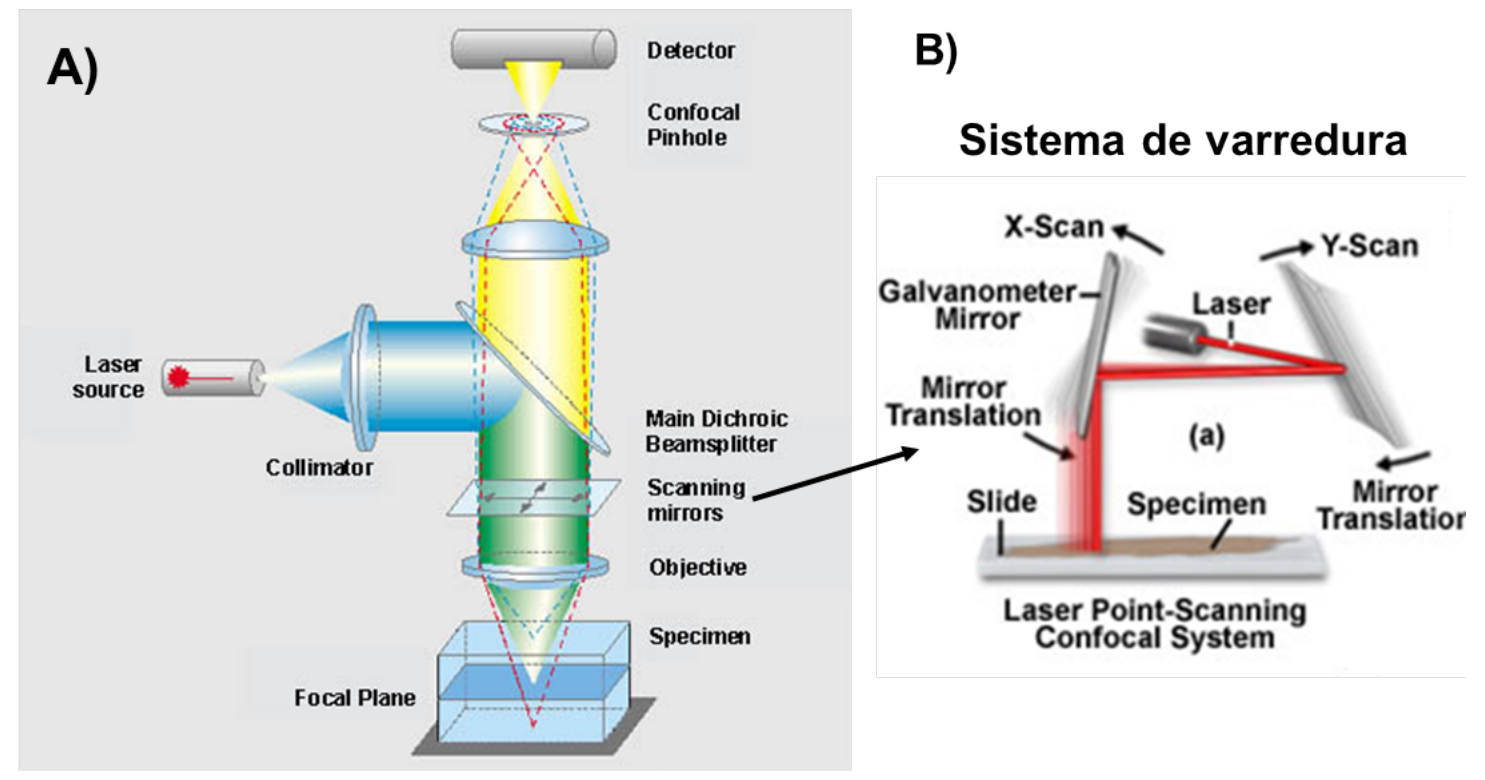

Figura 3.5: Imagem A) representa um esquema do microscópio confocal de varredura a laser (LSCM). Imagem B) ilustra o esquema de distribuição dos espelhos que compõem o sistema de varredura da amostras no LSCM. (Imagens extraída de: http://www.lbb.ethz.ch/Equipment/CLSM)

O sinal da emissão fluorescente é então separado do feixe de excitação por um espelho dicroico divisor de feixe, e é então canalizado para a fotomultiplicadora(PMT), onde será amplificado o sinal. Tipicamente, o LSCM usa fotomultiplicadoras (PMT) como detector, para melhor sensibilidade e rápida calibração. A capacidade do microscópio confocal em criar uma estreita secção óptica em pequenos e regulares intervalos ao longo do eixo óptico permite a reconstrução 3D das imagens. Com o uso de softwares especializados as imagens 2D podem ser combinadas de forma a criar a imagem 3D. A Figura 3.6 exemplifica a reconstrução 3D de uma célula a partir de um conjunto 2D de fatias.

Em resumo, a microscopia confocal é uma técnica que permite acessar a compartimentalização vascular e intersticial da DOX, que é uma molécula fluorescente, e possibilita a avaliação da concentração e penetração da droga através da análise da intensidade fluorescente e facilita o fatiamento das imagens de modo a possibilitar a reconstrução do sistema tridimensional. 


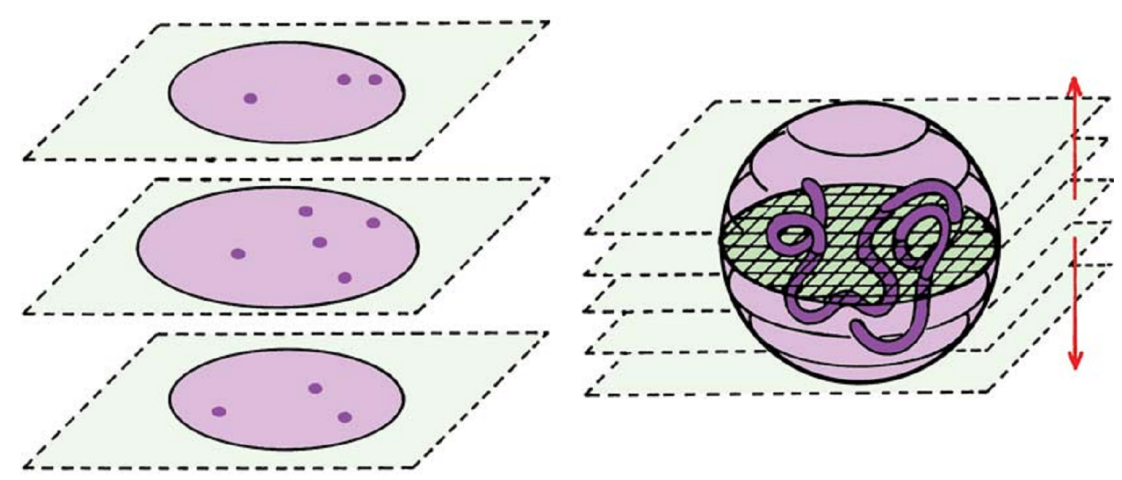

Figura 3.6: Exemplo da formação da imagem tridimensional de uma célula por microscopia confocal [Imagem extraída de (Lakowicz, 2006)-Figura 18.25].

\subsection{Materiais e Métodos}

\subsubsection{Animais}

Todos os experimentos e procedimentos foram previamente aprovados pelo comitê Institutional Animal Care and Use da Duke University. Os estudos foram realizados em camundongos fêmea CD1 nu/nu (Figura 3.7). Os camundongos CD1 não apresentam a glândula timo e por isso são incapazes de maturar os linfócitos-T. Como consequência dessa ausência, são imunodeficientes.

Figura 3.7: Imagem do camundongo utilizado nos experimentos de microscopia intravital.

Os camundongos nu/nu são empregados em muitos estudos de descoberta de novas drogas ou desenvolvimento de novas terapias, pois permitem o transplante e propagação eficiente de tecidos tumorais. Esta cepa de camundongo possibilita que linhas de células humanas sejam estabelecidas in vitro e então propagadas subcutaneamente nos mesmos, que por vez irão reconstituir o tumor sólido original. Tecidos tumorais humanos obtidos por biópsia ou autópsia podem também ser diretamente transplantados nestas cepas de 
camundongo.

Neste estudo foram usados 18 fêmeas CD1 nu/nu, pesando 25-28g, aleatoriamente divididas em 3 grandes grupos. Dentro destes grandes grupos ainda havia dois subgrupos: com tumor ou sem tumor. Os grupos foram divididos como: 1) Doxorrubicina livre, 2) Lipossomos DOX-LTSL sem a presença de aquecimento e 3) Lipossomos DOXLTSL+Hipertermia. Para todos os grupos, a dose de doxorrubicina foi de $5 \mathrm{mg} / \mathrm{kg}$ de massa do corpo do animal. Três animais foram utilizados no teste dos protocolos.

\subsubsection{Implantação do tumor}

Para implantação das células tumorais, primeiramente os camundongos foram anestesiados intraperitonealmente com cetamina (Dopalen- $80 \mathrm{mg} / \mathrm{kg}$ ) e xilazina (Anasedan$8 \mathrm{mg} / \mathrm{kg}$ ).Tão logo a anestesia fez efeito, fixou-se a cabeça do animal nas barras auriculares do aparelho estereotáxico (Figura 3.8). A seguir, realizou-se uma incisão longitudinal na pele e tecido subcutâneo expondo a região da calota craniana. Foi utilizado o peróxido de hidrogênio a fim de retirar a camada restante de tecido subcutâneo e permitir a melhor visualização das suturas. Utilizando uma broca odontológica foi feito um pequeno orifício para inserir a seringa Hamilton contendo as células tumorais.

A implantação do tumor ocorreu no hemisfério direito superior do cérebro entre a bregma e a sutura lambdóidea, para evitar os vasos visíveis. A implantação de $10^{6}$ células de D270 de gliomas humanos foi realizada a 3mm de profundidade e foram injetadas de forma lenta.

Após a implantação das células tumorais, os animais foram mantidos em condições ambientais controladas entre 12 a 14 dias, até que os tumores atingissem tamanhos suficientemente grande $(2-3 \mathrm{~mm})$ para aplicação da microscopia de fluorescência confocal. Alguns dos tumores implantados foram monitorados por MRI e o exemplo de massa tumoral encontrada após o crescimento é apresentada na Figura 3.9. 


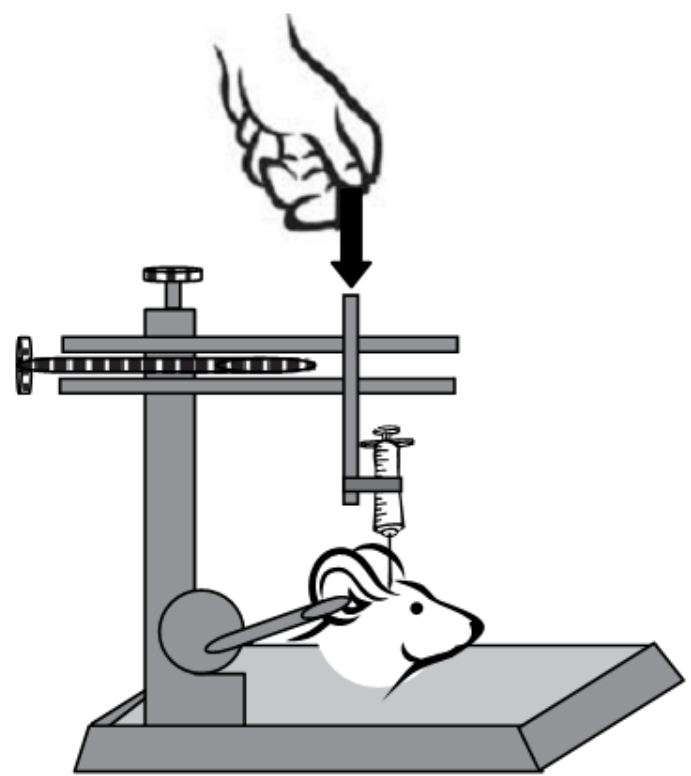

Figura 3.8: Ilustração do procedimento de implantação das células tumorais com auxílio do aparelho estereotáxico [Imagem extraída de (Allard et al., 2009)].

\subsubsection{Procedimento de craniotomia}

A microscopia intravital é uma técnica que permite observar diversos processos biológicos em animais vivos.Porém, é uma técnica de melhor óptica e como tal é sujeita com a alta taxa de absorção em tecidos biológicos, fazendo com que a penetrabilidade do feixe de luz seja limitada.O estudo intravital do cérebro sofre ainda com um fator adicional que é a presença da estrutura óssea craniana, que reveste todo o cérebro e dificulta a transmissão de feixes luz para o parênquima cerebral. A estrutura da cabeça dos ma-

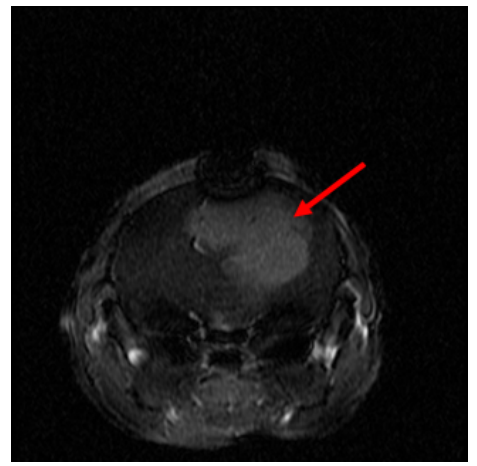

Figura 3.9: Imagem de MRI por aumento de contraste - DCE (Dynamic Contrast-Enhanced) do tumor induzido (seta vermelha) no cérebro do camundongo após 14 dias da implantação das células D270 de gliomas humanos. 
míferos é complexa e composta por diferentes camadas de tecidos além do parênquima (Figura 3.10).

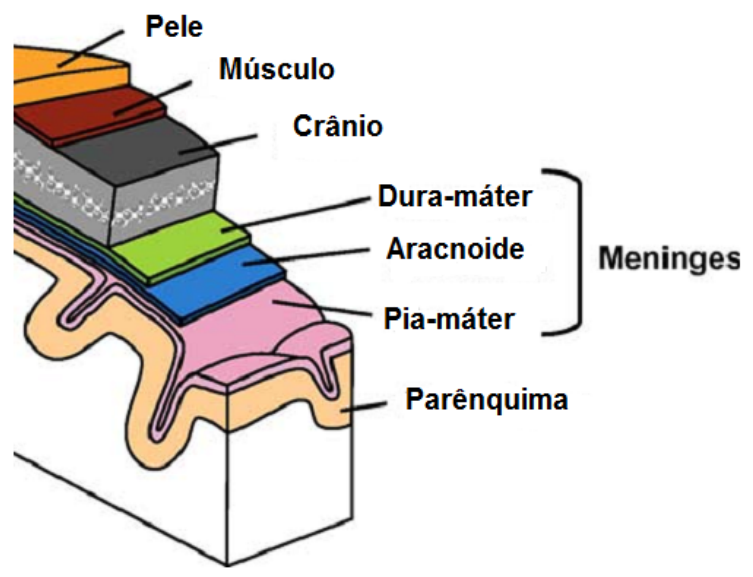

Figura 3.10: Ilustração de um corte da cabeça humana na região do lobo frontal. A ilustração apresenta as principais camadas de tecidos que a compõem a cabeça [Figura extraída de (Huynh et al., 2006)].

Uma forma de contornar as limitações impostas é através da remoção cirúrgica parcial e localizada da estrutura óssea que recobre o cérebro, permitindo assim que sejam empregados os mais diferentes métodos de microscopia. Portanto, a estratégia consiste em remover a camada de pele, músculo, osso e dura mater, formando assim uma "janela" craniana.

A "janela" craniana é um método que há décadas vem sendo utilizado como artifício para facilitar a investigação de questões relacionadas à circulação sanguínea e seus processos de regulação no cérebro (Cho et al., 2011; Chong et al., 2011). De modo geral, essa técnica tem sido utilizada como uma "janela aberta" em que permite uma direta observação da vasculatura intracranial, ou "janela fechada" no qual o crânio e a dura mater são removidos e substituídos por uma superfície fina transparante em que é selada a região. Com a preparação adequada, esta técnica permite a observação da mesma região cortical por até meses após a cirurgia.

A preparação da "janela" craniana neste projeto seguiu protocolos anteriormente definidos (Xu et al., 2007; Yang et al., 2010). A cirurgia ocorreu em ambiente estéril e consistiu na remoção de uma fatia retangular de osso $(4 \times 6 \mathrm{~mm})$, utilizando-se uma broca odontológica. A fatia era localizada entre a bregma e a sutura lambdoide, com o centro 
na sutura média-sagital. A“janela" craniana foi coberta por uma fina película de Mylarß que foi fixada ao crânio usando cola de cianoacrilato. Todo o procedimento cirúrgico foi conduzido com auxílio pela biomédica Dra. Christy Wilson.

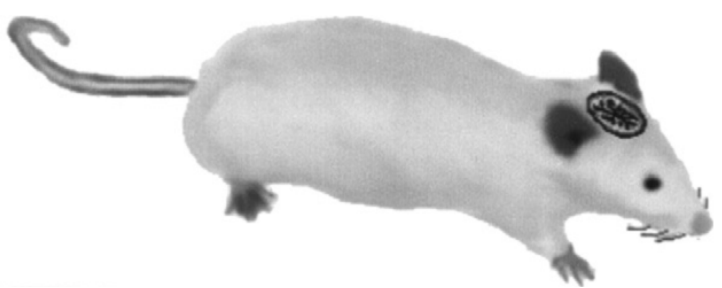

Figura 3.11: Ilustração exemplificando o resultado final do processo de craniotomia realizada nos camundongos e a criação da "janela" craniana [figura adaptada de (Jain, 2012)].

\subsubsection{Seleção das sondas fluorescentes}

O uso da fluorescência da doxorrubicina permite a direta observação do acúmulo intracelular e sua distribuição no tecido alvo. Uma das questões de interesse deste projeto consistiu em avaliar o impacto na capacidade dos lipossomos LSTL (diâmetro $\approx 100 \mathrm{~nm}$ ) transporem a BHE quando submetidos a processos de hipertermia moderada. Para avaliar essa propriedade de permeabilidade, necessita-se de um meio eficaz de localização dos lipossomos que seja independente da interação com a droga doxorrubicina.

A solução adequada foi testada anteriormente (Dreher, 2006; Manzoor et al., 2012), e consiste em marcar os lipossomos LSTL com fluoróforos fosfolipídicos cuja a emissão fluorescente seja suficientemente distinta da emissão da doxorrubicina, pois assim permite co-registro de ambas as sondas (droga e lipossomos), e evita o chamado "channel crosstalk". O crosstalk ocorre nas imagens de fluorescência, quando o espectro de excitação e/ou emissão de dois ou mais fluoróforos em um espécime se sobrepõem, tornando difícil isolar a atividade de cada fluoróforo.

A Figura 3.12 mostra a estrutura química esquemática e os espectros de excitação e emissão característicos da Doxorrubicina. A DOX possui espectros de emissão e excitação largos e é muito provável esse sinal estar presente em outros canais.

Em trabalhos anteriores, o co-resgitro da posição dos lipossomos e da doxorrubicina foi solucionado utilizando-se lipossomos marcados com sondas fluorescente com máximo de 


\section{Doxorrubicina (DOX)}<smiles>COc1cccc2c1C(=O)c1c(O)c3c(c(O)c1C2=O)C[C@@](O)(C(=O)CO)N[C@@]3(O)OC1CC2CC(N)C(O2)O1</smiles>
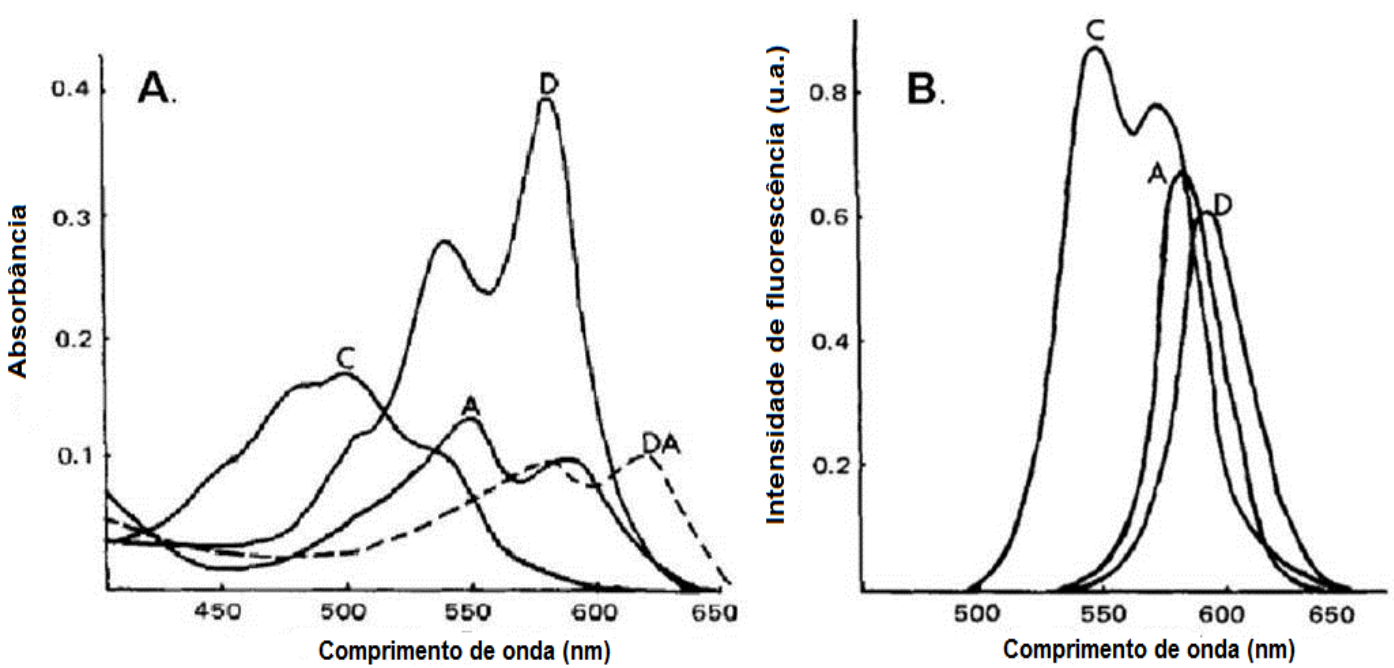

Figura 3.12: Formúla estrutural da molécula doxorrubicina (Sigma-aldrich). Espectros de absorção e emissão da DOX. As curvas em (A) representam o espectro de excitação da DOX em várias formas de protonação. Em pH fisiológico a DOX existe como monocatiônica e seu espectro possui a forma da curva "C" . As curvas em (B) são os correspondentes espectros de emissão fluorescente da DOX [Figura extraída de Sturgeon \& Schulman (1977)].

emissão na região da cor verde (510 nm), uma vez que o máximo de emissão da DOX ocorre normalmente na região do laranja $(585 \mathrm{~nm})$. Neste trabalho, utilizou-se como marcador dos lipossomos o fosfolipídio DOPE que possui uma Carboxifluoroceina ligada a sua cabeça polar (1,2-dioleoyl-sn-glycero-3-phosphoethanolamine-N-(carboxyfluorescein)) ou DOPECF. A estrutura química esquemática é apresentada na Figura 3.13. A fluoresceína possui espectro de absorção e emissão distintos da Doxorrubicina Figura 3.13.

Os espectros de absorção e emissão da fluoresceína foram obtidos no banco de dados da "Molecular Probes®".

Baseado nas características dos espectros de absorção e emissão de ambas as sondas, definiu-se que a melhor estratégia de aquisição das imagens seria excitar a carboxifluores- 


\section{DOPE-Carboxifluoresceína (DOPE-CF)}
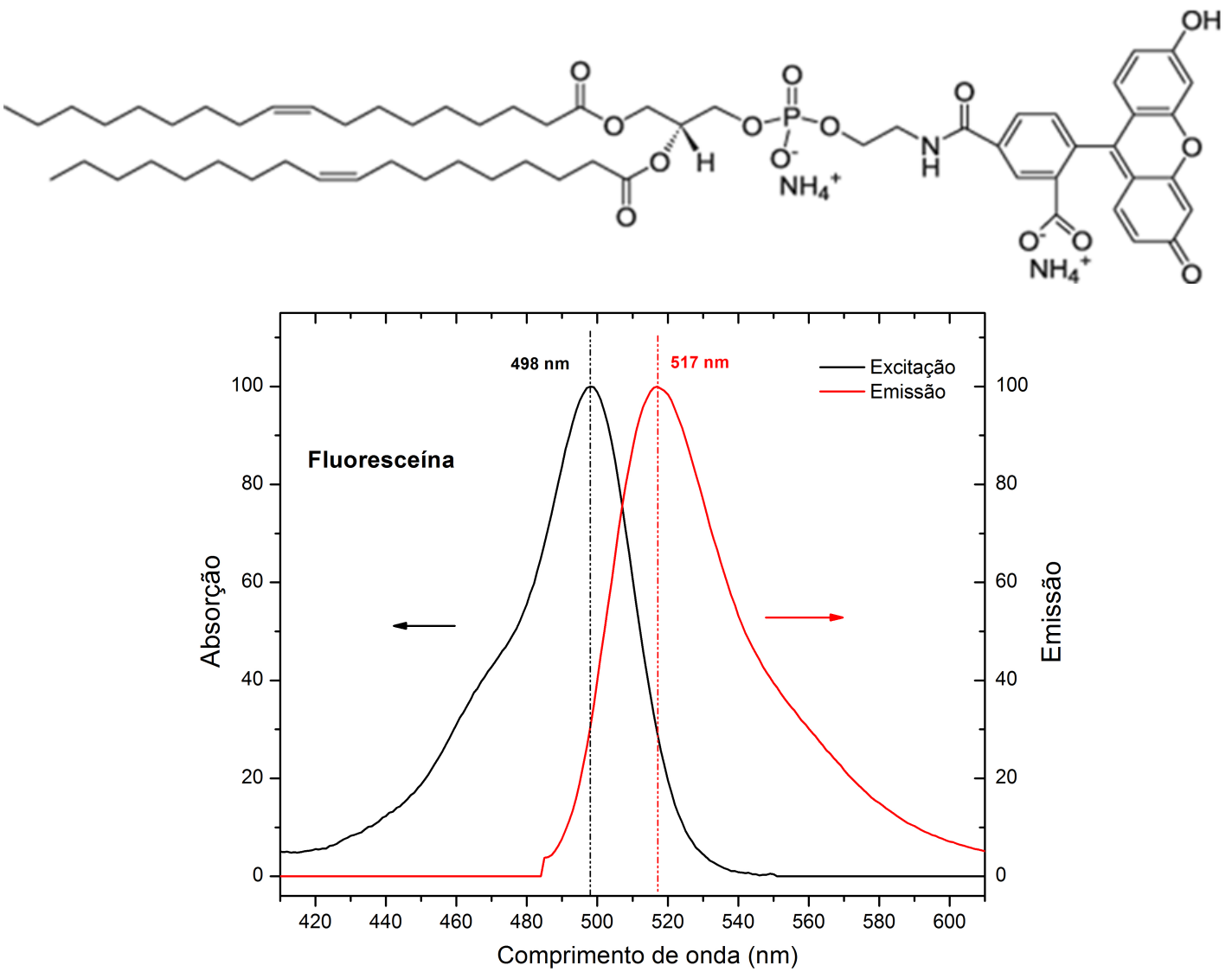

Figura 3.13: Formúla estrutural da molécula DOPE-Carboxifluoresceína (DOPE-CF) (Estrutura obtida em Sigma-aldrich). Espectro de absorção e emissão da carboxifluorescenína em tampão pH 8 (dados obtidos na Molecular Probes $\AA$ handbook).

ceína, ancorada nos lipossomos, com o laser centrado em 488 nm e monitorando a emissão com um filtro band pass de 505 a $530 \mathrm{~nm}$. No caso da DOX a excitação seria com o laser de $458 \mathrm{~nm}$ e a emissão controlada com um filtro long pass filter de $560 \mathrm{~nm}$. O cross talk dos canais foi minimizado utilizado-se um sistema de controle de imagem que permite a excitação de apenas um laser de cada vez, ao invés do dois simultaneamente.

Observando o espectro de emissão e excitação da DOX, imagina-se que alguma contribuição espúria da DOX deva ocorrer no canal da fluoresceína. Porém, como normalmente a DOX apresenta baixo rendimento quântico nas regiões tumorais, essa contribuição deve ser mínima. 


\subsubsection{Microscópio confocal de fluorescência intravital}

Todas as images de fluorescência foram adquiridas em um microscópio confocal da empresa alemã Zeiss, modelo LSM 780 upright, localizado no Light Microscopy Core Facility (LMCF) da Duke University. Este microscópio possui diversos lasers disponíveis, o que possibilita a excitação da amostra em diferentes comprimentos de onda (405, 458, 477, 488, 514, 561 e $633 \mathrm{~nm})$. Para todas as linhas de excitação, existem filtros de controle de banda. O microscópio utilizado e um esquema do arranjo experimental são apresentados na Figura 3.14.
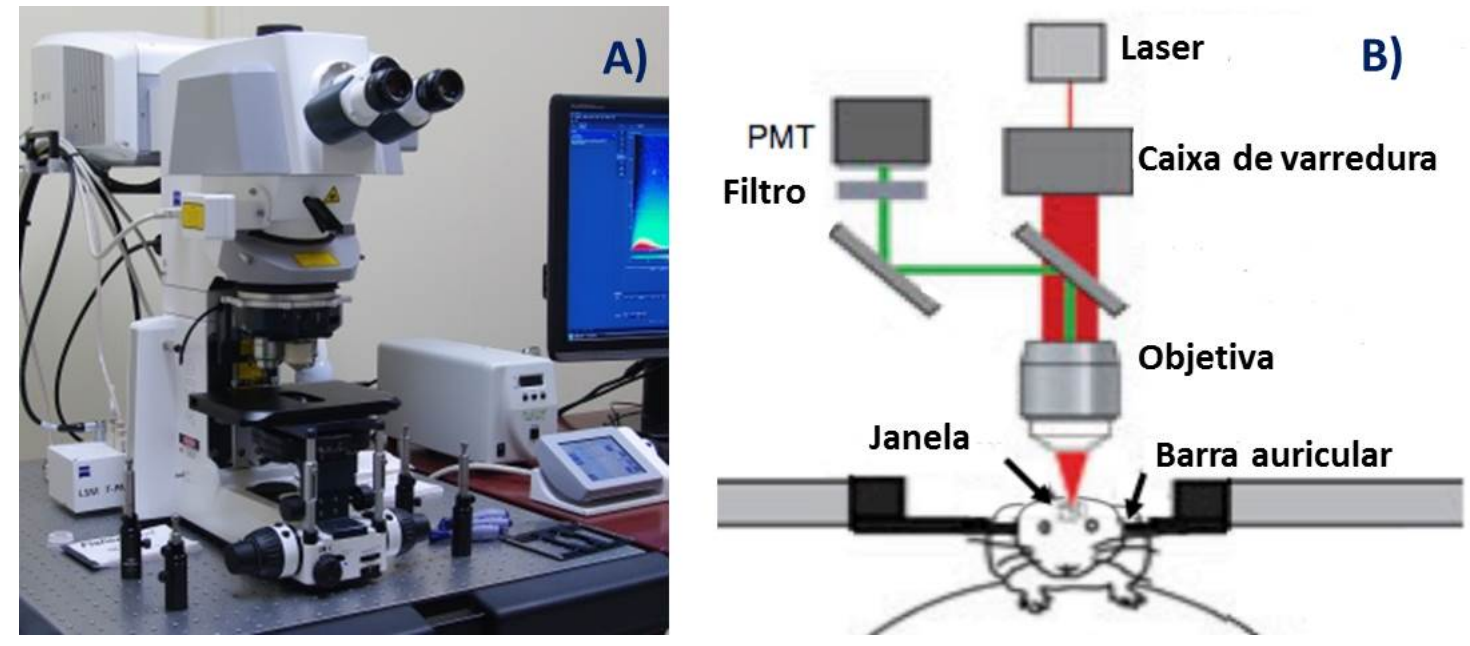

Figura 3.14: (A) Imagem do microscópio Zeiss 780 upright confocal localizado no LMCF. (B) Esquema do arranjo experimental utilizado para aquisição das imagens fluorescentes. O animal foi imobilizado no aparelho estereotáxico e a imagem foi coletada através da janela criada por craniotomia.

As imagens em baixa-magnificação foram obtidas com uma objetiva de 10x (0,45 Dry Zeiss Plan-Apochromat 1063-139 WD 2,0 mm) e a de alta-magnificação foi obtida com uma objetiva 20x (0,80 Dry Zeiss Plan-Apochromat 440640-9903 WD 0,55 mm).

\subsubsection{Aquisição das imagens}

Para o estudo da distribuição local de DOX, 3 grupos experimentais foram definidos: o grupo 1 foi submetido à DOX- livre sem uso de aquecimento $(n=3)$, o grupo 2 foi submetido à formulação DOX-LTSL sem o uso de calor $(n=3)$ e grupo 3 foi submetido à formulação DOX-LTSL com a influência de aquecimento $(n=6)$. 
O aquecimento foi promovido pelo mini-aplicador de micro-ondas desenvolvido especialmente para este fim. A confiabilidade do aquecimento foi testada e determinada no procedimento de dosimetria do capítulo anterior. Após o aquecimento, os animais foram posicionados sob o microscópio, conforme Figura 3.14.

Para injeção das formulações, a veia na cauda foi canulada e 0,1 mL de $50 \mathrm{mg} / \mathrm{mL}$ de Dox foi injetado na circulação sanguínea. Tipicamente, a injeção das formulações ocorreu após sete minutos de aquecimento, para que fosse garantido o equilíbrio térmico na região de interesse. A formulação marcada com fluoresceína de DOX-LTSL foi utilizada após um dia do encapsulamento da DOX.

As imagens foram adquiridas usando uma resolução planar de 1024 por 1024 pixels, com um campo de visão de 850 por $850 \mu \mathrm{m}$. Após a aquisição, as imagens foram analisadas utilizado-se o software ImageJ.

\subsubsection{Método de análise das imagens de fluorescência}

O principal objetivo do uso da microscopia de fluorescência neste projeto foi obter informações relevantes ao processo de entrega termo-estimulada de droga. Porém, antes de qualquer avaliação profunda, as imagens devem passar por uma etapa de processamento, para que se possa aumentar a qualidade e clareza das imagens. O processamento das imagens segue basicamente três etapas. A primeira consiste em subtrair a intensidade de fundo e reduzir o ruído da imagem, em seguida aplica-se a etapa de detecção e intensificação de determinadas características de interesse da imagem, e por último executa-se a etapa de quantificação de grandezas como área, volume e intensidade. A Figura 3.15 apresenta um exemplo da sequência de aplicação das etapas no processamento das imagens.

Após a extração dos canais (imagens 2 e 3 da Figura 3.15), executa-se o processamento da imagem de forma independente para cada canal. Para a redução da intensidade de fundo utilizou-se o algorítimo já instalado no "ImageJ" que responde pelo comando Subtract background. Este comando estima a intensidade de fundo da imagem usando um "rolling ball algorithm". Neste comando deve-se necessariamente determinar o ROI a 

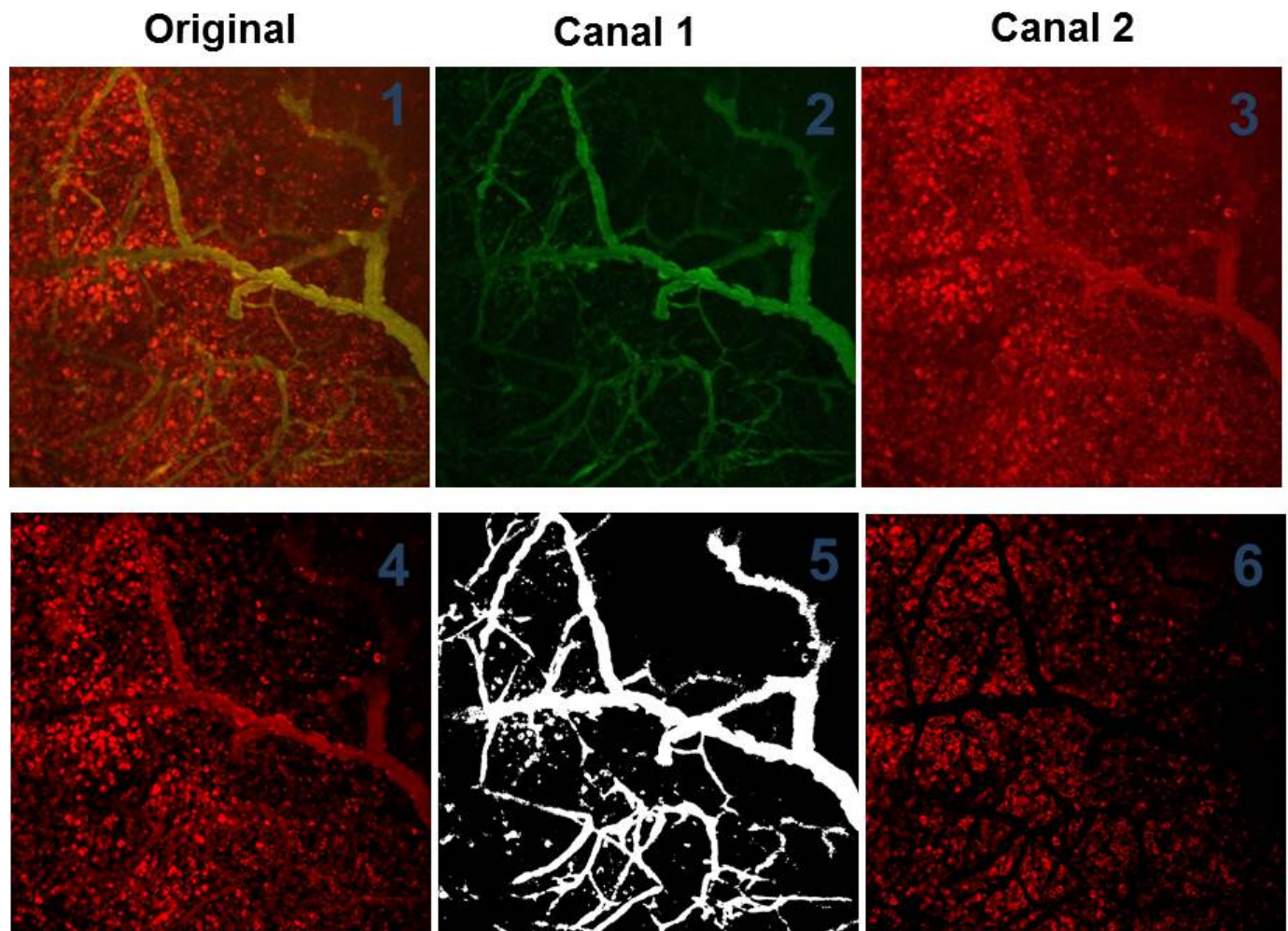

Pós-filtro

Máscara

Extravascular

Figura 3.15: Exemplo das etapas de processamento das imagens de fluorescência. A primeira ação a ser tomada é a extração dos canais $(2,3)$ da imagem original. Após a extração cada imagem passa por um processo de filtragem para redução de ruído e intensidade de fundo(4). Com melhora na qualidade da imagem é possível iniciar processos de intensificação e determinação de áreas de interesse. Imagem (5) apresenta a máscara vascular obtida a partir de imagens do canal 1. A última etapa consiste em medir a grandeza de interesse, no caso da imagem (6) apresenta-se a imagem resultante para o espaço extravascular, o que permite estimar a intensidade de DOX neste ambiente.

ser considerado na estimativa, e portanto deve-se garantir que esse raio seja maior que o maior objeto da imagem.

Após a subtração da intensidade de fundo, executou-se então a redução do ruído das imagens. Na microscopia de fluorescência são dois tipos de ruídos de maior peso: o ruido térmico e o ruido de leitura. Para eliminar o ruido térmico usou-se um o filtro de Média. O filtro Media foi escolhido em detrimento do filtro Gaussiano para assim tentar manter nítida as fronteiras vasculares e reduzir o efeito borrado. A Figura 3.16 apresenta um exemplo da imagem pré e pós filtragem.

Para delinear o ambiente extravascular e ambiente vascular foi necessário criar uma 


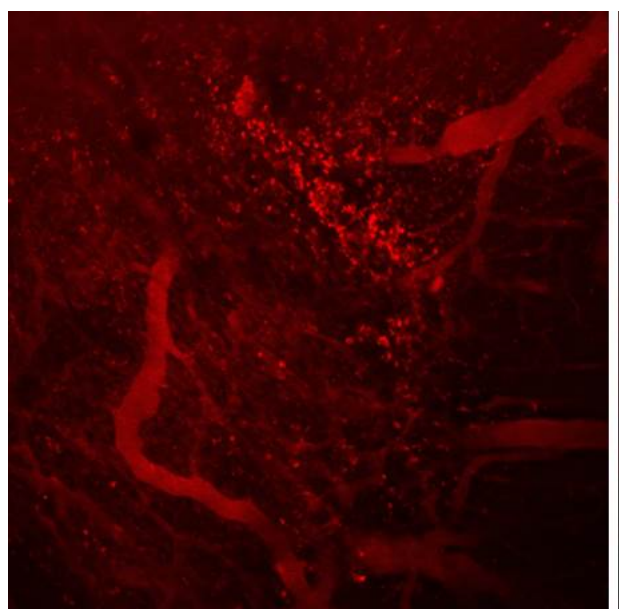

Original

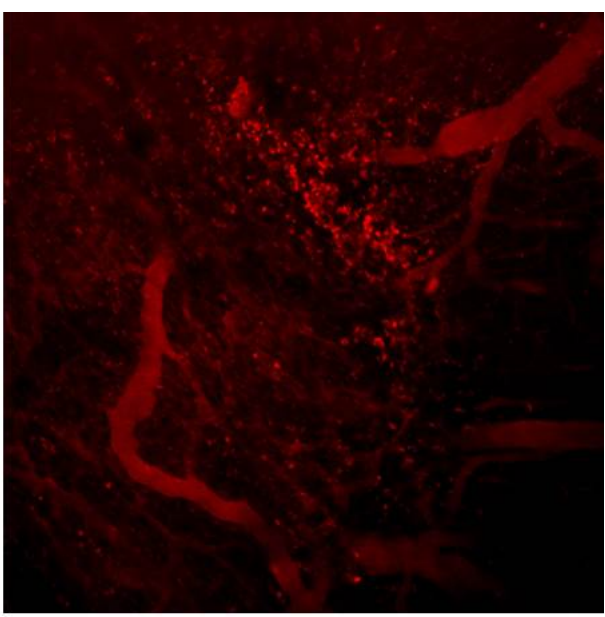

Pós-filtragem

Figura 3.16: Exemplo do impacto do processamento das imagens na característica da imagem original da DOX A imagem pós-filtragem é resultado do processo de subtração da intensidade de fundo e do processo de filtragem por Média.

máscara vascular presente nas imagens. Contudo, devido a limitações do próprio protocolo experimental utilizado, esta tarefa não é trivial. A criação da máscara vascular depende de garantir com confiabilidade que uma dada partícula fluorescente irá permanecer exclusivamente nos vasos sanguíneos durante todo o procedimento experimental. Fato que não pode ser garantido para as formulações DOX-LTSL.

A forma encontrada para estimar a máscara vascular foi utilizar as imagens da carboxifluresceína ancorada nos lipossomos LTSL, como referência, pois espera-se que a maioria dos lipossomos estejam no interior dos vasos. Porém, para evitar contribuições espúrias, executou-se uma sequência de procedimentos adicionais de filtro para tentar obter uma máscara mais fidedigna. O objetivo final sempre será obter uma imagem binária. Um exemplo das etapas de processamento está apresentado na Figura 3.17.

A máscara vascular foi obtida a partir das imagens de carboxifluoresceína e com auxílio de ferramentas adicionais de processamento. As imagens foram convertidas a imagens binárias utilizando-se um limiar manual. A seguir, um filtro Gaussiano foi aplicado à imagem. O Resultado final da máscara vascular binária foi obtido após os processos de: 1) close, 2)fill holes e 3) dilate.

A definição da máscara vascular permite separar o ambiente vascular do ambiente 


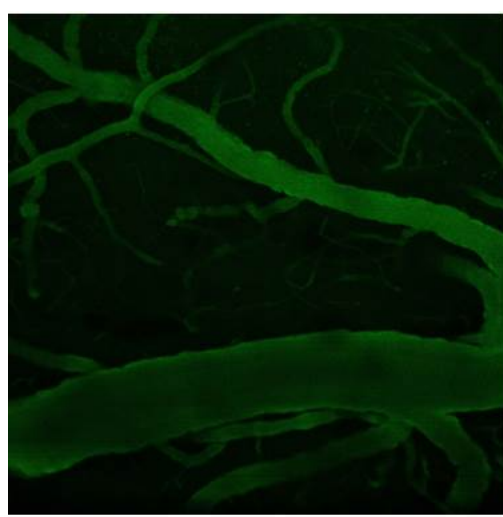

(A)

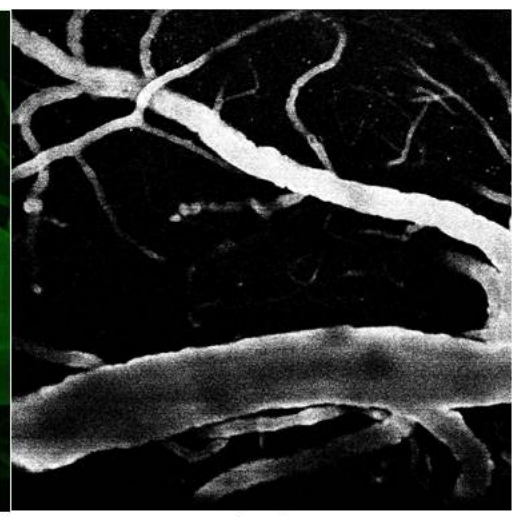

(B)

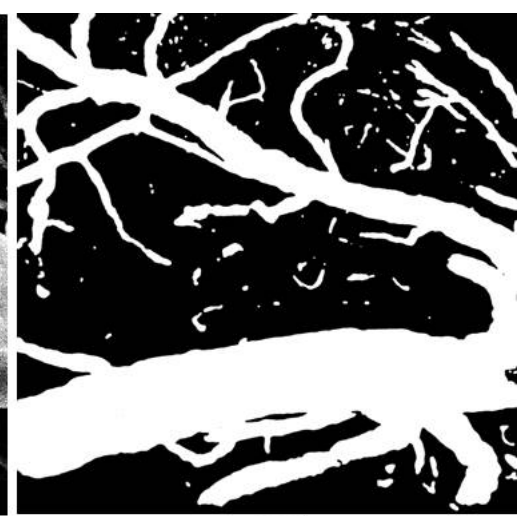

(C)

Figura 3.17: Exemplo das etapas de obtenção da máscara vascular. (A) Imagem da carboxifluoresceína após processamento inicial, (B) resultado da conversão da imagem colorida para binária, utilizando-se a definição manual do threshold e filtro Gaussiano, (C) Resultado final da máscara vascular binária após os processos de: 1) close, 2) fill holes e 3) dilate (imagej.nih.gov, 2014).

extravascular, e assim realizar análises mais precisas de distribuição e intensidade de DOX.

\subsubsection{Preparação dos lipossomos termosensíveis}

A formulação de lipossomos termosensíveis (LTSL) e subsequente encapsulamento da DOX foi preparada de acordo com o método descrito previamente (Wright, 2006). Os fosfolipídios 1,2-dipalmitoilfosfatidilcolina (DPPC - 85 mol\%), 1-estearoil-2-hidróxidofosfatidilcolina (MSPC - 9,8 mol\%), 1,2-distearoilfosfoetanolamina-[polietileno glicol-2000] (DSPE-PEG2000-5.2 mol\%) e 0,5 mol\% de DOPE-Carboxifluoresceína foram dissolvidos em uma solução de clorofórmio:metanol (4:1 vol/vol). Os solventes orgânicos foram removidos por rotoevaporação submetida a baixa pressão (Büchi Rotovapor R-124 rotoevaporator) até a formação de um filme lipídico homogêneo. Em seguida, o balão volumétrico foi deixado por 24 horas a baixa pressão para que não houvesse traços de solvente orgânico. Os filmes lipídicos foram hidratados (em uma concentração final de $100 \mathrm{mg} / \mathrm{mL}$ ) a $55^{\circ} \mathrm{C}$ por 30 minutos com tampão de ácido cítrico (300 mM) em pH 4,0.

Suspensões de vesículas unilamelares foram obtidas pelo método de extrusão (Northern Lipids Inc, Vancouver, Canada), em que as soluções foram passadas 10 vezes por um filtro de policarbonato (poro $0,1 \mu \mathrm{m}$ ) a $55^{\circ} \mathrm{C}$. A distribuição de tamanho médio da formulação de LTSL foi determinada por espalhamento de luz dinâmico. A dispersão de lipossomos 
foi diluída em água, e o diâmetro médio estava ao redor de $110 \mathrm{~nm}$. O encapsulamento da Doxorrubicina foi obtido pelo método de gradiente de pH (Mills, 2002) e a concentração de DOX foi estimada por medidas de acréscimo de fluorescência após o rompimento dos lipossomos com o surfactante Triton X-100 (Wright, 2006).

\subsubsection{Protocolo de aquecimento}

Após anestesiados, os camundongos foram posicionados no aparelho estereotáxico em posição prona. O mini-aplicador de micro-ondas foi posto em contato com a superfície da janela cranial no hemisfério direito do cérebro. Para cada grupo, o aplicador foi posicionado no centro do tumor com um pré-aquecimento de 10 minutos para que o equilíbrio térmico fosse atingido. A formulação DOX-LTSL $(5 \mathrm{mg} / \mathrm{kg})$ foi injetada através de veias na cauda do animal. Seguindo a administração do quimioterápico, a condição de hipertermia local foi mantida por mais 15 minutos em condição estacionária. Para evitar pertubação da vasculatura não foram utilizados sensores de temperatura diretamente no tumor ou superfície, a distribuição de temperatura foi determinada baseada nos dados do experimento de dosimetria e no valor de temperatura do sensor posicionado a profundidade de $4 \mathrm{~mm}$.

\subsection{Resultados e Discussões}

A fluorescência da Doxorrubicina facilita a sua localização no ambiente tumoral. Devido ao caráter pioneiro do arranjo experimental aqui utilizado, foi necessário verificar e validar todos os procedimentos e protocolos utilizados, para que fosse possível realizar uma análise mais detalhada de distribuição e acúmulo de droga. Logo, inicia-se este item de resultados com uma série de experimentos de validação do protocolo terapêutico e por fim apresenta-se alguns dados de distribuição da droga.

\subsubsection{Controle da disponibilização de DOX}

Ambientes com temperaturas próximas à temperatura de transição de fase principal dos LTSL $\left(\approx 42^{\circ} \mathrm{C}\right)$ são capazes de induzir a rápida liberação da DOX encapsulada. 
Ao volume tecidual que satisfaz essas condições de temperatura denomina-se "região de ativação". O conhecimento prévio da região de ativação é essencial a qualquer estratégia terapêutica que use os LTSL como agente terapêutico. A região de ativação é portanto delimitada através do conhecimento da distribuição local de temperatura, que na maioria das vezes possui acesso experimental restrito. No caso do cérebro dos camundongos, não existe técnica termométrica com resolução espacial suficiente para determinar a distribuição de temperatura com precisão, além do que, existe um alto grau de complexidade na questão das características de difusão do calor devido o pequeno volume de atuação.

No capítulo anterior, de desenvolvimento do mini-aplicador de micro-ondas, nós demonstramos, através de medições pontuais de temperatura, que o dispositivo foi capaz de produzir temperaturas hipertérmicas nas regiões superficiais do cérebro, no entanto, a estimativa do raio de ação foi apenas simulada computacionalmente. Nosso objetivo é promover a liberação termo-estimulada de DOX apenas no hemisfério diretamente abaixo do aplicador de micro-onda. Sendo assim, como primeira etapa deste trabalho buscou-se avaliar a capacidade de localização da liberação da DOX, assim como algumas outras propriedades de relevância ao protocolo terapêutico. Para este fim, utilizaram-se dois camundongos saudáveis como indivíduos de teste sob influência do dispositivo de aquecimento localizado no hemisfério direito do cérebro.

A figura 3.18 exemplifica as imagens obtidas com a microscopia confocal de fluorescência para os indivíduos-teste citados. As imagens foram coletadas para diversas regiões da superfície do cérebro, e aqui apresentamos a imagem representativa do conjunto. Todas as imagens foram adquiridas em condições normotérmicas, mas após os indivíduos terem sido submetidos a um período de 15 minutos em situação de hipertermia. Nestes experimentos a administração da solução de DOX-LTSL ocorreu após 5 minutos de pré-aquecimento, pois o momento de injeção dos lipossomos relacionado à aplicação da hipertermia pode alterar a eficacia antitumoral (Poon \& Borys, 2009). Com a disponibilidade experimental de aquisição de dois canais fluorescentes, foi possível observar a emissão fluorescente da doxorrubicina (sinal vermelho) e a emissão fluorescente da carboxifluoresceina (sinal verde) para a mesma região do espaço em instantes de tempo muito próximos. 
Hem. Esquerdo

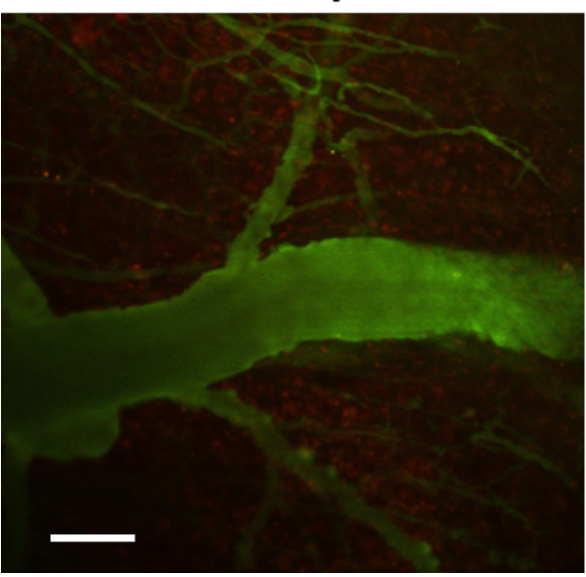

Hem. Direito

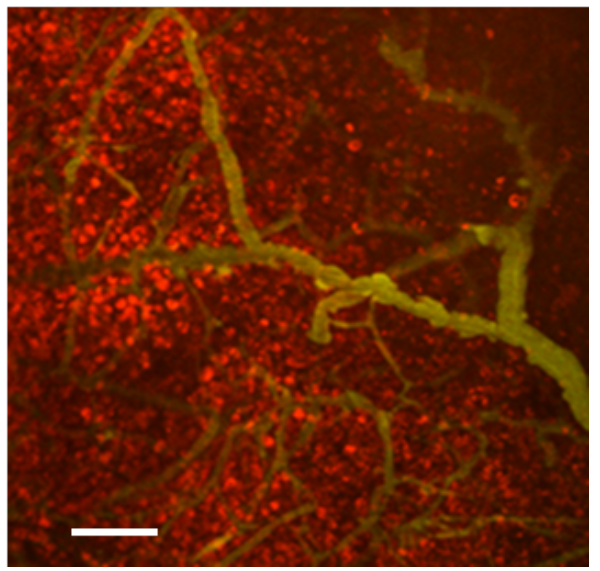

Figura 3.18: Imagens fluorescentes do pós-hipertermia do cérebro de um camundongo sadio. Comparação entre o hemisfério submetido ao aquecimento (Hem.Direito) e não aquecido (Hem.Esquerdo). Foram injetados $5 \mathrm{mg} / \mathrm{kg}$ de DOX-LTSL em veia na cauda dos camundongos. Barra de escala $=100 \mu \mathrm{m}$.

Avaliando as imagens da (Figura 3.18) é possível extrair algumas informações, mesmo que qualitativamente, importantes no processo terapêutico: o protocolo de administração sistêmica com dose de $5 \mathrm{mg} / \mathrm{kg}$, possibilitou a aquisição de imagens com alto grau de nitidez; as imagens demonstram que os lipossomos apresentam elevado grau de estabilidade no plasma sanguíneo, pois os mesmos persistem com níveis elevados de concentração mesmo após 20 min de sua injeção. Isto ocorre provavelmente, devido ao elevado tempo de circulação dos lipossomos, como consequência direta da presença dos fosfolipídios PEGlados na composição dos mesmos. A dose de DOX-LTSL de $5 \mathrm{mg} / \mathrm{kg}$ é considerada segura para administração sistêmica segundo estudos já publicados na literatura (Dreher, 2006; Manzoor et al., 2012).

O foco desta etapa era demonstrar a capacidade de controle e focalização da liberação/disponibilização de DOX. Observando as figuras em 3.18, que correspondem a imagens do hemisfério direito e esquerdo do cérebro no mesmo indivíduo, é evidente a diferença entre a disponibilidade de doxorrubicina livre entre as duas regiões. No hemisfério submetido à irradiação direta de micro-onda (hemisfério direito) é possível observar uma alta intensidade e grande área de ocupação do sinal fluorescente de DOX-livre. Já o hemisfério esquerdo (região isenta da irradiação direta) a emissão fluorescente associada 
à DOX é altamente suprimida e poucas são as regiões que apresentam DOX-livre.

Com intuito de fornecer uma análise mais quantitativa do efeito promovido pela hipertermia, executou-se o cálculo da intensidade média de doxorrubicina encontrada nas imagens obtidas. O resultado da avaliação quantitativa é apresentado na Figura 3.19.

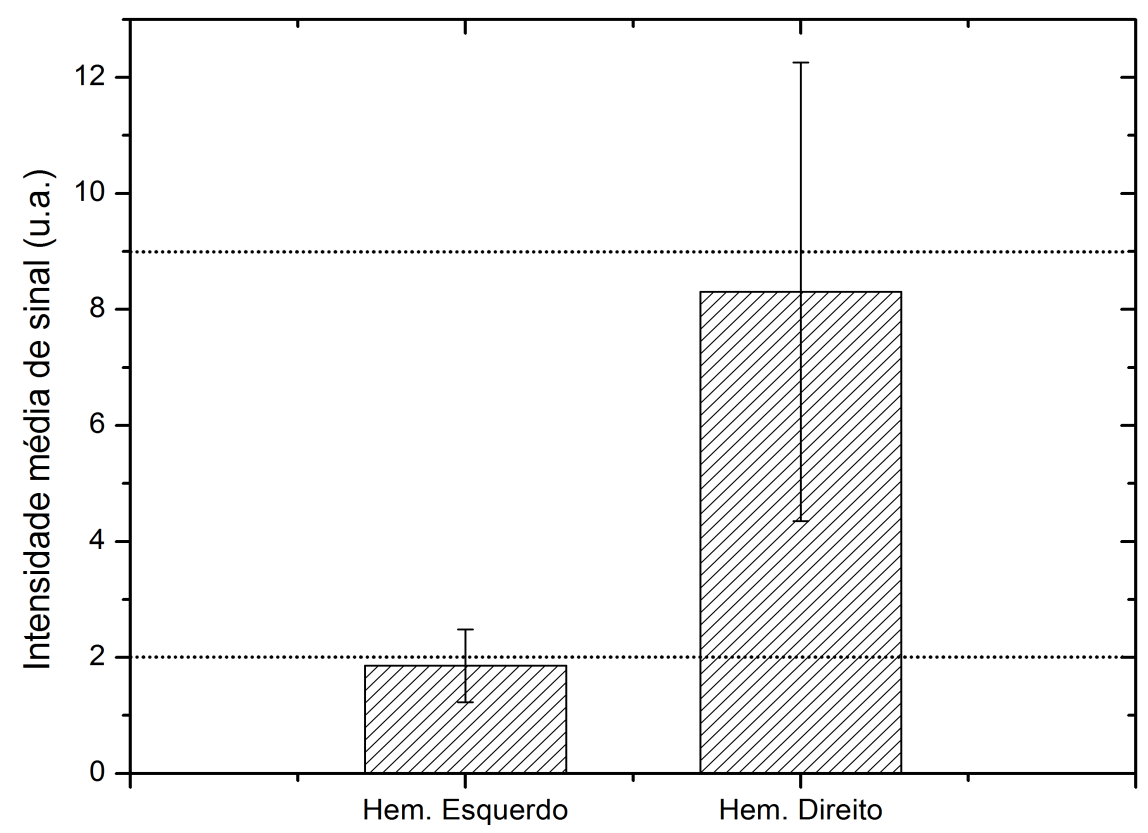

Figura 3.19: Análise quantitativa da intensidade média fluorescente da doxorrubicina livre na região do hemisfério direito e hemisfério esquerdo do cérebro de camundongos sadios após o procedimento de aquecimento de 15 minutos. O aplicador de micro-onda foi posicionado no hemisfério direito. Os dados representam a média de 6 imagens em locais distintos de dois camundongos e as barras de erros representam o desvio padrão do conjunto de imagens.

Através da análise quantitativa apresentada na Figura 3.19 fica demonstrada a capacidade de localização e liberação da droga em apenas um dos hemisférios. O resultado para estes primeiros testes implica que o volume de ativação induzido no cérebro dos camundongos não engloba o hemisfério esquerdo, pelo menos dentro do volume de observação da técnica de microscopia. Sendo assim, essa avaliação indica fortemente uma razoável focalização da região de atuação.

Os resultados desta etapa contribuíram de forma relevante ao projeto, pois através desta análise foi possível demonstrar conceitos fundamentais como: (1) O aumento da temperatura induzida pelo nosso aplicador de micro-onda é suficiente para a ativação do 
aumento de permeabilidade da bicamada lipídica e consequente liberação controlada da DOX encapsulada; (2) A área de tecido ativada por hipertermia está dentro do campo de visão do microscópio; (3) O dispositivo de aquecimento atua majoritariamente de forma localizada e possibilita o tratamento de apenas um dos hemisférios do cérebro; (4) e mais significativo, demonstramos os conceitos fundamentais de controle espacial de liberação da droga e o longo período de circulação dos lipossomos.

\subsubsection{Efeito de EPR nos tumores cerebrais}

Tumores sólidos em geral possuem características patofisiológicas únicas que distam em muito das observadas em tecidos ou órgãos sadios. Uma destas peculiaridades é o efeito de hiperpermeabildade da vasculatura tumoral, normalmente chamada de efeito de "Aumento da Permeabilidade e Retenção" (EPR). Estudos propõem que o arranjo vascular do microambiente tumoral compromete a estrutura e funcionalidade da BHE, mas não totalmente, e algum tipo de restrição seletiva ainda é preservada. Por isso, alguns autores procuram denominar a estrutura endotelial tumoral como barreira hematoencefálica tumoral (BHET) (Abbott et al., 2010).

Com intuito de visualizar esse efeito característico de aumento de permeabilidade dos vasos nas regiões tumorais, realizou-se um experimento teste em que se observou a distribuição e acúmulo de DOX-Livre no ambiente extravascular após sua administração intravenosa. Para isso, as imagens de microscopia confocal foram coletadas após 5 min da administração da droga. Na Figura 3.20 são apresentadas algumas das imagens coletadas no cérebro de dois camundongos (um sadio e um com tumor) submetidos a uma dose de 5 $\mathrm{mg} / \mathrm{kg}$ de Doxorrubicina sob condições normais de temperatura. Conjuntamente à injeção de DOX, para melhor visualizarmos os vasos sanguíneos, utilizou-se também uma solução do surfactante de Dextran-70 (70 KDa) marcado com a sonda fluorescente isotiocianato de fluoresceína (FITC).

Ao observar a Figura 3.20 é possível constatar que a estrutura vascular na região dos tumores possui maior grau de desorganização, como é postulado na literatura (Jain et al., 2007; Vajkoczy \& Menger, 2000). A presença de DOX nas regiões extravasculares são 

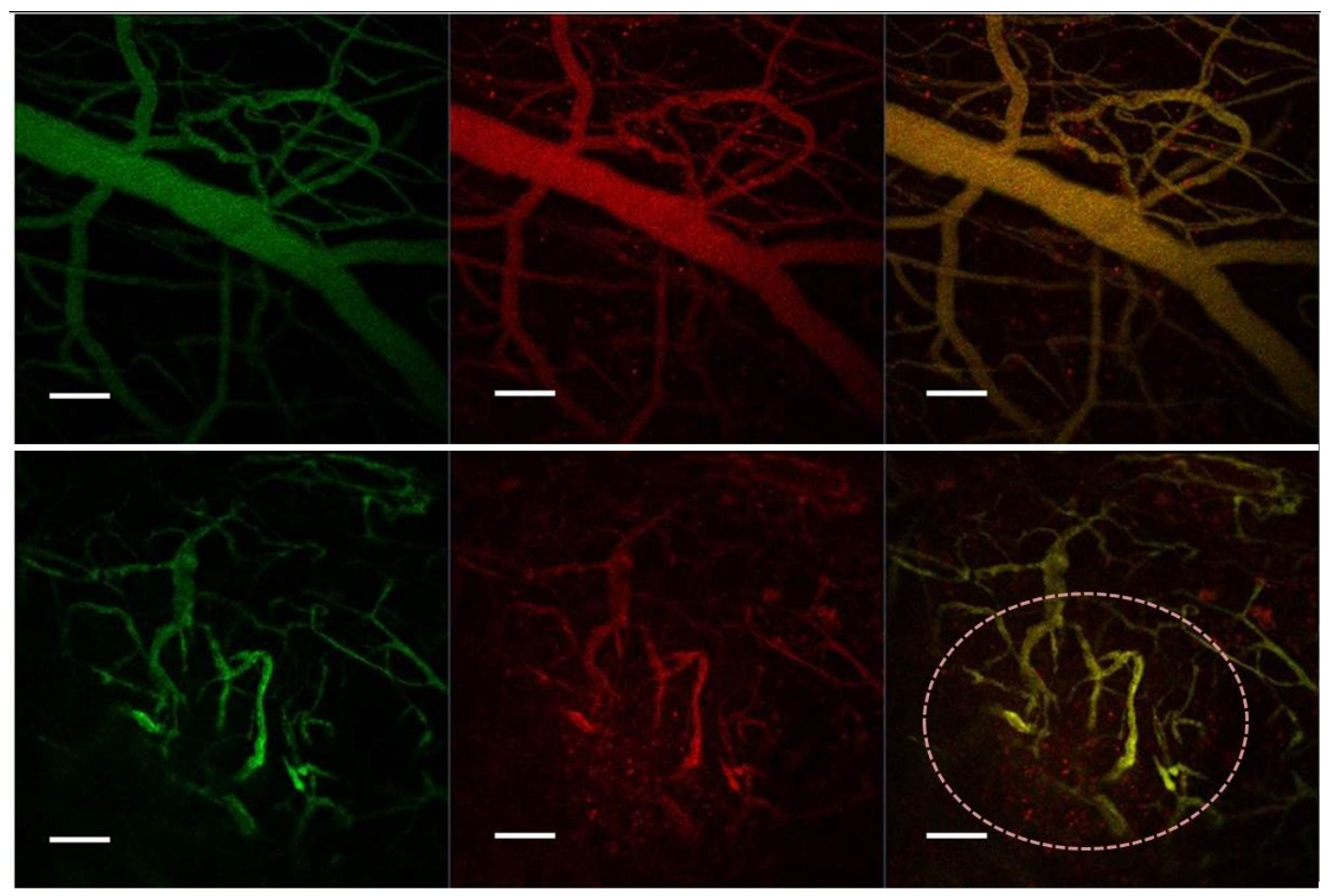

Figura 3.20: Imagens exemplificando o efeito de EPR. A linha superior apresenta as imagens para sinais fluorescentes do Dextran 70kDa marcado com FITC, DOX-livre e a combinação dos dois canais para um camundongo sadio. A linha inferior segue a mesma sequência de imagens com Dextran, DOX-livre e a combinação dos canais, mas para a região de tumor de um camundongo. Barra de escala $=100 \mu \mathrm{m}$.

mínimas em ambos os ambientes (sadio e tumoral), porém é possível detectar visualmente que a região tumoral apresenta um maior acúmulo de DOX no ambiente extravascular (área indicada por um círculo na figura 3.20). Justificando assim o modelo de EPR em tumores.

Sabe-se que a difusão ou convecção de partículas no interior do tecido tumoral varia com o tipo de tumor e microambiente. Diversos estudos na literatura buscaram avaliar a correlação do grau de permeabilidade transvascular com características físico-químicas das partículas, como tamanho e potencial de superfície, e propuseram que existem limites ao tamanho máximo da partícula capaz de transpor a parede dos vasos, esses limites máximos podem variar entre $200 \mathrm{~nm}$ a $1 \mu \mathrm{m}$ (Yuan et al., 1995), de acordo com o tipo de tumor. No entanto, o limite proposto no tamanho máximo das nanopartículas capazes de permear os vasos de tumores intracraniais é considerado significativamente menor. Acredita-se que mesmo que a vasculatura tumoral seja permeável a lipossomos de 100 
nm, o tamanho relativo do mesmo limita sua penetração a uma profundidade de uma ou duas camadas celulares a partir dos vasos sanguíneos.

Com este item se conclui que o modelo tumoral utilizado apresenta as devidas características básicas de permeabilidade e EPR, porém os efeitos sob a permeabilidade dos lipossomos deve ser investigado futuramente.

\subsubsection{Rompimento térmico da barreira hematoencefálica}

Como discutido no capítulo de introdução (Cap.1), a maioria das drogas hidrofílicas possuem baixa pernetrabilidade a BHE, e não são facilmente transportadas para o interior do parênquima cerebral. Atualmente, existem diversas metodologias reportadas na literatura que buscam promover a instabilidades da BHE e assim induzir um aumento no transporte de droga (Chen \& Liu, 2012; Patel et al., 2009).

Atualmente são poucos os relatos que estudaram os efeitos da elevação da temperatura moderada $\left(<43{ }^{\circ} \mathrm{C}\right)$ na funcionalidade da BHE (Kiyatkin \& Sharma, 2009; Lin et al., 1998; Sminia et al., 1994), muito devido a complexidade e alto custo dos experimentos. De modo geral, aceita-se que o aumento da temperatura promove aumento proporcional da permeabilidade da BHE. O objetivo desta etapa foi de avaliar se o aumento moderado da temperatura local é capaz de alterar a permeabilidade da DOX no parênquima cerebral. A Figura 3.21 apresenta imagens representativas para dois camundongos sadios submetidos ou não ao processo de hipertermia. Nestes indivíduos foi administradas a dose padrão de $5 \mathrm{mg} / \mathrm{ml}$ de DOX-LTSL.

As imagens A, B e C na figura 3.21 representam a emissão fluorescente da carboxifluoresceína, DOX e a composição dos sinais, respectivamente. Estas imagens foram obtidas para o animal que não foi submetido à hipertermia (temperatura basal). As imagens $\mathrm{D}, \mathrm{E}$ e $\mathrm{F}$ foram obtidas para o animal submetido à hipertermia $\left(\mathrm{Temp}=42{ }^{\circ} \mathrm{C}\right)$. A comparação das imagens de distribuição de DOX sob efeito da hipertermia e em condição controle demonstra claramente que a elevação da temperatura promove um aumento significativo da distribuição de DOX no ambiente intersticial, denotando assim um rompimento da BHE pela temperatura. Portanto, demonstramos que é possível induzir aumento de 

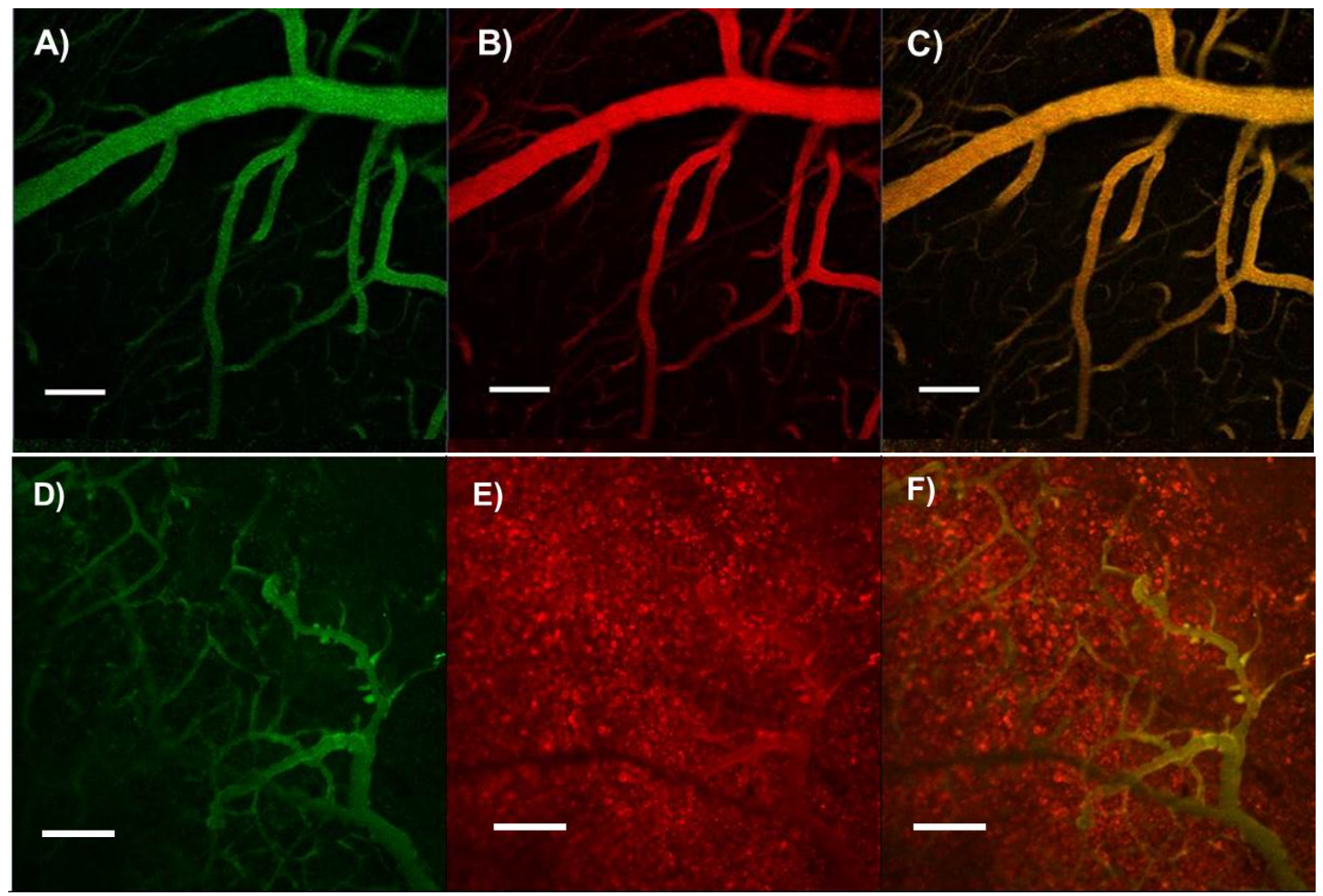

Figura 3.21: Efeito da elevação da temperatura na permeabilidade da doxorrubicina em camundongos sadios. As imagens na linha superior foram adquiridas para o hemisfério direito do cérebro após a injeção de $5 \mathrm{mg} / \mathrm{kg}$ de DOX-LTSL, porém na ausência de aquecimento. As imagens na linha inferior foram também adquiridas para o hemisfério direito do cérebro mas submetido ao aquecimento. A sequência dos sinais fluorescentes são: Lipossomos marcados com carboxifluorescína, DOX e a combinação dos dois canais. Barra de escala $=100 \mu \mathrm{m}$.

permeabilidade na BHE por aumento de temperatura moderado.

Este resultado possui implicações diretas na estratégia terapêutica da hipertermia. A primeira refere-se ao fato que o resultado contradiz o que foi postulado por Mcdannold (McDannold et al., 2004), que indicou como temperatura miníma para promover alguma alteração de permeabilidade na $\mathrm{BHE}$ o valor de $45^{\circ} \mathrm{C}$. Os resultados demonstram contundentemente que temperaturas próximas a $42{ }^{\circ} \mathrm{C}$ já são suficientes para produzir alterações significativas de permeabilidade. Adicionalmente, combinando esse resultado de microscopia com os resultados de estimativa de dose térmica, pode-se considerar que a probabilidade de indução de algum dano térmico é miníma, pois o protocolo terapêutico utilizado aplica doses térmicas muito inferiores as consideradas como limite de segurança, ou seja, novamente levanta-se a questão de que seja possível a indução de efeitos térmicos reversíveis na BHE. 


\subsubsection{Efeito da elevação da temperatura local na distribuição dos lipossomos}

As evidências de hiperpermeabildade da vasculatura de tumores sólidos fez com que também surgisse a hipótese de que lipossomos e outras partículas transportadoras de drogas possam extravasar passivamente as paredes de vasos sanguíneos, e acumular-se em maior quantidade em regiões tumorais. Porém, atualmente tem surgido novas evidências (Chen et al., 2008; Dreher et al., 2006b; Manzoor et al., 2012) que sugerem um efeito inverso, ou seja, de uma permeabilidade limitada, mesmo para partículas transportadoras de $100 \mathrm{~nm}$. Essa condição de permeabilidade possui influência direta em qualquer estratégia terapêutica. Neste item buscou-se investigar se os lipossomos LTSL extravasam os vasos na região dos tumores cerebrais. Na figura 3.22 apresentamos imagens dos LTSL nas regiões dos tumores em condições normotérmicas.
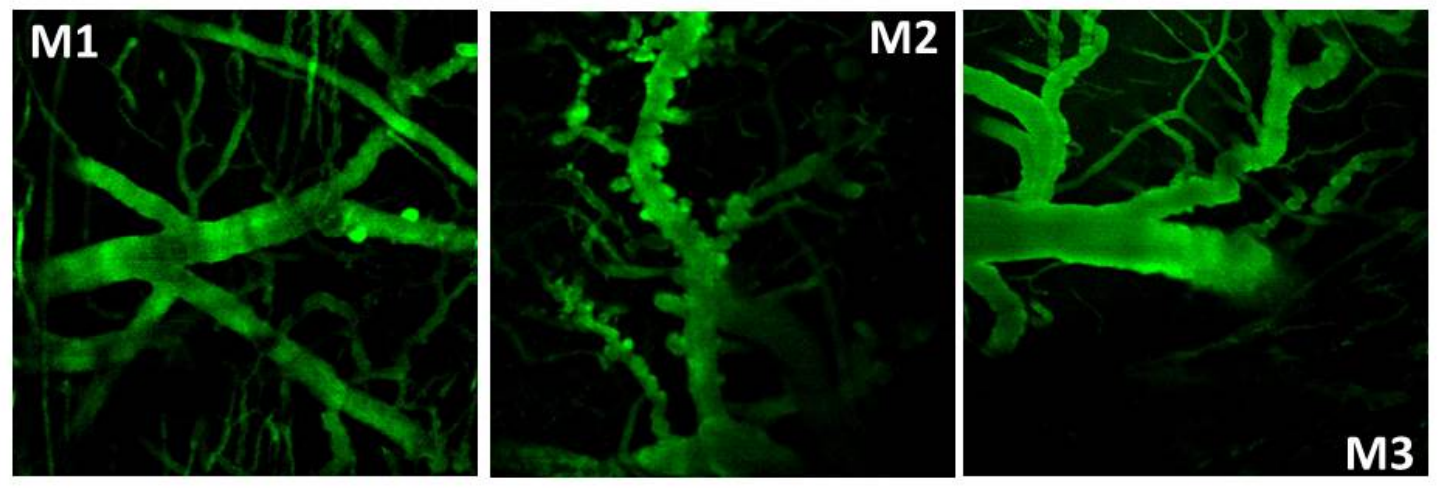

Figura 3.22: Imagens fluorescentes dos lipossomos marcados com carboxifluoresceína na região tumoral de três animais distintos (M1, M2, M3) em condições normotérmicas.

Para condições normais de temperatura (temperatura basal), constata-se que mesmo em regiões tumorais, onde a permeabilidade das paredes dos vasos já é aumentada, os lipossomos não foram capazes de extravasar para o ambiente extravascular de forma expressiva, indicando que partículas de tamanho de 100 nm já são muito grandes para sofrerem qualquer impacto do efeito de EPR.

Diversos autores (Gaber et al., 1996; Kong et al., 2000b, 2001) propuseram que a elevação da temperatura local de tumores sólidos deve aumentar o acúmulo de partículas na região de aquecimento. Com intuito de contribuir a essa discussão, apresenta-se 
imagens dos lipossomos marcados (figura 3.23) para regiões tumorais e sob influência de condições de hipertermia.
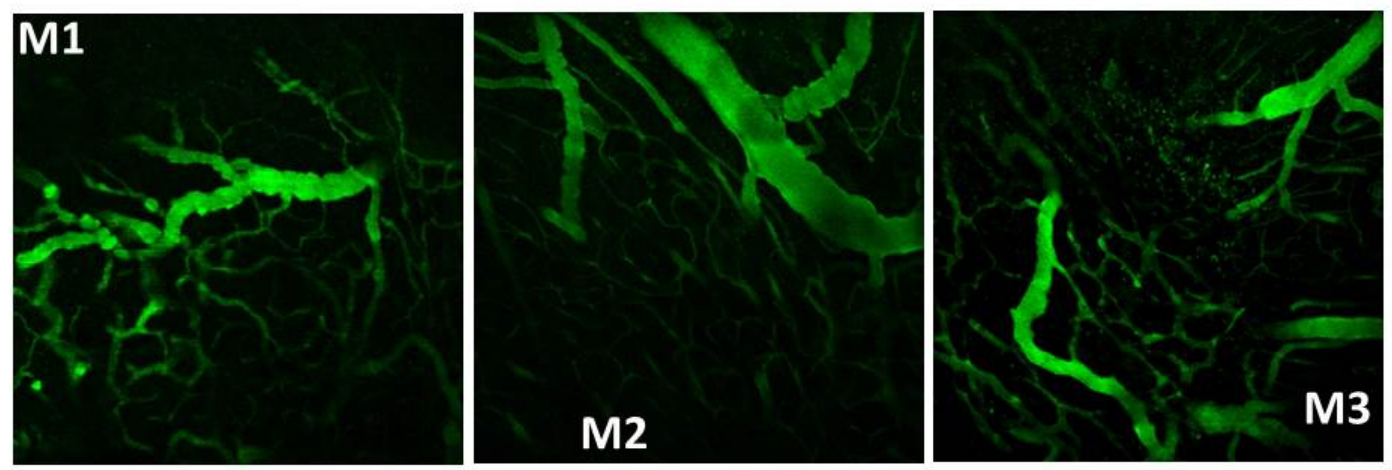

Figura 3.23: Imagens fluorescentes dos lipossomos marcados com carboxifluoresceína na região tumoral de três animais distintos (M1, M2, M3) submetidos a aplicação da hipertermia.

As imagens da Figura 3.23 não demonstram a presença de lipossomos na região extravascular para os três animais observados. Este resultado implica que mesmo sob condições de hipertermia durante aproximadamente 20 minutos os lipossomos permanecem na região intravascular. Com isso é possível propor que o efeito de liberação termoinduzida da DOX ocorre na região intravascular e somente depois de sua liberação é que a mesma extravasa para regiões do interior do parênquima cerebral. Esse resultado é muito importante para a estratégia terapêutica, principalmente quando pretende-se comparar efeitos entre diferentes transportadores.

\subsubsection{Efeito da elevação da temperatura na distribuição de DOX}

Como já discutido na figura 3.20, o acúmulo de DOX em regiões tumorais, para condições normotérmicas, possui baixa eficiência. Em muitos estudos, esse baixo acúmulo é apontado como o responsável pela baixa eficiência terapêutica. O uso de DOX-LTSL combinado com aquecimento local possui potencial para reverter essa condição. Com intuito de avaliar essas propriedades, executamos experimentos de hipertermia combinado com DOX-LTSL para três camundongos modelo. Nosso objetivo era de demonstrar que a elevação moderada da temperatura induz um efeito positivo na permeabilidade da DOX ao tecido tumoral. 
Analisando as imagens apresentadas na Figura 3.24 constata-se que existe um grande diferencial no uso da hipertermia combinado com DOX-LTSL. Qualitativamente, dois efeitos positivos podem ser destacados nestes resultados; o primeiro refere-se ao aumento do sequestro de DOX pelas células tumorais (que nas imagens podem ser constatados pelo grande número de núcleos vermelhos) e o segundo refere-se ao aumento da penetração da droga no interior do tumor, que pode chegar a mais de $30 \mu \mathrm{m}$ de distância dos vasos. A comparação destas imagens com as de controle demonstram ganhos significativos para a doxorrubicina que é transportada por lipossomos termosensíveis. Com intuito de obter uma análise quantitativa dos resultados na Figura 3.24, buscou-se determinar a intensidade média de fluorescência da região extravascular das imagens obtidas nas diferentes situações de injeção e hipertermia. O resultado desta análise é apresentado na Figura 3.25.

Os resultados quantitativo da Figura 3.25 sustentam os resultados apresentados na Figura 3.24. Como observado, a formulação DOX-LTSL + HT foi a estratégia terapêutica com a maior concentração de DOX e com um aumento relativo de 5 vezes à abordagem DOX-LTSL sem uso de aquecimento. A diferença na formulação DOX-livre, sem ou com aquecimento, não foi significativa. Entre DOX-livre e DOX-LSTL foi constatado aumento de apenas 1 vez. Como diversos resultados apresentados na literatura (Chen et al., 2008; Landon et al., 2011; Needham et al., 2000), os dados deste capítulo corroboram as ideias já aceitas no uso dos lipossomos termosensíveis. A vantagem desta abordagem está em simultaneamente promover a ruptura da BHE e estimular a liberação de droga. A estratégia térmica apresenta maior potencial terapêutico que estratégias não-térmicas. Baseado neste resultado pode-se considerar que a aplicação da termoterapia no tratamento de tumores no cérebro tem um grande potencial. 


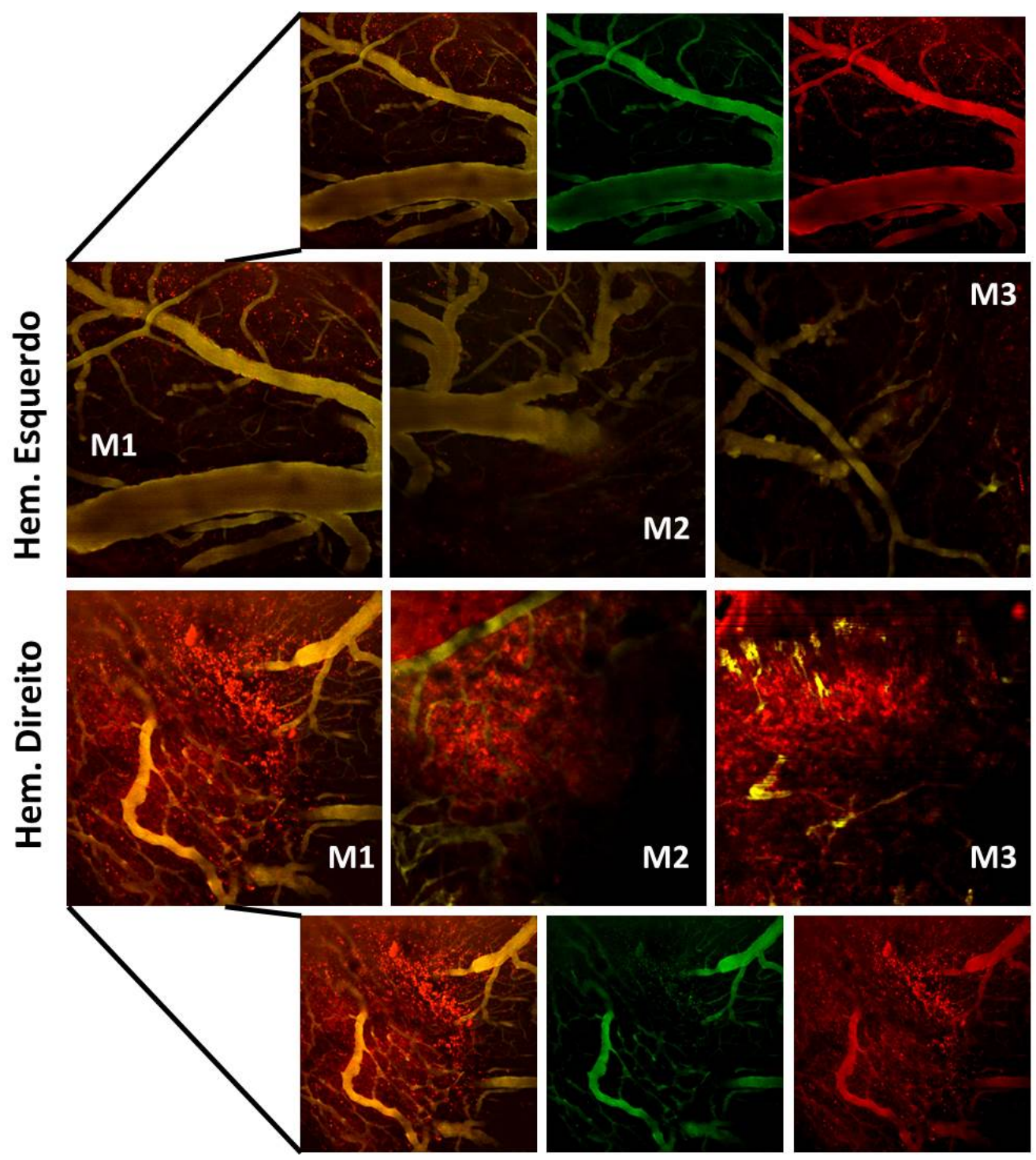

Figura 3.24: Imagens fluorescentes obtidas para o hemisfério direito (região do tumor) e esquerdo de três camundongos (M1, M2, M3), nos quais foram injetados $5 \mathrm{mg} / \mathrm{kg}$ de DOX-LTSL e submetidos a 15 minutos de hipertermia. As imagens são apresentadas como a composição dos dois canais de aquisição. Um canal é associado ao sinal proveniente da Dox e o outro canal associado ao sinal proveniente da carboxifluoresceína. As linhas de imagem superior e inferior exemplificam a decomposição das imagens do camundongo M1 nos dois canais de aquisição. 


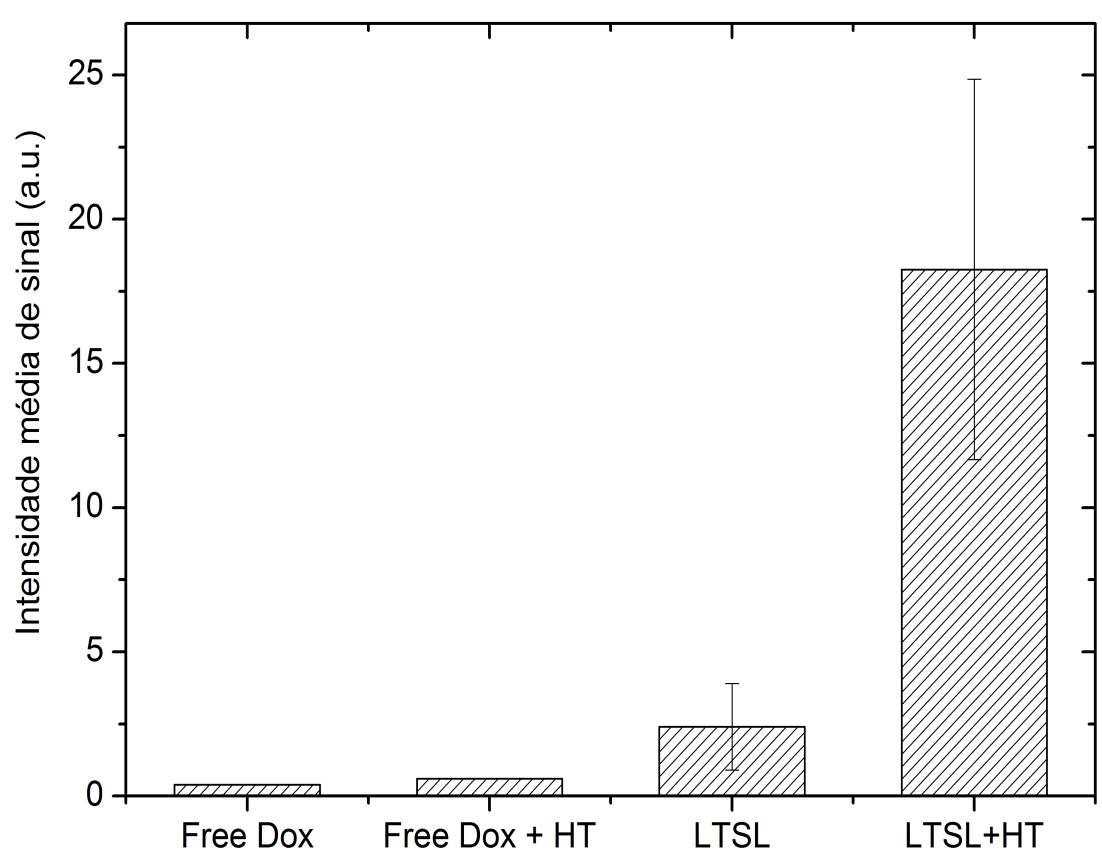

Figura 3.25: Media da intensidade fluorescente de DOX no ambiente intersticial tumoral para camundongos submetidos a injeções de DOX-livre (Free Dox), DOX-livre submetido à hipertermia $($ Free DOX $+\mathrm{HT})$, fromulação DOX-LTSL, e formulação DOX-LTSL subetimodo à hipertermia (DOX-LTSL $+\mathrm{HT}$ ), na dose de $5 \mathrm{mg} / \mathrm{kg}$. As intensidades médias são apresentadas como resultado da média de três experimentos com os respectivos desvios padrão.

\subsection{Conclusões}

Até o presente momento, não existia um método de aquecimento de baixo-custo que permitisse o estudo não-invasivo da hipertermia em camundongos com janelas craniais. Neste contexto, criou-se com sucesso um dispositivo de micro-onda específico para esta tarefa. De posse desse dispositivo, foi possível realizar os primeiros ensaios de aquecimento in vivo. Os ensaios iniciais por sua vez demonstraram alguns aspectos importantes do gerenciamento terapêutico da formulação DOX-LTSL em tumores cerebrais. Neste capítulo dois resultados se destacam quanto à relevância terapêutica: o primeiro referese a constatação de que temperaturas moderadas promovem alterações significativas na permeabilidade da BHE, mesmo nos tecidos sadios. O segundo refere-se ao fato de que os lipossomos termosensíveis permanecem no interior dos vasos, mesmo sob efeito da hipertermia. Apesar de contestar algumas propostas existentes na literatura (McDannold et al., 2004), de modo geral, os resultados apresentados aqui corroboram estudos anteriores 
(Kiyatkin \& Sharma, 2009; Yarmolenko et al., 2011).

Por fim, estes resultados demonstram que existe um grande benefício para a disponibilização de DOX a tumores cerebrais, não só com relação ao acúmulo total de droga, mas também com o grau de penetração e exposição aos quais as células foram submetidas. Devido os recentes avanços na instrumentação, e nos métodos de aplicação da hipertermia na região do cérebro, existe grande expectativa de que no futuro próximo possam surgir aplicações clínicas viáveis desta metodologia. 


\section{Capítulo 4}

\section{Análise in vivo da viabilidade de uso da magneto-hipertermia para aquecimento da bexiga}

Este capítulo descreve a investigação pré-clinica da viabilidade da termoterapia para tratar câncer de bexiga com a técnica de magneto-hipertermia. Foram realizados estudos dosimétricos em ratos para determinar as condições ideais de concentração e volume de fluido magnético, assim como, determinar a melhor amplitude de campo magnético. Os dados demonstram que o sistema de magneto-hipertermia produz calor localizado no lúmen da bexiga do rato com efetivo controle da temperatura e mínimo aquecimento do entorno. 


\subsection{Introdução}

O uso eficiente de nanopartículas magnéticas em processos de geração de calor tem sido explorado em diversas aplicações (Hilger, 2013; Kumar \& Mohammad, 2011). Um dos primeiros relatos abordando este tema direcionado a aplicações biológicas foi publicado por Gilchrist (Gilchrist et al., 1957). Contudo, desde a publicação pioneira de Gilchrist, vários estudos foram reportados e uma vasta literatura foi consolidada a respeito do tema. Atualmente, o conceito e as propriedades de aquecimento induzidos por acoplamento do campo magnético alternado com nanopartículas magnéticas já foram amplamente explorados na comunidade científica (Dennis \& Ivkov, 2013; Fortin et al., 2008; Hergt et al., 2006; Laurent et al., 2011). Neste projeto decidiu-se por estudar as limitações relacionadas à efetiva aplicação in vivo. O objetivo foi verificar a viabilidade no uso da abordagem de material magnético no aquecimento localizado de bexigas. Os resultados apresentados nesta tese contribuiriam para a definição do protocolo terapêutico de animais de grande porte.

Os dados e análises apresentados neste item foram sintetizados na publicação: Oliveira, T. R. e col.(2013) International Journal of Hyperthermia, (29) 1-10. "Magnetic fluid hyperthermia for bladder cancer: A preclinical dosimetry study". Este é um artigo pioneiro publicado na literatura que aborda o uso da magneto-hipertermia para o aquecimento da bexiga.

Como abordado no capítulo de introdução (Cap. 1), atualmente existe uma alta taxa de recidiva de tumores músculo-invasivos de bexiga, e isso tem motivado a busca por diversas terapias alternativas, como a termoquimioterapia (Colombo et al., 2003a; Lammers et al., 2011). A hipertermia, apesar dos diversos resultados positivos, padece de limitações que inviabilizam sua completa implementação como modalidade terapêutica. Um dos grandes desafios da técnica está em estabelecer meios viáveis de aquecimento a órgãos localizados em regiões de difícil acesso, mais profundas, sem que promova o superaquecimento de regiões vizinhas.

No caso do tratamento do câncer de bexiga, algumas tentativas de uso da hipertermia tem sido reportadas na literatura (Inman et al., 2014; Juang et al., 2014; Owusu et al., 
2013). No entanto, a inabilidade em monitorar e controlar a dissipação de calor no interior da bexiga tem atrasado significativamente o uso amplo desta técnica. Hoje em dia, a maioria dos estudos clínicos abordando a hipertermia no tratamento do câncer de bexiga tem utilizado, como método de aquecimento, um dispositivo composto de uma pequena antena de micro-onda (Synergo SB-TS System, Amstelveen, the Netherlands) inserida na bexiga (Figura 4.1) (Colombo et al., 2003b; Van der Heijden et al., 2004). Apesar dos estudos com o dispositivo Synergo ter apresentado resultados promissores, o baixo alcance de deposição de energia, e controle limitado do posicionamento da antena no interior do lúmen, têm provocado diversos efeitos colaterais, como dores pélvicas e lesões na parede da bexiga (Gofrit et al., 2004; Jacobsen \& Klemetsen, 2007; Moskovitz et al., 2012).
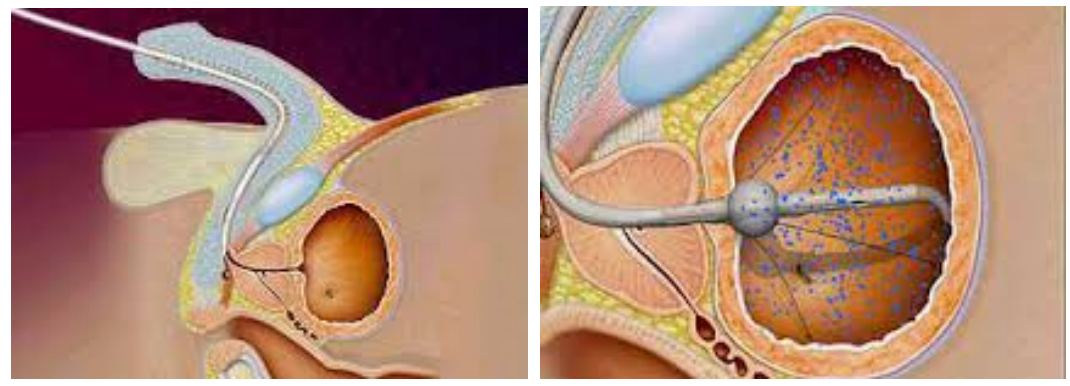

Figura 4.1: Ilustração do dispositivo Synergo, que introduz uma pequena antena de microondas no interior da bexiga para produzir calor em suas paredes internas (imagens retirada de: http://www.synergo-medical.com)

Diante deste cenário, novas metodologias, como os eletrodos capacitivos de radiofrequência (Hashimoto et al., 1991; Kakehi et al., 1990) ou RF phased array applicators (Juang et al., 2014; Yuan et al., 2012c), buscam superar o tradicional Synergo em eficiência de aquecimento e redução de incidência de efeitos colaterais. Assim, no contexto das novas metodologias, se propõe aqui a Magneto-hipertermia (MHT) como uma potencial opção ao procedimento padrão. A Magneto-hipertermia pode avançar significativamente sobre várias das limitações atualmente encontradas.

O modo de ação da MHT consiste em obter a requerida elevação de temperatura por meio da administração de um fluido magnético ao dado tecido alvo e na subsequente submissão desse alvo a um campo magnético alternado. O acoplamento magnético entre o fluido e campo alternado transfere energia eletromagnética contida no campo para as nanopartículas magnéticas contidas no fluido, que por sua vez irão dissipar localmente 
parte dessa energia na forma de calor. Este método pode trazer uma maior eficácia devido à dissipação de energia ocorrer somente em localidades onde existam campo magnético e nanopartícula simultaneamente, especificando assim sua área de atuação. O fluido a ser utilizado neste tipo de aplicação deve possuir características magnéticas especiais além de biocompatibilidade, pH neutro e salinidade fisiológica. Devido às características da interação magnética, a eficiência da produção de calor deste método depende fortemente das propriedades do campo e da estrutura e magnetismo das nanopartículas.

A aplicação da MHT para o tratamento do câncer de bexiga possui várias potenciais vantagens sobre o dispositivo Synergo e mesmo sobre outras abordagens baseadas em micro-onda ou RF. O aquecimento induzido por nanopartículas é sempre localizado e restrito a regiões que contenham material magnético e que estejam sujeitos à alta intensidade de campo. O fluido magnético é facilmente acumulado no interior da bexiga por uso de uma injeção direta da nanopartícula. A geração do campo magnético pode ser obtida utilizando-se uma das diversas configurações de bobina disponíveis (Stauffer et al., 1984b), que com grande confiabilidade geram campos magnéticos relativamente uniformes no interior do corpo do indivíduo e com baixo efeito de aquecimento indireto aos tecidos (Atkinson et al., 1984; Stauffer et al., 1984a, 1994). Por último, a fácil cateterização do sistema urinário facilita o controle da administração das partículas magnéticas no volume interno da bexiga, facilitando a modulação da concentração e volume injetados.

A estrutura do lúmen da bexiga permite que o fluido magnético permaneça em contato com o tecido tumoral sem muita interferência dos tecidos sadios. O urotélio, que consiste em uma camada espessa de células epiteliais com junções apertadas cobertas por uma camada de glicosaminoglicanas (Tyagi et al., 2006) irá limitar a absorção de moléculas ou particulados no sistema circulatório (GuhaSarkar \& Banerjee, 2010), o que também corresponde a uma vantagem deste sistema. Logo, a magneto-hipertermia apresenta-se com grande potencial para sobrepor as barreiras de homogenização e distribuição de calor no interior da bexiga, evitando o aquecimento não específico nos tecidos do entorno.

Na estratégia terapêutica da hipertermia, um dos principais critérios de otimização é a busca pela mínima dissipação de energia capaz de produzir a elevação de temperatura 
desejada. Na técnica de magneto-hipertermia, a deposição local de energia depende de diversos fatores locais, e são esses fatores de minimização que nortearam o estudo aqui apresentado.

\subsubsection{O magnetismo de nanopartículas}

(Texto baseado em: Andrä \& Nowak (2007); Gubin (2009))

As nanopartículas magnéticas (NPM) têm sido utilizadas em numerosas aplicações em biomedicina, como separação magnética, entrega de droga, ressonância magnética nuclear e hipertermia (Kumar, 2009; Pankhurst et al., 2003). No caso da hipertermia, o acoplamento magnético entre o fluido e o campo magnético determina a eficiência da terapia. Assim, o conhecimento das propriedades magnéticas das nanopartículas dispersas em um fluido é fundamental.

O magnetismo em geral surge das interações entre os movimentos orbital e de spin dos elétrons do átomo, produzindo um momento de dipolo magnético atômico. Existem várias classes de materiais magnéticos, e a forma convencional de classificá-los é a partir das características de respostas quando submetidos a um campo magnético externo em função da temperatura. Dentre as diferentes classes tem-se os materiais paramagnéticos, constituídos por átomos ou moléculas que possuem momento magnético permanente, consequência de elétrons desemparelhados. Quando submetidos a um campo magnético externo, o material paramagnético responde com alinhamento de seus dipolos em média paralelo ao campo.

Materiais paramagnéticos são chamados também de "não-magnéticos", pois na ausência de campo externo não possuem momento de dipolo magnético resultante. Mesmo após um processo de magnetização, o material não retém a magnetização quando o campo externo é retirado. Materiais paramagnéticos possuem seu comportamento também fortemente dependente da temperatura, que em baixos níveis de magnetização, seguem a lei de Curie (Buschow \& De Boer, 2003), pelo menos aproximadamente.

Os dois materiais de amplo uso em MHT, o óxido de ferro, magnetita $\left(\mathrm{Fe}_{3} \mathrm{O}_{4}\right)$ e maghemita $\left(\gamma \mathrm{Fe}_{2} \mathrm{O}_{3}\right)$, são classificados como ferrimagnéticos, isto é, apresentam uma 
magnetização intrínseca mesmo sem a presença de campo, devido ao alinhamento espontâneo dos momentos de dipolo magnético atômico. Todo processo de magnetização de um material gera domínios em sua estrutura, cada domínio possui uma orientação coletiva paralela dos momentos de dipolo atômico, mas os diferentes domínios possuem diferentes orientações do seu coletivo quando comparados entre si. A formação de domínios ocorre para reduzir a energia total do material. No entanto, quando o tamanho do material diminui, reduz-se também o número de domínios, até um determinado valor crítico, em que o material converte-se em uma partícula de domínio-único e novas propriedades magnéticas são observadas no material.

Pequenas partículas magnéticas exibem diversos fenômenos únicos como: superparamagnetismo (O’handley, 2000), tunelamento quântico da magnetização (Guéron et al., 1999) e aumento da coercividade magnética (Liou et al., 1999). Estas características magnéticas são fortemente influenciadas pelo chamado efeito de tamanho finito e efeito de superfície. A relevância destes efeitos aumenta conforme diminui o tamanho da partícula. O efeito de tamanho finito é resultado do confinamento quântico dos elétrons. Já os efeitos de superfície podem estar relacionados à quebra de simetria do cristal na interface da partícula, ou podem também estar relacionado com a ligação química do material magnético ("core") com superfícies de características distintas ("shell").

Com base na consideração energética, em 1930, Frenkel e Dorfman (Frenkel \& Dorfman, 1930) mostraram que partículas suficientemente pequenas constituem um material de domínio-único. Para muitos materiais, o limite dimensional entre multi-domínios e domínio-único está na ordem do nanômetro $(2 \mathrm{a} 800 \mathrm{~nm})$. No caso da magnetita $\left(\mathrm{Fe}_{3} \mathrm{O}_{4}\right)$ este limite de transição se aproxima dos $50 \mathrm{~nm}$. Como tipicamente as partículas utilizadas em MHT possuem o núcleo de ferro menor que $20 \mathrm{~nm}$, estas são partículas de domínio-único.

Embora partículas nanométricas de alto grau de magnetização possuam uma estrutura magnética complexa, em geral um conjunto de partículas de domínio-único nãointeragentes comportam-se como material paramagnético clássico, diferindo apenas no fato de possuírem elevado momento magnético efetivo por átomo. Ao manter o conjunto 
sob temperatura "T" e um campo aplicado "H", assumindo que os mesmos estejam em equilibro termodinâmico, as orientações dos momentos de dipolo magnético $\mu$, irão seguir uma distribuição de Boltzmann com respeito ao campo "H". Como esse sistema apresenta características clássicas do paramagnetismo, mas possui intensidade de $\mu$ muito maior que qualquer momento magnético atômico típico do material paramagnético, definiu-se o comportamento dessa magnetização diferenciada como efeito de "superparamagnetismo".

Nanofluidos são sistemas que contém nanopartículas homogeneamente dispersas em fluido, tal que a agitação Browniana supera os efeitos de deposição por gravidade. Portanto, um nanofluido estável é teoricamente possível desde que suas partículas sejam suficientemente pequenas (normalmente $<100 \mathrm{~nm}$ ). Manter a estabilidade da solução, entretanto, pode ser um desafio, pois partículas tendem a interagir formando assim agregados maiores. Normalmente, nanopartículas de nanofluidos são recobertas com surfactantes para buscar inibir a auto-agregação, e aumentar a estabilidade no meio.

Devido à peculiaridade de suas propriedades magnéticas, excelente biocompatibilidade e seu amplo potencial biomédico, o ferrofluido, constituído por nanopartículas superparamagnética de óxido de ferro (SPIONs), tem recebido grande atenção nos mais diferentes campos da ciência (Mahmoudi et al., 2011; Neuberger et al., 2005). No caso da magneto-hipertermia, a maioria das investigações foca no uso dos óxidos de ferro magnetita $\left(\mathrm{Fe}_{3} \mathrm{O}_{4}\right)$ e maghemita $\left(\gamma \mathrm{Fe}_{2} \mathrm{O}_{3}\right)$, pois o corpo humano apresenta alto grau de tolerância para estes compostos (Kumar \& Mohammad, 2011; Silva et al., 2011). Na natureza é possível encontrar diversos tipos de óxido de ferro, e na maioria dos compostos, o ferro existe no seu estado trivalente. Hematita $\left(\alpha \mathrm{Fe}_{2} \mathrm{O}_{3}\right)$, magnetita $\left(\mathrm{Fe}_{3} \mathrm{O}_{4}\right)$ e maghemita $\left(\gamma \mathrm{Fe}_{2} \mathrm{O}_{3}\right)$ representam os minerais a base de ferro com maior abundância. As diferenças entre os vários óxidos surgem dos diferentes arranjos espaciais das unidades de $\mathrm{FeO}_{6}$ e $\mathrm{FeO}_{4}$.

\subsubsection{Geração de calor por nanopartículas magnéticas}

O aquecimento de materiais magnéticos pela presença de um campo magnético alternado externo pode ser relacionado a diferentes mecanismos físicos. O principal processo 
de perda magnética é associado com os efeitos de histerese em situações de reversão da magnetização. No entanto, à medida que se reduz o tamanho das partículas, a barreira de energia para a magnetização também decresce e pode atingir valores similares aos da energia térmica. As propriedades magnéticas de partículas no intervalo de tamanho entre $100 \mathrm{~nm}$ e $1 \mathrm{~nm}$ são muito estudados, pois justamente neste intervalo ocorre a transição entre partículas de multi-domínios para partículas de domínio-único.

Em um sistema de partículas magnéticas a energia absorvida do campo magnético alternado é transformada/dissipada em calor por meio de pelo menos um dos seguintes mecanismos: processos de histerese, inversão da magnetização interna ou rotação da mesma quando em suspensão. A proporção de energia dissipada em cada um dos processos é extremamente dependente das propriedades do meio e do campo. Em geral, a tendência é que com o aumento da amplitude de campo e/ou a frequência tem-se um aumento da dissipação de calor. Contudo, na prática fatores técnicos e econômicos restringem o aumento ilimitado das características do campo (Hergt \& Dutz, 2007).

A correspondência entre histerese e dissipação de energia magnética na forma de calor naturalmente fornece a ideia que a histerese seja um processo fora de fase e processos irreversíveis devam ocorrer. As perdas de energia durante o processo de histerese estão associadas aos efeitos de remanência e coercividade que ocorrem durante um ciclo fechado de magnetização. Para um ciclo fechado, espera-se que a variação de energia interna do sistema seja zero, logo a área sob ciclo descrito pela magnetização "M" do material fornece o trabalho dissipado $\left(W_{\text {hys }}\right)$ na forma de calor por ciclo.

$$
W_{\text {hys }}=\mu_{0} \oint M_{H} d H
$$

em que $\mu_{0}$ é permeabilidade do vácuo, " $M_{H}$ " é a componente da magnetização paralela ao campo magnético " $\mathrm{H}$ ".

Rosensweig em (Rosensweig, 2002), estudou o mecanismo de geração de calor por fluidos magnéticos devido à presença de um campo magnético alternado, e desenvolveu uma relação entre dissipação e relaxação rotacional de partículas de domínio-único dispersas em meio líquido. Rosensweig considerou que caso seja possível assumir o campo magnético aplicado como um campo harmônico, e a amplitude do mesmo seja pequena o 
suficiente para que junto com a condição de frequências baixas a aproximação linear possa ser utilizada, é possível demonstrar que a potência dissipada por unidade de volume do material magnético pode ser descrita por:

$$
P=\mu_{0} \pi \chi " f H^{2}
$$

considerando $\chi^{\prime \prime}$ a componente imaginária da susceptibilidade magnética e $f$ a frequência do campo magnético aplicado. A Eq.4.2 é amplamente aceita como modelo para a potência de dissipação de ferrofluidos.

O aquecimento de partículas magnéticas submetidas a um campo magnético alternado pode ser entendida através das diversas barreiras de energia. Usualmente, com o decréscimo do tamanho das partículas, as barreiras de energia para a magnetização reversa tonam-se relativamente menores, e permitem assim que as flutuações térmicas promovam o fenômenos de relaxação. Em processos de relaxação da magnetização é natural assumir que o sistema possa ser descrito por uma equação simples de Debye para um campo oscilante, e que $\tau$ seja o tempo de relaxação característico da magnetização. Um típico ferrofluido, de partículas com distribuição de tamanho centrada em $20 \mathrm{~nm}$, em geral apresenta dois efeitos de relaxação predominantes, a relaxação Browniana e de Neel. A relaxação Browniana ocorre como consequência do movimento rotacional das partículas no meio líquido, e a de Neel ocorre quando a partícula permanece estática mas o momento magnético rotaciona no interior do cristal (Figura 4.2).

As constante de tempo Browniana e de Neel são expressas por,

$$
\tau_{B}=\frac{3 \eta V_{H}}{K_{B} T} \quad, \quad \tau_{N}=\tau_{0} e^{\left(\frac{K V}{K_{B} T}\right)}
$$

em que " $V_{H}$ " representa o volume hidrodinâmico da partícula, $\eta$ a viscosidade do meio e a energia anisotrópica da partícula é dada por "KV" (V volume da partícula).

Os processos de relaxação Browniana e de Neel ocorrem ao mesmo tempo, por isso o tempo de relaxação efetivo é dado por,

$$
\frac{1}{\tau}=\frac{1}{\tau_{B}}+\frac{1}{\tau_{N}}
$$

e este termo terá pesos diferentes conforme as propriedades das partículas. A partir da interpretação da componente imaginária da susceptibilidade magnética $\chi^{\prime \prime}$, a expressão geral 


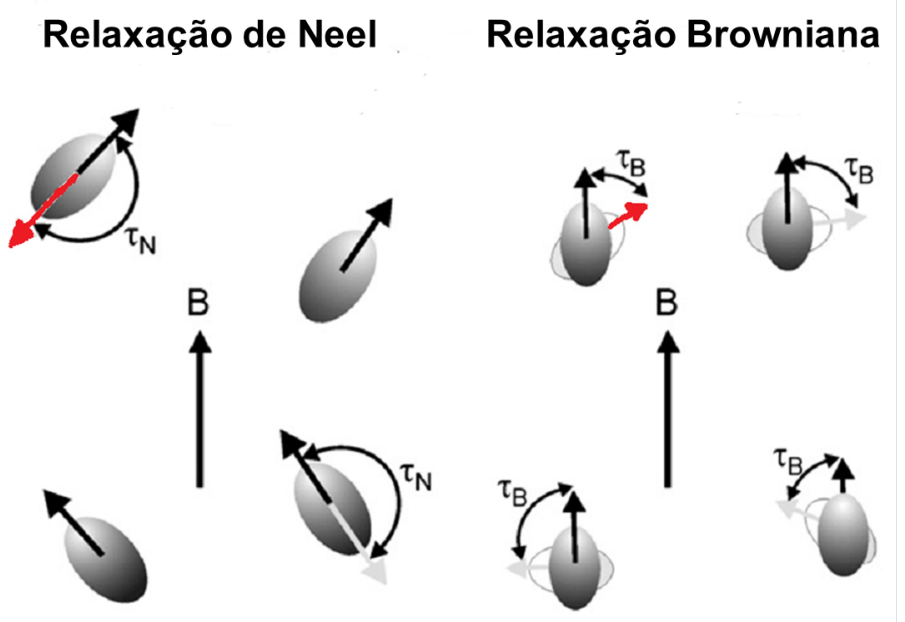

Figura 4.2: Ilustração dos dois mecanismos de relaxação magnética do fluido magnético sob influência do campo magnético. Os vetores vermelhos indicam a orientação do momento de dipolo magnético após o processo de relaxação (Imagem adaptada de (Laurent et al., 2011)).

para a potência dissipada (Eq.4.2), considerando a contribuição dos efeitos de relaxação, será descrita por:

$$
P=\pi \mu_{0} \pi \chi_{0} H^{2} f \frac{2 \pi f \tau}{1+(2 \pi f \tau)^{2}}
$$

Em meio líquido, o campo magnético alternado pode promover oscilações ou rotações das partículas. No caso em que o campo magnético não exceda certos valores críticos, a magnetização das partículas mantém-se essencialmente inalterada, e as partículas atuam como um imã permanente, e estarão sujeitas a um torque que promove aquecimento por fricção viscosa com o entorno. Baseado na teoria de fricção viscosa, a potência dissipada por uma esfera será:

$$
P=24 \pi^{2} \eta \frac{f^{2}}{\rho}
$$

sendo $\eta$ a viscosidade do meio, $\rho$ a densidade de massa do material e $f$ a frequência de oscilação da partícula.

A estimativa da demanda de potência que o sistema de nanopartículas deve fornecer ao meio para que se atinja as condições de hipertermia não é trivial. A potência requerida depende do grau de elevação de temperatura que se deseja, o volume da região de aquecimento, e a concentração máxima de partículas magnéticas que podem ser usadas 
devido a consequências toxicológicas. A elevação de temperatura na região de interesse é resultado do equilíbrio entre a competição de dois processos, o de geração de calor pelas nanopartículas magnéticas e o de resfriamento pelo tecido do entorno. No presente trabalho buscamos otimizar tanto as condições de exposição ao campo como as características de administração e acúmulo das NPM.

\subsection{Materiais e Métodos}

\subsubsection{Animais}

Foram utilizados vinte e cinco ratas da espécie Fischer 344 compradas do Charles River Laboratories (Wilmington, MA), todas com 8 a 15 semanas de idade e com peso médio de $162 \pm 17 \mathrm{~g}$. Todos os experimentos e procedimentos foram previamente aprovados pelo comitê do Institutional Animal Care and Use da Duke University. As ratas foram anestesiadas com Cetamina/Xilazina (40 mg/4 mg/kg). Com intuito de manter a temperatura corpórea durante os experimentos, os animais foram posicionados em uma almofada-gel, regulada para aproximadamente $38^{\circ} \mathrm{C}$.

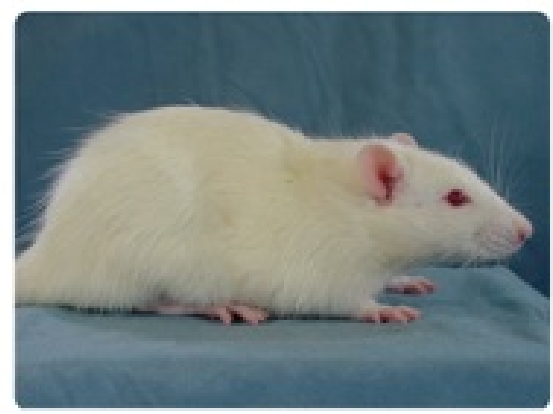

Figura 4.3: Imagem da rata Fischer 344 usada nos experimentos de magneto-hipertermia.

\subsubsection{Fluido magnético}

O fluido magnético utilizado neste estudo consistiu de nanopartículas de óxido de ferro (magnetita) a uma concentração estoque de $100 \mathrm{mg} / \mathrm{mL}$, dispersa em água e fornecida pela empresa Actium Biosystems (Boulder, CO). As partículas foram estabilizadas 
em água usando o surfactante dioctil sulfosuccinato de sódio. O tamanho do núcleo médio das partículas é de $20 \mathrm{~nm}$, usando a microscopia de transmissão eletrônica. A opção por magnetita $\left(\mathrm{Fe}_{3} \mathrm{O}_{4}\right)$ se deu através da análise da difração de raio-X. A caracterização magnética foi realizada por VSM (magnetometria de amostra vibrante) e a saturação da magnetização da nanopartícula de magnetita foi determinada como sendo aproximadamente $400 \mathrm{kA} / \mathrm{m}$. Após a cateterização da bexiga com um angiocateter de 18-gauge, um volume de $0,4 \mathrm{~mL}$ de fluído magnético foi incutido no interior da bexiga e o cateter foi fortemente selado. Ao final de 60 minutos, não foram observados vazamentos significativos de fluido.

\subsubsection{Medições de temperatura}

As medições de temperatura foram realizadas invasivamente com sete sensores de fibra-ótica distintos, de diâmetro de 0,42 mm (OpSens Technologies, Quebec, Canada). Os sensores de temperatura foram inseridos na vagina, reto, e músculo subcutâneo através de um cateter de 18-gauge (Figura 4.4A). Dois sensores de temperatura de 18-gauge foram inseridos através de portas ajustáveis (UPS-A, Gyrus Medical, Southborough, MA) montadas em cateter na bexiga, um dos sensores foi posicionado no interior da bexiga e o outro foi posicionado na uretra a aproximadamente $8 \mathrm{~mm}$ proximal da bexiga (Figura 4.4B). Com esta configuração de monitoramento, foi estimada uma temperatura corpórea através da média entre três sensores localizados no reto, boca e músculo subcutâneo. Uma temperatura adicional da superfície do animal foi adquirida com o posicionamento de um sensor na região abdominal acima da bexiga.

\subsubsection{O equipamento gerador de campo magnético}

Os experimentos de aquecimento in vivo foram executados com um aplicador de campo magnético dedicado a pequenos animais desenvolvido pela Actium Biosystems (Figura 4.5). O sistema opera na frequência de $40 \mathrm{kHz}$ e com campo variável até $6 \mathrm{kA} / \mathrm{m}$. Durante os experimentos, a intensidade de campo magnético é teoricamente determinada baseada em medidas de corrente elétrica que circula nas bobinas. A correlação entre 


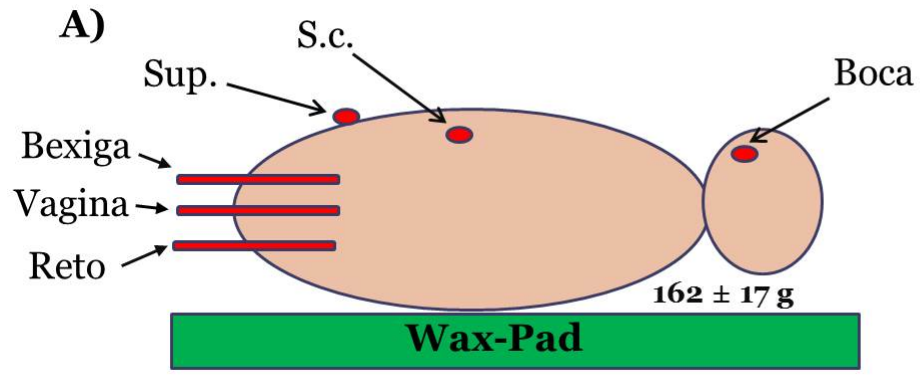

B)

Figura 4.4: Ilustração indicando as posições dos sensores de temperatura utilizados para monitorar a eficiência da magnetohipertermia em ratas. Ilustração A) apresenta uma visão geral da localização das sondas e a ilustração B) apresenta os dois sensores posicionados no interior do cateter que é introduzido na bexiga.

intensidade de campo magnético e corrente foram previamente validadas em procedimento de calibração no fabricante. A intensidade de campo magnético foi medida por um sensor de campo magnético em combinação com analisador de espectro. O campo magnético varia menos de $5 \%$ através da bexiga da rata.

O sistema de controle do equipamento fornece dois modos de controle: um modo permite o ajuste manual da intensidade de campo, o outro o ajuste é realizado automaticamente, baseado em um algoritmo de controle que usa um dos sensores de temperatura como alimentador de sinal. Esse algoritmo foi utilizado com objetivo de manter a temperatura no interior da bexiga constante. O procedimento de hipertermia foi realizado sem o uso de sistema de refrigeração.
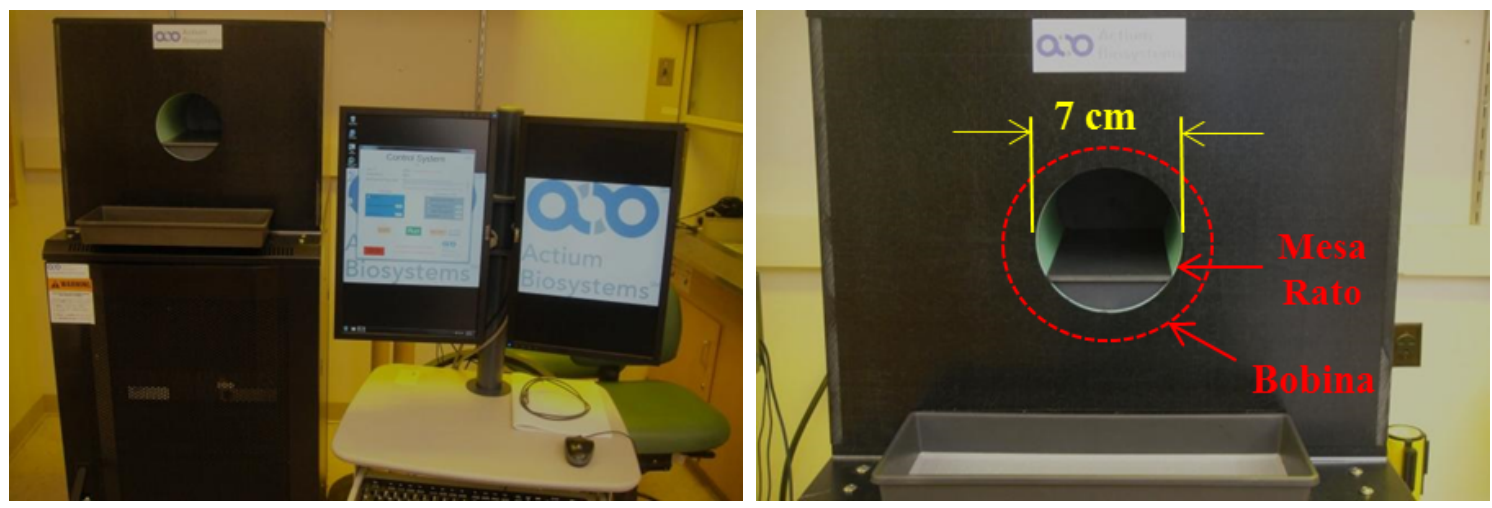

Figura 4.5: Ilustração do equipamento gerador de campo magnético para aplicação da magnetohipertermia em pequenos animais (Actium Biosystems) com detalhe para bobina indutora e a cavidade terapêutica.

Para testar a influência do campo magnético em processos de aquecimento não 
específicos, foram conduzidos alguns experimentos de controle que utilizaram $0,4 \mathrm{~mL}$ de solução salina incutida na bexiga das ratas. Elas foram expostas a um campo de 5,3 $\mathrm{kA} / \mathrm{m}$ por 1 hora sem utilização de nenhum sistema de controle da temperatura ambiente. Em uma segunda condição, depois de 1 hora foi adicionado um fluxo constante de ar, à temperatura ambiente, no interior da bobina de indução, para tentar resfriar o ambiente.

\subsubsection{Definição do parâmetro de "potência de dissipação especí- fica"}

A capacidade de aquecimento das nanopartículas pode ser avaliada por um parâmetro chamado de "Potência de Dissipação Específica" (SLP), que pode ser definido como a quantidade de energia convertida em calor por unidade de tempo e massa de material magnético (Hergt \& Dutz, 2007). Para avaliar o SLP, medidas de aumento de temperatura em função do tempo foram executadas para diferentes concentrações de nanopartículas e intensidade de campo. Todas as amostras continham $0,4 \mathrm{~mL}$ de fluido em um porta amostra de $1,5 \mathrm{~mL}$. Os recipientes com as amostras foram posicionados no centro da bobina indutora e isolados com $3 \mathrm{~cm}$ de isopor. Os valores de SLP foram calculados utilizado-se a Eq.(4.7).

$$
S L P=c_{s} \frac{m_{s}}{m_{N P}}\left(\frac{\triangle T}{\triangle t}\right)
$$

sendo " $c_{s}$ " o calor específico da amostra $(\mathrm{J} /(\mathrm{g} \cdot \mathrm{K}))$, " $m_{s}$ " a massa total de amostra, " $m_{N P}$ " a massa de nanopartícula na amostra $(\mathrm{g})$, e $\triangle T / \triangle t$ corresponde à inclinação nos 30 segundos iniciais da curva de elevação da temperatura versus tempo. O calor específico da amostra (" $c_{s}$ ") foi calculado através da média ponderada nas massas das capacidades caloríficas da água e da magnetita $\left(C_{\text {agua }}=4.184 \mathrm{~J} \mathrm{~g}^{-1} K^{-1}, C_{\text {magnetita }}=0.670 \mathrm{~J} \mathrm{~g}^{-1} K^{-1}\right)$.

\subsubsection{Imagens de ressonância magnética nuclear}

Para a detecção da presença de nanopartícula no lúmen da bexiga, foram utilizadas imagens de ressonância magnética nuclear (MRI). As imagens foram adquiridas em um tomógrafo 7-T para animais (Bruker Biospec, Bruker BioSpin MRI, Ettlingen, Germany) localizado no Duke Center for In Vivo Microscopy. Durante a aquisição das imagens, 
as ratas foram mantidas sob anestesia com 1-2\% de isoflurano. Executaram-se imagens tridimensionais, com uma sequência em short echo-time, radial-encoding que adquiriu 134.526 poses a partir do centro do espaço de Fourier e foram coletadas as uniformidades da periferia. O tempo de eco foi de $20 \mathrm{~ms}$ e o tempo de repetição foi de $8,7 \mathrm{~ms}$. O ângulo de flip foi de $6^{\circ}$, o campo de visão foi de $7 \mathrm{~cm}$ em todas as direções, e a largura da banda foi de $100 \mathrm{kHz}$. Os dados foram adquiridos em uma matriz 256 x 256 x 256 . O sinal proveniente da gordura foi suprimido. Como o MRI não permite o uso de grandes concentrações de material magnético, devido a um efeito de saturação do sinal, utilizou-se soluções de baixa concentração $(0,5 \mathrm{mg} / \mathrm{mL})$ de magnetita para aquisição das imagens.

Para determinar o volume capaz de induzir refluxo vesicoureteral em ratas, foram executados estudos de MRI em três ratas, que foram incutidas com diferentes volumes na bexiga $(0,2 \mathrm{~mL}$ a $0,7 \mathrm{~mL})$. As imagens da bexiga e dos rins foram intensificadas com a injeção do agente de contraste Gd-DTPA (Magnevist; Bayer Health Care Pharmaceuticals, Wayne, NJ). As imagens de MRI foram adquiridas usando um eco de gradiente de multifaces (200 passos de codificação de frequência, 200 passos de codificação de fase, 86 fatias). O tempo de eco foi 4,6 ms, e o tempo de repetição foi 1,24 s. O ângulo de flip foi de $90^{\circ}$ com uma largura de banda de $50 \mathrm{kHz}$. O campo de visão foi de $7 \mathrm{~cm}$ em ambos os planos de direção, e as fatias foram definidas com espessura de 0,35 mm. Novamente, o sinal proveniente da gordura foi suprimido. Baseado no método de segmentação por limitação, a presença de refluxo foi detectada monitorando-se o aumento do contraste nos rins antes e depois da injeção de Gd-DTPA. A linha de base inicial foi adquirida para todos as ratas. O volume da bexiga e dos rins foi definido por contorno manual. Foi realizada uma busca inicial para definir a distribuição de intensidade nos ratos na ausência de contraste, e o valor máximo encontrado foi definido como limiar de intensidade. Foram injetados volumes sequenciais de Gd-DTPA na bexiga, e o aumento do contraste nos rins foi computado. 


\subsection{Resultados e Discussões}

\subsubsection{Capacidade de geração de calor do fluido magnético in vitro}

Através do conhecimento empírico na aplicação clínica da hipertermia, tem-se que a taxa de aquecimento de $1^{\circ} \mathrm{C} /$ min é a que melhor se ajusta ao sentimento de conforto do paciente. Como já citado, a eficiência de aquecimento na magneto-hipertermia depende da quantidade total de material magnético disponível na região de interesse. Deve-se, entretanto, considerar que a adição de um agente exógeno ao corpo pode implicar em riscos toxicológicos. No caso do ferrofluido, os riscos toxicológicos sempre são associados com altas concentrações de ferro (Kim et al., 2006). O primeiro passo no processo de otimização da magneto-hipertermia está em buscar a menor concentração de ferrofluido capaz de produzir o aquecimento desejado. Logo, antes de qualquer estudo in vivo, devese conhecer o intervalo de possíveis concentrações que atendam aos requisitos mínimos de geração de calor, e garantam a elevação de $5^{\circ} \mathrm{C}$ na bexiga. Em outras palavras, é necessário conhecer as características de dissipação de energia das nanopartículas.

Para avaliar a citada geração de calor em função da concentração de nanopartícula, diluiu-se a solução original $(100 \mathrm{mg} / \mathrm{mL})$ em diferentes alíquotas, de volume final constante de $0,4 \mathrm{~mL}$ em recipientes de $1,5 \mathrm{~mL}$. As concentrações observadas variaram entre 0,5 mg/mL e 100 mg/mL. Porém, na Figura 4.6, apresentam-se apenas as curvas representativas de elevação de temperatura para as concentrações de magnetita de maior interesse. Todas as amostras foram submetidas a um campo magnético constante de $5,5 \mathrm{kA} / \mathrm{m}$.

Como esperado, a taxa de aumento de temperatura acompanhou o aumento de concentração do material magnético (Figura 4.6). As taxas de aquecimento médio foram estimados individualmente, e os resultados indicaram que a provável concentração mínima do fluido deve ser próximo à $50 \mathrm{mg} / \mathrm{mL}$, pois nesse intervalo a taxa de aquecimento observada foi de $1,6{ }^{\circ} \mathrm{C} / \mathrm{min}$. Entretanto, esta é apenas uma estimativa da taxa de dissipação, uma vez que o sistema in vitro não oferece perdas de calor significativas como no sistema in vivo. A amostra de maior concentração $(100 \mathrm{mg} / \mathrm{mL})$ promoveu uma taxa de aquecimento médio de $7,2^{\circ} \mathrm{C} / \mathrm{min}$. 


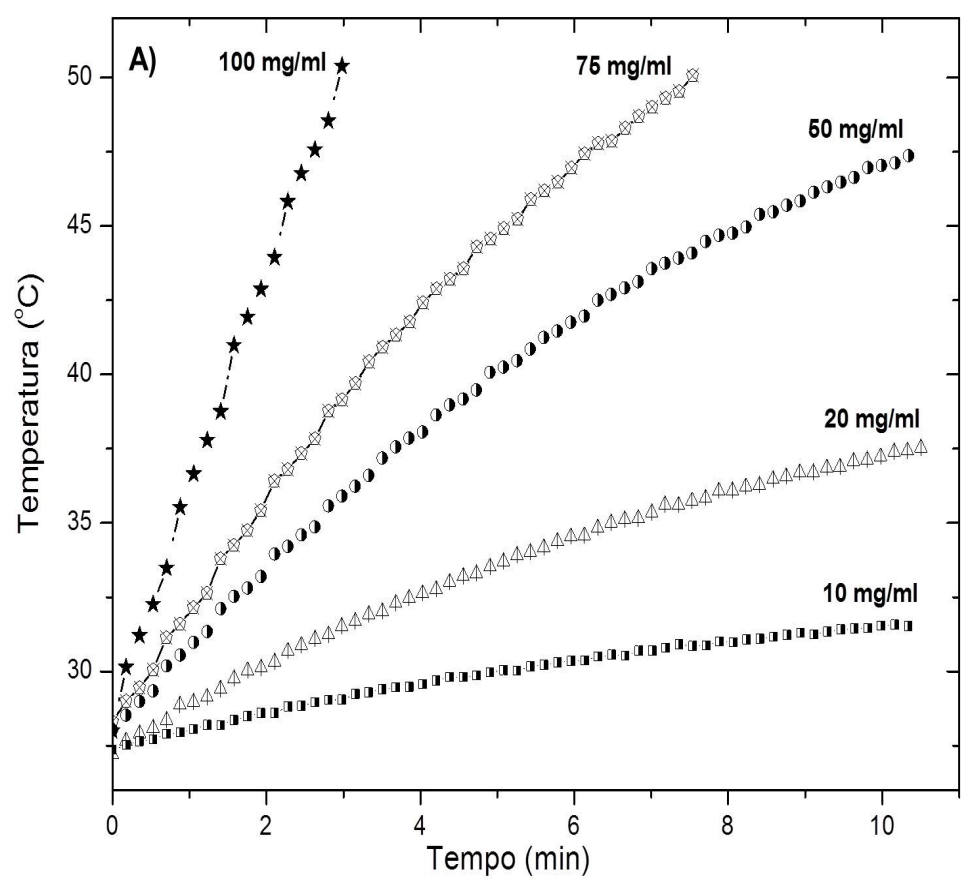

Figura 4.6: Características de aquecimento do ferrofluido Actium Biosystem. Elevação da temperatura para cinco concentrações distintas em $0,4 \mathrm{~mL}$ de fluido magnético na frequência de 40 $\mathrm{kHz}$ e amplitude de $5,5 \mathrm{kA} / \mathrm{m}$.

Além de conhecer a concentração ideal de ferrofluido, deve-se também determinar qual a resposta do calor gerado em função da variação da intensidade do campo magnético. Esse conhecimento é importante, pois permite realizar o planejamento terapêutico de forma mais eficiente, e auxilia na parametrização do controle em tempo real da temperatura do tecido alvo. A descrição matemática da deposição de energia por ferrofluidos, inicialmente proposta por (Rosensweig, 2002) (Eq.4.2), é amplamente aceita na comunidade científica, contudo existem certos limites de validade da mesma (Bordelon et al., 2011; Hergt et al., 2010). Sabe-se, que a relação entre intensidade de campo magnético $(\mathrm{kA} / \mathrm{m})$ e a deposição local de energia depende fortemente do tipo de fluido magnético utilizado (Bordelon et al., 2011); portanto, decidiu-se nesta etapa verificar se o sistema enquadra-se no regime de validade da aproximação de Rosensweig.

Para avaliar o regime de validade, primeiro adquiriu-se os perfis de elevação de temperatura e depois os valores dos parâmetros SLP do fluido magnético (Actium Biosystems) nas diversas amplitudes de campo magnético monitorado. A Figura 4.7 apresenta a estimativa para o parâmetro SLP em função da amplitude do campo magnético, na frequência 


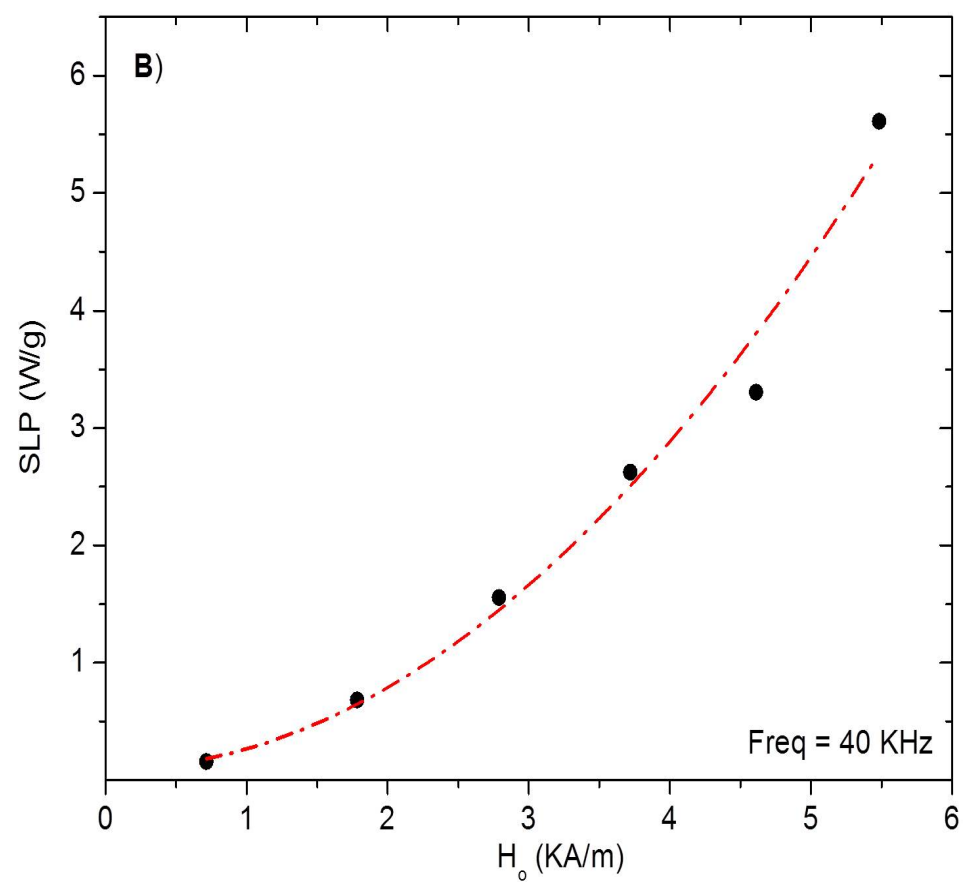

Figura 4.7: Características de aquecimento do ferrofluido Actium Biosystem. O parâmetro SLP (Potência de Dissipação Específica) em função da intensidade de campo magnético para uma amostra de $0,4 \mathrm{~mL}$ e $100 \mathrm{mg} / \mathrm{mL}$ de magnetita. A curva pontilhada vermelha representa o melhor ajuste para a função $S L P=\alpha f H^{2}\left(R^{2}=0,98\right)$

fixa de $40 \mathrm{kHz}$, de amostras com 0,4 mL de volume e $100 \mathrm{mg} / \mathrm{mL}$ de concentração.

Os resultados da Figura 4.7 indicam que o SLP calculado para a amplitude de 5,5 $\mathrm{kA} / \mathrm{m}$ foi de $5,6 \mathrm{~W} / \mathrm{g}$. A dependência do SLP com a amplitude do campo foi satisfatoriamente ajustado $\left(R^{2}=0,98\right)$ com a função de campo ao quadrado, $S L P=\alpha f H^{2}$ (sendo " $\alpha$ " uma constante), o que portanto corrobora com a descrição de Rosensweig (Eq. 4.2). Neste contexto, nossos resultados indicam que o aumento da amplitude de campo aumenta sistematicamente os valores de SLP, até amplitudes de $6,0 \mathrm{kA} / \mathrm{m}$.

\subsubsection{Características da administração do fluido magnético na bexiga}

Garantir que o fluido magnético acumule no tecido alvo em grandes quantidades, e de forma homogênea, é um dos principais desafios da aplicação clínica da magnetohipertermia. Devido a limitações na administração intravenosa de material magnético, as principais abordagens clínicas relatadas na literatura (Hergt \& Dutz, 2007; Maier- 
Hauff et al., 2007) foram executadas utilizando a injeção direta de material magnético no tecido alvo. O presente projeto se diferencia de todos os relatos anteriores, pois o alvo de interesse trata-se de um órgão flexível e de relativamente grande volume interno, que pode ser entendido como um balão interno ao corpo que deve ser preenchido com fluído magnético.

O desafio nessa etapa do projeto foi o de garantir que as NPM fossem administradas de modo seguro e sem promover danos significativos à estrutura da bexiga. Contudo, deve garantir que o material magnético internalizado na bexiga durante todo o período de tratamento seja mantido por aproximadamente uma hora, sem que ocorra vazamentos significativos.

Para avaliar o protocolo de injeção do fluido, existiam duas formas principais de verificação; uma seria através da dissecação do animal próximo à região abdominal, seguido de uma verificação visual e/ou microscópica do impacto das NPM nos órgãos envolvidos; já a segunda seria através do uso de técnicas não invasivas de imagem, para que, de forma indireta, fosse possível coletar informações locais dos órgãos. Neste projeto decidiu-se por executar os dois procedimentos, porém os dados da dissecação foram omitidos deste texto por questões regimentais da Duke University.

Para avaliar de modo não-invasivo a eficiência de injeção e distribuição das NPM na bexiga do rato, pode-se utilizar as técnicas convencionais de Tomografia Computadorizada (TC) e/ou a imagem por ressonância magnética nuclear (MRI). A presença de NPM em uma dada região do corpo gera contraste nas imagens de ambas as técnicas citadas, no entanto o grau de sensibilidade é fundamentalmente distinto. No caso da tomografia, somente concentrações elevadas de NPM são capazes de produzir alguma distinção de contraste na imagem, sendo considerada a concentração mínima detetável o valor de 10 mg/mL (Gneveckow et al., 2004). Já para o MRI, as condições de detectabilidade são inversas às da TC, pois em MRI somente pequenas concentrações de NPM são compatíveis com a técnica. Acredita-se que o valor máximo de concentração possível de ser visualizado com MRI esteja por volta de $1 \mathrm{mg} / \mathrm{mL}$ (Gneveckow et al., 2004), mas pode variar conforme a sequência de pulsos utilizada. 
Analisando as características de cada técnica, e avaliando os valores de concentrações limites de cada uma, constatou-se que existe um intervalo de concentração "cego", no qual ambas as técnicas não possuem sensibilidade $(1-10 \mathrm{mg} / \mathrm{mL})$. Dentro deste contexto, optou-se por priorizar o uso do MRI como método de avaliação. Esta decisão foi tomada baseando-se no critério de maior sensibilidade a baixas concentrações.

Nos itens a seguir, apresentamos os resultados para os estudos de viabilidade de injeção, e a possibilidade de indução de refluxo para os rins das ratas.

\section{Injeção e distribuição de nanopartícula na bexiga}

O protocolo de injeção e manutenção do fluido magnético no lúmen da bexiga foi desenvolvido especificamente para este projeto. Desta forma, o primeiro passo foi verificar se a estrutura da bexiga suportava grandes variações de volume, e se o sistema de contenção de fluido impedia eventuais vazamentos.

Antes de prosseguir com os resultados das imagens de MRI, apresenta-se na Figura 4.8 a ilustração da região anatômica onde a bexiga se localiza.
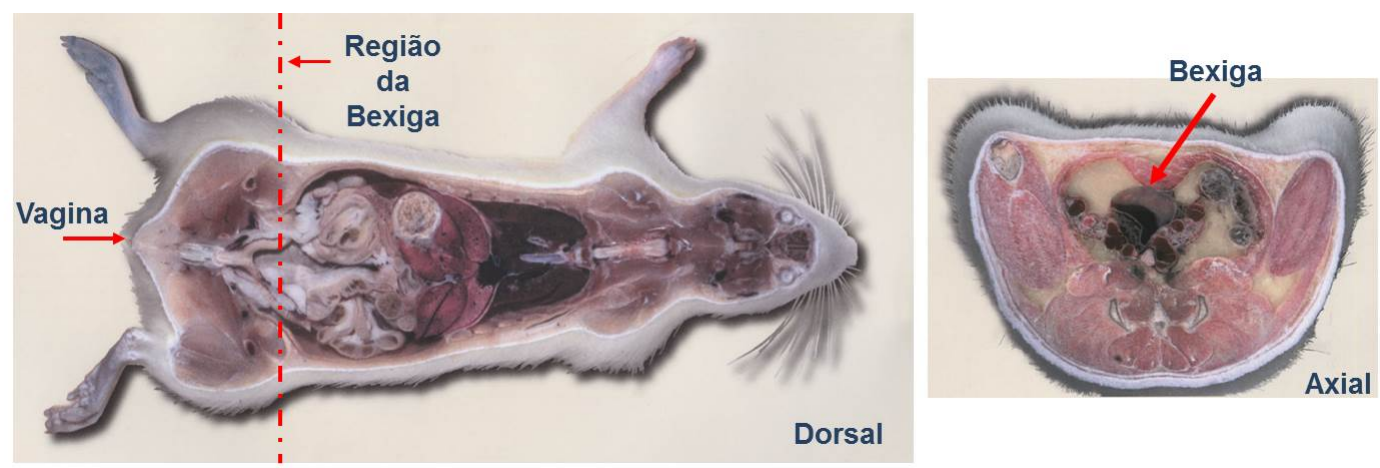

Figura 4.8: Cortes anatômicos do rato de laboratório (Coronal e Axial). O corte coronal destaca a região do corpo do rato onde normalmente a bexiga se encontra. O corte Axial mostra em maior detalhe a bexiga e seus tecidos vizinhos (Imgens retiradas do Handbook de anatomia animal "The Laboratory Rat").

A avaliação do protocolo de preenchimento da bexiga consiste basicamente em verificar se há ocorrência de vazamentos ou não, e se existe alguma perturbação na estrutura da bexiga. Com intuito de familiarização com o protocolo, primeiro, preferiu-se executar os procedimentos de injeção utilizando uma solução de contraste padrão, o gadolíneo 
(Gd-DTPA), pois assim se eliminaria qualquer possível incerteza na detectabilidade da NPM.

Exemplo das imagens de MRI obtidas da região abdominal dos animais são apresentadas na Figura 4.9; os diferentes cortes da bexiga do rato preenchida com $0,3 \mathrm{~mL}$ de solução salina/Gd-DTPA facilitam a localização e visualização da mesma. Além das imagens de MRI, a Figura 4.9 apresenta um esquema do sistema urinário/reprodutor da rata e uma ilustração da via de acesso da bexiga por cateterização da uretra.

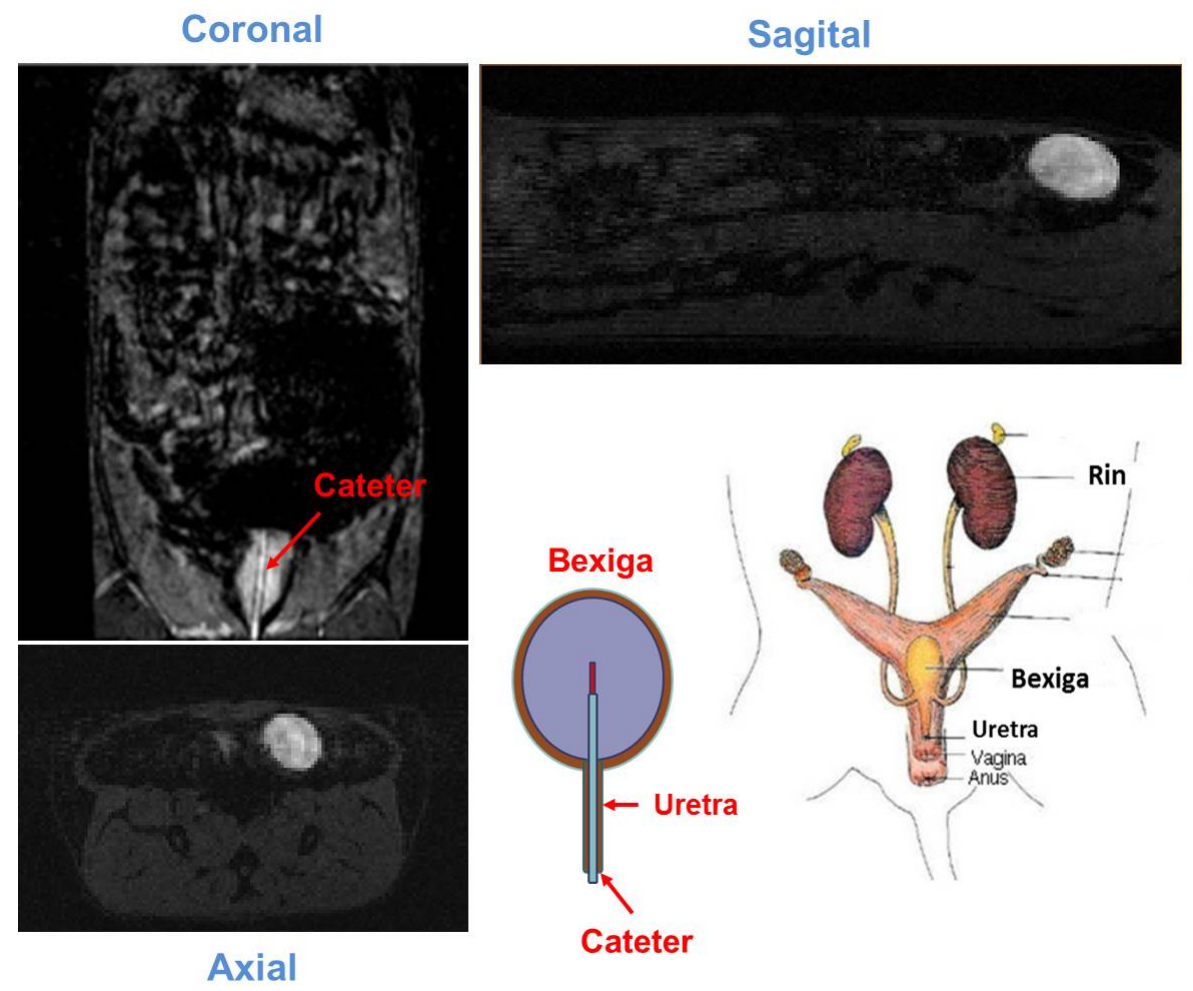

Figura 4.9: Imagens pré-tratamento de MRI nos três planos de cortes, tendo como destaque a bexiga da rata preenchida com $0,3 \mathrm{~mL}$ de solução de contraste (salina/gadolíneo). Apresentase também uma ilustração da estrutura anatômica do sistema urinário/reprodutivo, além do posicionamento esperado para o sensor de temperatura no interior da bexiga.

O agente de contraste Gd-DTPA possui a característica de aumentar a intensidade de sinal da região de localização, devido ao aumento do tempo de relaxação longitudinal $\left(T_{1}\right)$ das moléculas de água próximas a ele. Este efeito aumenta o brilho das imagens ponderadas em $T_{1}$. Avaliando as imagens (Figura 4.9), a bexiga preenchida pela solução contraste é facilmente localizada (região de maior brilho) nos diferentes cortes apresen- 
tados. No corte coronal é possível também visualizar a presença do cateter utilizado. A presença de grandes áreas negras na imagem é resultado da sequência de supressão de gordura utilizada. Neste momento, o protocolo apresentou-se viável e sem danos à estrutura da bexiga e saúde do animal, além de nenhum vazamento ter sido observado durante o período de 1 h.

Os resultados anteriores trouxeram confiabilidade ao protocolo de injeção e formaram a base para os estudo com a NPM. Uma vez que o MRI não permite o uso de alta concentração de material magnético, devido à geração de artefatos nas imagens, a distribuição de NPM na bexiga foi avaliada utilizando-se uma solução diluída de NMP a 0,5 $\mathrm{mg} / \mathrm{mL}$. A Figura 4.10 mostra a bexiga preenchida com $0,5 \mathrm{~mL}$ da solução diluída de nanopartículas.

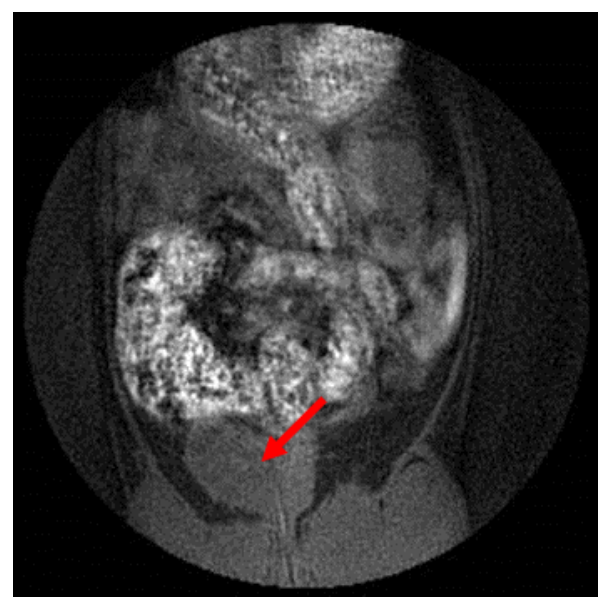

Figura 4.10: Imagem pré-tratamento de MRI da bexiga da rata preenchida com $0,5 \mathrm{~mL}$ de fluido magnético a $0,5 \mathrm{mg} / \mathrm{mL}$. A seta indica a bexiga e parte do cateter introduzido na mesma.

Ao contrário do Gd-DTPA, as características de contraste das NPM são a produção de decréscimo de intensidade do sinal local, ou redução do tempo de relaxação de imagens ponderadas em $T_{2}$. A bexiga contendo o fluido magnético injetado aparece na imagem da Figura 4.10 em um tom de cinza escuro (seta vermelha). Através da análise desta e das demais imagens é possível quantificar o volume de ocupação da bexiga. Para o período de 60 min, semelhante ao período de aquecimento, não foram observados vazamentos, e a diluição por efeito da urina foi mínimo. Esses resultados foram extremamente positivos e comprovaram que o protocolo estava adequado aos fins. 


\section{Determinação da possibilidade de refluxo para os rins}

O Refluxo Vesicoureteral (VUR) é definido como o efeito de fluxo reverso anormal de urina contida na bexiga para a região dos ureteres. A junção ureterovesical (união entre ureter e bexiga), em condições normais, funciona como uma válvula unidirecional que permite a passagem da urina do ureter para a região da bexiga e impede o retorno da mesma no sentido oposto. Este mecanismo é importante, pois protege os rins de um eventual contato com urina infectada por bactérias existentes na região da bexiga. $\mathrm{O}$ fenômeno de refluxo ocorre devido a um desequilíbrio em diversos fatores anatômicos e funcionais, porém é atribuído como fator majoritário a disfunção na junção ureterovesical.

A pressão interna na bexiga possui papel de facilitador da disfunção da junção ureterovesical, que em condições de alta pressão pode promover o rompimento da mesma. Estudos em ratos, avaliando a indução de refluxo aos rins em função da pressão interna da vesícula urinária, demonstraram a existência de refluxo para valores acima de um certo limite de pressão (Vercesi \& Constantinou, 1986). O volume de nanopartículas ideal, e a eficiência de geração de calor, devem respeitar os limites biológicos, e evitar qualquer efeito de refluxo, pois uma vez ocorrendo refluxo o fluido magnético terá grande chance de atingir o suporte sanguíneo dos rins e se espalhar pelo corpo inteiro. Sendo assim, determinar os volumes máximos suportados na bexiga, para a espécie de roedor utilizada, torna-se uma tarefa essencial ao sucesso desse projeto.

A variação do volume incutido na bexiga não somente modula a massa total de partículas magnéticas, mas também modifica a troca de calor entre as paredes da bexiga e os tecidos ao redor, uma vez que a relação volume de nanopartícula por área superficial da parede da bexiga também se altera. Espera-se que pequenos volumes de nanopartículas apresentem maior troca de calor com o entorno em relação a volumes maiores. Portanto, o objetivo em magneto-hipertermia aplicada à bexiga será sempre utilizar o maior volume possível de nanopartícula.

Neste item foram realizados experimentos que permitiram a avaliação da incidência de refluxo em ratas para uma dada variação de volume interno da bexiga. A técnica utilizada foi novamente a MRI, combinada com o agente de contraste gadolíneo. A proposta 
era de monitorar a intensidade do sinal nos rins em função do aumento de volume da bexiga, para assim verificar se existe alguma alteração de seu comportamento médio do sinal. Antes de iniciar a avaliação do refluxo foi necessário verificar a correlação entre o volume injetado no sistema e o volume interno induzido na bexiga. Para realizar esse cálculo de volume interno da bexiga foi necessário gerar artificialmente um sólido que representasse as condições da bexiga.

O sólido que representa o volume ocupado pela bexiga foi gerado a partir do processo de segmentação manual das imagens. O processo consiste em selecionar manualmente a área correspondente ao objeto desejado em todas as fatias coletadas. Após a seleção de todas as fatias, o software Avizo gera um sólido correspondente a seleções ou "segmenta" as seleções. A Figura 4.11 exemplifica o processo de segmentação com o software Avizo.
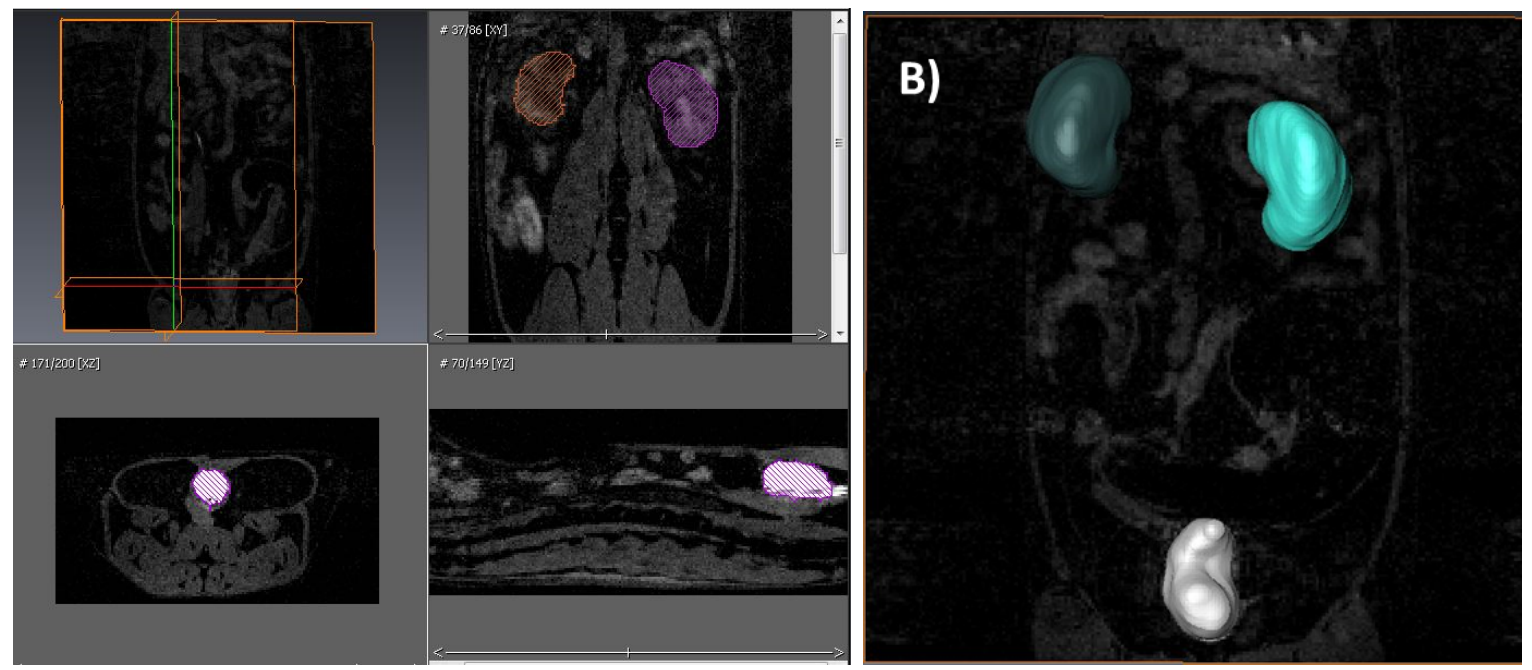

Figura 4.11: Exemplo das etapas do processo de segmentação dos rins e bexiga utilizando o software Avizo. Em A) observa-se o processo de seleção das estruturas. Em B) observa-se o resultado final do sólido gerado.

Na Figura 4.11 destaca-se o processo de seleção das regiões de interesse. Nela é possível verificar a seleção feita para a bexiga e os dois rins, e o processo é repetido para todas as fatias adquiridas. Na imagem B) já é possível verificar o resultado final da segmentação em que sólidos representando os rins e a bexiga foram gerados. Após a obtenção do sólido, o software Avizo executa numericamente a integração dessa geometria, e fornece como resultado o volume estimado do sólido. Utilizando-se esse procedimento foi possível avaliar a relação entre o volume injetado pela seringa no cateter e o volume 
contido na bexiga. O volume injetado da bexiga variou entre $0,2 \mathrm{~mL}$ e $0,7 \mathrm{~mL}$ para três animais distintos e o resultado é apresentado na Figura 4.12.

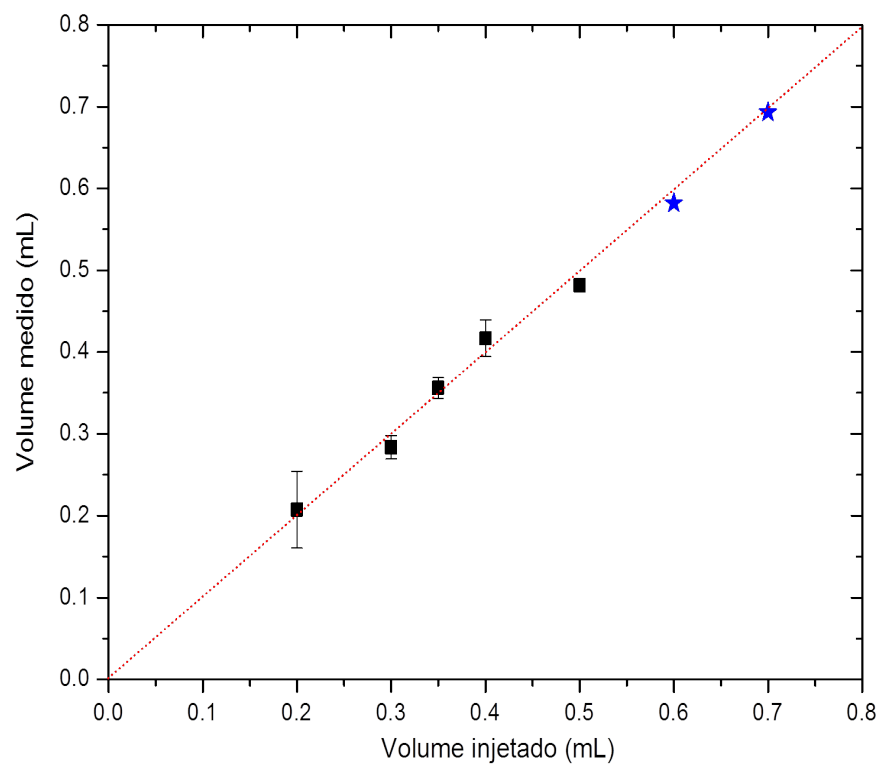

Figura 4.12: Correlação entre volume injetado no cateter que atinge a bexiga e o volume medido por segmentação das imagens de MRI.

Analisando a Figura 4.12 constata-se uma excelente associação entre o volume injetado e o volume obtido com o processo de segmentação das imagens de MRI. Com esse resultado podemos garantir que o volume de preenchimento da bexiga é muito próximo ao injetado no sistema. Baseado nesta constatação, partiu-se para os ensaios de refluxo, que consistiram em injetar diferentes volumes, da mesma solução de contraste (salina/GdDTPA), no lúmen da bexiga e verificar se em algum momento a solução contrastante ascende aos rins.

O método desenvolvido para realizar a tarefa de avaliação de refluxo consistiu em, primeiramente, determinar a distribuição de intensidade de sinal normalmente encontrada na região dos rins. Em seguida, avaliou-se a distribuição de intensidade para a região da bexiga na presença da solução de contraste. A avaliação das distribuições de intensidade permitiu determinar para quais valores de intensidade é possível distinguir entre o sinal proveniente de variações estruturais dos rins e aquelas devido à presença de agente de contraste. O resultado deste levantamento de intensidades pode ser visualizado na Figura 4.13. Nela é possível identificar as regiões utilizadas no levantamento de intensidade, e os 
histogramas de intensidades.
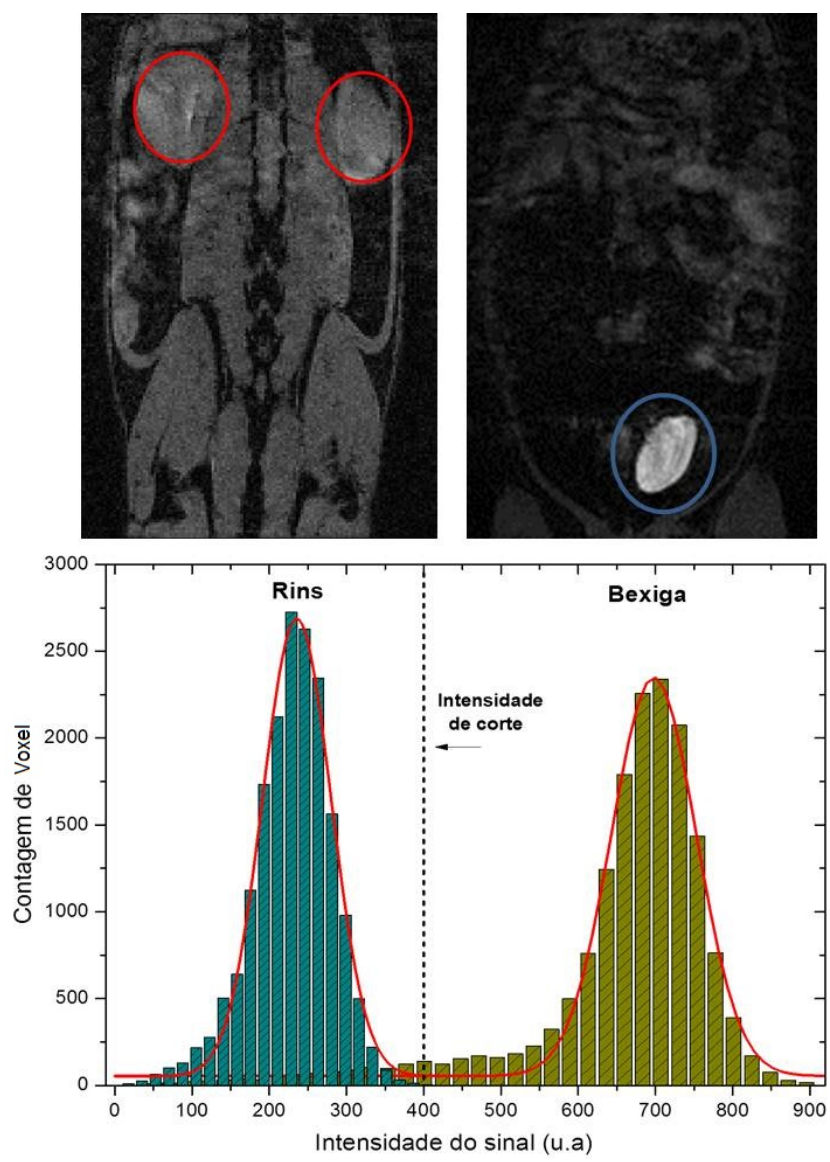

Figura 4.13: Detalhe das áreas consideradas para determinar a distribuição de intensidade. Distribuição da intensidade do sinal de MRI nos volumes segmentados.

O histograma de intensidades da Figura 4.13 nos permite considerar o valor médio da distribuição para os rins como sendo 230 (u.a.), e o valor máximo obtido de aproximadamente 400 (u.a.). Considerando a mesma análise para a bexiga na presença do agente de contraste, observa-se um valor médio de 705 (u.a.). A diferença na distribuição de intensidade de uma região que possui agente de contraste e uma região que não o possui é evidente. Sendo assim, para evitar um falso sinal positivo ao refluxo, na região dos rins decidiu-se por executar um processo de filtragem, que permite contabilizar somente os "voxels" com intensidades acima de um determinado valor limite pré-estipulado, e os "voxels" restantes seriam considerados como passivo de refluxo ou influenciados pela presença de agente de contraste.

O limite de intensidade usado no processo de filtragem foi definido empiricamente 
como 400 (u.a). Logo, para exemplificar os efeitos desse processo, apresenta-se o "antes" e "depois" na Figura 4.14.

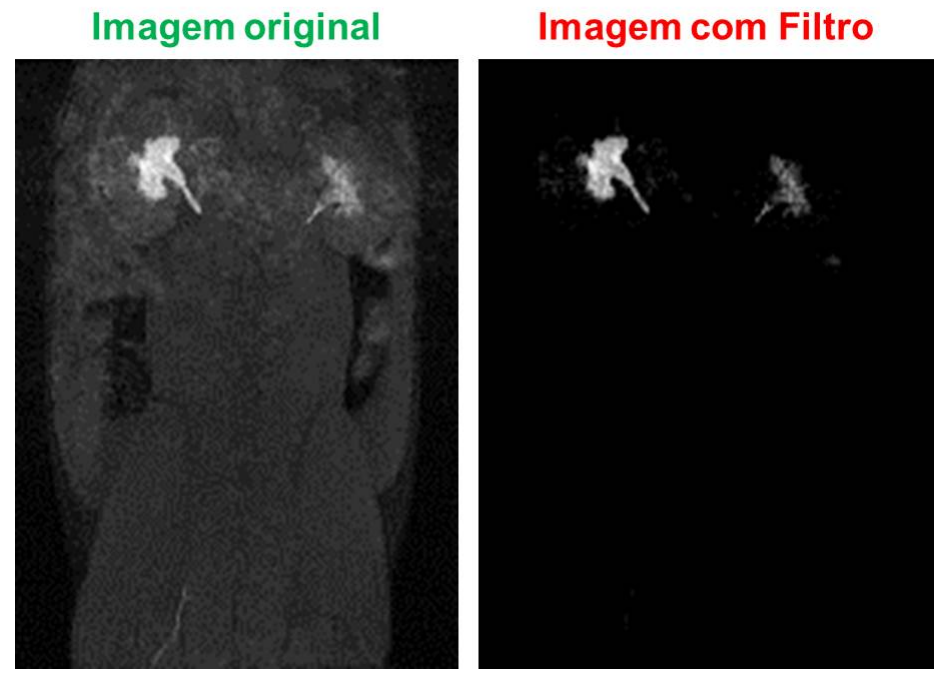

Figura 4.14: Exemplo do processo de filtragem das imagens de MRI por valor de intensidade do voxel. O filtro foi definido para excluir áreas com intensidade menor ou igual a 400 (u.a).

O resultado do processo de filtragem eliminou todos os voxels com valores menores ou iguais a 400 (u.a). A imagem resultante apresenta grande área com intensidade de sinal zero (ou preta), pois somente alguns voxels foram preservados, o que deve indicar presença de agente de contraste nesta área preservada.

Com a metodologia definida foi então possível analisar os efeitos da variação do volume interno da bexiga na incidência de refluxo $(0,2$ a $0,7 \mathrm{~mL})$. Nesta etapa foram utilizados três sujeitos para realização dos ensaios. A Figura 4.15 mostra o resultado para o monitoramento da intensidade do sinal de MRI na região do rim direito e esquerdo em função dos volumes injetados na bexiga.

O resultado na Figura 4.15 indica um aumento crescente da intensidade do sinal total nos rins à medida que aumenta o volume injetado, fato que pode ser interpretado como a ocorrência de refluxo. Os dados mostram que o refluxo aos rins aumenta significativamente para volumes superiores a 0,4 mL. O efeito de refluxo ocorreu de forma assimétrica entre os dois rins, e curiosamente este fato foi observados em todos as demais ratas monitoradas. O efeito assimétrico também é observado em humanos, estes dados demonstram a necessidade de limitar o volume injetado na bexiga para valores entre $0,35-0,4 \mathrm{~mL}$, e 


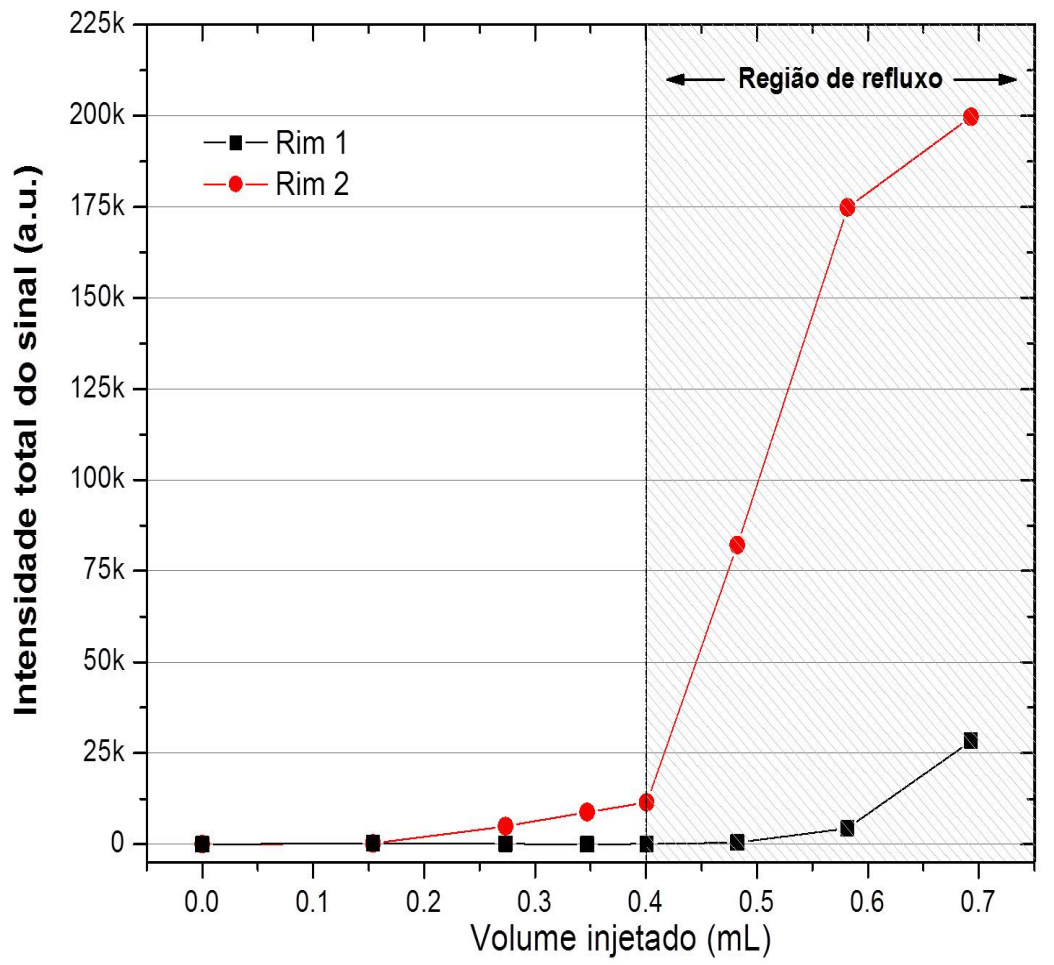

Figura 4.15: Intensidade de sinal de MRI para a região dos rins em função do volume de solução de Gd-DTPA injetado no lúmen da bexiga de uma rata. O volume da bexiga foi determinado pelo processo de segmentação manual. A área em destaque indica a região provável de ocorrência de refluxo.

assim garantir maior segurança ao procedimento de magneto-hipertermia.

A afirmação postulada anteriormente, de existência de refluxo, pode ser visualmente confirmada usando-se o método de segmentação por assinatura da intensidade do "voxel", ou seja, "voxels" que satisfaçam certas condições de intensidade são considerados parte do mesmo objeto ou sistema. Como ficou claro na Figura 4.14, existem grandes diferenças de intensidade entre regiões submetidas à solução contraste e regiões ausentes do mesmo. Aplicando o processo de segmentação para "voxels" com intensidade maior que 500 (u.a) é possível visualizar quais regiões do corpo da rata foram submetidas à presença de contraste (Figura 4.16).

Visualmente, é clara a existência de refluxo, sendo evidente o caminho percorrido pela solução contrastante (Figura 4.16). Na imagem é possível identificar a uretra, a bexiga, o ureter e os rins, não havendo margem a dúvida quanto à existência de refluxo. 


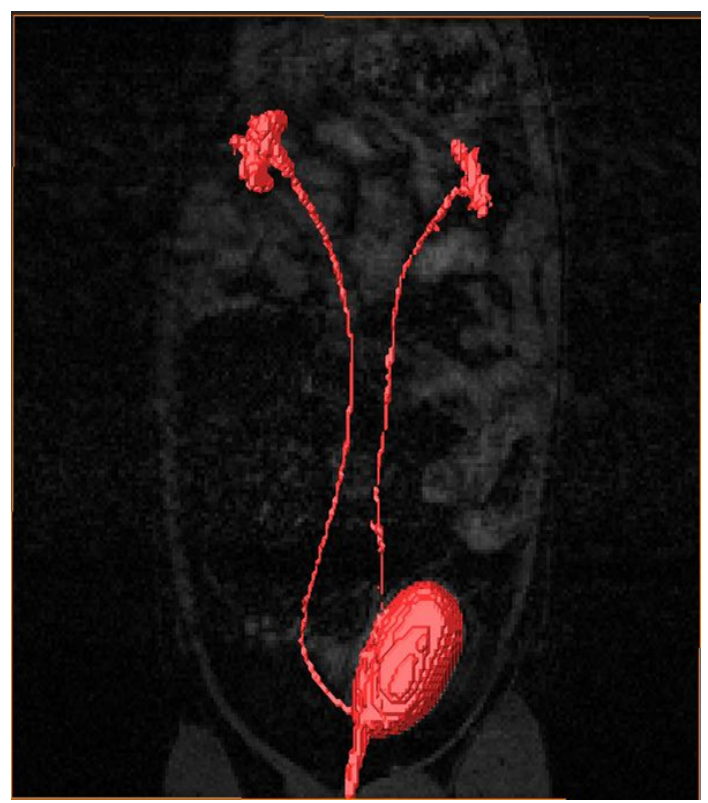

Figura 4.16: Resultado do processo de segmentação com assinatura por intensidade do sinal de MRI. As imagens segmentadas foram obtidas com a injeção de $0,7 \mathrm{~mL}$, no lúmen da bexiga, de solução de contraste (salina/gadolíneo). A estrutura vermelha indica o sólido gerado a partir de "voxels" que apresentam intensidade de sinal semelhante.

\subsubsection{Eficiência de aquecimento do fluido magnético in vivo}

Para qualquer aplicação clínica da hipertermia é essencial o controle preciso da temperatura na região de interesse e nos tecidos vizinhos. A elevação da temperatura em tecidos biológicos é dependente de propriedades locais, como a perfusão sanguínea e a dispersão homogênea das partículas magnéticas no tecido alvo. Na sistemática da aplicação da magneto-hipertermia, as três principais variáveis de controle da dissipação de energia local, uma vez definido o fluído magnético a ser utilizado, são: amplitude e frequência do campo magnético e a quantidade total de material magnético no local desejado. Como a frequência do campo é fixa e pré-estipulada pelo fabricante do equipamento, foi possível controlar a quantidade de material magnético e a amplitude do campo como opção da deposição de energia local.

Muitas das aplicações de magneto-hipertermia buscam controlar a quantidade de material magnético local através do número de injeções na região de interesse, uma vez que em muitos tecidos o fluido não se difunde e permanece concentrado em regiões próximas a sua injeção. No caso da magneto-hipertermia aplicada à bexiga, a situação é diferente, pois 
somente uma injeção será permitida e requerida para se obter uma distribuição homogênea do fluido magnético no interior da bexiga. Contudo, essa abordagem tenta modular a deposição de energia, alterando o volume total de fluido injetado e/ou a concentração total de nanopartícula.

Como já discutido, o objetivo central na aplicação da magneto-hipertermia é sempre utilizar a menor quantidade de material magnético possível, para assim minimizar os efeitos colaterais induzidos pelas nanopartículas. No item 4.3.1, que aborda o estudo in vitro, foi apresentada uma estimativa de concentração mínima de $50 \mathrm{mg} / \mathrm{mL}$. Baseado nos dados obtidos, nos próximos itens serão apresentados os resultados para o estudo da variação da concentração de nanopartícula, e o estudo para a variação de volume injetado no interior da bexiga das ratas, com intuito de propor as condições ideais de aplicação do fluido magnético.

\section{Efeito da variação da concentração de nanopartículas magnéticas}

Através dos resultados apresentados para a incidência de refluxo para a espécie de rato utilizada, foi estabelecido que volumes maiores de $0,4 \mathrm{~mL}$ podem produzir refluxo aos rins. Sendo assim, para avaliar in vivo nossa habilidade de aquecimento, definiu-se como volume padrão o valor de $0,4 \mathrm{~mL}$, e variou-se a concentração do fluido magnético entre 25 e $100 \mathrm{mg} / \mathrm{mL}$.

A Figura 4.17(A) apresenta curvas representativas para o perfil de temperatura do interior da bexiga dos ratos durante os primeiros 25 minutos sob influência do campo magnético, para quatro concentrações distintas de nanopartícula. Em todos os experimentos, os seis primeiros minutos foram utilizados para monitorar a temperatura basal dos sujeitos. Durante esse período, as temperaturas foram adquiridas sem a presença de campo magnético (campo zero), e depois foi acionado o campo magnético para o seu valor máximo. Os dados apresentados na figura 4.17(B) indicam o intervalo máximo e mínimo das temperaturas atingidas após 15 minutos da incidência de campo em função da concentração de nanopartícula injetada (estão representados pelo menos 3 experimentos distintos para cada ponto). Analisando o resultado obtido, constata-se que a concentração 

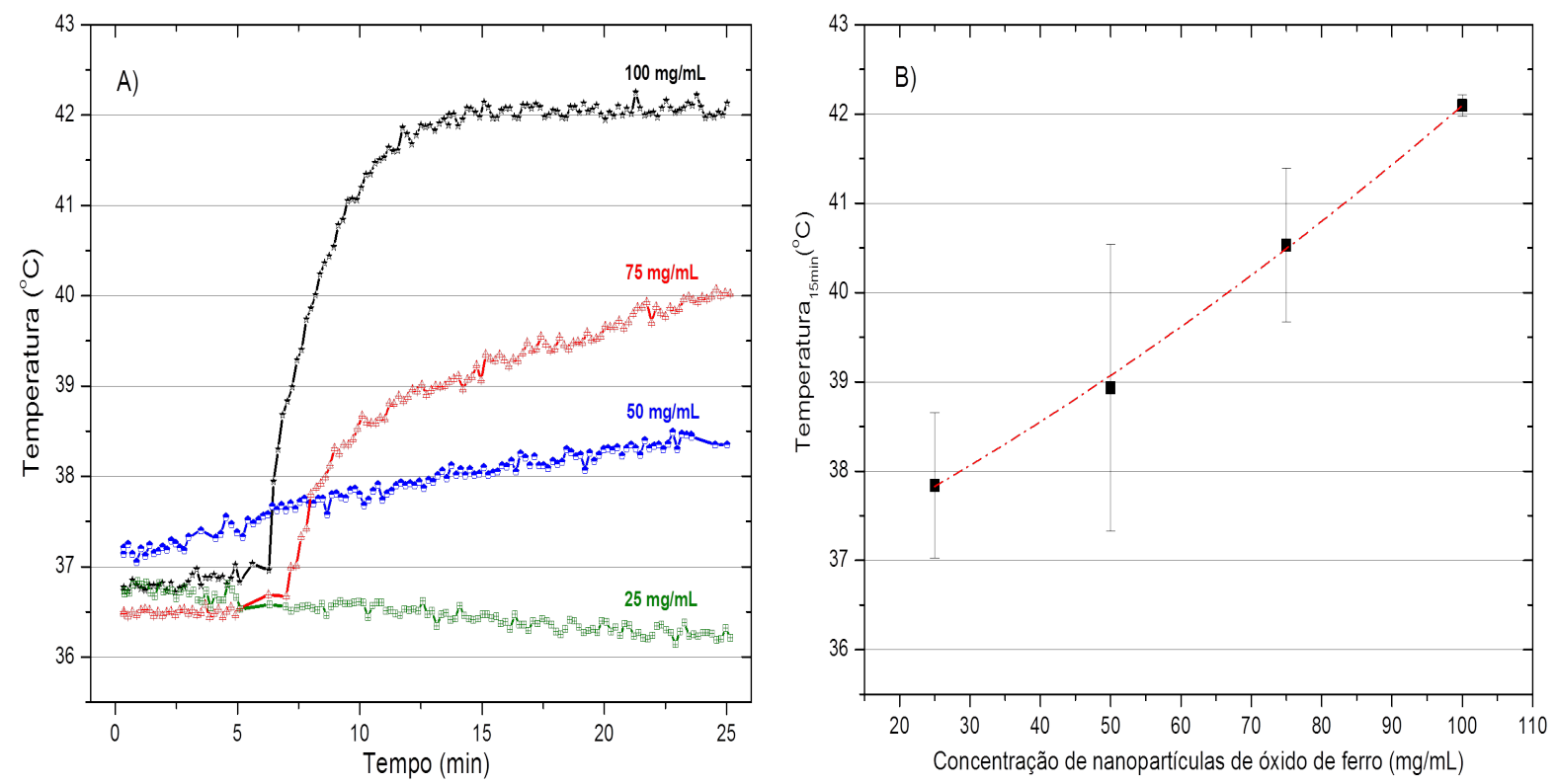

Figura 4.17: Temperatura obtida no interior da bexiga do rato devido a exposição a uma amplitude de campo magnético de $5,5 \mathrm{kA} / \mathrm{m}$, a uma frequência de $40 \mathrm{kHz}$. (A) Representa os perfis de taxa de aquecimento para quatro concentrações diferentes $(25-100 \mathrm{mg} / \mathrm{mL})$ de $0,4 \mathrm{~mL}$ de fluido magnético injetado na bexiga do rato, e (B) apresenta as temperaturas atingidas no interior da bexiga após 15 minutos de aquecimento em função da concentração de material magnético. As barras representam os valores máximos e mínimos obtidos para pelo menos três animais por ponto.

que melhor se ajusta aos requisitos da hipertermia é a concentração de $100 \mathrm{mg} / \mathrm{mL}$, pois atinge a temperatura desejada de $42{ }^{\circ} \mathrm{C}$ em menos de $10 \mathrm{~min}$. Embora o volume alvo seja menor, os resultados são consistentes com as concentrações usadas em aplicações clínicas da magneto-hipertermia aplicada a tumores de próstata e intracranianos.

\section{Efeito da variação do volume de fluído magnético}

Complementarmente a modulação da concentração, alterou-se também o volume injetado no interior da bexiga $(0,2,0,3$, e $0,4 \mathrm{~mL})$ para uma concentração fixa. A concentração de nanopartícula utilizada neste caso foi de $100 \mathrm{mg} / \mathrm{mL}$.

A Figura 4.18(A) indica que o volume de maior dissipação de calor na bexiga é o volume de 0,4 mL. Neste caso, a temperatura elevou-se rapidamente ao valor desejado, e o controle automático da amplitude de campo magnético se fez necessário para que se pudesse manter constante a temperatura de $42^{\circ} \mathrm{C}$ no interior da bexiga. 

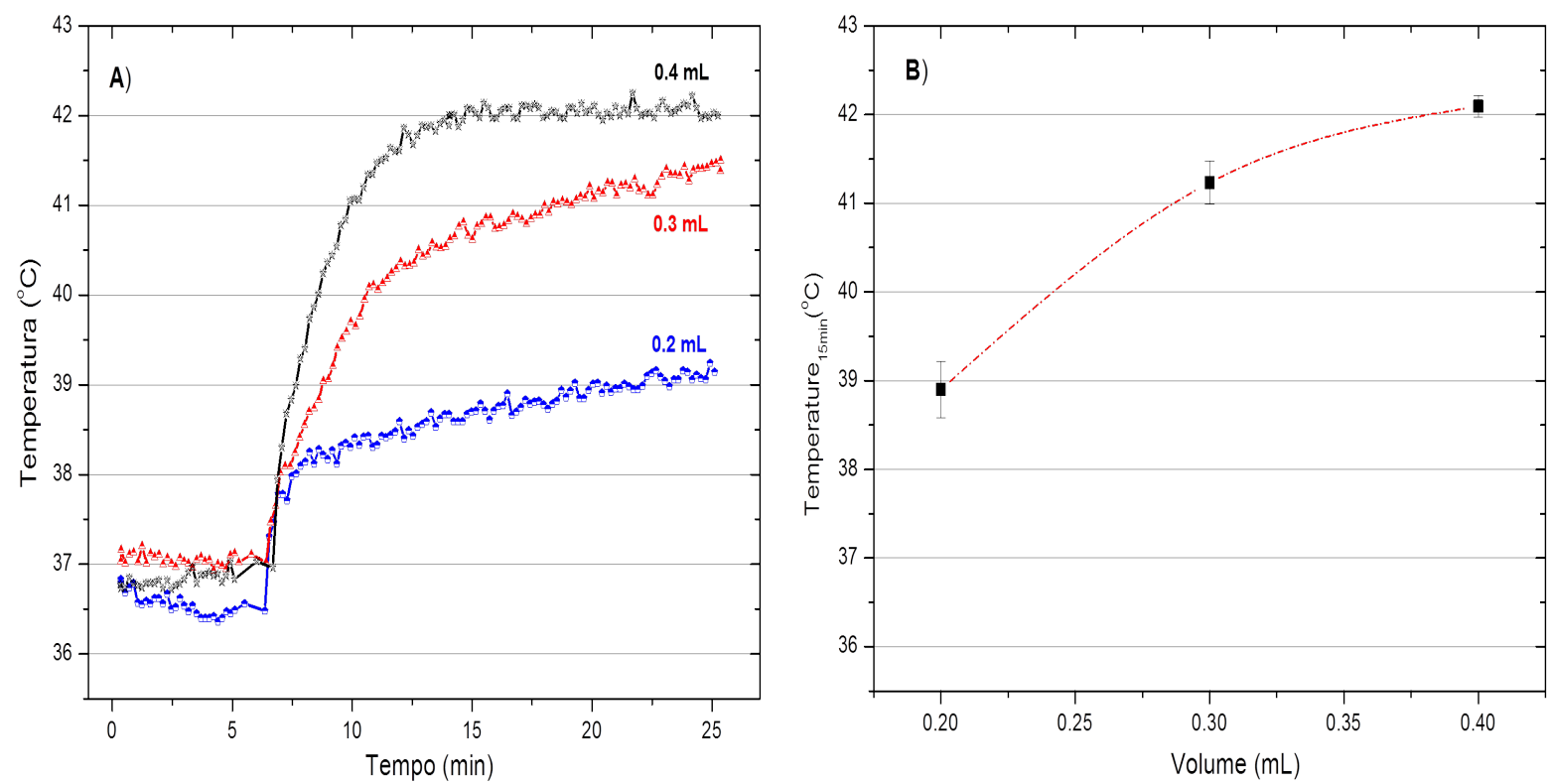

Figura 4.18: Temperaturas obtidas no interior da bexiga da rata seguindo a exposição a uma amplitude de campo magnético de $5,5 \mathrm{kA} / \mathrm{m}$ a uma frequência de $40 \mathrm{kHz}$. (A) Representa os perfis de taxa de aquecimento para três volumes diferentes $(0.2-0,4 \mathrm{~mL})$ de $100 \mathrm{mg} / \mathrm{mL}$ de fluido magnético injetados na bexiga da rata, e (B) apresenta as temperaturas atingidas no interior da bexiga após 15 minutos de aquecimento em função do volume injetado na bexiga. As barras representam os valores máximos e mínimos obtidos para pelo menos três animais por ponto.

A figura 4.18(B) demonstra que a máxima temperatura atingida no interior da bexiga depende do aumento do volume de fluido magnético. A variação do volume incutido não apenas varia a massa total de partículas magnéticas, mas também modifica taxa de troca de calor entre as paredes da bexiga e o tecido ao redor, uma vez que a razão de volume de nanopartícula para a área superficial da bexiga também se altera. Portanto, volumes pequenos de nanopartícula em contato direto com tecido perfundido, tendem a sofrer uma maior perda por condução térmica para o tecido resfriado. Em contraste, volumes grandes de nanopartículas promovem maior elevação da temperatura com a mesma taxa de potência de absorção, por que existem maiores quantidades de nanopartícula produzindo calor centralmente no volume interno sem contato algum com os tecidos perfundidos. Este resultado está de acordo com o encontrado por (Hergt \& Dutz, 2007) que indicaram que a potência específica de aquecimento para uma dada elevação de temperatura aumenta drasticamente com a diminuição do tamanho do tumor. 


\subsubsection{Características de controle do equipamento}

Por este estudo se tratar dos primeiros experimentos in vivo realizados por algum dos equipamentos da Actium Biosystem, tornou-se necessário realizar alguns testes de controle do equipamento devido à imprecisão de informações do fabricante. O primeiro teste realizado foi com relação ao algoritmo de controle e estabilidade de temperatura no tecido alvo, e o segundo consistiu na verificação do impacto de aquecimento não-específico no sujeito durante o todo período de tratamento.

\section{Controle automático da amplitude de campo magnético}

O controle e estabilidade da temperatura durante o tratamento de hipertermia é uma preocupação de qualquer modalidade de aquecimento, e em muitas situações o controle da deposição de energia é complexo e com grande heterogeneidade entre os diversos tecidos. Nesta etapa nós avaliamos a qualidade e segurança do algoritmo de controle do campo magnético fornecido com o equipamento da Actium. Durante cada experimento, a amplitude de campo magnético foi automaticamente controlada, e usando como referência a temperatura no interior da bexiga. O objetivo foi manter constante a temperatura de tratamento de $42^{\circ} \mathrm{C}$. Os testes iniciais mostraram que o algoritmo desenvolvido pelo fabricante era impreciso, com limitações de controle. Diversas opiniões foram transmitidas ao fabricante e através de um processo interativo e colaborativo foi possível chegar a padrões aceitáveis.

O controle rápido do campo é extremamente importante para garantir a correta dose térmica no tecido alvo. A Figura 4.19 ilustra a dependência temporal da amplitude do campo magnético requerido para manter a temperatura terapêutica durante o período típico de tratamento da bexiga. O controle do campo foi realizado de forma automática.

A temperatura terapêutica foi atingida para todos os animais testados com 100 $\mathrm{mg} / \mathrm{mL}$ de nanopartícula. Para a maioria dos tratamentos, a temperatura estacionária foi obtida com amplitudes de campo magnético entre 3,5 e 4,5 kA/m. Como indica a Figura 4.19, a temperatura no lúmen da bexiga foi satisfatoriamente mantida a $42^{\circ} \mathrm{C}$ durante todo o período de tratamento, demonstrando assim a eficiência do sistema de 


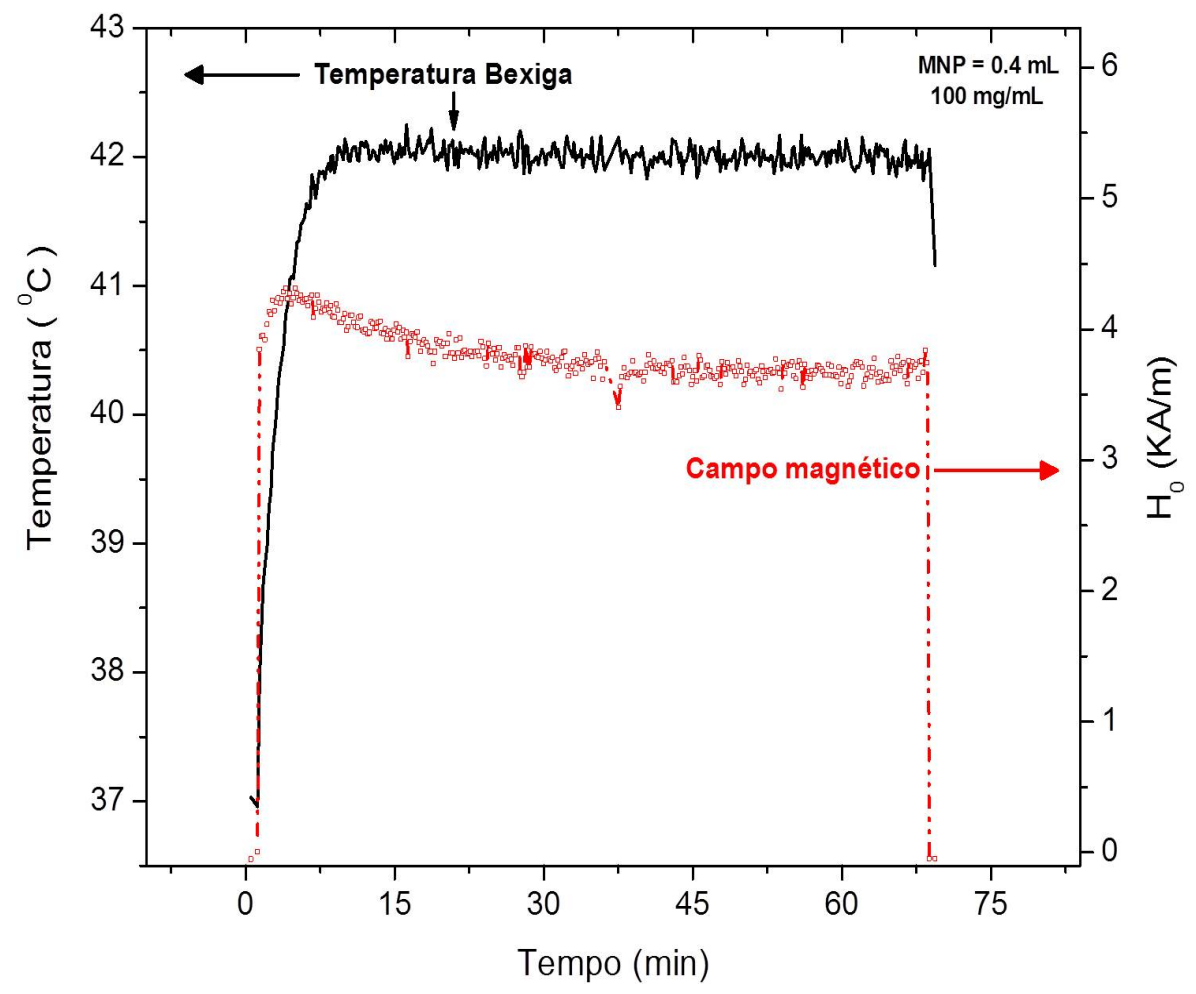

Figura 4.19: Típico perfil do comportamento temporal da amplitude de campo magnético (curva vermelha, eixo direito) aplicado durante a magneto-hipertermia (nanopartículas - 0,4 mL of 100 $\mathrm{mg} / \mathrm{mL}$ ) para uma temperatura desejada de $42^{\circ} \mathrm{C}$, no interior da bexiga da rata (curva preta, eixo esquerdo).

controle.

\section{Calor não-específico induzido em regiões externas à bexiga}

Uma das principais preocupações no uso da magneto-hipertermia é garantir total segurança ao paciente submetido no campo magnético alternado. A exposição a campos eletromagnéticos oscilantes resulta no surgimento de correntes internas ao corpo, consequência da lei de indução, dependente do mecanismo de acoplamento e da frequência de oscilação. O campo elétrico interno e a densidade de corrente induzida são relacionados pela lei de Ohm:

$$
\vec{J}=\sigma \vec{E}
$$

sendo " $\sigma$ "a condutividade elétrica do meio.

Como citado, a interação do corpo humano com campos magnéticos oscilantes re- 
sulta na indução de campos elétricos e correntes circulantes (correntes de eddy) no mesmo. As magnitudes do campo induzido e a densidade de corrente são proporcionais ao raio de circulação, a condutividade elétrica dos tecidos, a razão de oscilação e a magnitude da densidade de fluxo magnético. Para uma dada magnitude e frequência de campo magnético, tem-se que quanto maior a dimensão do raio de circulação, maior o campo elétrico induzido. O exato caminho e magnitude das correntes induzidas irá depender da condutividade elétrica de cada tecido do corpo. A presença de correntes induzidas no corpo promove um aquecimento direto e não-específico dos tecidos biológicos por efeito joule. Esse aquecimento não-específico é considerado proporcional ao quadrado do produto da intensidade de campo magnético, à frequência de oscilação, e ao raio de circulação da corrente no tecido (Eq.4.9) (Ivkov et al., 2005).

$$
S A R_{e d d y} \propto \sigma f^{2} \cdot H^{2} \cdot r^{2}
$$

sendo "SAR"a taxa de absorção de energia para um dado tecido, medido em $\mathrm{W} / \mathrm{g}$ de tecido, "r"o raio de exposição da região, "f"e "H"são a frequência e amplitude do campo magnético.

Com o intuito de identificar a possibilidade da indução de calor não-específico ao corpo dos ratos quando estiverem no interior da bobina, dois animais foram submetidos à incidência de campo magnético com amplitude semelhante a utilizada no processo de magneto-hipertermia $(5,3 \mathrm{kA} / \mathrm{m})$, durante o período de $1 \mathrm{~h}$, e sem a inoculação de fluído magnético. Para buscar manter as condições normotérmicas dos ratos, foram utilizadas mantas de aquecimento $\left(36-37^{\circ} \mathrm{C}\right)$.

A Figura 4.20 apresenta as curvas de temperatura obtidas para seis pontos distintos de monitoramento em um dos ratos observados. Após 63 minutos sob incidência do campo magnético, imprimiu-se um fluxo forçado de ar para tentar minimizar os impactos da elevação da temperatura do próprio ambiente da cavidade da bobina.

As curvas de temperatura da Figura 4.20 mostram que a temperatura no interior da bobina sofreu uma elevação de $4,5^{\circ} \mathrm{C}$ durante os 60 min de experimento, muito devido à dissipação por efeito joule nos fios da bobina indutora. Esse aumento de temperatura no ambiente, por sua vez, produziu um pequeno impacto na temperatura corpórea, como 


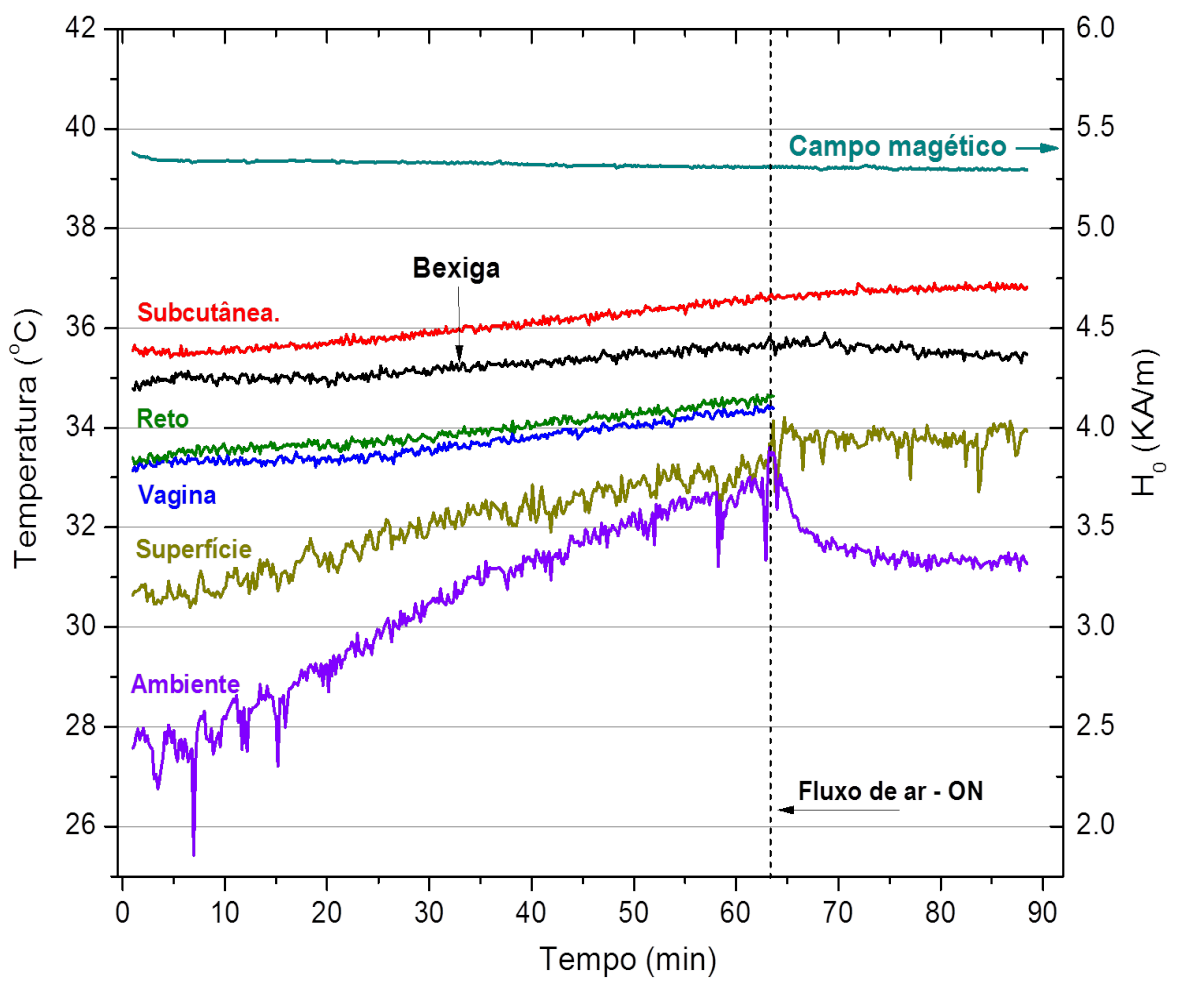

Figura 4.20: Temperatura corpórea da rata sob incidência de campo magnético com intensidade de $5,3 \mathrm{kA} / \mathrm{m}$ e frequência de $40 \mathrm{kHz}$. Na bexiga foram injetados $0,4 \mathrm{~mL}$ de solução salina. Observa-se um aumento significativo na temperatura ambiente da bobina.

pode ser evidenciado nos pontos monitorados. A superfície da pele foi a região que sofreu maior impacto devido à proximidade com o ar. De modo geral, todas as elevações de temperatura observadas podem ser consideradas pequenas, como no caso da bexiga que sofreu um acréscimo de $0,4^{\circ} \mathrm{C}$ durante os 90 -min de campo magnético ligado. Devido o aumento não-específico de temperatura ser pequeno, quando comparado com o aumento desejado com o fluído magnético, os experimentos subsequentes foram realizados sem o fluxo de ar. Nossos resultados demonstram claramente que os valores estipulados para a intensidade de campo e frequência satisfazem os requisitos de mínima deposição direta de energia.

\subsubsection{Ensaios de controle e estabilidade da temperatura in vivo}

O objetivo final de qualquer metodologia de aquecimento é o de promover a elevação de temperatura em uma dada região restrita de interesse, de modo controlado e eficiente. 
A partir da simulação computacional do sistema de magneto-hipertermia, a distribuição de temperatura local foi estimada para a região de atuação do sistema. Entretanto, tornouse essencial a validação experimental in vivo dessa distribuição, devido às limitações do modelo computacional utilizado. Sendo assim, foram realizados ensaios de verificação da distribuição e estabilidade da temperatura local nos indivíduos teste.

Para executar a atividade foram incutidos $0,4 \mathrm{~mL}$ de fluido magnético na bexiga de cinco ratos, e estes foram submetidos ao campo magnético por 70 minutos. O controle do sistema foi realizado de modo automático, tal que fosse garantida a estabilidade da temperatura no interior da bexiga. A Figura 4.21 apresenta os valores médios obtidos para as temperaturas monitoradas nos diversos pontos do corpo do rato: na bexiga, vagina, e para um conjunto de quatro sondas distribuídas pelo corpo (uretra, reto, boca, abdome subcutâneo). As barras verticais representam o desvio padrão dos valores médios. Neste experimento o campo magnético foi acionado a partir do tempo " 0 ".

Observando os resultados obtidos na figura 4.21 constata-se que o tempo médio requerido para elevar a temperatura no interior da bexiga ao valor alvo $\left(42^{\circ} \mathrm{C}\right)$ foi inferior a 10 min. Tempo considerado satisfatório para aplicações clínicas. Durante o período de 60 minutos da hipertermia, a temperatura corpórea elevou-se em 1,0 a $1,5^{\circ} \mathrm{C}$, na ausência de um sistema de resfriamento. O controle automático do campo magnético foi capaz de manter uma variação da temperatura no interior da bexiga (curva vermelha) menor que $0,2^{\circ} \mathrm{C}$. Após 60 minutos a $42^{\circ} \mathrm{C}$ o campo magnético foi desligado, e a temperatura sofreu um rápido decréscimo.

A Figura 4.21 também mostra que a temperatura na vagina exibe uma grande variabilidade quando comparada a outras regiões do corpo. Esta variabilidade pode ser explicada como uma imprecisão na posição da sonda. Devido à proximidade da bexiga, a vagina é sujeita a uma grande dependência com a posição da sonda. Apesar desta variação, as temperaturas observadas na vagina são claramente distintas das observadas na bexiga, o que demonstra a efetiva localização do calor no interior do alvo que era a bexiga.

Com intuito de apresentar uma ideia mais ampla sobre a distribuição da tempe- 


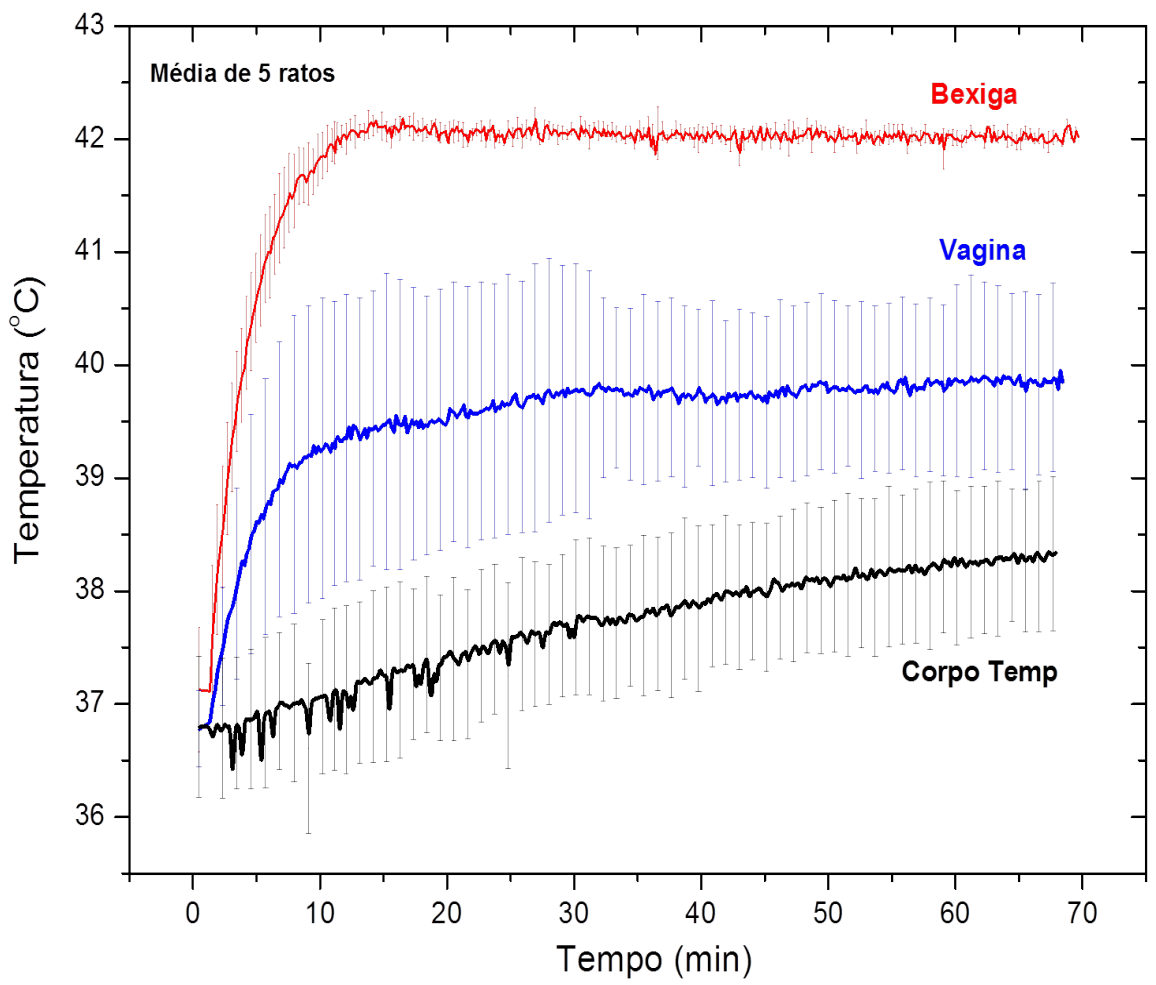

Figura 4.21: Temperaturas médias obtidas em cinco raaos distintas durante uma hora de tratamento de magneto-hipertermia. Estas curvas demostram a excelente localização do aquecimento na região da bexiga (curva vermelha) quando comparado com regiões do entorno, vagina (curva azul) e multi-regiões (curva preta). A curva descrita como "Corpo temp"(curva preta) representa a média da temperatura entre diversas regiões monitoradas ( subcutânea, reto e oral). A concentração de nanopartículas utilizada para todos os experimentos foi de $100 \mathrm{mg} / \mathrm{mL}$.

ratura na rata, durante o período de tratamento, apresenta-se na tabela 4.1 os valores estacionários para as temperaturas monitoradas nas sete posições especificadas neste experimento.

Tabela 4.1: Temperaturas médias, obtidas na condição estacionária, para diferentes localizações em cinco ratos submetidos à magneto-hipertermia. O desvio padrão é apresentato entre os parenteses.

\begin{tabular}{cccccccc}
\hline & Ambiente & Subcutânea & Bexiga & Uretra & Vagina & Reto & Boca \\
\hline $\begin{array}{c}\text { Temperatura } \\
\left({ }^{\circ} \mathrm{C}\right)\end{array}$ & $31(2)$ & $38.1(0.8)$ & $42.0(0.2)$ & $39.6(0.8)$ & $39.8(0.8)$ & $38.3(0.7)$ & $37.6(0.8)$ \\
\hline
\end{tabular}

Como mostra a Tabela 4.1, os tecidos do entorno foram mantidos abaixo dos $40^{\circ} \mathrm{C}$ na condição de estabilidade, enquanto a bexiga foi mantida a $42^{\circ} \mathrm{C}$. Estes resultados demonstram a habilidade de localização da dissipação de energia no interior da bexiga 
através do uso da magneto-hipertermia.

\subsection{Conclusões}

Este trabalho investigou, pela primeira vez, a viabilidade da aplicação da magnetohipertermia para o aquecimento da bexiga. Usando um sistema de aquecimento centrado em $40 \mathrm{KHz}$, foi possível aquecer localmente a bexiga de ratas quando esta foi incutida com fluido magnético. Adicionalmente, definiu-se um protocolo de cateterização que permitiu o preenchimento seguro da bexiga com apenas uma injeção de nanopartículas, além de preservar o fluido armazenado durante os 60 minutos de tratamento.

Através de ensaios de refluxo, definiu-se a existência de limite no volume de injeção na ordem de $0,35-0,4 \mathrm{~mL}$ na bexiga, para que não ocorra refluxo aos rins. A temperatura no interior da bexiga foi repetidamente aquecida a $42^{\circ} \mathrm{C}$ em 10 minutos com $100 \mathrm{mg} / \mathrm{mL}$ de magnetita, e esta temperatura foi mantida por um controle automático durante o período de tratamento. Este estudo demonstrou um aquecimento localizado na bexiga das ratas com a técnica de magneto-hipertermia, com efeitos mínimos de aquecimento nos tecidos do entorno. Este trabalho foi publicado no International Journal of Hyperthermia em setembro de 2013 (29(8): 835-844).

Experimentos futuros com esse procedimento são necessários para investigar a eficiência e benefícios do tratamento de magneto-hipertermia aplicado à bexiga. 


\section{Capítulo 5}

\section{Conclusões gerais}

Neste trabalho, desenvolveu-se métodos, protocolos e instrumentação que auxiliam o estudo in vivo da distribuição termo-estimulada de quimioterápicos.

O desenvolvimento de carreadores de drogas termosensíveis para o combate ao câncer tem aumentado significativamente nos últimos anos. No entanto, existe uma grande lacuna quanto à disponibilidade de equipamentos comercias que possibilitem o estudo da eficiência destes transportadores no nível pré-clínico. Por isso, grupos de pesquisa que atuam nesta área devem desenvolver o seu próprio aparato experimental de aquecimento. Nesta tese, apresentam-se três etapas de trabalho: primeiro, discute-se o desenvolvimento de um mini-aplicador de micro-onda capaz de aquecer localmente, e de forma controlada, um dos hemisférios do cérebro do camundongo; em seguida, utilizando o protocolo de aquecimento pré-estabelecido, foi monitorada, por microscopia confocal de fluorescência, a distribuição da droga doxorrubicina na região de tumores de glioblastoma em camundongos; e por último, avaliou-se a viabilidade do uso do método de magneto-hipertermia para o aquecimento localizado da bexiga de ratos.

O aplicador de micro-onda escolhido para a função de aquecer parte do cérebro do camundongo foi a guia de onda retangular, com radiação eletromagnética de $3,7 \mathrm{GHz}$. O projeto, construção e teste de eficiência de aquecimento in vivo foram todos eles desenvolvidos pela primeira vez neste trabalho. Através dos experimentos dosimétricos, demostrou-se que 5W é a potência de excitação necessária para atingir a temperatura de $42^{\circ} \mathrm{C}$ na superfície do cérebro do camundongo. A temperatura local foi monitorada por 
dois sensores ópticos de modo invasivo em todo o protocolo. Todo o procedimento de aquecimento e monitoramento da temperatura foi definido tal que garantisse a sobrevivência, sem grandes sequelas, dos animais utilizados no estudo. Com a definição de um protocolo seguro de aquecimento do cérebro, foi possível realizar ensaios de distribuição da doxorrubicina por microscopia confocal.

O uso da microscopia confocal de fluorescência permitiu avaliar os efeitos do aquecimento local e moderado na distribuição da doxorrubicina encapsulada em lipossomos termosensíveis na região de tumores modelo de glioblastoma. Com o uso do mini-aplicador de micro-onda, desenvolvido neste projeto e posicionado no hemisfério direito do cérebro do camundongo, foi possível demonstrar a eficiência na termo-seleção na liberação de doxorrubicina, com concentrações de droga livre superiores na região aquecida. Através da marcação fluorescente dos lipossomos com a sonda carboxifluoresceína, foi possível também monitorar a distribuição local dos lipossomos. Os resultados mostraram que não ocorre extravasamento nas paredes dos vasos, o que indica uma liberação intravascular. Complementarmente, o estudo quantitativo da distribuição de doxorrubicina nos tumores indicou um aumento de pelo menos 5 vezes de acúmulo do medicamento em regiões submetidas à hipertermia. O protocolo desenvolvido aqui mostrou que a temperatura constante de $42^{\circ} \mathrm{C}$, por um período de 15 min, pode ser utilizada de modo seguro sem a indução de danos térmicos significativos.

De modo geral, concluímos com esse trabalho que temperaturas moderadas promovem alterações significativas na permeabilidade da barreira hematoencefálica, mesmo nos tecidos sadios. O uso do aquecimento local promove grande benefício à entrega de doxorrubicina a tumores cerebrais, não só com relação ao acúmulo total de droga, mas também com o grau de penetração e exposição aos quais as células são submetidas.

O estudo do uso da magneto-hipertermia, que utiliza nanopartículas magnéticas sob ação de campo magnético oscilante, como agente gerador de calor no aquecimento de bexigas, não apresenta registros anteriores na literatura, logo consideramos este trabalho como pioneiro da área. Os resultados dosimétricos obtidos apontaram para uma excelente localização do calor na região interna da bexiga, e grande preservação dos tecidos vizinhos. 
Para a espécie de rato utilizada, observou-se a incidência de refluxo aos rins para volumes incutidos na bexiga maiores que $0,4 \mathrm{~mL}$. O protocolo de aquecimento definido nesta etapa demonstrou que o interior da bexiga foi repetidamente aquecido a $42^{\circ} \mathrm{C}$ em menos de 10 minutos, portanto, considera-se como viável a utilização da magneto-hipertermia no aquecimento localizado da bexiga. 


\section{Referências Bibliográficas}

Abbott, N Joan, Patabendige, Adjanie AK, Dolman, Diana EM, Yusof, Siti R, \& Begley, David J. 2010. Structure and function of the blood-brain barrier. Neurobiology of disease, 37(1), 13-25.

Allard, E., Passirani, C., \& Benoit, J. P. 2009. Convection-enhanced delivery of nanocarriers for the treatment of brain tumors. Biomaterials, 30(12), 2302-2318.

Andrä, Wilfried, \& Nowak, Hannes. 2007. Magnetism in medicine: a handbook. John Wiley \& Sons.

Aoki, H, Kakinuma, K, Morita, K, Kato, M, Uzuka, T, Igor, G, Takahashi, H, \& Tanaka, R. 2004. Therapeutic efficacy of targeting chemotherapy using local hyperthermia and thermosensitive liposome: evaluation of drug distribution in a rat glioma model. International journal of hyperthermia, 20(6), 595-605.

Arunachalam, Kavitha, Maccarini, Paolo F, Schlorff, Jaime L, Birkelund, Yngve, Jacobsen, Svein, \& Stauffer, Paul R. 2009. Design of a water coupling bolus with improved flow distribution for multi-element superficial hyperthermia applicators. International Journal of Hyperthermia, 25(7), 554-565.

Atkinson, W. J., Brezovich, I. A., \& Chakraborty, D. P. 1984. Usable frequencies in hyperthermia with thermal seeds. Biomedical Engineering, IEEE Transactions on, 7075 .

Au, J.L.S., Jang, S.H., Zheng, J., Chen, C.T., Song, S., Hu, L., \& Wientjes, M.G. 2001. Determinants of drug delivery and transport to solid tumors. Journal of controlled release, $\mathbf{7 4}(1), 31-46$. 
Azocar, J., Yunis, E. J., \& Essex, M. 1982. Sensitivity of human natural killer cells to hyperthermia. The Lancet, $\mathbf{3 1 9}(8262)$, 16-17.

Balanis, Constantine A. 1989. Advanced engineering electromagnetics. Vol. 20. Wiley New York.

Becker, M. J., de Marie, S., Fens, M. H. A. M., Hop, W. C. J., Verbrugh, H. A., \& BakkerWoudenberg, I. A. J. M. 2002. Enhanced antifungal efficacy in experimental invasive pulmonary aspergillosis by combination of AmBisome with Fungizone as assessed by several parameters of antifungal response. Journal of Antimicrobial Chemotherapy, 49(5), 813-820.

Bordelon, D. E., Cornejo, C., Gruttner, C., Westphal, F., DeWeese, T. L., \& Ivkov, R. 2011. Magnetic nanoparticle heating efficiency reveals magneto-structural differences when characterized with wide ranging and high amplitude alternating magnetic fields. Journal of Applied Physics, 109(12), 124904.

Bovie, W. T. 1928. From Cushing H. Electrosurgery as an aid to the removal of intracranial tumors with a preliminary note on a new surgical-current generator. Surg Gynecol Obstet, 47, 751-784.

Buschow, KH Jürgen, \& De Boer, Frank R. 2003. Physics of magnetism and magnetic materials. Vol. 92. Springer.

Bussolino, F., Arese, M., Audero, E., Giraudo, E., Marchio, S., Mitola, S., Primo, L., \& Serini, G. 2003. Biological aspects of tumour angiogenesis. Cancer Modeling and Simulation, Preziosi, L., Ed., Boca Raton, FL: Chapman \& Hall/CRC Press, 1-22.

cancer.gov. 2014a. Cancer Statistics. http://www.cancer.gov/statistics.

cancer.gov. 2014b. Chemoradiation May Help Some Patients with Bladder Cancer Avoid Radical Surgery. http://www.cancer.gov/ncicancerbulletin/050112/page2.

Cann, S. A. H., Van Netten, J. P., \& Van Netten, C. 2003. Dr William Coley and tumour regression: a place in history or in the future. Postgraduate medical journal, 79(938), $672-680$. 
Canters, RAM, Wust, P, Bakker, JF, \& Van Rhoon, GC. 2009. A literature survey on indicators for characterisation and optimisation of SAR distributions in deep hyperthermia, a plea for standardisation. International Journal of Hyperthermia, 25(7), 593-608.

Carpentier, Alexandre, McNichols, Roger J, Stafford, R Jason, Guichard, Jean-Pierre, Reizine, Daniel, Delaloge, Suzette, Vicaut, Eric, Payen, Didier, Gowda, Ashok, \& George, Bernard. 2011. Laser thermal therapy: Real-time MRI-guided and computercontrolled procedures for metastatic brain tumors. Lasers in surgery and medicine, 43(10), 943-950.

celsion.com. 2014. Pipeline within a Product. http://www.celsion.com/links.cfm.

Chen, Q., Krol, A., Wright, A., Needham, D., Dewhirst, M. W., \& Yuan, F. 2008. Tumor microvascular permeability is a key determinant for antivascular effects of doxorubicin encapsulated in a temperature sensitive liposome. International Journal of Hyperthemia, 24(6), 475-482.

Chen, Y., \& Liu, L. 2012. Modern methods for delivery of drugs across the blood-brain barrier. Advanced drug delivery reviews, 64(7), 640-665.

Cho, E. E., Drazic, J., Ganguly, M., Stefanovic, B., \& Hynynen, K. 2011. Two-photon fluorescence microscopy study of cerebrovascular dynamics in ultrasound-induced bloodbrain barrier opening. Journal of Cerebral Blood Flow and Metabolism, 31(9), 18521862.

Chong, Kyuha, Ku, Taeyun, Choi, Kyungsun, Choi, Myunghwan, Yoon, Jonghee, \& Choi, Chulhee. 2011. Current Optical Imaging Techniques for Brain Tumor Research: Application of in vivo Laser Scanning Microscopy Imaging with a Cranial Window System. InTech, Rijeka, 155-72.

cnx.org. 2014. Body Fluids and Fluid Compartments. http://cnx.org/content/m46411/latest/.

Collin, Robert E. 2007. Foundations for microwave engineering. John Wiley \& Sons. 
Colombo, R., Salonia, A., Da Pozzo, L. F., Naspro, R., Freschi, M., Paroni, R., PavoneMacaluso, M., \& Rigatti, P. 2003a. Combination of intravesical chemotherapy and hyperthermia for the treatment of superficial bladder cancer: preliminary clinical experience. Critical reviews in oncology/hematology, 47(2), 127-139.

Colombo, R., Do Pozzo, L. F., Salonia, A., Rigatti, P., Leib, Z., Baniel, J., Caldarera, E., \& Pavone-Macaluso, M. 2003b. Multicentric study comparing intravesical chemotherapy alone and with local microwave hyperthermia for prophylaxis of recurrence of superficial transitional cell carcinoma. Journal of Clinical Oncology, 21(23), 4270-4276.

Danhier, F., Feron, O., \& Préat, V. 2010. To exploit the tumor microenvironment: Passive and active tumor targeting of nanocarriers for anti-cancer drug delivery. Journal of Controlled Release, 148(2), 135-146.

Davidson, David B. 2005. Computational electromagnetics for RF and microwave engineering. Cambridge University Press.

De Greef, M, Kok, HP, Correia, D, Bel, A, \& Crezee, J. 2010. Optimization in hyperthermia treatment planning: The impact of tissue perfusion uncertainty. Medical physics, 37(9), 4540-4550.

De Greef, M, Kok, HP, Bel, A, \& Crezee, J. 2011. 3D versus 2D steering in patient anatomies: A comparison using hyperthermia treatment planning. International Journal of Hyperthermia, 27(1), 74-85.

DeAngelis, Lisa M. 2001. Brain tumors. New England Journal of Medicine, 344(2), $114-123$.

Dennis, C. L., \& Ivkov, R. 2013. Physics of heat generation using magnetic nanoparticles for hyperthermia. International Journal of Hyperthermia, 29(8), 715-729.

Dervishi, Elvis, Larrat, Benoit, Pernot, Mathieu, Adam, Clovis, Marie, Yannick, Fink, Mathias, Delattre, Jean-Yves, Boch, Ann-Laure, Tanter, Mickael, \& Aubry, JeanFrancois. 2013. Transcranial high intensity focused ultrasound therapy guided by 7 
TESLA MRI in a rat brain tumour model: A feasibility study. International Journal of Hyperthermia, 29(6), 598-608.

Dewhirst, M. W., Cao, Y., \& Moeller, B. 2008. Cycling hypoxia and free radicals regulate angiogenesis and radiotherapy response. Nature Reviews Cancer, 8(6), 425-437.

Dewhirst, M.W., Kimura, H., Rehmus, S.W., Braun, R.D., Papahadjopoulos, D., Hong, K., \& Secomb, T.W. 1996. Microvascular studies on the origins of perfusion-limited hypoxia. The British journal of cancer. Supplement, 27, S247.

Dreher, M. R., Liu, W. G., Michelich, C. R., Dewhirst, M. W., Yuan, F., \& Chilkoti, A. 2006a. Tumor vascular permeability, accumulation, and penetration of macromolecular drug carriers. Journal of the National Cancer Institute, 98(5), 335-344.

Dreher, Mattew Robert. 2006. Título da tese: "Drug Delivery To Solid Tumors With Elastin-Like Polypeptide Drug Carriers". Duke University, Department of Biomedical Engineering.

Dreher, Matthew R, Liu, Wenge, Michelich, Charles R, Dewhirst, Mark W, Yuan, Fan, \& Chilkoti, Ashutosh. 2006b. Tumor vascular permeability, accumulation, and penetration of macromolecular drug carriers. Journal of the National Cancer Institute, 98(5), 335344 .

Drummond, D. C., Meyer, O., Hong, K. L., Kirpotin, D. B., \& Papahadjopoulos, D. 1999. Optimizing liposomes for delivery of chemotherapeutic agents to solid tumors. Pharmacological Reviews, 51(4), 691-743.

Duncan, R. 2003. The dawning era of polymer therapeutics. Nature Reviews Drug Discovery, 2(5), 347-360.

El-Kareh, A. W., \& Secomb, T. W. 2000. A mathematical model for comparison of bolus injection, continuous infusion, and liposomal delivery of doxorubicin to tumor cells. Neoplasia, 2(4), 325-338.

Fletcher, Roger. 2013. Practical methods of optimization. John Wiley \& Sons. 
Fortin, Jean-Paul, Gazeau, Florence, \& Wilhelm, Claire. 2008. Intracellular heating of living cells through Néel relaxation of magnetic nanoparticles. European Biophysics Journal, 37(2), 223-228.

Foster, KR, \& Schepps, JL. 1981. Dielectric properties of tumor and normal tissues at radio through microwave frequencies. The Journal of microwave power, 16(2), 107-119.

Franckena, Martine, Canters, Richard, Termorshuizen, F, Van Der Zee, Jacoba, \& Van Rhoon, Gerard. 2010. Clinical implementation of hyperthermia treatment planning guided steering: A cross over trial to assess its current contribution to treatment quality. International Journal of Hyperthermia, 26(2), 145-157.

Frenkel, J., \& Dorfman, J. 1930. Spontaneous and induced magnetisation in ferromagnetic bodies. Nature, 126(3173), 274-275.

Gaber, M. H., Wu, N. Z., Hong, K. L., Huang, S. K., Dewhirst, M. W., \& Papahadjopoulos, D. 1996. Thermosensitive liposomes: Extravasation and release of contents in tumor microvascular networks. International Journal of Radiation Oncology Biology Physics, 36(5), 1177-1187.

Gabriel, Camelia, Gabriel, Sami, \& Corthout, E. 1996a. The dielectric properties of biological tissues: I. Literature survey. Physics in medicine and biology, 41(11), 2231.

Gabriel, S, Lau, RW, \& Gabriel, Camelia. 1996b. The dielectric properties of biological tissues: II. Measurements in the frequency range $10 \mathrm{~Hz}$ to $20 \mathrm{GHz}$. Physics in medicine and biology, 41(11), 2251.

Gabriel, Sami, Lau, RW, \& Gabriel, Camelia. 1996c. The dielectric properties of biological tissues: III. Parametric models for the dielectric spectrum of tissues. Physics in medicine and biology, 41(11), 2271.

Gasselhuber, A., Dreher, Matthew R, Partanen, Ari, Yarmolenko, Pavel S, Woods, David, Wood, Bradford J, \& Haemmerich, Dieter. 2012. Targeted drug delivery by high intensity focused ultrasound mediated hyperthermia combined with temperature-sensitive 
liposomes: Computational modelling and preliminary in vivo validation. International Journal of Hyperthermia, 28(4), 337-348.

Gasselhuber, Astrid, Dreher, Matthew R, Negussie, Ayele, Wood, Bradford J, Rattay, Frank, \& Haemmerich, Dieter. 2010. Mathematical spatio-temporal model of drug delivery from low temperature sensitive liposomes during radiofrequency tumour ablation. International Journal of Hyperthermia, 26(5), 499-513.

Gennis, R. B. 1989. Biomembranes: molecular structure and function. Springer.

Gilchrist, RK, Medal, Richard, Shorey, William D, Hanselman, Russell C, Parrott, John C, \& Taylor, C Bruce. 1957. Selective inductive heating of lymph nodes. Annals of surgery, 146(4), 596.

Gneveckow, Uwe, Jordan, Andreas, Scholz, Regina, BRüSS, Volker, Waldöfner, Norbert, Ricke, Jens, Feussner, Annelie, Hildebrandt, Bert, Rau, Beate, \& Wust, Peter. 2004. Description and characterization of the novel hyperthermia-and thermoablation-system MFH@ 300F for clinical magnetic fluid hyperthermia. Medical physics, 31(6), 14441451.

Gofrit, ON, Shapiro, A, Pode, D, Sidi, A, Nativ, O, Leib, Z, Witjes, JA, Van Der Heijden, AG, Naspro, R, \& Colombo, R. 2004. Combined local bladder hyperthermia and intravesical chemotherapy for the treatment of high-grade superficial bladder cancer. Urology, 63(3), 466-471.

Gong, W.and Wang, Z., Liu, N., Lin, W., Wang, X., Xu, D., Liu, H., Zeng, C., Xie, X., Mei, X., et al. 2011. Improving efficiency of adriamycin crossing blood brain barrier by combination of thermosensitive liposomes and hyperthermia. Biological and Pharmaceutical Bulletin, 34(7), 1058-1064.

Gonzalez, D. G., Vandijk, J. D. P., Blank, L. E. C. M., \& Rumke, P. 1986. Combined Treatment with Radiation and Hyperthermia in Metastatic Malignant-Melanoma. Radiotherapy and Oncology, 6(2), 105-113. 
Gordon, C. J., Long, Merrit D., Fehlner, K. S., \& Stead, A. G. 1986a. Body temperature in the mouse, hamster, and rat exposed to radiofrequency radiation: an interspecies comparison. Journal of thermal biology, 11(1), 59-65.

Gordon, C. J., Long, Merritt D., \& Fehlner, K. S. 1986b. Temperature regulation in the unrestrained rabbit during exposure to $600 \mathrm{MHz}$ radiofrequency radiation. International Journal of Radiation Biology, 49(6), 987-997.

Greenbaum, Elias. 2004. Biological and medical physics, biomedical engineering. Springer.

Gubin, Sergey P. 2009. Magnetic nanoparticles. John Wiley \& Sons.

Guéron, S., Deshmukh, M. M., Myers, E.B., \& Ralph, D.C. 1999. Tunneling via individual electronic states in ferromagnetic nanoparticles. Physical review letters, 83(20), 4148.

GuhaSarkar, S., \& Banerjee, R. 2010. Intravesical drug delivery: challenges, current status, opportunities and novel strategies. Journal of Controlled Release, 148(2), 147159.

Hanahan, D., \& Weinberg, R. A. 2000. The hallmarks of cancer. cell, 100(1), 57-70.

Hashimoto, T., Hisazumi, H., Nakajima, K., \& Matsubara, F. 1991. Studies on endocrine changes induced by $8 \mathrm{MHz}$ local radiofrequency hyperthermia in patients with bladder cancer. International journal of hyperthermia, 7(4), 551-557.

Hayward, J. N. 1968. Brain temperature regulation during sleep and arousal in the dog. Experimental neurology, 21(2), 201-212.

Hayward, J. N., \& Baker, M. A. 1969. A comparative study of the role of the cerebral arterial blood in the regulation of brain temperature in five mammals. Brain Res, 16(2), $417-40$.

Hergt, R., \& Dutz, S. 2007. Magnetic particle hyperthermia-biophysical limitations of a visionary tumour therapy. Journal of Magnetism and Magnetic Materials, 311(1), $187-192$ 
Hergt, R., Dutz, S., Müller, R., \& Zeisberger, M. 2006. Magnetic particle hyperthermia: nanoparticle magnetism and materials development for cancer therapy. Journal of Physics: Condensed Matter, 18(38), S2919.

Hergt, R., Dutz, S., \& Zeisberger, M. 2010. Validity limits of the Neel relaxation model of magnetic nanoparticles for hypertheMRIa. Nanotechnology, 21(1), 015706.

Hildebrandt, Bert, Wust, Peter, Ahlers, Olaf, Dieing, Annette, Sreenivasa, Geetha, Kerner, Thoralf, Felix, Roland, \& Riess, Hanno. 2002. The cellular and molecular basis of hypertheMRIa. Critical reviews in oncology/hematology, 43(1), 33-56.

Hilger, I. 2013. In vivo applications of magnetic nanoparticle hyperthermia. International Journal of Hyperthermia, 29(8), 828-834.

Hobohm, U. 2005. Fever therapy revisited. British journal of cancer, 92(3), 421-425.

Hockel, M., \& Vaupel, P. 2001. Tumor hypoxia: definitions and current clinical, biologic, and molecular aspects. Journal of the National Cancer Institute, 93(4), 266-276.

Holback, H., \& Yeo, Y. 2011. Intratumoral drug delivery with nanoparticulate carriers. Pharmaceutical research, 28(8), 1819-1830.

Holland, F. 2003. Principles of medical oncology, in Cancer Medicine. B.C.Decker Inc.

Howles, G. P., Bing, K. F., Qi, Y., Rosenzweig, S. J., Nightingale, K. R., \& Johnson, G. A. 2010. Contrast-enhanced in vivo magnetic resonance microscopy of the mouse brain enabled by noninvasive opening of the blood-brain barrier with ultrasound. Magnetic Resonance in Medicine, 64(4), 995-1004.

Huynh, G. H., Deen, D. F., \& Szoka, F. C. 2006. Barriers to carrier mediated drug and gene delivery to brain tumors. Journal of Controlled Release, 110(2), 236-259.

Hynynen, K. 2010. MRI-guided focused ultrasound treatments. Ultrasonics, 50(2), 221229. 
Hynynen, K., McDannold, N., Vykhodtseva, N., \& Jolesz, F. A. 2001. Noninvasive MR Imaging-guided Focal Opening of the Blood-Brain Barrier in Rabbits 1. Radiology, 220(3), 640-646.

imagej.nih.gov. 2014. Documentation. http://imagej.nih.gov/ij/docs/index.html.

Inman, Brant A, Stauffer, Paul R, Craciunescu, Oana A, Maccarini, Paolo F, Dewhirst, Mark W, \& Vujaskovic, Zeljko. 2014. A pilot clinical trial of intravesical mitomycin-C and external deep pelvic hyperthermia for non-muscle-invasive bladder cancer. International Journal of Hyperthermia, 30(3), 171-175.

Issels, R. D. 2008. Hyperthermia adds to chemotherapy. European Journal of Cancer, 44(17), 2546-2554.

Issels, R. D., Lindner, L. H., Verweij, J., Wust, P., Reichardt, P., Schem, B. C., AbdelRahman, S., Daugaard, S., Salat, C., Wendtner, C. M., Vujaskovic, Z., Wessalowski, R., Jauch, K. W., Durr, H. R., Ploner, F., Baur-Melnyk, A., Mansmann, U., Hiddemann, W., Blay, J. Y., \& Hohenberger, P. 2010a. Neo-adjuvant chemotherapy alone or with regional hypertheMRIa for localised high-risk soft-tissue sarcoma: a randomised phase 3 multicentre study. Lancet Oncology, 11(6), 561-570.

Issels, R. D., Lindner, L. H., Reichardt, P., Schem, B., Wendtner, C., Wessalowski, R., Jauch, K., Mansmann, U., Blay, J., \& Hohenberger, P. 2010b. Neo-Adjuvant Chemotherapy with Regional HypertheMRIa (Rht)for Localized High-Risk Soft-Tissue Sarcoma (Hr-Sts) with Abdominal/Retroperitoneal Location. Annals of Oncology, 21, 411-411.

Ivkov, Robert, DeNardo, Sally J, Daum, Wolfgang, Foreman, Allan R, Goldstein, Robert C, Nemkov, Valentin S, \& DeNardo, Gerald L. 2005. Application of high amplitude alternating magnetic fields for heat induction of nanoparticles localized in cancer. Clinical Cancer Research, 11(19), 7093s-7103s.

Jacobsen, S, \& Klemetsen, O. 2007. Active antennas in medical microwave radiometry. Electronics Letters, 43(11), 606-608. 
Jacobson, K., \& Papahadjopoulos, D. 1975. Phase-Transitions and Phase Separations in Phospholipid Membranes Induced by Changes in Temperature, Ph, and Concentration of Bivalent-Cations. Biochemistry, 14(1), 152-161.

Jain, R. K. 1987a. Transport of molecules across tumor vasculature. Cancer and Metastasis Reviews, 6(4), 559-593.

Jain, R. K. 1987b. Transport of Molecules in the Tumor Interstitium - a Review. Cancer Research, 47(12), 3039-3051.

Jain, R. K. 2001. Delivery of molecular and cellular medicine to solid tumors. Advanced drug delivery reviews, 46(1), 149-168.

Jain, R. K. 2005. Normalization of tumor vasculature: an emerging concept in antiangiogenic therapy. Science, $\mathbf{3 0 7}(5706), 58-62$.

Jain, R. K. 2012. Delivery of molecular and cellular medicine to solid tumors. Advanced drug delivery reviews, 64, 353-365.

Jain, R. K., Di Tomaso, E., Duda, D. G., Loeffler, J. S., Sorensen, A. G., \& Batchelor, T. T. 2007. Angiogenesis in brain tumours. Nature Reviews Neuroscience, 8(8), 610622.

Johannsen, M., Thiesen, B., Wust, P., \& Jordan, A. 2010. Magnetic nanoparticle hyperthermia for prostate cancer. International Journal of Hyperthermia, 26(8), 790-795.

Joines, William T, Zhang, Yang, Li, Chenxing, \& Jirtle, Randy L. 1994. The measured electrical properties of normal and malignant human tissues from 50 to $900 \mathrm{MHz}$. Medical physics, 21(4), 547-550.

Juang, T., Stauffer, P. R., Craciunescu, O. A., Maccarini, P. F., Yuan, Y., Das, S. K., Dewhirst, M. W., Inman, B. A., \& Vujaskovic, Z. 2014. Thermal dosimetry characteristics of deep regional heating of non-muscle invasive bladder cancer. International Journal of Hyperthermia, 30(3), 176-183. 
Kakehi, M., Ueda, K., Mukojima, T., Hiraoka, M., Seto, O., Akanuma, A., \& Nakatsugawa, S. 1990. Multi-institutional clinical studies on hyperthermia combined with radiotherapy or chemotherapy in advanced cancer of deep-seated organs. International Journal of Hyperthermia, 6(4), 719-740.

Kakinuma, K., Tanaka, R., Takahashi, H., Sekihara, Y., Watanabe, M., \& Kuroki, M. 1996. Drug delivery to the brain using thermosensitive liposome and local hyperthermia. International journal of hyperthermia, 12(1), 157-165.

Kataoka, K., Harada, A., \& Nagasaki, Y. 2001. Block copolymer micelles for drug delivery: design, characterization and biological significance. Advanced Drug Delivery Reviews, 47(1), 113-131.

Kim, J. S., Yoon, T. J., Yu, K. N., Kim, B. G., Park, S. J., Kim, H. W., Lee, K. H., Park, S. B., Lee, J. K., \& Cho, M. H. 2006. Toxicity and tissue distribution of magnetic nanoparticles in mice. Toxicological Sciences, 89(1), 338-347.

Kiyatkin, E. A., \& Sharma, H. S. 2009. Permeability of the blood-brain barrier depends on brain temperature. Neuroscience, 161(3), 926-939.

Kok, H. P., Correia, D., De Greef, Martijn, Van Stam, Gerard, Bel, Arjan, \& Crezee, Johannes. 2010. SAR deposition by curved CFMA-434 applicators for superficial hyperthermia: Measurements and simulations. International journal of hyperthermia, 26(2), 171-184.

Konerding, MA, Malkusch, W, Klapthor, B, Van Ackern, C, Fait, E, Hill, SA, Parkins, C, Chaplin, DJ, Presta, Mand, \& Denekamp, J. 1999. Evidence for characteristic vascular patterns in solid tumours: quantitative studies using corrosion casts. British journal of cancer, 80(5-6), 724 .

Kong, G., Anyarambhatla, G., Petros, W. P., Braun, R. D., Colvin, O. M., Needham, D., \& Dewhirst, M. W. 2000a. Efficacy of liposomes and hyperthermia in a human tumor xenograft model: Importance of triggered drug release. Cancer Research, 60(24), 69506957. 
Kong, G., Braun, R. D., \& Dewhirst, M. W. 2000b. Hyperthermia enables tumor-specific nanoparticle delivery: effect of particle size. Cancer research, 60(16), 4440-4445.

Kong, G., Braun, R. D., \& Dewhirst, M. W. 2001. Characterization of the effect of hyperthermia on nanoparticle extravasation from tumor vasculature. Cancer Research, 61(7), 3027-3032.

Koziel, Slawomir, \& Ogurtsov, Stanislav. 2014. Antenna Design by Simulation-Driven Optimization. Springer.

Kumar, C. S. S. R., \& Mohammad, F. 2011. Magnetic nanomaterials for hyperthermiabased therapy and controlled drug delivery. Advanced drug delivery reviews, 63(9), 789-808.

Kumar, Challa S. S. R. 2009. Nanomaterials for the Life Sciences, vol.4: Magnetic Nanomaterials. WILEY-VCH Verlag GmbH Co. KGaA, Weinheim.

Lagendijk, J.J.W. 2000. Hyperthermia treatment planning. Physics in medicine and biology, 45(5), R61.

Lakowicz, Joseph R. 2006. Principles of Fluorescence Spectroscopy. 3 edn. Springer.

Lammers, R. J. M., Witjes, J. A., Inman, Brant A., Leibovitch, I., Laufer, M., Nativ, O., \& Colombo, R. 2011. The role of a combined regimen with intravesical chemotherapy and hyperthermia in the management of non-muscle-invasive bladder cancer: a systematic review. European urology, 60(1), 81-93.

Landon, C. D., Park, J. Y., Needham, D., \& Dewhirst, M. W. 2011. Nanoscale drug delivery and hyperthermia: the materials design and preclinical and clinical testing of low temperature-sensitive liposomes used in combination with mild hyperthermia in the treatment of local cancer. The open nanomedicine journal, $\mathbf{3}, 38$.

Langer, R. 1998. Drug delivery and targeting. Nature, 392(6679 Suppl), 5-10.

Lankelma, Jan. 2002. Tissue transport of anti-cancer drugs. Current pharmaceutical design, 8(22), 1987-1993. 
Lankelma, Jan, Fernndez Luque, Rafael, Dekker, Henk, Schinkel, Wim, \& Pinedo, Herbert M. 2000. A mathematical model of drug transport in human breast cancer. $M i$ crovascular research, 59(1), 149-161.

Lankelma, Jan, Fernández Luque, Rafael, Dekker, Henk, \& Pinedo, Herbert M. 2003. Simulation model of doxorubicin activity in islets of human breast cancer cells. Biochimica et Biophysica Acta (BBA)-General Subjects, 1622(3), 169-178.

Lasic, D. D., \& Papahadjopoulos, D. 1995. Liposomes Revisited. Science, 267(5202), $1275-1276$.

Lasic, Danilo D. 1988. The mechanism of vesicle formation. Biochemical Journal, 256(1), $1-11$.

Laurent, Sophie, Dutz, Silvio, Häfeli, Urs O, \& Mahmoudi, Morteza. 2011. Magnetic fluid hyperthermia: focus on superparamagnetic iron oxide nanoparticles. Advances in Colloid and Interface Science, 166(1), 8-23.

Lazebnik, Mariya, Madsen, Ernest L, Frank, Gary R, \& Hagness, Susan C. 2005. Tissuemimicking phantom materials for narrowband and ultrawideband microwave applications. Physics in medicine and biology, 50(18), 4245.

Li, Z., Vogel, M., Maccarini, P. F., Stakhursky, V., Soher, B. J., Craciunescu, O. I., Das, S., Arabe, O. A, Joines, W. T., \& Stauffer, P. R. 2011. Improved hyperthermia treatment control using SAR/temperature simulation and PRFS magnetic resonance thermal imaging. International Journal of Hyperthermia, 27(1), 86-99.

Lian, T., \& Ho, R.J.Y. 2001. Trends and developments in liposome drug delivery systems. Journal of pharmaceutical sciences, 90(6), 667-680.

Lin, J. C, \& Lin, Mei F. 1982. Microwave hyperthermia-induced blood-brain barrier alterations. Radiation research, 89(1), 77-87.

Lin, James C. 2011. Electromagnetic fields in biological systems. CRC press. 
Lin, James C, Yuan, Philip MK, \& Jung, Donald T. 1998. Enhancement of anticancer drug delivery to the brain by microwave induced hyperthermia. Bioelectrochemistry and bioenergetics, 47(2), 259-264.

Liou, S. H., Huang, S., Klimek, E., Kirby, R. D., \& Yao, Y. 1999. Enhancement of coercivity in nanometer-size CoPt crystallites. Journal of applied physics, 85(8), 43344336.

Lipowsky, Reinhard. 1991. The conformation of membranes. Nature, 349(6309), 475-481.

Lüdemann, Lutz, Wlodarczyk, Waldemar, Nadobny, Jacek, Weihrauch, Mirko, Gellermann, Johanna, \& Wust, Peter. 2010. Non-invasive magnetic resonance thermography during regional hyperthermia. International Journal of Hyperthermia, 26(3), 273-282.

Maeda, Hiroshi, Fang, Jun, Inutsuka, Takao, \& Kitamoto, Yasunori. 2003. Vascular permeability enhancement in solid tumor: various factors, mechanisms involved and its implications. International immunopharmacology, 3(3), 319-328.

Maher, E. A., Furnari, F. B., Bachoo, R. M., Rowitch, D. H., Louis, D. N., Cavenee, W. K., \& DePinho, R. A. 2001. Malignant glioma: genetics and biology of a grave matter. Genes \& development, 15(11), 1311-1333.

Mahmoudi, Morteza, Sant, Shilpa, Wang, Ben, Laurent, Sophie, \& Sen, Tapas. 2011. Superparamagnetic iron oxide nanoparticles (SPIONs): development, surface modification and applications in chemotherapy. Advanced drug delivery reviews, 63(1), 24-46.

Maier-Hauff, Klaus, Rothe, Ronny, Scholz, Regina, Gneveckow, Uwe, Wust, Peter, Thiesen, Burghard, Feussner, Annelie, von Deimling, Andreas, Waldoefner, Norbert, Felix, Roland, et al. 2007. Intracranial thermotherapy using magnetic nanoparticles combined with external beam radiotherapy: results of a feasibility study on patients with glioblastoma multiforme. Journal of neuro-oncology, 81(1), 53-60.

Manzoor, A. A., Lindner, L. H., Landon, C. D., Park, J. Y., Simnick, A. J., Dreher, M. R., Das, S., Hanna, G., Park, W., Chilkoti, A., Koning, G. A., ten Hagen, T. L. M., Needham, D., \& Dewhirst, M. W. 2012. Overcoming Limitations in Nanoparticle Drug 
Delivery: Triggered, Intravascular Release to Improve Drug Penetration into Tumors. Cancer Research, 72(21), 5566-5575.

McDaniel, Jonathan R, Callahan, Daniel J, \& Chilkoti, Ashutosh. 2010. Drug delivery to solid tumors by elastin-like polypeptides. Advanced drug delivery reviews, 62(15), $1456-1467$.

McDannold, N., Vykhodtseva, N., Jolesz, F. A., \& Hynynen, K. 2004. MRI investigation of the threshold for thermally induced blood-brain barrier disruption and brain tissue damage in the rabbit brain. Magnetic resonance in medicine, 51(5), 913-923.

McDannold, N., Clement, G., Black, P., Jolesz, F., \& Hynynen, K. 2010. Transcranial MRI-guided focused ultrasound surgery of brain tumors: Initial findings in three patients. Neurosurgery, 66(2), 323.

Medel, Ricky, Monteith, Stephen J, Elias, W Jeffrey, Eames, Matthew, Snell, John, Sheehan, Jason P, Wintermark, Max, Jolesz, Ferenc A, \& Kassell, Neal F. 2012. Magnetic resonance-guided focused ultrasound surgery: Part 2: A review of current and future applications. Neurosurgery, 71(4), 755-763.

Meunier, Gérard. 2010. The finite element method for electromagnetic modeling. Vol. 33. John Wiley \& Sons.

Mills, Jeffrey K. 2002. Título da tese: "Triggered Release of Liposome Contents: Mechanism Involved in Membrane Permeability and Compromise". Duke University, Department of Mechanical Engineering and Material Science.

Minchinton, Andrew I, \& Tannock, Ian F. 2006. Drug penetration in solid tumours. Nature Reviews Cancer, 6(8), 583-592.

Moeller, Benjamin J, Richardson, Rachel A, \& Dewhirst, Mark W. 2007. Hypoxia and radiotherapy: opportunities for improved outcomes in cancer treatment. Cancer and Metastasis Reviews, 26(2), 241-248. 
Moghimi, S. M., \& Szebeni, J. 2003. Stealth liposomes and long circulating nanoparticles: critical issues in pharmacokinetics, opsonization and protein-binding properties. Progress in Lipid Research, 42(6), 463-478.

Moghimi, S. M., Hunter, A. C., \& Murray, J. C. 2001. Long-circulating and target-specific nanoparticles: Theory to practice. Pharmacological Reviews, 53(2), 283-318.

Moriyama, Eiji, Salcman, Michael, \& Broadwell, Richard D. 1991. Blood-brain barrier alteration after microwave-induced hyperthermia is purely a thermal effect: I. Temperature and power measurements. Surgical neurology, 35(3), 177-182.

Moros, Eduardo. 2012. Physics of thermal therapy: fundamentals and clinical applications. CRC Press.

Moskovitz, B., Halachmi, S., Moskovitz, M.I., Nativ, O., \& Nativ, O. 2012. 10-year singlecenter experience of combined intravesical chemohyperthermia for nonmuscle invasive bladder cancer. Future Oncology, 8(8), 1041-1049.

Mullbacher, A. 1984. Hyperthermia and the generation and activity of murine influenzaimmune cytotoxic T cells in vitro. Journal of virology, 52(3), 928-931.

Muller, P.J., \& Wilson, B.C. 1986. An update on the penetration depth of $630 \mathrm{~nm}$ light in normal and malignant human brain tissue in vivo. Physics in medicine and biology, 31(11), 1295.

Needham, D., Anyarambhatla, G., Kong, G., \& Dewhirst, M. W. 2000. A new temperature-sensitive liposome for use with mild hyperthermia: Characterization and testing in a human tumor xenograft model. Cancer Research, 60(5), 1197-1201.

Neuberger, Tobias, Schöpf, Bernhard, Hofmann, Heinrich, Hofmann, Margarete, \& Von Rechenberg, Brigitte. 2005. Superparamagnetic nanoparticles for biomedical applications: possibilities and limitations of a new drug delivery system. Journal of Magnetism and Magnetic Materials, 293(1), 483-496.

niremf.ifac. 2011. Calculation of the Dielectric Properties of Body Tissues in the frequency range $10 \mathrm{~Hz}$ - $100 \mathrm{GHz}$. http://niremf.ifac.cnr.it/tissprop/htmlclie/htmlclie.htm. 
O'handley, Robert C. 2000. Modern magnetic materials: principles and applications. Vol. 830622677. Wiley New York.

Oliver, G., \& Detmar, M. 2002. The rediscovery of the lymphatic system: old and new insights into the development and biological function of the lymphatic vasculature. Genes $\&$ development, 16(7), 773-783.

Owusu, Richmond A, Abern, Michael R, \& Inman, Brant A. 2013. Hyperthermia as adjunct to intravesical chemotherapy for bladder cancer. BioMed research international, 2013.

Pankhurst, Q. A., Connolly, J., Jones, S. K., \& Dobson, J. 2003. Applications of magnetic nanoparticles in biomedicine. Journal of physics D: Applied physics, 36(13), R167.

Papahadjopoulos, D., Allen, T. M., Gabizon, A., Mayhew, E., Matthay, K., Huang, S. K., Lee, K. D., Woodle, M. C., Lasic, D. D., Redemann, C., \& Martin, F. J. 1991. Sterically Stabilized Liposomes - Improvements in Pharmacokinetics and Antitumor Therapeutic Efficacy. Proceedings of the National Academy of Sciences of the United States of America, 88(24), 11460-11464.

Pardridge, William M. 2005. The blood-brain barrier: bottleneck in brain drug development. NeuroRx, 2(1), 3-14.

Pardridge, William M. 2007. Blood-brain barrier delivery. Drug discovery today, 12(1), $54-61$.

Patel, Mayur M, Goyal, Bhoomika R, Bhadada, Shraddha V, Bhatt, Jay S, \& Amin, Avani F. 2009. Getting into the brain. CNS drugs, 23(1), 35-58.

Paulides, M. M., Stauffer, P. R., Neufeld, Esra, Maccarini, Paolo F, Kyriakou, Adamos, Canters, Richard AM, Diederich, Chris J, Bakker, Jurriaan F, \& Van Rhoon, Gerard C. 2013. Simulation techniques in hyperthermia treatment planning. International Journal of Hyperthermia, 29(4), 346-357. 
Paulides, MM, Bakker, JF, Neufeld, E, Zee, J van der, Jansen, PP, Levendag, PC, \& Van Rhoon, GC. 2007. The HYPERcollar: A novel applicator for hyperthermia in the head and neck*. International Journal of Hyperthermia, 23(7), 567-576.

Pelosi, Giuseppe, Coccioli, Roberto, \& Selleri, Stefano. 2009. Quick finite elements for electromagnetic waves. Artech House.

Pennes, H. H. 1948. Analysis of tissue and arterial blood temperatures in the resting human forearm. Journal of applied physiology, 1(2), 93-122.

Ponce, A. M., Viglianti, B. L., Yu, D. H., Yarmolenko, P. S., Michelich, C. R., Woo, J., Bally, M. B., \& Dewhirst, M. W. 2007a. Magnetic resonance imaging of temperaturesensitive liposome release: Drug dose painting and antitumor effects. Journal of the National Cancer Institute, 99(1), 53-63.

Ponce, Ana M, Vujaskovic, Zeljko, Yuan, Fan, Needham, David, \& Dewhirst, Mark W. 2006. Hyperthermia mediated liposomal drug delivery. International Journal of Hyperthermia, 22(3), 205-213.

Ponce, Ana M, Viglianti, Benjamin L, Yu, Daohai, Yarmolenko, Pavel S, Michelich, Charles R, Woo, Janet, Bally, Marcel B, \& Dewhirst, Mark W. 2007b. Magnetic resonance imaging of temperature-sensitive liposome release: drug dose painting and antitumor effects. Journal of the National Cancer Institute, 99(1), 53-63.

Poon, R.T.P., \& Borys, N. 2009. Lyso-thermosensitive liposomal doxorubicin: a novel approach to enhance efficacy of thermal ablation of liver cancer.

Pozar, David M. 2009. Microwave engineering. John Wiley \& Sons.

Pries, A. R., Hopfner, M., le Noble, F., Dewhirst, M. W., \& Secomb, T. W. 2010. The shunt problem: control of functional shunting in normal and tumour vasculature. Nature Reviews Cancer, 10(8), 587-593.

Rahmat-Samii, Y., \& Michielssen, E. 1999. Electromagnetic optimization by genetic algorithms. John Wiley \& Sons, Inc. 
Reddy, L. H. 2005. Drug delivery to tumours: recent strategies. Journal of pharmacy and pharmacology, 57(10), 1231-1242.

Ricard, Damien, Idbaih, Ahmed, Ducray, François, Lahutte, Marion, Hoang-Xuan, Khê, \& Delattre, Jean-Yves. 2012. Primary brain tumours in adults. The Lancet, 379(9830), 1984-1996.

Rosenberg, S. A., Yang, J. C., \& Restifo, N. P. 2004. Cancer immunotherapy: moving beyond current vaccines. Nature medicine, 10(9), 909-915.

Rosensweig, Ronald E. 2002. Heating magnetic fluid with alternating magnetic field. Journal of magnetism and magnetic materials, 252, 370-374.

Roth, J. A., \& Cristiano, R. J. 1997. Gene therapy for cancer: what have we done and where are we going? Journal of the National Cancer Institute, 89(1), 21-39.

Sapareto, S. A., Hopwood, L. E., Dewey, W. C., Raju, M. R., \& Gray, J. W. 1978. Effects of Hyperthermia on Survival and Progression of Chinese-Hamster Ovary Cells. Cancer Research, 38(2), 393-400.

Shao, Pengyu, Wang, Bochu, Wang, Yazhou, Li, Jun, \& Zhang, Yiqiong. 2011. The application of thermosensitive nanocarriers in controlled drug delivery. Journal of $\mathrm{Na}$ nomaterials, 2011, 17.

Shen, R. N., Lu, L., Young, P., Shidnia, H., Hornback, N. B., \& Broxmeyer, H. E. 1994. Influence of elevated temperature on natural killer cell activity, lymphokine-activated killer cell activity and lectin-dependent cytotoxicity of human umbilical cord blood and adult blood cells. International Journal of Radiation Oncology Biology Physics, 29(4), $821-826$.

Sherman, J. H., Hoes, K., Marcus, J., Komotar, R. J., Brennan, C. W., \& Gutin, P. H. 2011. Neurosurgery for brain tumors: update on recent technical advances. Current neurology and neuroscience reports, 11(3), 313-319.

Shipton, E. A. 2012. Advances in delivery systems and routes for local anaesthetics. Trends in Anaesthesia and Critical Care, 2(5), 228-233. 
Silva, André C, Oliveira, Tiago R, Mamani, Javier B, Malheiros, SM, Malavolta, Luciana, Pavon, Lorena F, Sibov, Tatiana T, Amaro Jr, Edson, Tannus, Alberto, Vidoto, EL, et al. 2011. Application of hyperthermia induced by superparamagnetic iron oxide nanoparticles in glioma treatment. Int J Nanomedicine, 6(3), 591-603.

Sminia, P.J.G.J., Van Der Zee, J., Wondergem, J., \& Haveman, J. 1994. Effect of hyperthermia on the central nervous system: a review. International journal of hyperthermia, 10(1), 1-30.

Song, C. W. 1984. Effect of Local Hyperthermia on Blood-Flow and Microenvironment a Review. Cancer Research, 44(10), 4721-4730.

Song, C. W., Shakil, A., Osborn, J. L., \& Iwata, K. 1996. Tumour oxygenation is increased by hyperthermia at mild temperatures. International Journal of HypertheMRIa, 12(3), $367-373$.

Speicher, P. J., Beasley, G. M., Jiang, B., Lidsky, M. E, Palmer, G. M., Scarbrough, P. M., Mosca, Paul J., Dewhirst, M. W., \& Tyler, D. S. 2014. Hypoxia in melanoma: using optical spectroscopy and EF5 to assess tumor oxygenation before and during regional chemotherapy for melanoma. Annals of surgical oncology, 21(5), 1435-1440.

Stauffer, P. R., Cetas, T. C., \& Jones, R. C. 1984a. Magnetic induction heating of ferromagnetic implants for inducing localized hyperthermia in deep-seated tumors. $B i$ omedical Engineering, IEEE Transactions on, 235-251.

Stauffer, PAUL R, Cetas, Thomas C, Fletcher, Anne M, Deyoung, Donald W, Dewhirst, MARK W, Oleson, James R, \& Roemer, ROBERT B. 1984b. Observations on the use of ferromagnetic implants for inducing hyperthermia. Biomedical Engineering, IEEE Transactions on, 76-90.

Stauffer, PR, \& Maccarini, PF. 2011. Evolution of antenna performance for applications in thermal medicine. Pages 3080-3083 of: Antennas and Propagation (EUCAP), Proceedings of the 5th European Conference on. IEEE. 
Stauffer, P.R., Sneed, P.K., Hashemi, H., \& Phillips, T.L. 1994. Practical induction heating coil designs for clinical hyperthermia with ferromagnetic implants. Biomedical Engineering, IEEE Transactions on, 41(1), 17-28.

Strohbehn, John W, Curtis, Elizabeth H, Paulsen, Keith D, Yuan, Xingchao, \& Lynch, Daniel R. 1989. Optimization of the absorbed power distribution for an annular phased array hyperthermia system. International Journal of Radiation Oncology Biology Physics, 16(3), 589-599.

Stupp, R., Mason, W. P., van den Bent, M. J., Weller, M., Fisher, B., Taphoorn, M. J. B., Belanger, K., Brandes, A. A., Marosi, C., Bogdahn, U., Curschmann, J., Janzer, R. C., Ludwin, S. K., \& Gorlia, T. 2005. Radiotherapy plus concomitant and adjuvant temozolomide for glioblastoma. New England Journal of Medicine, 352(10), 987-996.

Sturgeon, R. J., \& Schulman, S. G. 1977. Electronic absorption spectra and protolytic equilibria of doxorubicin: direct spectrophotometric determination of microconstants. Journal of pharmaceutical sciences, 66(7), 958-961.

Szasz, A., Szasz, N., \& Szasz, O. 2011. Hyperthermia Results and Challenges. Pages 17-88 of: Oncothermia: Principles and Practices. Springer.

Tatum, James L. 2006. Hypoxia: importance in tumor biology, noninvasive measurement by imaging, and value of its measurement in the management of cancer therapy. International journal of radiation biology, 82(10), 699-757.

Tempany, C. M. C., McDannold, N. J., Hynynen, K., \& Jolesz, F. A. 2011. Focused ultrasound surgery in oncology: overview and principles. Radiology, 259(1), 39-56.

Tomasovic, S. P., \& Klostergaard, J. 1989. Hyperthermic modulation of macrophagetumor cell interactions. Cancer and Metastasis Reviews, 8(3), 215-229.

Trzaska, Hubert. 2005. Electromagnetic field measurements in the near field. Noble Publishing Corporation Atlanta. 
Turner, PF, Tumeh, A, \& Schaefermeyer, T. 1989. BSD-2000 approach for deep local and regional hyperthermia: physics and technology. Strahlentherapie und Onkologie: Organ der Deutschen Röntgengesellschaft.../et al], 165(10), 738.

Tyagi, Pradeep, Wu, Pao-Chu, Chancellor, Michael, Yoshimura, Naoki, \& Huang, Leaf. 2006. Recent advances in intravesical drug/gene delivery. Molecular pharmaceutics, 3(4), 369-379.

Vajkoczy, P., \& Menger, M. D. 2000. Vascular microenvironment in gliomas. Journal of neuro-oncology, 50(1-2), 99-108.

Valvano, Jonathan W. 2011. Tissue thermal properties and perfusion. Pages 455-485 of: Optical-Thermal Response of Laser-Irradiated Tissue. Springer.

Van der Gaag, M.L., De Bruijne, M., Samaras, T., Van der Zee, J., \& Van Rhoon, G.C. 2006. Development of a guideline for the water bolus temperature in superficial hyperthermia. International journal of hyperthermia, 22(8), 637-656.

Van der Heijden, AG, Kiemeney, LA, Gofrit, ON, Nativ, O, Sidi, A, Leib, Z, Colombo, R, Naspro, R, Pavone, M, Baniel, J, et al. 2004. Preliminary European results of local microwave hyperthermia and chemotherapy treatment in intermediate or high risk superficial transitional cell carcinoma of the bladder. European urology, 46(1), $65-72$.

van der Zee, J., Gonzalez, D. G., van Rhoon, G. C., van Dijk, J. D. P., van Putten, W. L. J., \& Hart, A. A. M. 2000. Comparison of radiotherapy alone with radiotherapy plus hypertheMRIa in locally advanced pelvic tumours: a prospective, randomised, multicentre trial. Lancet, 355(9210), 1119-1125.

Van Meir, E. G., Hadjipanayis, C. G., Norden, A. D., Shu, H. K., Wen, P. Y., \& Olson, J. J. 2010. Exciting New Advances in Neuro-Oncology: The Avenue to a Cure for Malignant Glioma. CA: a cancer journal for clinicians, 60(3), 166-193.

Van Rhoon, G. C. 2012. External Electromagnetic Methods and Devices. Pages 139-158 
of: Physics of Thermal Therapy - Fundamentals and Clinical Applications. CRC Press, Taylor and Francis Group.

Van Rhoon, GC, Rietveld, PJM, \& Van der Zee, J. 1998. A 433 MHz Lucite cone waveguide applicator for superficial hyperthermia. International journal of hyperthermia, 14(1), 13-27.

Vander Vorst, André, Rosen, Arye, \& Kotsuka, Youji. 2006. RF/Microwave interaction with biological tissues. Vol. 181. John Wiley \& Sons.

Vaupel, P., \& Horsman, M. R. 2010. Tumour perfusion and associated physiology: characterization and significance for hyperthermia. International Journal of HypertheMRIa, 26(3), 209-210.

Vaupel, P., \& Mayer, A. 2007. Hypoxia in cancer: significance and impact on clinical outcome. Cancer and Metastasis Reviews, 26(2), 225-239.

Vaupel, P. W., \& Kelleher, D. K. 2010. Pathophysiological and vascular characteristics of tumours and their importance for hyperthermia: Heterogeneity is the key issue. International Journal of HypertheMRIa, 26(3), 211-223.

Vaupel, Peter, Kallinowski, Friedrich, \& Okunieff, Paul. 1989. Blood flow, oxygen and nutrient supply, and metabolic microenvironment of human tumors: a review. Cancer research, $\mathbf{4 9}(23), 6449-6465$.

Vercesi, LAP, \& Constantinou, CE. 1986. Pressure evaluation of the antireflux ability of the rat ureterovesical junction. Urologia internationalis, 41(3), 192-195.

Vergnaud, Jean-Maurice, \& Rosca, Iosif-Daniel. 2010. Assessing Bioavailablility of Drug Delivery Systems: Mathematical Modeling. CRC press.

Viglianti, Benjamin L, Ponce, Ana M, Michelich, Charles R, Yu, Daohai, Abraham, Sheela A, Sanders, Linda, Yarmolenko, Pavel S, Schroeder, Thies, MacFall, James R, et al. 2006. Chemodosimetry of in vivo tumor liposomal drug concentration using MRI. Magnetic resonance in medicine, 56(5), 1011-1018. 
Vlachos, F, Tung, YS, \& Konofagou, EE. 2010. Permeability assessment of the focused ultrasound-induced blood-brain barrier opening using dynamic contrast-enhanced MRI. Physics in medicine and biology, 55(18), 5451.

Vrouenraets, M. B., Visser, G. W. M., Snow, G. B., \& van Dongen, G. A. M. S. 2003. Basic principles, applications in oncology and improved selectivity of photodynamic therapy. Anticancer Research, 23(1B), 505-522.

Weissleder, Ralph, \& Pittet, Mikael J. 2008. Imaging in the era of molecular oncology. Nature, 452(7187), 580-589.

Wen, P. Y., \& Kesari, S. 2008. Malignant gliomas in adults. New England Journal of Medicine, 359(5), 492-507.

Westphal, M., \& Lamszus, K. 2011. The neurobiology of gliomas: from cell biology to the development of therapeutic approaches. Nature Reviews Neuroscience, 12(9), 495-508.

Witte, Marlys H, Jones, Kimberly, Wilting, Jörg, Dictor, Michael, Selg, Manuel, McHale, Noel, Gershenwald, Jeffrey E, \& Jackson, David G. 2006. Structure function relationships in the lymphatic system and implications for cancer biology. Cancer and Metastasis Reviews, 25(2), 159-184.

Wright, Alexander Matthew. 2006. Título da tese: "Drug Loading and Release From a Thermally Sensitive Liposome". Duke University, Department of Mechanical Engineering and Material Science.

Xu, Hua-Tai, Pan, Feng, Yang, Guang, \& Gan, Wen-Biao. 2007. Choice of cranial window type for in vivo imaging affects dendritic spine turnover in the cortex. Nature neuroscience, 10(5), 549-551.

Yang, G., Pan, Feng, Parkhurst, Christopher N, Grutzendler, Jaime, \& Gan, Wen-Biao. 2010. Thinned-skull cranial window technique for long-term imaging of the cortex in live mice. Nature protocols, 5(2), 201-208.

Yarmolenko, P. S., Zhao, Y. L., Landon, C., Spasojevic, I., Yuan, F., Needham, D., Viglianti, B. L., \& Dewhirst, M. W. 2010. Comparative effects of thermosensitive 
doxorubicin-containing liposomes and hypertheMRIa in human and murine tumours. International Journal of Hyperthermia, 26(5), 485-498.

Yarmolenko, Pavel S, Moon, Eui Jung, Landon, Chelsea, Manzoor, Ashley, Hochman, Daryl W, Viglianti, Benjamin L, \& Dewhirst, Mark W. 2011. Thresholds for thermal damage to normal tissues: an update. International Journal of Hyperthermia, 27(4), $320-343$.

Yatvin, M. B., Weinstein, J. N., Dennis, W. H., \& Blumenthal, R. 1978. Design of Liposomes for Enhanced Local Release of Drugs by Hyperthermia. Science, 202(4374), $1290-1293$.

Yu, B., Shah, A., Wang, B., Rajaram, N., Wang, Q., Ramanujam, N., Palmer, G. M., \& Dewhirst, M. W. 2013. Monitoring of cycling hypoxia and angiogenesis in FaDu head and neck tumors using a side-firing sensor. Pages 85781E-85781E of: SPIE BiOS.

Yuan, F., Dellian, M., Fukumura, D., Leunig, M., Berk, D. A., Torchilin, V. P., \& Jain, R. K. 1995. Vascular permeability in a human tumor xenograft: molecular size dependence and cutoff size. Cancer research, 55(17), 3752-3756.

Yuan, Hsiangkuo, Khoury, Christopher G, Wilson, Christy M, Grant, Gerald A, Bennett, Adam J, \& Vo-Dinh, Tuan. 2012a. In vivo particle tracking and photothermal ablation using plasmon-resonant gold nanostars. Nanomedicine: Nanotechnology, Biology and Medicine, 8(8), 1355-1363.

Yuan, Y., Wyatt, C., Maccarini, P., Stauffer, P., Craciunescu, O., MacFall, J., Dewhirst, M., \& Das, S. K. 2012b. A heterogeneous human tissue mimicking phantom for RF heating and MRI thermal monitoring verification. Physics in medicine and biology, $57(7), 2021$.

Yuan, Y, Cheng, K. S., Craciunescu, O. I., Stauffer, P. R., Maccarini, P. F., Arunachalam, K., Vujaskovic, Z., Dewhirst, M. W., \& Das, S. K. 2012c. Utility of treatment planning for thermochemotherapy treatment of nonmuscle invasive bladder carcinoma. Medical physics, 39(3), 1170-1181. 
Zagar, T. M., Oleson, J. R., Vujaskovic, Z., Dewhirst, M. W., Craciunescu, O. I., Blackwell, K. L., Prosnitz, L. R., \& Jones, E. L. 2010. Hyperthermia combined with radiation therapy for superficial breast cancer and chest wall recurrence: A review of the randomised data. International Journal of HypertheMRIa, 26(7), 612-617.

Zhang, A., Mi, X., Yang, G., \& Xu, L. X. 2009. Numerical study of thermally targeted liposomal drug delivery in tumor. Journal of Heat Transfer, 131(4), 043209.

Zhang, H.G., Mehta, K., Cohen, P., \& Guha, C. 2008. Hyperthemia on immune regulation: a temperature's story. Cancer letters, 271(2), 191-204.

Zhao, J., Salmon, H., \& Sarntinoranont, M. 2007. Effect of heterogeneous vasculature on interstitial transport within a solid tumor. Microvascular research, 73(3), 224-236. 
Apêndice A

Artigos publicados ou em fase de
submissão relacionados à Tese

A.1 Magnetic fluid hyperthermia for bladder cancer: A preclinical dosimetry study 
Anexo A 


\section{Apêndice B}

\section{Lista completa de publições durante o período de Doutorado}

\section{B.1 Primeiro autor}

1. Oliveira, T.R., Stauffer, P.R., Lee, C.T., Landon, C.D., Etienne, W., Ashcraft, K.A., Mcnerny, K.L., Mashal, A., Nouls, J., Maccarini, P.F., Beyer, W.F., Inman, B., Dewhirst, M.W. (2013) International Journal of Hyperthermia,(29) 1-10. "Magnetic fluid hyperthermia for bladder cancer: A preclínical dosimetry study".

2. Oliveira T.R., Lee C.T., Etienne W., C. Landon, M. W. Dewhirst, and Paul R. Stauffer; "Preclínical investigation of magnetic fluid hyperthermia for thermochemotherapy of bladder cancer". (2013) Proc. SPIE 8584, Energy-based Treatment of Tissue and Assessment VII 85840D.

3. Oliveira T.R., Duarte E.L., Lamy M.T., Vandenbranden M., Ruysschaert J.M.,Lonez C., (2012) Langmuir, 28 (10), 4640-4647. "Temperature-dependence of cationic lipid bilayer intermixing: Possible role of interdigitation".

4. Oliveira T.R., Benatti C.R., Lamy M. T., (2011) BBA-Biomembranes, 1808, 2629-2637. "Structural characterization of the interaction of the polyene antibiotic Amphotericin B with DODAB bicelles and vesicles". 
5. Oliveira T.R., Lamy M.T., Paula U.M., Guimaraes L.L., Toledo M.S., Takahashi H.K., Straus A.H., Lindsey C.J, Paiva T.B. (2009) Braz. J. Med. Biol. Res. 42 (8), 844 853. "Structural properties of lipid reconstructs and lipid composition of normotensive and hypertensive rat vascular smooth muscle cell membranes".

\section{B.2 Co-autor}

6. Rodrigues, D.B, Maccarini, P.F., Salahi, S., Oliveira T.R., Pereira, P.J. S., Limão-Vieira, P., Snow, B.W., Reudink, D., Stauffer, P.R. (2014) IEE-TBME "Design and optimization of an ultra-wideband and compact microwave antenna for radiometric monitoring of brain temperature".

7. Stauffer, P.R., Snow, B.W., Rodrigues, D.B., Salahi, S., Oliveira T.R., Reudink, D., Maccarini, P.F. (2014) Neuroradiology Journal 27, 3-12. "Non-Invasive Measurement of Brain Temperature with Microwave Radiometry: Demonstration in a Head Phantom and clínical Case".

8. Rozenfeld J. H.K., Duarte E.L., Oliveira T.R., Lonez C., Ruysschaert J.M., Lamy M. T., (2013) Langmuir. 29 (35), p.11102-8. "Oligonucleotide-induced overcharging affects phase transition but not interdigitation of diC14-amidine bilayers".

9. Inman, B.A., Etienne,W., Rubin, R., Owusu, R.A., Oliveira T.R., Rodriques, D.B., Maccarini, P.F., Stauffer, P.R., Dewhirst, M.W. (2013), International Journal of Hyperthermia 29 (3), p.206-210. "The impact of temperature and urinary constituents on urine viscosity and its relevance to bladder hyperthermia treatment".

10. Stauffer P.R., D.B. Rodriques, Salahi S., Topsakal E., Oliveira T.R., Prakash A., D'Isidoro, F., Reudink D., Snow B.W., Maccarini P.F.; "Stable Microwave Radiometry System for Long Term Monitoring of Deep Tissue Temperature" (2013) Proc. SPIE 
8584, Energy-based Treatment of Tissue and Assessment VII, 85840R.

11. Silva A.C., Oliveira T. R., Mamani J. B., Malheiros S.M.F, Pavon L.F., Sibov T.T., Amaro Jr E, Gamarra L.F.(2011) International Journal of Nanomedicine, (6) 591-603. "Application of hyperthermia induced by superparamagnetic iron oxide nanoparticles in glioma treatment".

12. Rozenfeld J. H.K., Oliveira T.R., Lamy M.T., Carmona-Ribeiro A. M., (2011) BBA-Biomembranes, 1808 649-655. "Interaction of cationic bilayer fragments with a model oligonucleotide".

13. Silva, A.C. ; Oliveira T.R. ; Mamani, J.B. ; Malheiros S.M.F ; Pavon L.F. ; Sibov T.T. ; Amaro Jr, E ; Gamarra, L F., (2010) Einstein (São Paulo) 8 ,361-367. Magnetohipertermia para o tratamento de gliomas: estudos experimentais e clínicos. 